FINNISH METEOROLOGICAL INSTITUTE

CONTRIBUTIONS No. 158

\title{
Measurements and modelling of seasonal snow characteristics for interpreting passive microwave observations
}

\author{
LEENA LEPPÄNEN
}

Finnish Meteorological Institute

Sodankylä, Finland

\author{
Institute for Atmospheric and Earth System Research (INAR) \\ Faculty of Science \\ University of Helsinki \\ Helsinki, Finland
}

DOCTORAL DISSERTATION

To be presented for public discussion with permission of the Faculty of Science of the University of Helsinki, in Auditorium 107 of Athena (Siltavuorenpenger $3 \mathrm{~A}$, Helsinki), on the $19^{\text {th }}$ December, 2019, at 12 o'clock. 


\section{Author's contact details}

Leena Leppänen

Finnish Meteorological Institute

Space and Earth Observation Centre

Tähteläntie 62

99600 Sodankylä, Finland

leena.leppanen@fmi.fi

\section{Supervisors}

Professor Jouni Pulliainen

Space and Earth Observation Centre

Finnish Meteorological Institute, Finland

Emeritus Professor Matti Leppäranta

Institute for Atmospheric and Earth System Research (INAR)

University of Helsinki, Finland

\section{Reviewers}

Docent Esko Kuusisto

Finnish Environment Institute, Finland

Professor Jaan Praks

Department of Electronics and Nanoengineering

Aalto University, Finland

\section{Custos}

Professor Petteri Uotila

Institute for Atmospheric and Earth System Research (INAR)

University of Helsinki, Finland

\section{Opponent}

Dr. Charles Fierz

WSL Institute for Snow and Avalanche Research SLF, Switzerland

ISSN: 0782-6117

ISBN (paperback): 978-952-336-090-7

ISBN (pdf): 978-952-336-091-4

DOI: https://doi.org/10.35614/isbn.9789523360914

http://ethesis.helsinki.fi

Edita Prima Oy

Helsinki 2019 
Published by Finnish Meteorological Institute

(Erik Palménin aukio 1)

P.O. Box 503

FIN-00101 Helsinki

Finland
Series title, number and report code of publication

Finnish Meteorological Institute

Contributions 158, FMI-CONT-158

Date

December 2019

\section{Author}

Leena Leppänen

ORCID iD 0000-0003-1605-8306

Title

Measurements and modelling of seasonal snow characteristics for interpreting passive microwave observations

Abstract

Information on snow water equivalent (SWE) of seasonal snow is used for various purposes, including longterm climate monitoring and river discharge forecasting. Global monitoring of SWE is made feasible through remote sensing. Currently, passive microwave observations are utilized for SWE retrievals. The main challenges in the interpretation of microwave observations include the spatial variability of snow characteristics and the inaccurate characterization of snow microstructure in retrieval algorithms. Even a minor variability in snow microstructure has a notable impact to microwave emission from the snowpack. This thesis work aims to improve snow microstructure modelling and measurement methods, and understanding the influence of snow microstructure to passive microwave observations, in order to enable a more accurate SWE estimation from remote sensing observations.

The thesis work applies two types of models: physical snow models and radiative transfer models that simulate microwave emission. The physical snow models use meteorological driving data to simulate physical snow characteristics, such as SWE and snow microstructure. Models are used for different purposes such as hydrological simulations and avalanche forecasting. On the other hand, microwave emission models use physical snow characteristics for predicting microwave emission from a snowpack. Microwave emission models are applied for the interpretation of spaceborne passive microwave remote sensing observations, for example. In this study, physical snow model simulations and microwave emission model simulations are compared with field observations to investigate problems in characterizing snow for microwave emission models. An extensive set of manual field measurements of snow characteristics is used for the comparisons. The measurements are collected from taiga snow in Sodankylä, northern Finland. The representativeness of the measurements is defined by investigating the spatial and temporal variability of snow characteristics.

The work includes studies on microwave emission modelling from natural snowpacks and from excavated snow slabs. Radiometric observations of microwave emission from natural snowpacks are compared with simulations from three microwave emission models coupled with three physical snow models. Additionally, 
homogenous snow samples are excavated from the natural snowpack during the Arctic Snow Microstructure Experiment, and the incident snow characteristics and microwave emission characteristics are measured with an experimental set-up developed for this study. Predictions of two microwave emission models are compared with the radiometric observations of collected snow samples. The results indicate that none of the model configurations can accurately simulate the microwave emission from natural snowpack or snow samples. The results also suggest that the characterization of microstructure in the applied microwave emission models is not adequate.

Publishing unit

Finnish Meteorological Institute

Space and Earth Observation Centre

\begin{tabular}{lll}
\hline Classification (UDC) & Keywords \\
$551.321 .7,551.322,528.8,550.3$ & $\begin{array}{l}\text { Snow, remote sensing, microwave radiation, } \\
\text { microstructure }\end{array}$ \\
\hline ISSN and series title & ISBN \\
$0782-6117$ & $978-952-336-090-7$ & \\
Finnish Meteorological Institute & & \\
Contributions & & Pages \\
\hline DOI & Language & 164 \\
https://doi.org/10.35614/isbn.9789523360914 & English &
\end{tabular}


Julkaisija

\section{IImatieteen laitos}

(Erik Palménin aukio 1)

PL 503, 00101 Helsinki
Julkaisun sarja, numero ja raporttikoodi

Finnish Meteorological Institute

Contributions 158, FMI-CONT-158

Päiväys

Joulukuu 2019

Tekijä

Leena Leppänen

ORCID iD 0000-0003-1605-8306

Nimeke

Kausittaisen lumipeitteen mittaukset ja mallinnus passiivisten mikroaaltohavaintojen tulkinnassa

Tiivistelmä

Kausittaisen lumipeitteen vesiarvoa voidaan hyödyntää useissa tarkoituksissa, esimerkiksi pitkäaikaisessa ilmastonseurannassa ja jokien tulvaennustuksessa. Lumen vesiarvoa on mahdollista seurata maailmanlaajuisesti kaukokartoituksen avulla, jossa tällä hetkellä hyödynnetään passiivisia mikroaaltohavaintoja. Haasteita mikroaaltohavaintojen tulkinnassa ovat muun muassa lumen ominaisuuksien alueellinen vaihtelu ja epätarkka lumen mikrorakenteen määrittely. Jopa pieni vaihtelu lumen mikrorakenteessa vaikuttaa huomattavasti lumipeitteen mikroaaltoemissioon. Tutkimuksen tavoitteena on kehittää lumen mikrorakenteen mallintamista ja mittausmenetelmiä sekä ymmärrystä lumen mikrorakenteen vaikutuksesta passiivisiin mikroaaltohavaintoihin, jotta kaukokartoitushavainnoista saadaan määritettyä vesiarvo entistä tarkemmin.

Tutkimuksessa on käytetty kahdentyyppisiä malleja: fysikaalisia lumimalleja ja mikroaaltoemissiomalleja. Fysikaaliset lumimallit käyttävät meteorologista mittausaineistoa lumen ominaisuuksien kuten vesiarvon tai lumen mikrorakenteen mallintamiseen. Näitä malleja on kehitetty eri tarkoituksiin kuten hydrologiseen seurantaan ja lumivyöryennustukseen. Sen sijaan mikroaaltoemissiomalleja käytetään passiivisten mikroaaltokaukokartoitushavaintojen tulkinnassa. Tässä työssä tutkitaan ongelmia lumen ominaisuuksien esitystavassa mikroaaltoemissiomalleissa. Tutkimuksessa on verrattu mittauksia fysikaalisten lumimallien ja mikroaaltoemissiomallien simulaatioihin. Työssä on käytetty Sodankylässä tehtyjä kattavia mittauksia pohjoisen havumetsävyöhykkeen lumen ominaisuuksista. Mittausten edustavuutta on analysoitu tutkimalla lumen ominaisuuksien alueellista ja ajallista vaihtelua.

Työssä hyödynnetään sekä luonnollisen lumipeitteen että luminäytteiden mittauksia ja mallinnusta. Mikroaaltoemissiohavaintoja luonnollisesta lumipeitteestä on verrattu kolmen eri mikroaaltoemissiomallin simulaatioihin yhdistettynä kolmen eri fysikaalisen lumimallin tuloksiin. Lisäksi lumipeitteestä on otettu näytteitä, ja tarkoitukseen suunniteltua mittausasetelmaa on käytetty lumen ominaisuuksien sekä mikroaaltoemission mittaamiseen. Kahden mikroaaltoemissiomallin simulaatioita on verrattu luminäytteistä tehtyihin mikroaaltoemissiohavaintoihin. Tulokset osoittavat että mikään malliyhdistelmistä ei mallinna tarkasti mikroaaltoemissiota luonnollisesta lumipeitteestä tai luminäytteistä. Tulokset viittaavat myös siihen, että mikroaaltoemissiomalleissa käytetty mikrorakenteen esitystapa ei ole sopiva. 
Julkaisijayksikkö

IImatieteen laitos

Avaruus- ja kaukokartoituskeskus

Luokitus (UDK) Asiasanat

551.321.7, 551.322, 528.8, 550.3

Lumi, kaukokartoitus, mikroaaltosäteily, mikrorakenne

ISSN ja avainnimeke

ISBN

0782-6117

978-952-336-090-7

Finnish Meteorological Institute

Contributions

\begin{tabular}{lll}
\hline DOI & Kieli & Sivumäärä \\
https://doi.org/10.35614/isbn.9789523360914 & Englanti & 164 \\
\hline
\end{tabular}




\section{Preface}

The research described in this thesis was carried out at the Finnish Meteorological Institute in Sodankylä, Finland during 2012-2019. A part of the work was funded by the Väisälä Fund of the Finnish Academy of Science and Letters and the Henry Ford Foundation.

I would like to express my gratitude for my supervisor from FMI, Prof. Jouni Pulliainen, and my supervisors from the University of Helsinki, Emeritus Prof. Matti Leppäranta and Prof. Petteri Uotila, who has provided support and enabled delivering this thesis. I thank pre-examiners, Docent Esko Kuusisto and Prof. Jaan Praks, for careful review of the thesis. I am also grateful for my opponent Dr. Charles Fierz for his time and review. I thank also all co-authors of the publications included the thesis for their priceless work, comments and support during the analysis and writing processes.

I am very grateful for my previous and present group leaders, Dr. Timo Sukuvaara and Dr. Juha Lemmetyinen, who both has provided valuable support, encouragement and guidance during the whole process. I wish to thank my past and present colleagues in Sodankylä. I am especially grateful for Dr. Anna Kontu who taught snow measurements for me and co-authored most of the publications included to this thesis. Especially I would like to thank Henna-Reetta Hannula, Hanne Suokanerva, Aleksi Rimali, Markku Ahponen, Jyrki Mattanen, Ilkka Mikkola, Anita Sassali, Dr. William Maslanka, Dr. Qinghuan Li, Antti Raaterova, Santeri Lintula, Juha Karhu, Riika Ylitalo and all the other people who has participated to the manual snow pit measurements.

I am grateful also for my colleagues in Helsinki who has provided important support. Especially I would like to thank Dr. Roberta Pirazzini for the opportunity to participate to the Antarctic expedition in 2014-2015 even though that data did not ended up to this thesis. I am grateful for Prof. Timo Vihma for valuable opportunity of the EuRuCAS research visit in St. Petersburg in 2015. I would like to thank Dr. Outi Meinander, Dr. Ali Nadir Arslan, Dr. Kimmo Rautiainen and Dr. Terhikki Manninen for fruitful collaboration, conversations and support during these years.

I would like to thank all COST ES1404 HarmoSnow, INTERACT and SPICE partners for conversations, collaboration and support. I thank also other international collaborators who has been working with me and supported me with the thesis, especially Dr. Martin Schneebeli, Dr. Tibor Fülop, Dr. Mel Sandells, Dr. Jürgen Helmert, Dr. Juan Ignacio Lopez Moreno, and Prof. Aynur Şensoy Şorman. Finally, I thank my family and friends for continuous support and encouragement towards this thesis.

Sodankylä, 25 $5^{\text {th }}$ November 2019

Leena Leppänen 


\section{Contents}

\section{Abstract \\ Preface}

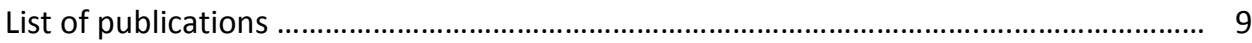

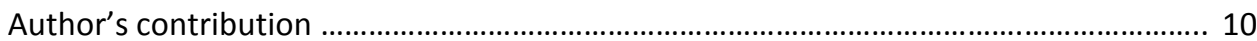

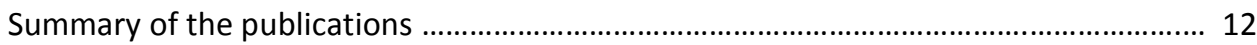

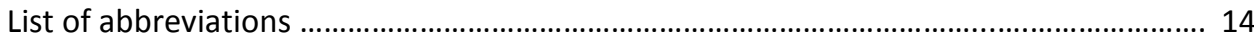

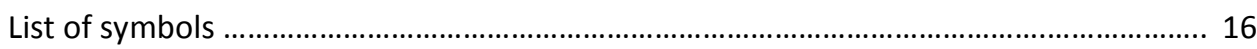

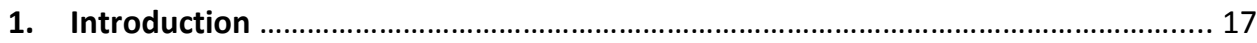

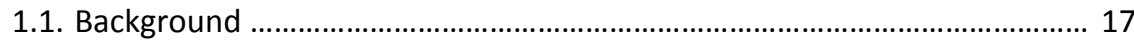

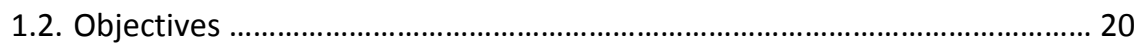

1.3. Connection to progress in snow research ................................................... 22

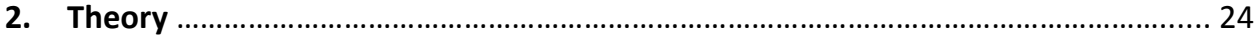

2.1. Microwave radiation in snow ..................................................................... 24

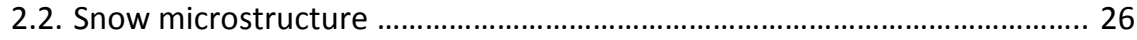

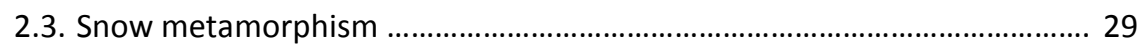

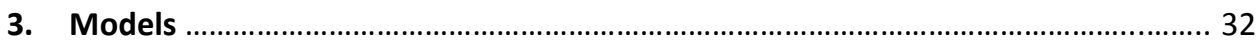

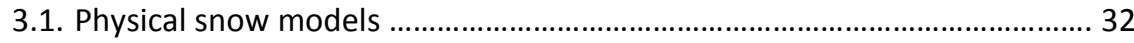

3.2. Microwave emission models .................................................................... 35

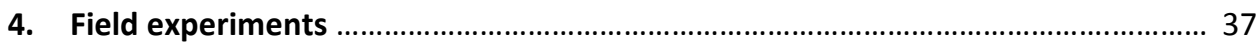

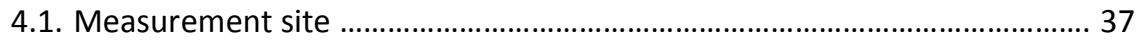

4.2. Snow pit measurements ........................................................................... 41

4.3. Microwave radiometer measurements ........................................................ 43

4.4. Arctic Snow Microstructure Experiment ..................................................... 45

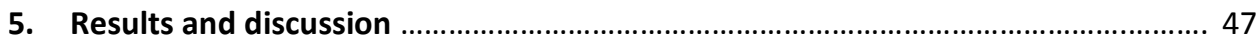

5.1. Empirical relationship between reflectance and specific surface area ...... 47

5.2. Comparison of measured and simulated snow properties ......................... 50

5.3. Comparison of measured and simulated brightness temperatures ........... 54

5.4. Temporal and spatial variability of snow macrostructural properties ....... 59

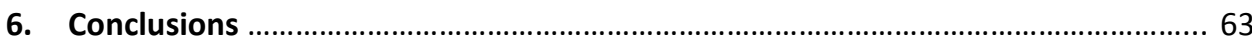

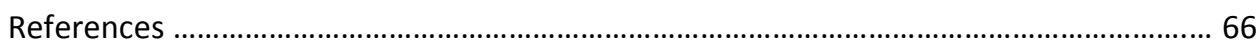




\section{List of publications}

This dissertation consists of following publications, which are referred with the roman numbers in the text.

I Leppänen, L., and Kontu, A. (2018) Analysis of QualitySpec Trek Reflectance from Vertical Profiles of Taiga Snowpack. Geosciences, 8(11), 404, doi: 10.3390/geosciences8110404.

II Leppänen, L., Kontu, A., Vehviläinen, J., Lemmetyinen, J., and Pulliainen, J. (2015) Comparison of traditional and optical grain size field measurements with SNOWPACK simulations in a taiga snowpack. J. Glaciol. Vol.61, No. 225, doi: 10.3189/2015JoG14J026.

III Sandells, M., Essery, R., Rutter, N., Wake, L., Leppänen, L., and Lemmetyinen, J. (2017) Microstructure representation of snow in coupled snowpack and microwave emission models, The Cryosphere, 11, 229-246, doi:10.5194/tc-11-229-2017.

IV Maslanka, W., Leppänen, L., Kontu, A., Sandells, M., Lemmetyinen, J., Schneebeli, M., Proksch, M., Matzl, M., Hannula, H.-R., and Gurney, R. (2016) Arctic Snow Microstructure Experiment for the development of snow emission modelling, Geosci. Instrum. Method. Data Syst., 5, 85-94, doi:10.5194/gi-5-85-2016, 2016.

V Leppänen L., Kontu A., Hannula, H-R., Sjöblom, H., and Pulliainen J. (2016) Sodankylä snow survey program, Geosci. Instrum. Method. Data Syst., 5, 163-179, doi:10.5194/gi5-163-2016.

Publications I-V are reprinted with permission and copyrighted as follows:

- $\quad$ Publications I, III, IV and V are open access articles available under the CC BY 3.0 or 4.0 licenses.

- Publication II is reprinted from the Journal of Glaciology with permission of the International Glaciological Society. 


\section{Author's contribution}

Publication I “Analysis of QualitySpec Trek Reflectance from Vertical Profiles of Taiga Snowpack" Manuscript idea and methods were planned by Leena Leppänen and Anna Kontu. Data collection, analysis and visualizations were made by Leena Leppänen. Original draft of the manuscript was written by Leena Leppänen and both authors contributed to editing of the manuscript.

Publication II "Comparison of traditional and optical grain size field measurements with SNOWPACK simulations in a taiga snowpack"

Anna Kontu, Juha Lemmetyinen and Leena Leppänen had original idea for the manuscript. Anna Kontu and Leena Leppänen participated to the field measurements. Data analysis was made by Leena Leppänen and Anna Kontu. Juho Vehviläinen conducted simulations. Visualizations were made by Leena Leppänen and Juho Vehviläinen. Manuscript was prepared by Leena Leppänen with contributions from all co-authors.

Publication III "Microstructure representation of snow in coupled snowpack and microwave emission models"

Leena Leppänen participated to the field measurements, provided analyzed snow pit observations and contributed to preparation of the manuscript.

Publication IV "Microstructure Experiment for the development of snow emission modelling"

Juha Lemmetyinen, Mel Sandells, and Martin Schneebeli planned the experiment with help of William Maslanka. William Maslanka had the main responsibility in organizing and carrying out the measurements. Leena Leppänen had the responsibility of organizing measurements as the local operator, including implementation of measurement setup and participation to measurement procedure. Anna Kontu and Henna-Reetta Hannula participated in the experimental measurements. William Maslanka conducted data processing and simulations. Margret Matzl provided the micro-CT data set. Martin Proksch provided the SMP analysis. William Maslanka and Leena Leppänen prepared the manuscript with contributions from all coauthors. 
Publication V "Sodankylä snow survey program"

Leena Leppänen and Anna Kontu planned the manuscript idea. Leena Leppänen, Anna Kontu and Henna-Reetta Hannula participated to the field measurements. Data analysis and visualization was made by Leena Leppänen and Anna Kontu. Leena Leppänen and Anna Kontu prepared the manuscript with contributions from all co-authors. Leena Leppänen had main responsibility on the sections 2.3.2, 2.3.4, 2.3.6, 2.3.7, 2.3.8, 3.1 and 3.2, and Anna Kontu had main responsibility on the sections $2.3 .1,2.3 .3,2.3 .5,3.3,3.4$ and 3.5 .

Table I. Author's contribution to different parts of the studies and the manuscript preparations. Major is addressed to the cases when contribution was larger than that of the co-authors, moderate is for contribution similar to that of the co-authors, and minor is for smaller contribution than that of the co-authors.

\begin{tabular}{c|l|l|l|l|l} 
Publication & $\begin{array}{l}\text { Original } \\
\text { idea }\end{array}$ & Methodology & Field work & Data analysis & $\begin{array}{l}\text { Manuscript } \\
\text { preparation }\end{array}$ \\
\hline I & Major & Major & Major & Major & Major \\
\hline II & Moderate & Major & Moderate & Moderate & Major \\
\hline III & No & No & Major & Minor & Minor \\
\hline IV & Minor & Minor & Moderate & Minor & Moderate \\
\hline V & Moderate & Major & Moderate & Moderate & Major
\end{tabular}




\section{Summary of the publications}

Publication I describes a novel instrument, QualitySpec Trek, which measures spectral reflectance with wavelengths of $350-2500 \mathrm{~nm}$. The instrument was originally built for mineral detection measurements and had not been tested earlier for snow microstructure observations. The reflectances of snow profiles that were observed with QualitySpec Trek were compared with specific surface area observations that were measured from snow profiles with the IceCube instrument. An empirical linear relationship was found between the specific surface area and a reflectance index $Q$. The variability from sampling and the measurement of IceCube was tested by repeating the procedures.

Publication II includes a comparison of measured and simulated snow parameters. The SNOWPACK model was used to simulate snow properties based on meteorological input data. The simulated traditional grain size and optical grain size were compared with values that were measured from snow pits. The traditional grain size was estimated from macro-photographs, and the optical grain size was derived from specific surface area observations made with IceCube. The sources of grain size measurement errors were discussed. In addition, density simulations were compared to density profile observations. The conclusion was that the optical grain size had larger bias than the traditional grain size but better correlation with the simulation results. In any case, SNOWPACK is able to simulate density and grain size with reasonable accuracy for taiga snow.

Publication III compares measured and simulated snow parameters on one hand and microwave brightness temperatures on the other. The Jules Investigation Model (JIM) snow model parametrizations included 32 different model configurations. The simulations of snow depth and snow water equivalent were compared with the observations. The JIM parametrizations were coupled with grain sizes that were simulated with three microstructure models (SNow THERmal Model (SNTHERM), Met Office Surface Exchange Scheme (MOSES), and SNow, ICe, and Aerosol Radiation (SNICAR)). The results were compared with optical grain size that was derived from specific surface area observations with IceCube. The comparison indicated that greater variability originates from the microstructure models than from the JIM parametrization. Tower-based brightness temperature observations were compared with simulations with three microwave emission models (Helsinki University of Technology (HUT), Microwave Emission Model for Layered Snowpacks (MEMLS), and Dense Media Radiative Transfer Multi-Layer model (DMRT-ML)) coupled with the JIM parametrization and three microstructure models. The simulations that were based on JIM configurations covered the observed brightness temperature in almost every different frequency, polarization, and year combination. The results did not indicate any microstructure and emission model combination 
to be clearly superior to the others. However, fitting the grain size with scaling factors improved results in most cases. The difference in the scaling factors was larger between the microstructure models than between the microwave emission models.

Publication IV describes the Arctic Snow Microstructure Experiment and compares observed brightness temperatures and microwave emission model simulation results. The experiment included excavation of snow samples, microwave radiometric observations, and in-situ observations by using several advanced instruments from the homogenous snow samples with an experimental set-up. No similar experiment had been previously conducted for taiga snow. Brightness temperatures were simulated with HUT and MEMLS microwave emission models that applied the in-situ observations to set model parameters. The simulations were made for two experimental set-ups; the snow samples were on a reflecting base and on an absorbing base, to calculate the reflectivity and transmissivity of the snow samples. The HUT model simulations were better on average for the absorbing base, and MEMLS was slightly better for the reflecting base.

Publication $\mathbf{V}$ presents a description of manual snow observations made in the Arctic Space Centre of Finnish Meteorological Institute (previously the Arctic Research Centre) in Sodankylä in northern Finland. The study includes description of measurement sites, snow measurement methods, data sets of snow pit observations, daily snow depth measurements, snow depth and SWE observations, and snow courses and lake ice observations. Example data for each data set gives an overview of the spatial and temporal variability of snow depth and SWE in the area. The publication also provides information on general snow properties in the experiment site that is relevant to this work. 


\section{List of abbreviations}

\begin{tabular}{|c|c|}
\hline ASMEx & Arctic Snow Microstructure Experiment \\
\hline ASSSAP & Alpine Snow Specific Surface Area Profiler \\
\hline COST & Collaboration in Science and Technique \\
\hline DF & Decomposing and fragmented precipitation particles \\
\hline $\mathrm{DH}$ & Depth hoar \\
\hline DISORT & $\begin{array}{l}\text { Discrete Ordinates Radiative Transfer Program for a Multi-Layered Plane- } \\
\text { Parallel Medium }\end{array}$ \\
\hline DMRT-ML & Dense Media Radiative Transfer Multi-Layer model \\
\hline DUFISSS & DUal Frequency Integrating Sphere for Snow SSA \\
\hline ESA & European Space Agency \\
\hline FC & Faceted crystals \\
\hline FMI-ARC & Arctic Space Centre of Finnish Meteorological Institute \\
\hline GCW & Global Cryosphere Watch \\
\hline $\mathrm{H}$ & Horizontal polarization \\
\hline HUT & Helsinki University of Technology \\
\hline IF & Ice formations \\
\hline IOA & Intensive Observation Area \\
\hline IRIS & InfraRed Integrating Sphere \\
\hline JIM & Jules Investigation Model \\
\hline IASC & International Arctic Science Committee \\
\hline MEMLS & Microwave Emission Model for Layered Snowpacks \\
\hline Micro-CT & Microcomputed tomography \\
\hline
\end{tabular}




\begin{tabular}{|c|c|}
\hline NosREx & Nordic Snow Radar Experiment \\
\hline MF & Melt forms \\
\hline MOSES & Met Office Surface Exchange Scheme \\
\hline PP & Precipitation particles \\
\hline QST & QualitySpec Trek \\
\hline RG & Rounded grains \\
\hline RMSE & Root mean square error \\
\hline SCAR & Scientific Committee on Antarctic Research \\
\hline $\mathrm{SH}$ & Surface hoar \\
\hline SMP & Snow MicroPenetrometer \\
\hline SMOS & Soil Moisture and Ocean Salinity \\
\hline SNICAR & SNow, ICe, and Aerosol Radiation \\
\hline SNTHERM & SNow THERmal Model \\
\hline SPICE & Solid Precipitation Intercomparison Experiment \\
\hline SSA & Specific surface area \\
\hline SWE & Water equivalent of snow cover \\
\hline $\mathrm{V}$ & Vertical polarization \\
\hline WMO & World Meteorological Organization \\
\hline
\end{tabular}


List of symbols

$D_{0} \quad$ Optical grain size

$P_{c} \quad$ Exponential correlation length

$\rho_{\text {ice }} \quad$ Density of ice

$\rho_{\text {snow }} \quad$ Density of snow

$R_{1160} \quad$ Reflectance at $1160 \mathrm{~nm}$

$R_{1260} \quad$ Reflectance at $1260 \mathrm{~nm}$

Q Reflectance index

SSA Specific surface area 


\section{Introduction}

\subsection{Background}

Every year, seasonal snow covers approximately $50 \%$ of terrestrial areas of the northern hemisphere (Brown and Robinson, 2011). Snow has a very high albedo (0.8-0.9) compared to the ocean and forest (0.1-0.2). As a result, most of the incident solar radiation on snow is reflected and scattered back to the atmosphere (Armstrong and Brun, 2008). Therefore, not much solar energy is absorbed by snow-covered ground, which leads to lower air temperatures in the troposphere. Decreased temperatures also allow for the accumulation of snow on the ground and a longer duration of the seasonal snow cover. On the other hand, decreasing snow cover leads to increasing absorption of radiation on the ground, higher temperature in the troposphere, and consequent increased melting of the snow cover. This positive feedback mechanism strengthens the effect of climate change (Qu and Hall, 2014).

Seasonal snow is a large water reservoir that ties water during accumulation and releases water during the melting season. Therefore, seasonal snow has a large effect on the global water cycle and ecology (Barnett and others, 2005; van Dijk and others, 2014; Niittynen and others, 2018). Additionally, snow has low thermal conductivity, which weakens soil frost formation and prevents the melting of permafrost, glaciers, and ice sheets in snow covered areas (Hardy and others, 2001; Romanovsky and others, 2010; Vaughan and others, 2012). Consequently, snow is an important factor in climate models (Brutel-Vuilmet and others, 2013), numerical weather predictions (de Rosnay and others, 2014), and climate change research (Derksen and Brown, 2012). Seasonal snow is also important for natural hazards such as flooding and avalanches (Bartelt and Lehning, 2002; Hamlet and Lettenmaier, 2007); for tourism, traffic, snow loads over building roofs, and for reindeer herding (Breiling and Charamaza, 1999; Norrman and others, 2000; Strasser, 2008; Turunen and others, 2016). Snow cover exhibits high spatial and temporal variations that originate from weather conditions (temperature, precipitation, wind and solar radiation), land cover type, vegetation, and landforms. Interception has also an influence to snow characteristics (Lundberg and Koivusalo, 2003; Rutter and other, 2009). Canopy interception cause challenges particularly for hydrological monitoring on forested areas (Hedstrom and Pomeroy, 1998). Additionally, snow crystals and snow cover stratification undergo continuously metamorphic processes. Therefore, there is large variation in snow cover characteristics even in small scales (Derksen and others, 2009; Rutter and others, 2014).

Snow characteristics include both macrostructural and microstructural properties. For instance, snow depth, the height of snowpack as described in Fierz and others (2009), and snow water equivalent (SWE) are macrostructural properties of the snow cover. These properties can be measured with manual and automated methods (Kinar and Pomeroy, 2015; Pirazzini and others, 2018). The time series of macrostructural properties are important for climate research 
purposes; some of these series cover more than 100 years (Brown and Braaten, 1998). The macrostructural measurements have been used for operational weather services, hydrological monitoring and services, and research applications (Pirazzini and others, 2018). On the other hand, the size, shape, bonding, and orientation of the snow crystals characterize the snow microstructure. The microstructural properties have been measured manually or with semiautomated methods, but fully automated methods have not been developed (Pirazzini and others, 2018). The measurements have been made for avalanche predictions and research applications, for example (e.g. Brun, 1989; Pirazzini and others, 2018).

A simple description of taiga snow crystal properties was presented in 1858 (Wolley, 1858). The first collection of the snow crystal photographs was presented by Bentley and Humphreys (1931), and the first snow crystal classification and discussion on crystal formation was published by Nakaya (1954) on the basis of photographs of natural and artificial snow crystals. Sommerfeld and La Chapelle (1970) presented classification of metamorphism based on physical processes, and the theory of wet and dry snow metamorphism was improved by Colbeck $(1973 ; 1980 ; 1982)$. Traditionally, snow microstructure has been defined visually as twodimensional size of snow crystals and named traditional grain size (Fierz and others, 2009). Other definitions of snow microstructure include parameters such as optical grain size, specific surface area (SSA), and correlation length. Optical grain size is the size of optically equivalent grains defined from optical reflectance observations (Matzl and Schneebeli, 2006; Painter and others, 2007). Specific surface area describes the surface area of snow crystals per mass (Legagneux and others, 2002). While direct SSA measurements require laboratory equipment (Legagneux and others, 2002), optical reflectance-based methods have been developed for the field experiments (e.g., Gallet and others, 2009). Correlation length is a theoretically defined parameter that describes the length scale of the autocorrelation function of the structural properties of snow (Mätzler, 2002).

Physical snow models simulate the evolution of macrostructural and microstructural snow parameters by using observational or simulated meteorological information. Models have been developed for different purposes such as avalanche forecasting (Bartelt and Lehning, 2002; Brun and others, 1992), hydrology (Rutter and others, 2008), climate modelling (Armstrong and Brun, 2008), and the modelling of spatial snow distribution (Liston and Elder, 2006). Since there are different model types, model parametrizations are often different and have varying driving parameters; similarly, there is a variance of the output products from the models. Snow microstructure evolution has been usually parametrized as a function of the grain size or SSA, and the snowpack has been described either as one layer or a horizontally stacked system of several homogenous layers. 
Global observations of SWE have been performed since 1972 through microwave satellite remote sensing (Dong, 2018; Rees, 2005). Passive microwave radiometers measure the naturally emitted microwave radiation (brightness temperature) that originates from ground and snow. Extinction of the radiation by absorption and scattering has been related to amount of snow in the signal path of the radiation. Consequently, it has been proposed that SWE can be derived from the observed microwave radiation by using two frequencies to separate the emission of the snowpack from the background radiation (Chang and others, 1987; Kunzi and others, 1976). Spaceborne microwave radiometers typically have good temporal coverage, and observations are not dependent on solar radiation or weather. However, spatial resolution is typically in the range of 5-50 km (Foster and others, 1984; Dong, 2018). Due to the coarse spatial resolution, one passive microwave observation from space can include contributions from several land cover types, varying vegetation, different landforms, and snow with differing characteristics (Derksen and others, 2005; Derksen and others, 2009; Kelly and Chang, 2003; Lemmetyinen and others, 2009; Mätzler, 1994). In addition, satellite observations of snow cover are affected by snow intercepted in the forest canopy (Cohen and others, 2015). However, Li and others (2019) showed that the intercepted snow had limited influence to microwave emissivity of a scots pine in northern Finland.

Microwave emission models can be applied for SWE retrievals from the brightness temperature observations. Empirical and semi-empirical emission models have been developed with airborne and tower-based measurements. In these measurements, atmospheric components can be disregarded, and it is possible to precisely conduct ground truth in-situ measurements (e.g., Pulliainen and others, 1999; Wiesmann and Mätzler, 1999). In addition, theoretical models for SWE retrievals have been developed (e.g., Picard and others, 2013). Microwave emission models simulate brightness temperature by using snow properties such as snow depth, layering, temperature, moisture and microstructure. The snow microstructure, which has been described in the models with grain size or correlation length, has a large effect on observed microwave emission due to the grains' scattering properties (Armstrong and others, 1993; Löwe and Picard, 2015; Mätzler, 2002). Consequently, snow microstructure representation in the SWE retrieval algorithms is essential for the retrieval of SWE from passive microwave observations.

Spaceborne passive microwave observations are also dependent on other parameters such as snow wetness, vegetation, soil properties, and atmospheric properties. Several algorithms for retrieving SWE from the satellite brightness temperature observations have been developed in recent decades. Due to the large amount of ancillary information required by purely theoretical emission models, retrieval algorithms are typically based on either empirical or semi-empirical approaches (e.g., Chang and others, 1987; Goodison and Walker, 1993; Kelly, 2009; Takala and others, 2011). Several methods have been used to express snow microstructure in the retrieval algorithms. In early approaches, microstructure was treated as fixed (e.g., Chang and others, 
1987). Snow microstructure can also be expressed through artificial neural networks that are trained with microwave emission model inversions for the grain size, as in Tedesco and Jayaratnam (2016). An algorithm by Takala and others (2011) applied a proxy; the brightness temperature simulations are fitted to observations by adjusting an effective grain size. Takala and others have presented a hemispherical SWE product; the simulations are driven with the interpolation of snow depth data from weather stations and are fitted to the satellite brightness temperature measurements. Hancock and others (2013) demonstrated that the SWE product presented by Takala and others, which combines the observation data and the satellite data, is more accurate than products that are only based on the satellite data. Combining field measurements, physical snow model simulations, and satellite data can produce the most accurate retrievals for snow cover characteristics (Sturm, 2015).

The interpretation of passive microwave observations can have inaccuracies that originate from the description of radiative transfer in models and the quality of driving data (e.g., Pan and others, 2016; Picard and others, 2018). On the other hand, simulations of physical snow models could be used in driving data for the microwave emission models (Kontu and others, 2017). Therefore, validation of physical snow models and microwave emission models in boreal forest zone is needed. In addition, measurements of snow microstructure are typically slow and exposed to various errors. Therefore, rapid and accurate methods could be improved for the microstructure characterization to support the improvement and validation of the microwave emission models. In addition, the natural spatial variability of the snow characteristics is another challenge in the interpretation of the passive microwave observations.

\subsection{Objectives}

The ultimate aim is to enable more accurate SWE inversions from remote sensing observations by applying microwave emission models with a description for snow microstructure. The objective of the thesis is to develop understanding of measurement methods, modelling of snow microstructure, and the influence of snow microstructure to interpretation of passive microwave observations. The work was based on an extensive measurement set of snow characteristics, brightness temperatures, and meteorological data that was collected from the Arctic Space Centre of Finnish Meteorological Institute (FMI-ARC). The thesis consist of four parts: 
1) Testing of a novel near-infrared reflectance-based measurement method and exploring an empirical relationship between reflectance and SSA for rapid and repeatable SSA measurements in the future (Publication I).

The field observations of snow microstructure would be enhanced if easier, faster, and more accurate methods could be found. A novel optical spectrometer, QualitySpec Trek (QST), was tested for the reflectance measurements of snow, and a microstructure-related index was derived.

2) Comparison of the physical snow modeling results with manual snow measurements for future utilization of snowpack simulations in SWE retrieval from remote sensing data (Publications II and III).

Physical snow models are applied for simulation of snow characteristics. Performance of SWE, density, snow depth, and microstructure simulations was assessed in the study by comparing simulations with field measurements. The purpose was to estimate the suitability of the physical snow models for the simulations of snow characteristics in taiga snowpack.

3) Comparison of microwave emission model simulations with brightness temperature observations to define the suitable approach to improve models in future (Publications III and IV).

Microwave emission models are applied for SWE retrieval. The tower-based brightness temperature observations from the natural snowpack and snow samples that were excavated from the natural snow were compared with simulations from microwave emission models that were driven with measured and simulated snow characteristics. The purpose was to investigate the influence of the microwave emission models with different snow microstructure presentations to brightness temperature simulations.

4) Description of the manual snow measurement methods with overview to spatial and temporal variability of the snow properties in Sodankylä to study the general variability of bulk snow properties in the taiga snowpack of the boreal forest zone (Publication V).

The spatial resolution of the spaceborne passive microwave radiometers is in the scale of tens of kilometers. Therefore, snow properties are likely to vary in the area that is covered by a single observation. The spatial variability of snow depth and SWE in the experiment site was investigated on the basis of the manual snow measurements. 


\subsection{Connection to progress in snow research}

The topic of this thesis is related to other recent research on snow microstructure and its connection to microwave emissions. Roy and others (2013) have studied the feasibility of SSA for microwave emission modelling. They have suggested that the scaling of SSA values produces better simulation results than values without scaling; the stickiness and size distribution of snow grains may cause a need for the scaling of SSA. A theoretical study by Löwe and Picard (2015) has demonstrated that a scaling factor to relate optical grain size with microwave effective grain size is related to snow type. Roy and others (2016) studied the uncertainties of microwave emission modelling by describing snow microstructure with SSA. Their results indicate that measurement error of SSA, which was assumed to be $12 \%$, limits the accuracy of simulations. Roy and others also discussed that combing various types of microstructural information such as information from microcomputed tomography (micro-CT) could improve the brightness temperature simulations.

Royer and others (2017) used different parameters for microstructure characterization and presented a comparison of different microwave emission models. Their results suggest that SSA needs scaling with a model-specific factor to minimize errors between simulations and brightness temperature observations. However, according to their results, SSA is the most relevant single parameter for snow microstructure characterization, although micro-CT could produce more precise microstructure characterization for brightness temperature simulations with a longer processing time. Picard and others (2018) have presented a model for microwave emission and backscattering that combines several existing model configurations, thereby enabling the testing of different approaches. Picard and others proposed that the determination of snow microstructure requires a third parameter that characterizes larger-scale structural correlations of the ice matrix. The other two required parameters are the density and SSA, or grain size. Currently, information on the third parameter is only attainable from micro-CT measurements. Since the third parameter is one source of uncertainties in the simulation, the authors discussed that the empirical autocorrelation function that is derived from the micro-CT measurements is a promising method to characterize snow microstructure for microwave emission modelling.

Kontu and others (2017) validated microwave emission model simulations coupled with physical snow model simulations. They found that the physical snow model simulations are applicable for driving a microwave emission model when a year-dependent scaling factor is used. The need for the scaling might originate from winter-dependent biases that are related to snow structure; however, layer information was lost in averaging values for the whole snowpack (Kontu, 2018). Maslanka and others (2019) presented a new extinction coefficient model based on SSA; this model is to be used with a microwave emission model. This approach improved microwave 
emission model simulations compared to simulations that are based on the traditional grain size.

In Finland, several recent PhD theses are concerned with the remote sensing of snow. Anttila (2019) investigated snow surface roughness and albedo by using optical remote sensing and terrestrial laser scanning. Kontu (2018) studied the effect of snow microstructure and subnivean water bodies on the microwave remote sensing by validating physical snow model and microwave emission model simulations. Takala (2018) presented an algorithm for SWE retrieval applying one of the microwave emission models that is used in this thesis. In addition, Korhonen (2019) presented work on winter hydrology in Finland affected by maximum SWE and melting of snow.

This work contributes to other current international topics about snow research and snow cover monitoring. The most important issues are the intercomparison, harmonization, and recommendation of snow measurement methods. These topics are important because snow measurements are made with differing methods and for differing purposes due to the versatile snow community. The following activities are related to the measurement of snow properties: Workshop on Liquid Water in Snow in 2014, three snow grain size workshops in 2013-2014, the Collaboration in Science and Technique (COST) Action HarmoSnow including The European Snow Booklet in 2015-2018 (Haberkorn, 2019; Helmert and others, 2018; Pirazzini and others, 2018), the World Meteorological Organization (WMO) Solid Precipitation Intercomparison Experiment (SPICE) in 2012-2015 (Nitu and others, 2018), and five Snow Science Winter Schools in 2015-2019. The snow grain size workshops aimed to define commonly used microstructural parameters and to perform inter-comparisons of the measurement methods for these variables. There was a clear need for these activities because novel techniques have been developed in the last decade but have not been comprehensively compared. The series of snow grain size workshops indicated that there is an interest across the snow community to define parameters and measurement methods to describe the snow microstructure. In addition, field campaigns related to the planning of new satellite missions, such as the Nordic Snow Radar Experiment (NoSREx, Lemmetyinen and others, 2016) and SnowEx (Kim and others, 2017), are relevant to this thesis. In addition, the Scientific Committee on Antarctic Research (SCAR), International Arctic Science Committee (IASC), and Global Cryosphere Watch (GCW) have conducted several activities that are of note.

This thesis includes following sections: Section 2 describes interaction of microwave radiation and snow, defines snow microstructural parameters, and describes theory of snow metamorphism. The physical snow models and microwave emission models used in this study are presented in Section 3. In Section 4 is introduced the field experiments, after which the results are presented and discussed in Section 5. Finally, Section 6 outlines the main conclusions. 


\section{Theory}

This section presents the main parts of the theory which this study is based on. Section 2.1 describes the interaction of microwave radiation and snow. Section 2.2 introduces different definitions for the snow microstructure. Section 2.3 describes the snow metamorphism processes.

\subsection{Microwave radiation in snow}

The radiative transfer equation presented by Chandrasekhar (1960) describes the directional transfer of radiation in a medium by three phenomena: increase of energy by emission, energy loss by absorption, and energy redistribution by scattering. Electromagnetic radiation is emitted due to the natural thermal motion of particles. Absorption occurs due to the transformation of radiation energy to other energy forms such as heat. Scattering changes direction of the radiation. Absorption and scattering contributes to extinction, which is the total loss of energy, in the direction of propagation. Radiative transfer theory has been applied to simulate the propagation of microwave radiation in natural snowpacks (Foster and others, 1984).

Natural microwave radiation is emitted by soil or ice below the snowpack. In addition, snow also emits microwave radiation, as all bodies with thermal energy do. Emission of natural microwave radiation is related to emissivity, which is defined as the ratio of real emitted radiation to black body radiation at the same temperature (Ulaby and others, 1981). Emissivity depends on the frequency of radiation. Liquid water and ice have clearly different emissivities (Stiles and Ulaby, 1980). High microwave emission originates from the liquid water, and therefore wet snow has a higher microwave emission signature with larger range of variability than dry snow does (Mätzler, 1987). Wet snow is not considered in this work. The emissivity of the ground depends on soil moisture and soil type, which also needs to be considered when modelling the natural microwave emission (e.g., Hallikainen and others, 1986). In addition to the amount of the original emission, observed microwave radiation depends on the extinction inside the snowpack. Sketches of extinction inside the snowpack with effects of frequency and grain size are presented in Figure 1. 
a

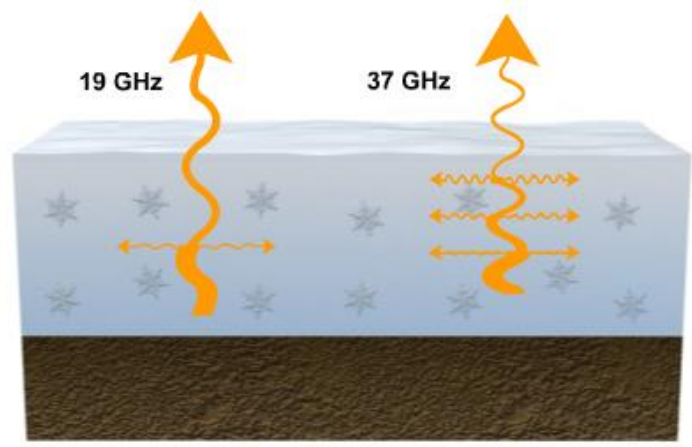

(CThe COMET Program

b

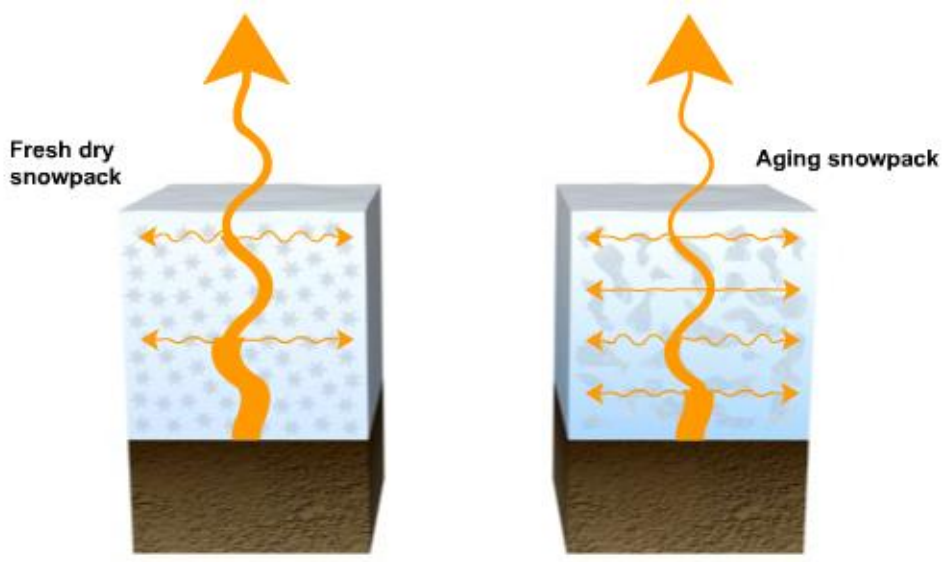

(c)The COMET Program

Figure 1. Sketches of extinction of microwave radiation in snowpack, with the effects of a) frequency and b) grain size. The source of this material is the COMET $^{\circledR}$ Website at http://meted.ucar.edu/ of the University Corporation for Atmospheric Research, sponsored in part through cooperative agreement(s) with the National Oceanic and Atmospheric Administration, U.S. Department of Commerce. (C)1997-2017 University Corporation for Atmospheric Research. All Rights Reserved. 
The total extinction of microwave radiation in snow is dependent on the total amount of snow in the signal path and the physical characteristics of the snowpack, which includes density, microstructure, liquid water content, and temperature (Mätzler, 1987). In addition, layer interfaces have a major effect on horizontal reflection, especially with hard crust layers. Also, the interface between soil and snow affects the scattering of the soil emitted radiation. The amount of extinction is also dependent on the frequency (wavelength) of the radiation. Low frequencies (around $18 \mathrm{GHz}$ with wavelength $15 \mathrm{~mm}$ ) penetrate snow deeper than high frequencies (around $36 \mathrm{GHz}$ with wavelength $0.8 \mathrm{~mm}$ ) because scattering dominates at the higher frequencies (shorter wavelengths) due to the size of the snow grains. When the grains are much smaller than the wavelength, scattering is occasional. Instead of scattering, absorption dominates at the lower frequencies (longer wavelengths). When interpretation of the SWE from the passive microwave observations is conducted, the difference of two frequencies is used to separate the effect of the snowpack from the background radiation and to reduce effect of snow physical temperature (Chang and others, 1987; Kelly and Chang, 2003; Kunzi and others, 1976).

Polarization describes the orientation of the electromagnetic waves in radiation. Radiation that originates from the natural snow and ground is typically not primarily polarized. However, the snowpack has horizontal structures that affect the polarization of radiation when observed from a tilted angle from the nadir. Therefore, the observations are usually made with two orthogonal polarizations: horizontal $(H)$ and vertical $(V)$.

\subsection{Snow microstructure}

Snowpacks are complex media wherein ice forms both granular and sintered structures (Colbeck, 1997; Hagenmuller and others, 2014). Grains, which are also called as crystals, have different shapes and sizes (LaChapelle, 1969). Orientation of the grains and the bonding between the grains also varies (Kry, 1975). These properties are described by the snow microstructure (Dozier and others, 1987). It is not easy to define a single parameter that describes the microstructure, and several different definitions exist (Mätzler, 2002; Pirazzini and others, 2018). In addition, the parameters also have many measurement techniques (Pirazzini and others, 2018). Some commonly used parameters and measurement methods are described in the following paragraphs.

The traditional method is to observe snow grain size, which is defined as the largest extent of an average grain (Fierz and others, 2009). The estimation is made visually on a reference grid with the bare eye or through the use of tools such as a hand lens. Another technique is to make the observations from macro-photographs (Section 4.2). The traditional grain size only describes a two-dimensional property of the microstructure. The method is problematic because removing the sample from the snowpack breaks grains and the bondings between them, and usually only a small portion of the grains in the layer are represented in a sample. Observer- 
related errors arise in the visual estimation. The value for the grain size is difficult to estimate, especially when the sample includes a wide range of sizes. On the other hand, sieving has been used to determine the grain size (Granberg, 1985; Sturm and Benson, 1997). The method is efficient for a large number of grains, but errors originate from broken snow grains and bondings.

Optical grain size is the theoretically defined diameter of identical spheres that have the same optical properties and equal volume-to-surface ratio as the original non-spherical grains (Warren, 1982; Grenfell and Warren, 1999). The optical grain size is observed with optical methods, such as with an illuminated contact probe that is connected to a spectrometer (Painter and others, 2007). On the other hand, the microwave-effective grain size is the size of identical snow grains, which produces an observed microwave signal (e.g. Pulliainen, 2006). Both the optical and microwave-effective grain size can be obtained using model inversions from reflectance or brightness temperature observations (e.g., Kontu and others, 2017; Langlois and others, 2010; Painter and others, 2007; Pirazzini and others, 2015).

Specific surface area (SSA) is a parameter that is defined as the ratio of surface area of air-ice interface to snow mass (unit $\mathrm{kgm}^{-3}$ ) or, alternatively, to volume (unit $\mathrm{m}^{-1}$ ). Snow metamorphism has been demonstrated to be related to evolution of SSA (e.g., Taillandier and others, 2006). Specific surface area depends on both grain size and shape and describes the three-dimensional microstructure better than the traditional grain size. Originally, SSA was measured with the methane absorption method, which involves the snow surface absorbing methane particles and allows definition of the surface area of a certain snow mass (Brunauer and others, 1938; Legagneux and others, 2002). This method is accurate but requires laboratory facilities. Therefore, optional indirect methods based on optical reflectance have been developed. These methods, which can be made with relative ease under field conditions, are based on the assumption that grain properties dominate snow reflectance at wavelengths between 850-1500 $\mathrm{nm}$. Domine and others (2006) and Matzl and Schneebeli (2006) have argued that it is possible to define a correlation between SSA and reflectance. The DUal Frequency Integrating Sphere for Snow SSA (DUFISSS, Gallet and others, 2009), its commercial version IceCube (see Section 4.2.), the InfraRed Integrating Sphere (IRIS, Montpetit and others, 2012) and the Alpine Snow Specific Surface Area Profiler (ASSSAP, Arnaud and others, 2011) measure the reflectance of an infrared laser beam with an integrating sphere from a snow sample. The calculation of SSA is based on calibration measurements and results from the Discrete Ordinates Radiative Transfer Program for a Multi-Layered Plane-Parallel Medium (DISORT) model (Stamnes and others, 2000) that are calibrated with the methane absorption method. Moreover, reflectance from near-infrared photography is exponentially related to SSA (Matzl and Schneebeli, 2006). Specific surface area is related to the optical grain size with an empirical equation that is based on equations in Legagneux and others (2002) and Kokhanovsky and Zege (2004) as 


$$
S S A=\frac{6}{\rho_{\text {ice }} \cdot D_{0}},
$$

where SSA is specific surface area, $\rho_{i c e}$ is density of ice and $D_{0}$ is optical grain size.

The scattering properties of the snow structure can be described with a theoretical correlation function (Debye and others, 1957; Vallese and Kong, 1981). Correlation length, on the other hand, can be defined as a derivative of the correlation function. Correlation length is a theoretical parameter that describes the average distance where variations of snow properties are uncorrelated (Toure and others, 2008). Values closer than the correlation length are correlated, while values at greater distances are increasingly random. The correlation length is related to SSA; however Proksch and others (2015) have argued that the relationship is valid only at the origin of correlation function, and that an exponential correlation length, which is defined from the simplified exponential form of the correlation function, is suitable length scale also further from the origin of correlation function. The exponential correlation function is different from the original correlation function depending on the snow type (Krol and Löwe, 2016; Mätzler, 2002). The exponential correlation length $P_{c}$ is related to SSA (Mätzler, 2002) as

$$
P_{c}=\frac{3\left(1-\frac{\rho_{\text {Snow }}}{\rho_{\text {ice }}}\right)}{S S A}
$$

where $\rho_{\text {snow }}$ is density of snow and $\rho_{\text {ice }}$ is density of ice. Montpetit and others (2013) presented relationship of the exponential correlation length $P_{c}$ and optical grain size as

$$
P_{c}=\frac{2}{3}\left(1-\frac{\rho_{\text {snow }}}{\rho_{\text {ice }}}\right) D_{0}
$$

Exponential correlation length can be evaluated from stereology, such as binary pictures of snow sections (Wiesmann and others, 1998), and the micro-CT (Coleou and others, 2001; Heggli and others, 2009), where snow sample is imaged with an x-ray device to create a threedimensional model of snow. Micro-CT is the most comprehensive method to observe the snow microstructure, and parameters other than exponential correlation length such as SSA and density can be also derived. In addition, exponential correlation length and SSA can be derived with empirical algorithms from Snow MicroPenetrometer (SMP, Schneebeli and Johnson, 1998) measurements (Proksch and others, 2015), which measure the force needed to break the bonds between the grains. 
Snow grains have different shapes depending on the stage of the metamorphism. Deformation of the grains by metamorphic processes is described in Section 2.3. The grain shape can be observed with the traditional visual method and micro-CT. The natural grain shapes are divided into several main classes (Figure 2): precipitation particles (PP), decomposing and fragmented precipitation particles (DF), rounded grains (RG), faceted crystals (FC), surface hoar (SH), depth hoar (DH), and melt forms (MF). In addition, there is the ice formations (IF) class, where single grains are not recognizable, but this class is rare in taiga snow. The classes are again divided into several sub-classes (Fierz and others, 2009).

a

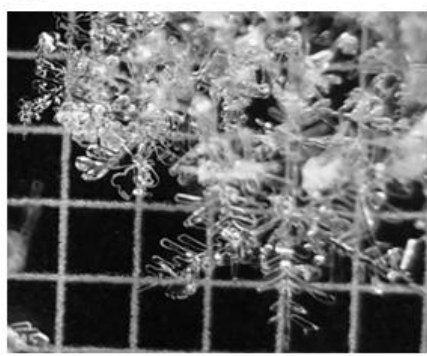

d

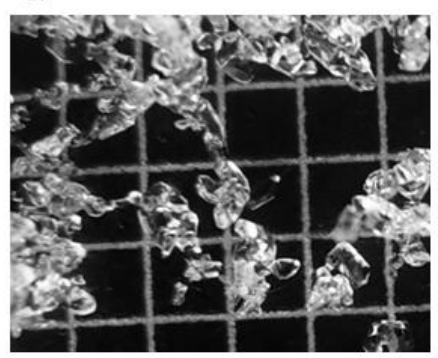

g

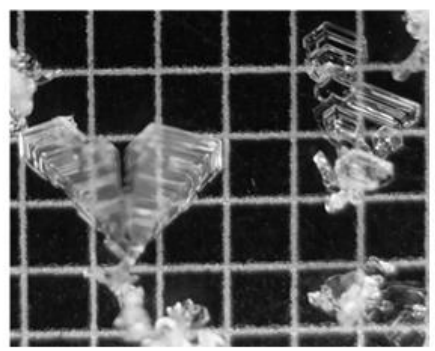

b

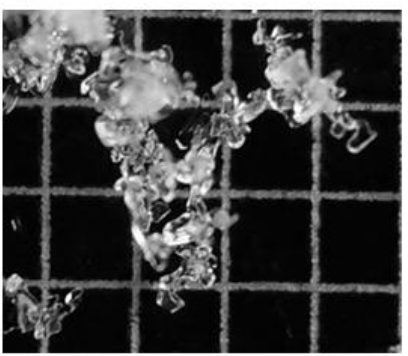

e

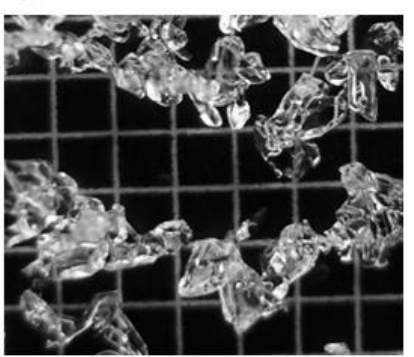

$\mathrm{h}$

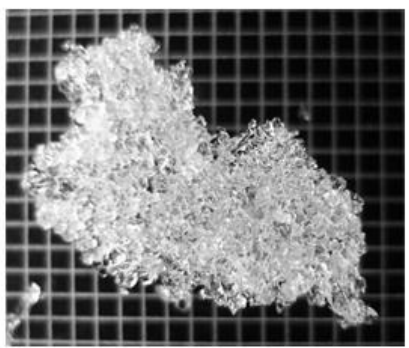

C

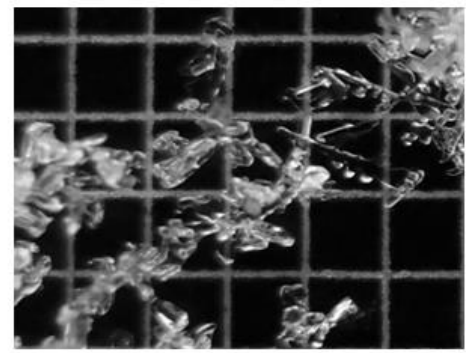

$\mathrm{f}$

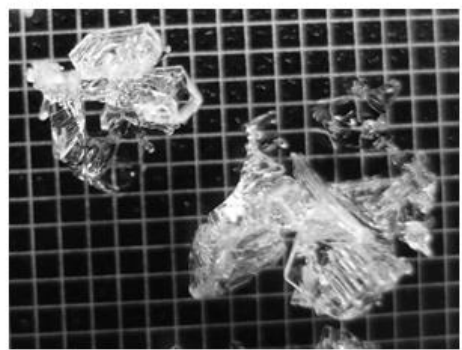

i

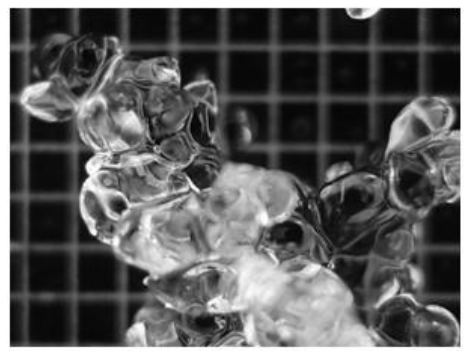

Figure 2. Examples of grain types against 1-mm reference grid from taiga snowpack in Sodankylä. a) PP stellars and dendrites, b) PP irregular, c) DF, d) RG, e) FC, f) DH, h) SH, i) MF crust and j) MF clusters. 


\subsection{Snow metamorphism}

In the atmosphere, snow particles are formed from water vapour or frozen water drops in the clouds and are deformed to different shapes depending on the formation height, water vapour saturation level, and temperature (Cotton and others, 1986; Fierz and others, 2009). When the snowflakes have reached the ground, the grain deformation continues as snow metamorphism. Metamorphism describes the deformation of the snow microstructure and is mainly driven by the temperature gradient between the ground and the snow surface, sintering processes, snow liquid water content, pressure generated by the snowpack, and wind. Rasmus (2005) presented a detailed description of the snow metamorphism.

Temperature gradient metamorphism with kinetic growth is common in dry taiga snow conditions (Colbeck, 1982) and the prevailing snow conditions in Sodankylä. The temperature gradient originates from the temperature difference between the ground and atmosphere. Usually, the ground temperature is relatively stable; it is close to $0^{\circ} \mathrm{C}$ due to the insulating effect of the snowpack, while the air temperature varies more. The most effective metamorphism exists at the bottom of snowpack, where ice sublimates from under the grains and is transported by diffusion and water vapour deposits to the top of the grains. The deposition originates from the decrease of the air temperature between the snow grains inside the snowpack because the saturation water vapour pressure is lower in colder conditions. The phenomenon creates depth hoar crystals (Figure 2f), which can grow into large and layered grains with diameter of several millimeters. When the temperature gradient is smaller and further from the ground, rounded grains (Figure $2 \mathrm{~d}$ ) transform into larger faceted crystals (Figure 2e) by the similar sublimation and deposition process that creates the depth hoar crystals. However, the direction of the grain growth varies. Surface hoar (Figure $2 \mathrm{~g}$ ) is created in certain weather conditions; essentially, when the air is saturated with water vapour and is deposited to growing grains in the snow surface. For example, the effect of the temperature gradient metamorphism over 500 hours in a laboratory experiment is presented in Figure 3.

Equi-temperature (or equilibrium) metamorphism can be observed in isothermal conditions (Brun, 1989). Equi-temperature metamorphism creates rounded grains (Figure 2d) from precipitated particles by sintering because the saturation water vapour pressure depends on the local surface curvature (Figure $2 \mathrm{a}, \mathrm{b}$ ). As a result, concave features tend to become convex, and bonds form between snow grains (Rasmus, 2005). This metamorphism is much slower than the temperature gradient metamorphism. Wet snow metamorphism exists mostly in the melting season, when liquid water content is high (Brun, 1989). Available liquid water increases the grain growth. Low liquid water content favors cluster formation, and high liquid water content favors rounded crystals (Colbeck, 1983). Melt forms (Figure $2 \mathrm{~h}, \mathrm{i}$ ) are created by melting; either in the surface due to surface heat flux, or in the interior snowpack (as in melting season) due to solar radiation and the percolation of liquid precipitation through the surface. Melted 
snow can refreeze to a hard crust layer (Figure $2 \mathrm{~h}$ ) or clusters with large grain size. In addition, strong wind can create crust layers by purely mechanical metamorphism. These crust layers are usually thin $(<1 \mathrm{~cm})$ in taiga snow. Horizontal ice layers originate from the percolation of rain or melt water to the snowpack, which refreezes horizontally, typically along layer interfaces.

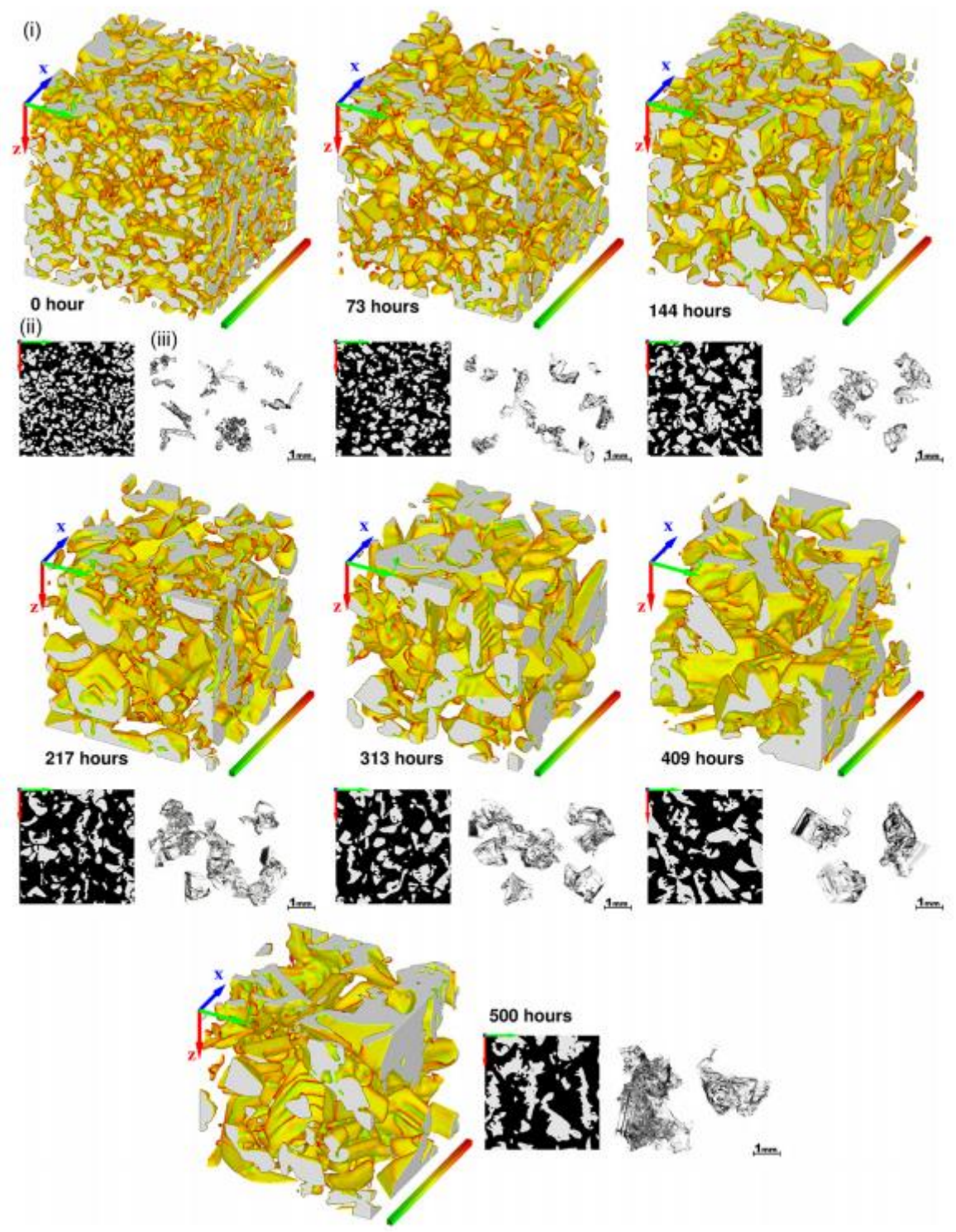

Figure 3. Evolution of snow microstructure during temperature gradient metamorphism, i) 3-D images of snow, ii) cross sections of 3-D images, and iii) photos of snow grains. Image: Calonne and others, 2014. 


\section{Models}

This section introduces models used in this study. Section 3.1 present the physical snow models used for the simulations of snow characteristics. Section 3.2 describes the microwave emission models applied for the brightness temperature simulations.

\subsection{Physical snow models}

Several physical models that describe the evolution of the snowpack have been developed for different purposes. Horizontal variations in snow structure are simulated by the SnowModel (Liston and Elder, 2006). The Jules Investigation Model (JIM; Essery and others, 2013) is a collection of physical snow models that do not parametrize the snow microstructure. Therefore, JIM was coupled with microstructure evolution models in this study. Evolution of the snow microstructure can be modelled with shape and size parameters. The physical snow model SNOWPACK (Lehning and others, 2002a and 2002b) and the numerical snow metamorphism model Crocus (Brun and others, 1992; Vionnet and others, 2012) simulate the microstructure with both size and shape parameters. In addition, some of the models simulate the microstructure without considering the shape of grains. The SNow THERmal Model (SNTHERM, Jordan, 1991) and the Met Office Surface Exchange Scheme (MOSES, Essery and others, 2001) use grain radius, and the SNow, ICe, and Aerosol Radiation (SNICAR, Flanner and Zender, 2006) uses SSA to describe the snow microstructure. This study validated simulations of SNOWPACK and JIM coupled with the microstructure models (SNTHERM, MOSES and SNICAR) (Table 1). In addition, JIM simulations were applied for driving microwave emission models.

SNOWPACK is a physical model of snow metamorphism that is developed for avalanche research (Lehning and others, 2002a and 2002b). The model simulates three types of the grain metamorphism for layered snowpack: equi-temperature metamorphism, temperature gradient metamorphism, and wet snow metamorphism. The wet snow case is not used in this study. The parameters that are required by the model are air temperature, relative humidity, wind speed and direction, incoming and outgoing shortwave radiation, snow depth, snow temperature, and ground temperature. The shape parameters of the model are dendricity and sphericity. Both shape parameters have values between 0 and 1 . The sphericity describes the ratio of round versus faceted shapes. Dendricity describes the part of the original shapes that remains in the layer. The shape parameters are based on the Crocus model. The number of layers is not restricted and increases in response to snow depth or precipitation. The size parameters used in the model are grain size and bond size. During equi-temperature metamorphism, the temperature gradient is small, and the grain size is equal to the diameter of a sphere. The grain growth rate is a function of temperature, sphericity, and grain size. The temperature gradient metamorphism assumes that grains grow as plates so that thickness of the plates is constant (Baunach and others, 2001), and the grain size is the length of the plate. The grain growth rate 
is described as the function of the grain size, mass flux inside a layer between grains, mass flux between two layers, growing grain size (length of the plate), and snow depth. The optical grain size has been defined by Vionnet and others (2012) in the dendritic case to be a function of dendricity and sphericity. The optical grain size has been defined in the non-dendritic case to be a function of the traditional grain size simulated by the model.

JIM combines different parametrizations for physical processes in 1701 different model configurations. JIM can be used to study snowpack parametrizations impact on the simulation of snow parameters. The subset includes different representations for compaction, the density of new snow, thermal conductivity, liquid water flow, albedo, surface extent and snow fraction, but the model does not include microstructure evolution. This study used representations of compaction, density of new snow, thermal conductivity, and liquid water flow, so that there are 63 model configurations in the subset. The input parameters for the model are soil permittivity, precipitation, air temperature, and shortwave radiation. The model outputs layer thickness, temperature profile, and density profile.

SNTHERM is a snow model that describes the evolution of the snow properties to predict snow mass and energy fluxes. SNTHERM presents the grain growth on the basis of the rate of water vapor transport through the snow, which is relative to the temperature gradient. In the case of dry snow, the growth of the grain diameter is a function of the temperature gradient, grain diameter, snow temperature, air pressure, and variation of saturation vapor pressure with snow temperature.

MOSES is a land-surface model that was developed to simulate water and energy fluxes at the soil-atmosphere interface. It describes snow evolution as a function of the grain size and snow age. The change of the snow grain radius in a time step is presented as a function of initial grain radius, temperature-dependent grain area growth rate (unit $\mathrm{m}^{2} \mathrm{~s}^{-1}$ ), and snowfall rate (unit $\mathrm{kg}$ $\left.\mathrm{m}^{-2} \mathrm{~s}^{-1}\right)$.

SNICAR models radiation penetrated in the snowpack by using a method for spectral albedo calculation that was presented by Wiscombe and Warren (1980). The model uses a lookup table for empirical parameters, which are dependent on density, temperature, and temperature gradient. The microstructure evolution is described with an equation that depends on the initial SSA and the empirical parameters. 
Table 1. Physical snow models used in the work.

\begin{tabular}{|c|c|c|}
\hline $\begin{array}{l}\text { Physical } \\
\text { snow model }\end{array}$ & $\begin{array}{l}\text { Parameters used for defining microstructure } \\
\text { evolution }\end{array}$ & $\begin{array}{l}\text { Output applied in the } \\
\text { work }\end{array}$ \\
\hline SNOWPACK & $\begin{array}{l}\text { 1) equi-temperature metamorphism: } \\
\text { temperature, sphericity, and grain size } \\
\text { 2) temperature gradient metamorphism: } \\
\text { grain size, mass flux inside a layer } \\
\text { between grains, mass flux between two } \\
\text { layers, growing grain size (length of the } \\
\text { plate), and snow depth }\end{array}$ & $\begin{array}{l}\text { traditional grain size } \\
\text { profile, optical grain } \\
\text { size profile, layer } \\
\text { number, layer } \\
\text { thickness, density } \\
\text { profile }\end{array}$ \\
\hline JIM & - & $\begin{array}{l}\text { layer thickness, } \\
\text { temperature profile, } \\
\text { and density profile }\end{array}$ \\
\hline SNTHERM & $\begin{array}{l}\text { temperature gradient, grain diameter, snow } \\
\text { temperature, air pressure, and variation of } \\
\text { saturation vapor pressure with snow } \\
\text { temperature }\end{array}$ & grain size \\
\hline MOSES & $\begin{array}{l}\text { snow age and grain size, which is presented } \\
\text { as a function of initial grain radius, } \\
\text { temperature-dependent grain area growth } \\
\text { rate, and snowfall rate }\end{array}$ & grain size \\
\hline SNICAR & $\begin{array}{l}\text { initial SSA and the empirical parameters } \\
\text { which are dependent on density, } \\
\text { temperature, and temperature gradient }\end{array}$ & SSA \\
\hline
\end{tabular}




\subsection{Microwave emission models}

Several snow microwave emission models exist for simulating the microwave brightness temperature of snow through different approaches. The three models used in this study are presented in the following paragraphs and in Table 2. Other models such as strong fluctuation theory (Stogryn, 1986) have been presented in literature.

The Helsinki University of Technology (HUT) snow emission model (Pulliainen and others, 1999 and Lemmetyinen and others, 2010) is a semi-empirical model to simulate the microwave brightness temperature of one homogenous layer or multilayer snowpack. The layers are defined by depth, temperature, density, traditional grain size, moisture, salinity and SWE. The total extinction coefficient is originally calculated from field observations for $18-90 \mathrm{GHz}$ (Hallikainen and others, 1987) by using average observed grain diameter (close to the traditional grain size). However, Roy and others (2004) presented more accurate results that produce an extinction coefficient based on an empirical correction to the Rayleigh scattering expression. In addition, Kontu and Pulliainen (2010) introduced an empirical correction to translate measured bulk grain size to an effective microwave grain size. When this grain size was used in conjunction with the HUT model, it provided a closer match to space-borne radiometer observations than when the original measured grain size was used.

The Microwave Emission Model for Layered Snowpacks (MEMLS) (Wiesmann and Mätzler, 1999; Mätzler and Wiesmann, 1999) simulates the microwave brightness temperature of homogenous layers for frequencies between 5-100 GHz. The layers are defined by depth, temperature, density, and exponential correlation length. There are several options to represent the scattering coefficient that are based on empirical and theoretical definitions. Empirical scattering coefficient that is defined from field observations by Wiesmann and others (1998) is calculated as function of exponential correlation length. The empirical version is suitable only for certain exponential correlation length and density scales, which were present in the experimental data. The improved Born approximation (Mätzler, 1998; Mätzler and Wiesmann, 1999) can also be used for calculating a theoretical scattering coefficient.

The Dense Media Radiative Transfer Multi-Layer model (DMRT-ML) (Picard and others, 2013) simulates the microwave emission of the multilayer snowpack for frequencies between 1-200 $\mathrm{GHz}$. The layers are defined by optical grain size, density, temperature, stickiness, and liquid water content. The model assumes grains to be sticky hard spheres. Extinction and scattering coefficients are based on the DMRT (Tsang and others, 2000) model. The scattering coefficient depends on the radius of the spheres (grains) and the potential of grains to form clusters, which is related to stickiness. Stickiness has no value from the field observations, and therefore two different estimations - "less sticky" and "very sticky" - are used in this study. The directions of energy propagation are not fixed or limited in DMRT-ML, unlike the HUT and MEMLS models. 
Table 2. Microwave emission models used in the work.

\begin{tabular}{|c|c|c|c|}
\hline $\begin{array}{l}\text { Microwave } \\
\text { emission } \\
\text { model }\end{array}$ & $\begin{array}{l}\text { Directions of } \\
\text { propagation of } \\
\text { electromagnetic } \\
\text { waves }\end{array}$ & $\begin{array}{l}\text { Parameters } \\
\text { defining } \\
\text { layers }\end{array}$ & $\begin{array}{l}\text { Representations of the } \\
\text { extinction/scattering coefficients } \\
\text { applied in the work }\end{array}$ \\
\hline HUT & $\begin{array}{l}\text { propagation in two } \\
\text { directions (simplified } \\
\text { single-stream } \\
\text { approach that } \\
\text { considers only } \\
\text { forward- } \\
\text { propagation, but } \\
\text { considers two total } \\
\text { fluxes propagating in } \\
\text { opposing direction) }\end{array}$ & $\begin{array}{l}\text { depth, } \\
\text { temperature, } \\
\text { density, } \\
\text { traditional } \\
\text { grain size, } \\
\text { moisture, } \\
\text { salinity, SWE }\end{array}$ & $\begin{array}{l}\text { Extinction coefficient is calculated by } \\
\text { 1) Hallikainen and others (1987): } \\
\text { average observed grain diameter } \\
\text { (close to the traditional grain size) } \\
\text { 2) Roy and others (2004): an } \\
\text { empirical correction to the } \\
\text { Rayleigh scattering expression } \\
\text { 3) Kontu and Pulliainen (2010): an } \\
\text { empirical correction to translate } \\
\text { measured bulk grain size to an } \\
\text { effective microwave grain size }\end{array}$ \\
\hline MEMLS & $\begin{array}{l}\text { propagation in six } \\
\text { orthogonal } \\
\text { directions (two-flux } \\
\text { model that considers } \\
\text { both the forward } \\
\text { and backward } \\
\text { propagation) }\end{array}$ & $\begin{array}{l}\text { depth, } \\
\text { temperature, } \\
\text { density, } \\
\text { exponential } \\
\text { correlation } \\
\text { length }\end{array}$ & $\begin{array}{l}\text { 1) Empirical scattering coefficient is } \\
\text { calculated as function of } \\
\text { exponential correlation length } \\
\text { 2) Theoretical scattering coefficient } \\
\text { is calculated by the improved } \\
\text { Born approximation }\end{array}$ \\
\hline DMRT-ML & $\begin{array}{l}\text { no limit for } \\
\text { directions of } \\
\text { propagation }\end{array}$ & $\begin{array}{l}\text { optical grain } \\
\text { size, density, } \\
\text { temperature, } \\
\text { stickiness, } \\
\text { liquid water } \\
\text { content }\end{array}$ & $\begin{array}{l}\text { Scattering coefficient is related to } \\
\text { stickiness estimated as } \\
\text { 1) "less sticky" } \\
\text { 2) "very sticky" }\end{array}$ \\
\hline
\end{tabular}




\section{Field experiments}

This section introduces field experiments performed for this study. Section 4.1 describes the measurement site in Sodankylä and Section 4.2 presents the snow pit measurements. Section 4.3 introduces the microwave radiometer measurements. Section 4.4 presents the Arctic Snow Microstructure Experiment, including snow pit measurements and radiometric measurements of snow samples extracted from natural snowpacks.

\subsection{Measurement site}

Field measurements were performed at the Arctic Space Centre of Finnish Meteorological Institute (FMI-ARC) in Sodankylä (67.367 N, 26.629 E), which is located in northern Finland in the taiga snow region. The most common land cover types in northern Finland and Sodankylä are forest, bog, and surface water areas. Publication $\mathrm{V}$ presents all the measurement sites at FMI-ARC and measured data sets related to snow cover. The snow measurements are made for purposes of the remote sensing-related research and for the operative weather services. Operative snow depth measurements started in 1909, and SWE was measured operationally from the 1910s until the 1950s. SWE measurements started again in two locations (forest and open) in the 1970s and were performed until 2019. In addition, snow course monitoring with 80 snow depth and 8-11 SWE measurements have been made since 1959 in co-operation with the Finnish Environment Institute.

Snow pit measurements have been made since 2006 for research purposes. Measurements are made weekly, except in the winters of 2006-2010, when measurements were made twice per week, and in the winter of 2014-2015, when they were made biweekly. Measurements are performed in several locations, but this study uses the data mainly from the Intensive Observation Area (IOA), which has been the primary site for snow measurements until autumn 2018. The IOA is located in a forest clearing that is surrounded by a sparse coniferous forest (Figure 4). In addition to the snow pit measurements, the available reference measurements of snow on the ground include SWE with a weighing snow scale and an instrument based on the attenuation of gamma radiation, snow temperature profile, and snow depth with two ultrasonic sensors (Leppänen and others, 2018). The main purpose of the site has been to host tower and mast-based instruments: optical spectroradiometers, microwave radiometers, and microwave scatterometers have been installed at the site. These instruments have been used for the development of microwave emission and reflectance models in addition to other calibration or validation activities of satellite instruments (e.g., Lemmetyinen and others, 2016; Rautiainen and others, 2012; Salminen and others, 2009). 


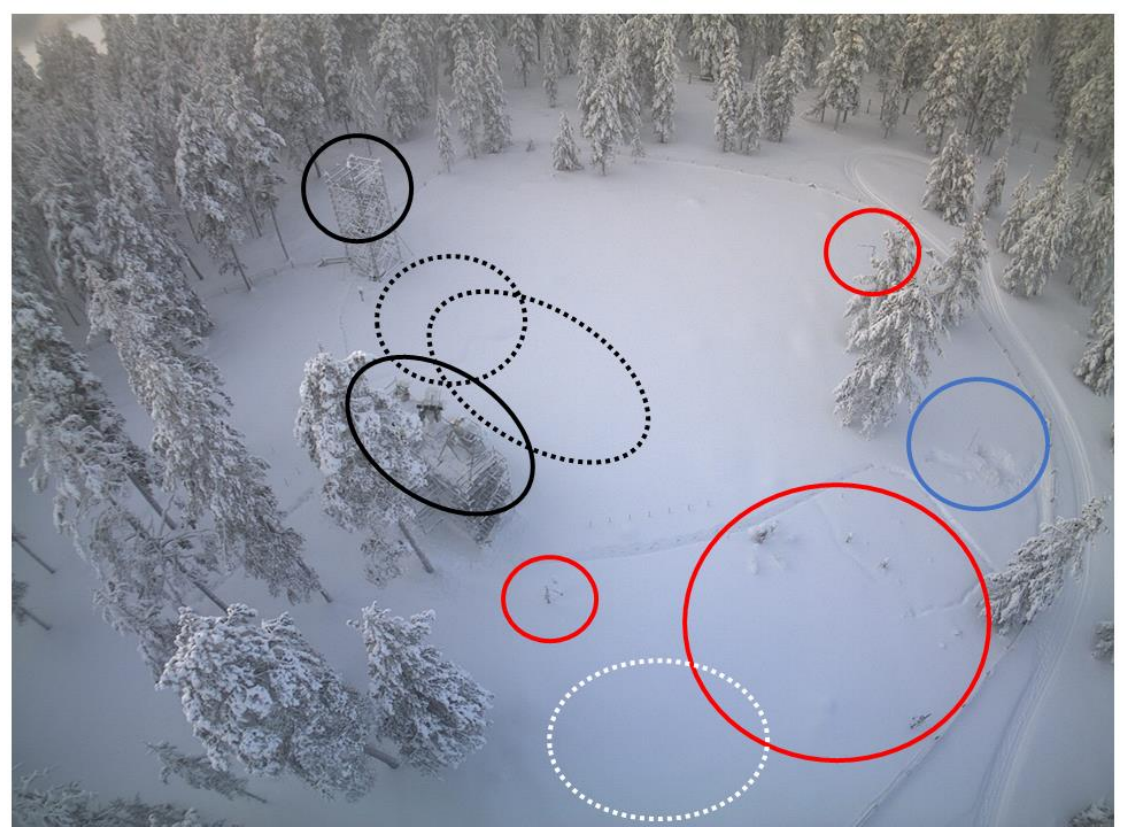

Figure 4. Approximate locations at the Intensive Observation Area (IOA) are marked in the figure: snow pit measurements (blue), automated snow and soil measurements (red), microwave instruments (black), their footprint areas (dashed black), and the open observation area of the optical instrument (dashed white). Optical measurements are made from the mast, where the photo was taken.

Typically, the snow cover in Sodankylä persists from November to May. The maximum snow depth values (around 80-100 cm) are measured usually in March, and the melting season begins at the end of March or beginning of April (Pirinen and others, 2012). Snow is typically dry before the melting season, although the snow surface experiences occasional melt-refreeze cycles. Snow depth and air temperature for the winters of 2011-2012 and 2012-2013 are presented in Figure 5, and snowpack stratigraphy (layers with grain types) is presented in Figure 6 for the same period. The snow metamorphic processes that are described in Section 2.3 are visible in the stratigraphy, which are highly related to air temperature and snow accumulation. The annual variability of stratigraphy has major effects on the uncertainties of simulations of physical snow models and microwave emission models, which is apparent in the results of Sections 5.2 and 5.3, which use data from 2011-2013. 
a

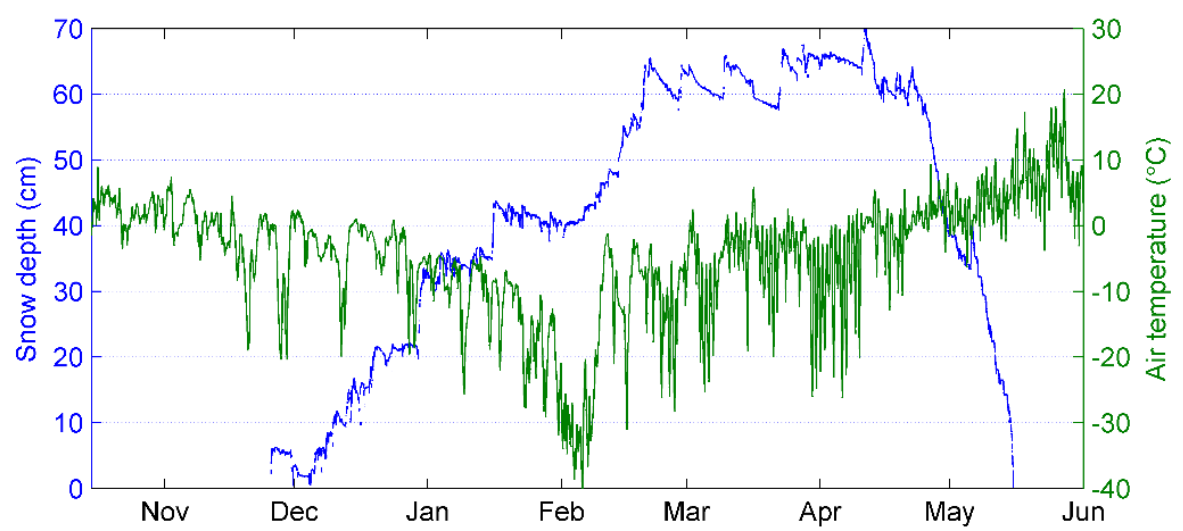

b

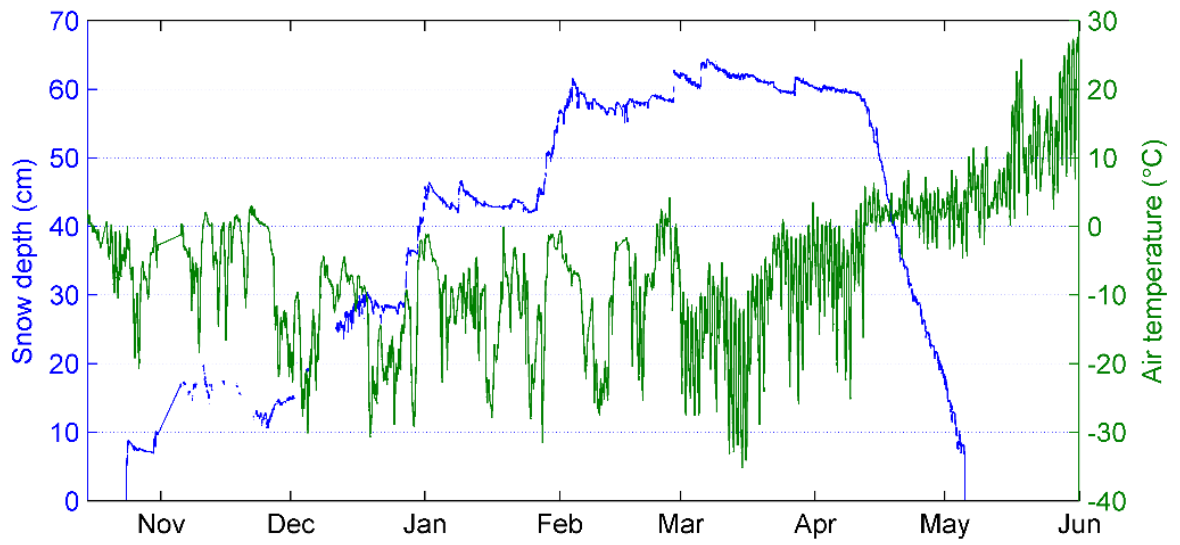

Figure 5. Snow depth (blue) and air temperature (green) for a) 2011-2012 and b) 2012-2013. 


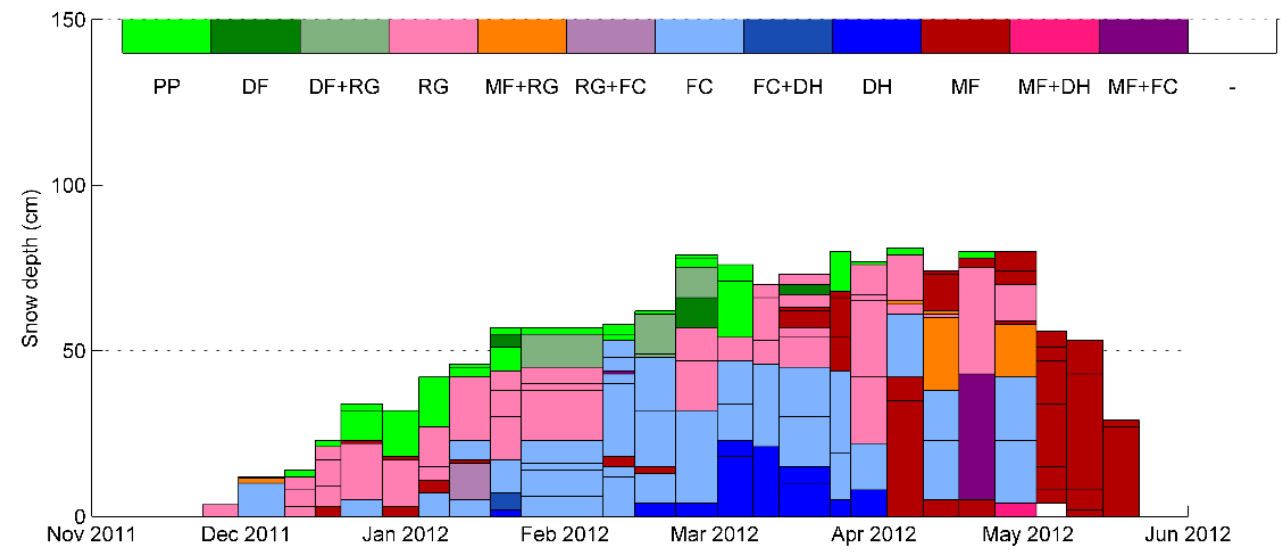

b

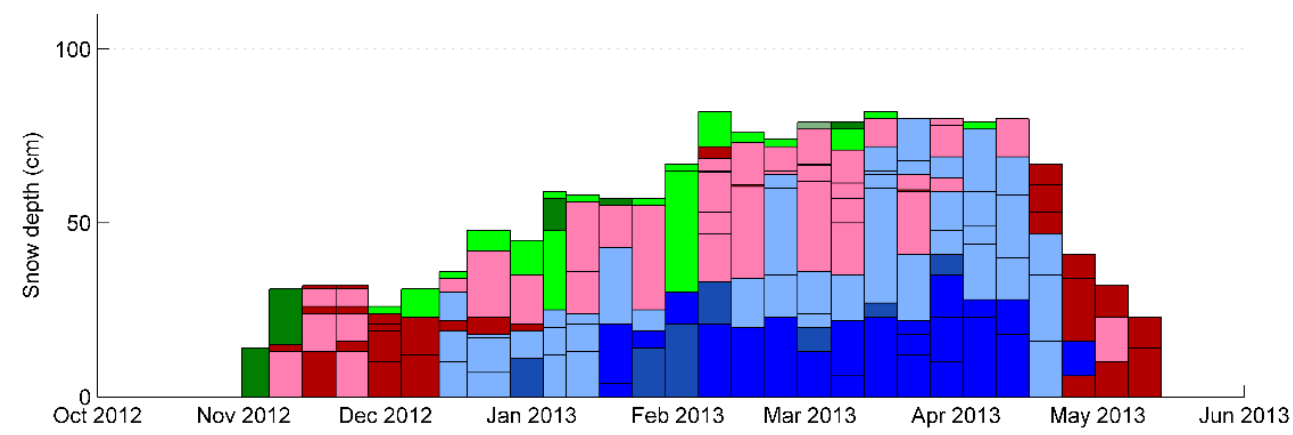

Figure 6. Stratigraphy measured in a) 2011-2012 and b) 2012-2013. Grain type classes are shown in different colors: precipitation particles (PP), decomposing and fragmented precipitation particles (DF), rounded grains (RG), melt forms (MF), faceted crystals (FC), and depth hoar (DH). 


\subsection{Snow pit measurements}

Macrostructural and microstructural parameters were measured with several methods in the snow pits, although the measured parameters and methods varied between winters. Snow pits were made in the same area, but the measurement location was moved every time so that untouched snow was measured each time. The smooth wall of the snow pit was constructed to face the south so that it was shaded from the solar radiation. The detailed description of methods is presented in Publications I and V. The measurements described below were made at the IOA.

Bulk SWE and snow depth was measured at the site between 2006-2018. Bulk SWE was measured with a $70 \mathrm{~cm}$-high Korhonen-Melander sampler (Figure 7a), and snow depth was measured with a wooden probe as depicted in Figure $7 \mathrm{~b}$. The temperature profile with $10 \mathrm{~cm}$ intervals was measured manually from 2006 to 2015 (Figure 7c), when it was fully replaced with automated temperature sensors. The density profile with $5 \mathrm{~cm}$ intervals was measured between 2009-2018. A triangular sampler was used before 2015, after which it was replaced with selfmade rectangular sampler (Figure 7d). Liquid water content and density were measured at a 10 cm vertical spacing between 2009-2015 with the SnowFork instrument (Sihvola and Tiuri, 1986), which measures the relative and imaginary permittivity of snow between two metal spikes (Figure 7e).

Snow stratigraphy was defined with macro-photographs of the grains between 2006-2018. Traditional grain size, grain type, hardness, and wetness were estimated for every layer (Figures $7 \mathrm{~b}, \mathrm{f})$. Macro-photographs were taken from the snow samples of every layer against a 1-mm reference grid (Figure $7 \mathrm{~g}$ ), and macro-photography-based traditional grain size with a precision of $0.25 \mathrm{~mm}$ and grain type were estimated in post-processing. The SSA profile with IceCube (A2 Photonic Sensors) was measured with 3-cm intervals in 2012-2017 and in 2017-2018 by sampling every layer. IceCube measures the reflectance of a $1310 \mathrm{~nm}$ laser from the snow sample surface with an integrating sphere (Gallet and others, 2009). The sample was taken with a spatula or separate tool and packed to the sample holder (Figure $7 \mathrm{~h}$ ). The sample surface was smoothened and was measured with the instrument by placing the sample below the laser (Figure 7i). Calibration measurements are made in conjunction with every measurement occasion with differently shaded calibration targets. Reflectance is converted to SSA by software that is provided by the manufacturer. SMP (Schneebeli and Johnson, 1998; Schneebeli and others, 1999) was used between 2014-2016 to define layers, density profile, and SSA profile (Figure $7 \mathrm{j}$ ). 

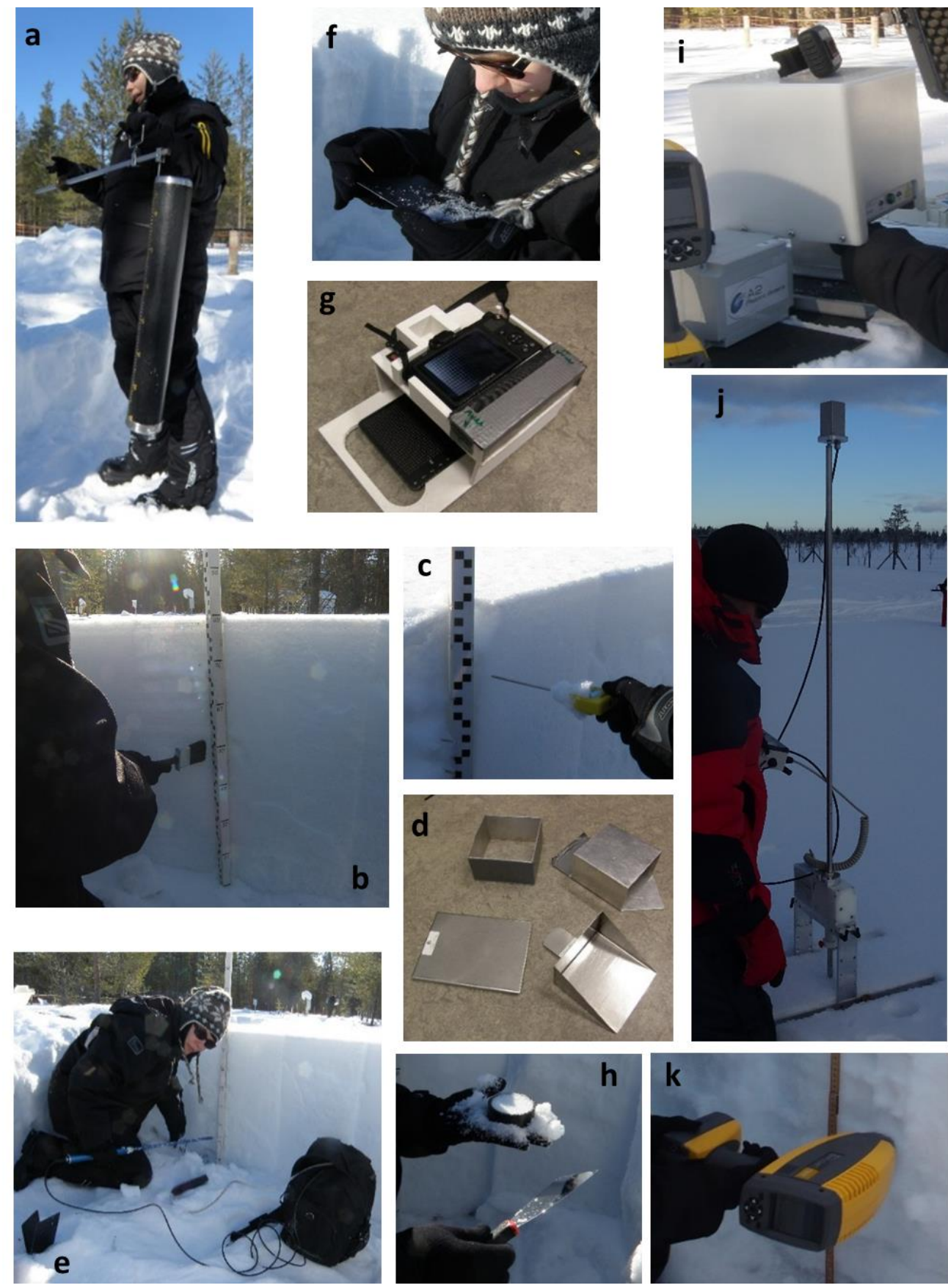

Figure 7. Photos of snow pit instrumentation: a) bulk SWE with Korhonen-Melander sampler, b) stratigraphy, c) temperature, d) $500 \mathrm{~cm}^{3}$ and $250 \mathrm{~cm}^{3}$ density cutters, e) SnowFork, f) visual estimation of snow grains, g) camera and stand for macro-photography, h) IceCube sampling, i) IceCube, j) SMP, and k) QST. Modified from Publication V. 
Reflectance profiles with QST (QualitySpec Trek, ASD Inc.) were measured in 2017. The QST uses an internal light source to measure the spectral bidirectional reflectance of $350-2500 \mathrm{~nm}$. The light source and fiber optic cable are behind a transparent window. The window has a diameter of approximately $1 \mathrm{~cm}$. The viewing configuration is similar to the illuminated contact probe that is manufactured by ASD Inc. (Painter and others, 2007) so that the angle from the instrument window to the light source is $55^{\circ}$ and the angle to the fiber optic is $78^{\circ}$. The fiber optic cable has a field of view of $25^{\circ}$. Additional calibration is made with a white calibration target at the beginning of every measurement occasion. At the end of measurements, the instrument calibration is verified with an internal grey target. The measurements were made with $2-5 \mathrm{~cm}$ intervals from the vertical profile of a snow pit (Figure $7 \mathrm{k}$ ) or from sampled snow that was prepared for the IceCube measurements. The window needed to be in stationary physical contact with the snow during the spectrum averaging time, which was set to 1 or $2 \mathrm{~s}$. The instrument scanned the entire wavelength range at a speed of 10 times per second and produced an average of those measurements. The resulting reflectance is the absolute reflectance; the reflectance is normalized with the reference reflectance.

\subsection{Microwave radiometer measurements}

A radiometer is a passive instrument that measures the natural thermal emission of a target. In microwave radiometry, the emission is typically restricted to a distinct frequency band (see Section 2.1). A radiometer consists of an antenna that spatially collects the observed radiation, a receiver that amplifies the signal and filters it to the desired frequency band, and a detector that converts the signal intensity to a detectable form (such as voltage). The observed signal is so small, that the thermal noise produced by the instrument is usually larger than it, necessitating careful calibration.

Three radiometer systems with seven frequencies were installed at the IOA (Lemmetyinen and others, 2016; Leppänen and others, 2018; Rautiainen and others, 2012). The SodRad1 radiometer had frequencies of $10.6,18.7,36.5$, and $89 \mathrm{GHz}$ in 2009-2011 and frequencies of 10.6, 18.7, 21, and $36.5 \mathrm{GHz}$ from 2011 onwards. The observations of $18-37 \mathrm{GHz}$ are often used for snow measurements for historical reasons (Chang and others, 1987). A difference of two frequencies is typically used for SWE retrievals, as described in Section 2.1. The SodRad2 radiometer has frequencies of 89 and $150 \mathrm{GHz}$, which are above the frequency limit of the common snow microwave emission models (see Section 3.2). However, the SodRad2 radiometer could be used to detect radiation from the snow surface until a depth of $10 \mathrm{~cm}$ and be compared with optical observations. In addition, the ESA ELBARA II radiometer measures at 1.4 GHz frequency which is typically used for soil moisture and frost observations. 
The radiometers were installed on a $4 \mathrm{~m}$-high tower in the IOA (Figure 8); SodRad1 was installed in 2009-2018, and SodRad2 was installed in 2012-2016. The radiometers measure horizontally and vertically polarized radiation. Instruments are continuously calibrated by measuring the background noise with the internal target by switching the measurement between the measurement target and internal target. The occasional absolute calibration for the radiometers was made with a liquid nitrogen target and a target at air temperature (which is the ambient target) to convert voltages to brightness temperatures by fitting the calibration curve between two points. A regular daily calibration check is made by measuring the sky at the nadir, which exhibits a relatively stable and predictable brightness temperature, especially for low microwave frequencies.

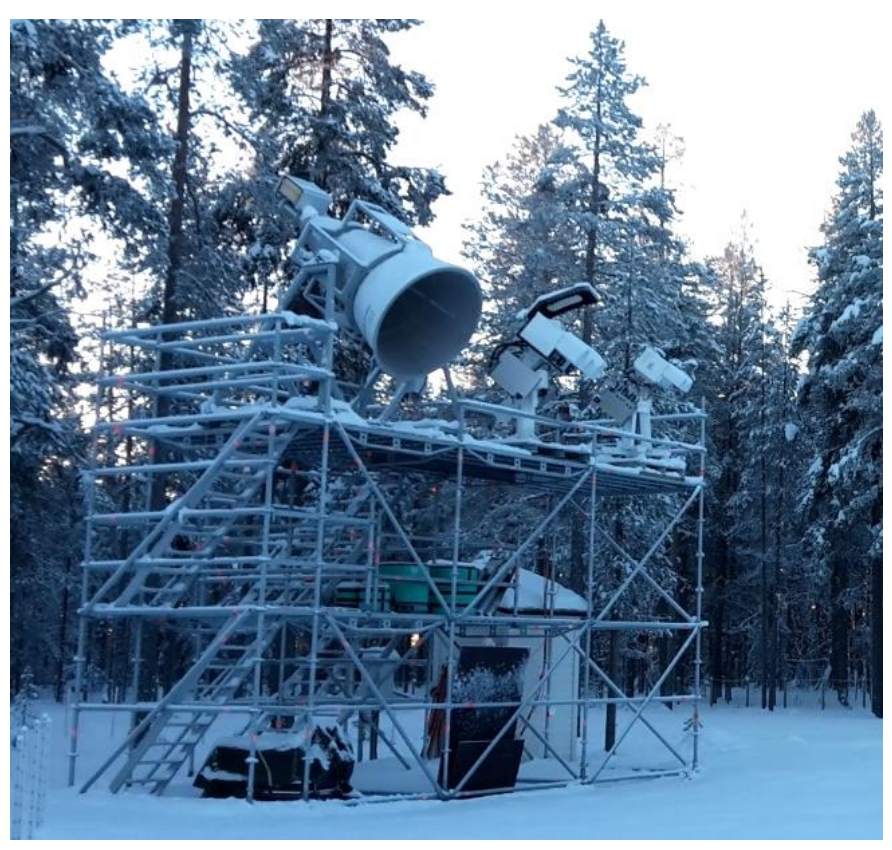

Figure 8. Tower-based ESA ELBARA II (left), SodRad1 (middle), and SodRad2 (right) radiometers at IOA. 


\subsection{Arctic Snow Microstructure Experiment}

The Arctic Snow Microstructure Experiment (ASMEx) aimed to investigate the extinction of the microwave radiation in snow by using homogenous snow samples that were extracted from the natural snowpack. The experiment mainly used the same measurement devices as for observations of the natural snow in FMI-ARC. However, ASMEx had an experimental setup for the measurements (Figure 9a). The homogenous snow samples were slabs of 5-15 cm height and were extracted from the natural snowpack and delivered up to the tower to stand under the radiometers (Figure 9b). Measurements were performed with SodRad1 and SodRad2 radiometers; first with a reflective base (metal plate), and second with an absorbing base that was made of an absorbing material (Figure 9c). The measurements with the two setups enabled reflectivity and transmissivity calculations. Radiometric measurements were also made from the respective sky angles to note background radiation for the reflective base observations. After the radiometric measurements, snow homogeneity was confirmed with 12 SMP measurements across the slab (Figure 9d). After removal of the plastic frame, macrophotography-based traditional grain size and grain type, SSA, temperature, and density were measured with the same methods as for the snow pits (Section 4.2 and Figure 7). In addition, two samples for microCT were taken from the middle of the slab. A total of 14 dry snow slabs were measured during two winter seasons in 2013-2015. The experiment is described with more detail in Publication IV. 
a

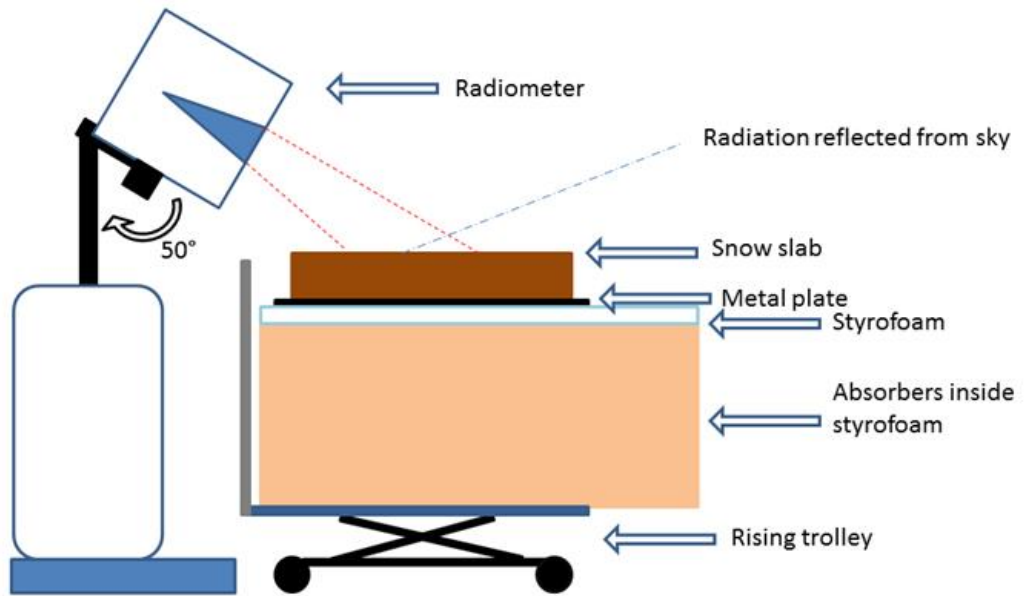

b

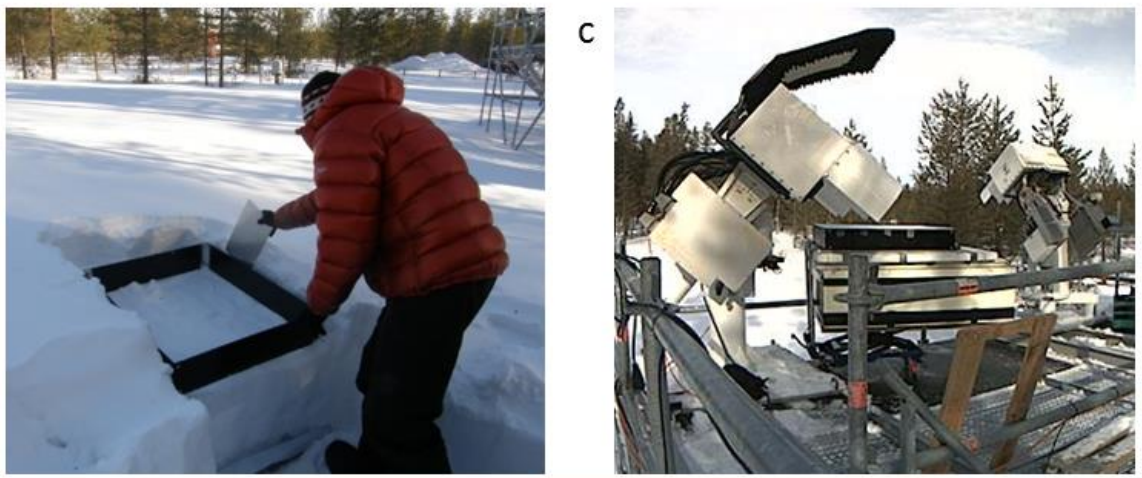

d

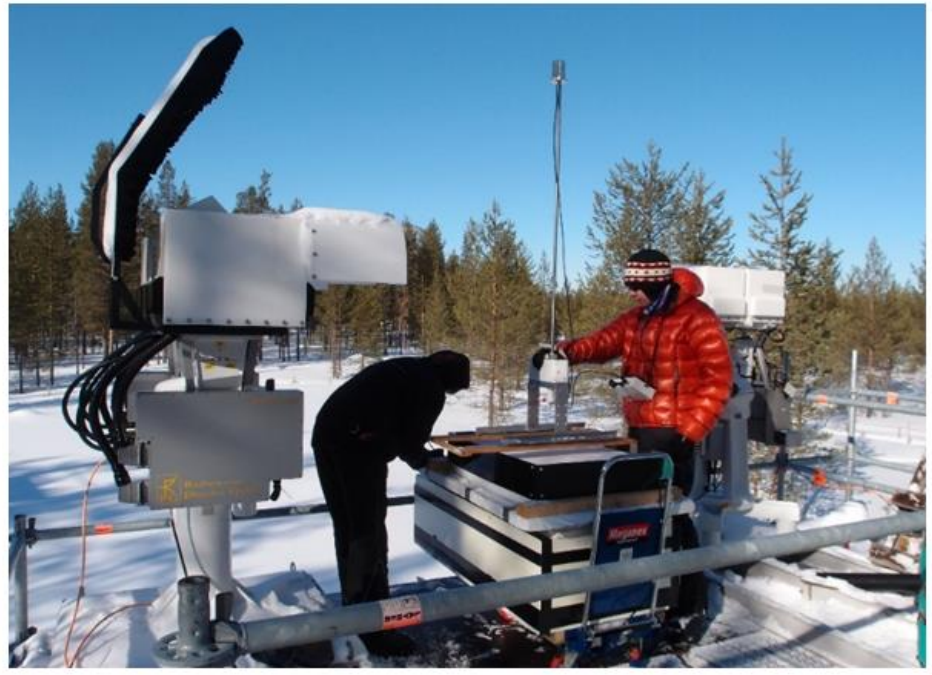

Figure 9. a) ASMEx setup. Reprinted from Publication IV. b) Excavation of snow slab for ASMEx. Modified from Publication IV. c) Radiometric measurement of the slab with SodRad1 radiometer. d) SMP measurement from the snow slab. 


\section{Results and discussion}

This section summarizes the most important findings from Publications I-V and provides a discussion of the study's results. Section 5.1 presents the results from Publication I, where the QST was tested for the snow reflectance measurements and compared with SSA measurements. Section 5.2 compares the measured and simulated snow depth, density, SWE, and microstructure from Publication II for the SNOWPACK model and from Publication III for the JIM coupled with SNTHERM, SNICAR, and MOSES models. Section 5.3 presents the results from Publication III for the measurements of a natural snowpack, where the measured microwave brightness temperatures were compared with the HUT, MEMLS, and DMRT-ML simulations. The section also presents results from Publication IV for the ASMEx measurements, where the measured microwave brightness temperatures were compared with the HUT and MEMLS simulations. Section 5.4 presents results from Publication $V$ that demonstrate the variability of bulk snow properties of snow depth and SWE at the Sodankylä experiment site.

\subsection{Empirical relationship between reflectance and specific surface area}

QualitySpec Trek (Section 4.2 and Figure 7k) is a novel method for making contact measurements of spectral reflectance. This method was developed for measurements of minerals, soil, and vegetation (Hu and others, 2017; Peng and others, 2016). The suitability of QST for snow reflectance measurements has not been studied. Publication I describes the results of the testing, including a comparison with SSA. The measurements with QST were made from February to April in 2017 during five regular snow pit measurements, when the SSA profile was also measured with IceCube (Section 4.2 and Figure 7i). The QST measurement profiles were made twice vertically directly from the snowpack, once from the sampled snow for IceCube, and twice from the snowpack and sampled snow.

The values of $1160 \mathrm{~nm}$ and $1260 \mathrm{~nm}$ wavelengths were used from spectrums of QST for the analyses on the basis of results presented by Hyvärinen and Lammasniemi (1985). Reflectance at $1260 \mathrm{~nm}$ has a larger ice absorption coefficient than reflectance at $1160 \mathrm{~nm}$, and the difference between $1260 \mathrm{~nm}$ and $1160 \mathrm{~nm}$ reflectances corresponds approximately to the depth of the absorption feature. An empirical relationship between SSA and reflectance was studied with a reflectance index. A reflectance index $Q$ is defined so that

$$
Q=\frac{R_{1260}}{R_{1160}-R_{1260}}
$$

where $R_{1160}$ is the reflectance at $1160 \mathrm{~nm}$, and $R_{1260}$ is the reflectance at $1260 \mathrm{~nm}$. SSA measurements were interpolated for $1 \mathrm{~cm}$ intervals to allow for comparison of the reflectance and SSA profiles from the same heights. A linear empirical relationship was found between the 
$Q$-index and SSA (Figure 10) with profile-respective correlation coefficients of $0.85-0.98$. However, there were approximately constant 0.2 vertical differences in the lines fitted to the measurements from the snowpack and the sampled snow (Figure 10), which possibly originate from absorption by the sample holder. Single outliers exist in the measurements of 21 March for the sampled snow (five lowest $Q$-index values in Figure 10b), which are expected to originate from the melting of the samples before QST measurements due to the distinct procedure of additionally weighing the samples.

Sampling for the IceCube measurement is a relatively slow and difficult process for a nonexperienced person. However, a method that uses an illuminated contact probe connected to a spectrometer, which was introduced by Painter and others (2007), does not require sampling. Inter-comparison of the contact probe and IceCube measurements were made in the international grain size workshop (see Section 1.3); the unpublished results indicated larger bias for the contact probe than IceCube as compared to other instruments participated to the workshop. Neither of the instruments are hand-held, and it is especially difficult and slow to change measurement location with IceCube. As a hand-held portable instrument, QST is easier and faster to use in field conditions. QST is a potentially effective method to measure the $Q$ index for the retrieval of SSA information from snow; however, a more comprehensive dataset that includes the evaluation of the $Q$-index for other snow types besides taiga snow would be required for the development of a robust retrieval algorithm. 


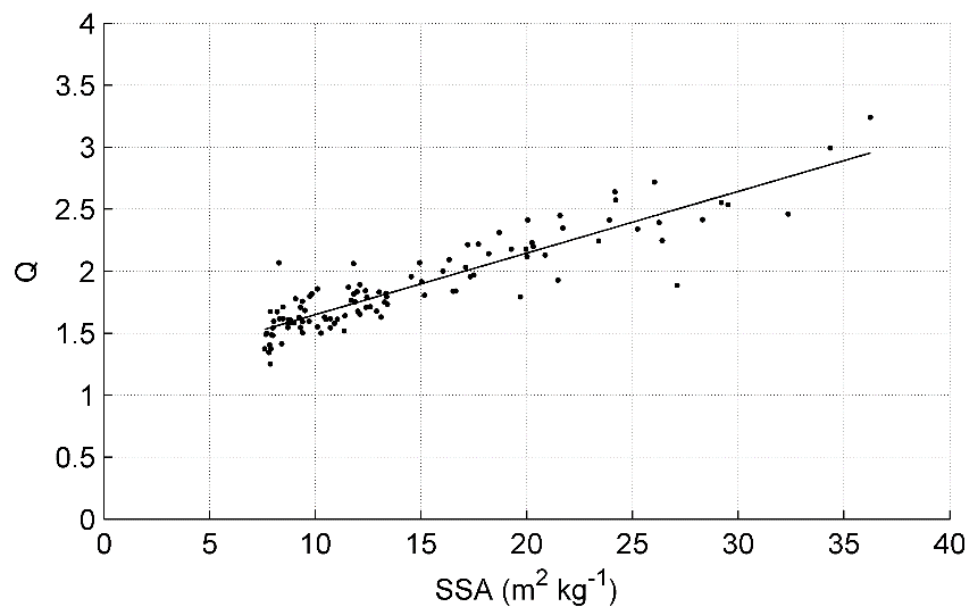

b

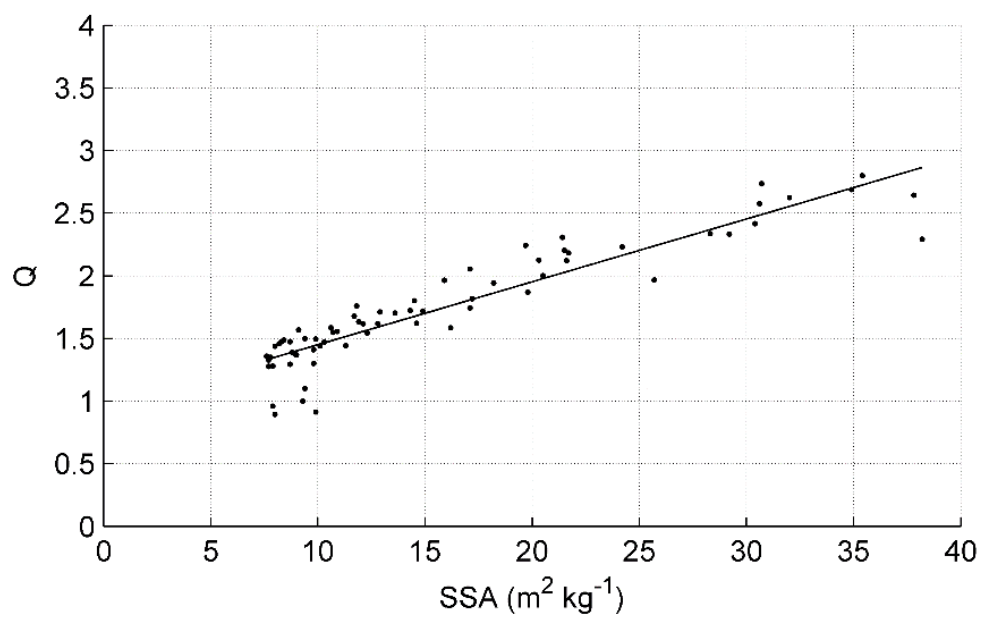

Figure 10. Comparison of reflectance-based $Q$-index and SSA; a) the QST measurements made from the snowpack, and b) the QST measurements from the sampled snow. Reprinted from Publication I. 


\subsection{Comparison of measured and simulated snow properties}

Simulated snow depth, density, SWE, traditional grain size, and SSA are compared to observed values in Publications II and III. Publication II compared measured values with SNOWPACK model estimates, and Publication III compared measured values with JIM configurations by using microstructures from the SNICAR, SNTHERM and MOSES models for the two winter seasons of 2011-2013. Snow depth, air temperature, and snow stratigraphy are presented for the same period in Figures 5 and 6 . Typically, SNOWPACK simulated more layers than detected in the snow pit stratigraphy observations (Figure 6). The number of layers in SNOWPACK is relative to accumulation periods, which explains the difference. Thus, layer-by-layer comparison of the snow characteristics is not relevant. Therefore, measured and simulated values were weighed with SWE or the height of a given layer and averaged over the whole snowpack. Similar averaging of the layer properties was also applied for JIM simulations.

The SNOWPACK-simulated density values were lower than the observed values, with a bias of $33 \mathrm{~kg} \mathrm{~m}^{-3}$ and $-30 \mathrm{~kg} \mathrm{~m}^{-3}$ on average for the dry snow seasons of 2011-2012 and 2012-2013 respectively. JIM configurations with microstructures from the SNICAR, SNTHERM, and MOSES models had less differences during the accumulation periods than the melting periods for both snow depth and SWE. For SWE, variations in the melting periods originated from a different presentation of liquid water flow in the snow. For snow depth, there were notable variations between JIM configurations due to the representation of densification and initial density. For 2011-2012, simulated SWE was lower than the measurements until the end of January and then were higher until the beginning of melting period. Simulated SWE was higher than the measurement for most of the season of 2012-2013. Simulated snow depth had by visual estimation a smaller difference to measurements for the second winter than the first.

The SNOWPACK model provides traditional and optical grain size for each layer. The maximum values of the traditional grain size were $2.75 \mathrm{~mm}$ for measured and $2.5 \mathrm{~mm}$ for simulated. The maximum values of the optical grain size were $1.25 \mathrm{~mm}$ for measured and $1.5 \mathrm{~mm}$ for simulated. Minimum values varied between $0-0.25 \mathrm{~mm}$. The time series of the measured and the SNOWPACK-simulated grain sizes are presented in Figure 11. For the traditional grain size, the average bias and root mean square error (RMSE) between measured and simulated values was smaller $(0.19 \mathrm{~mm}$ and $0.37 \mathrm{~mm}$, respectively) than for the optical grain size $(0.50 \mathrm{~mm}$ and 0.53 $\mathrm{mm}$, respectively). For traditional grain size, the bias and RMSE were larger for the second winter than the first, which might originate from melting in the beginning of accumulation period, as is evident from Figure 6. However, the average correlation coefficient was better for the optical grain size $(0.74)$ than for the traditional grain size $(0.47)$. The ratio between the measured and the simulated values was 2.1 for the optical grain size and 1.2 for the traditional grain size. 

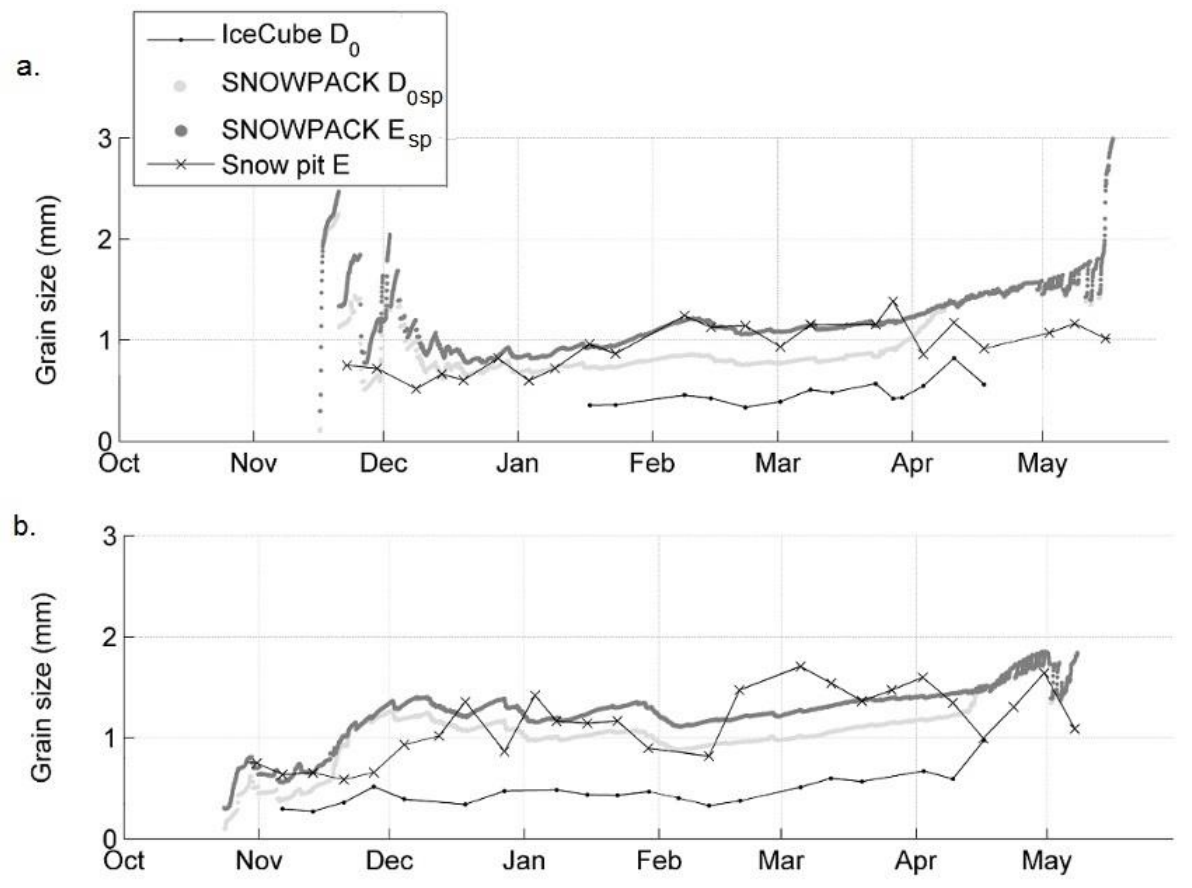

Figure 11. Measured traditional grain size (x), optical grain size (.), SNOWPACK-modelled traditional grain size (dark grey line), and optical rain size (light grey line) for a) 2011-2012 and b) 2012-2013. Simulations are driven with meteorological, radiation, and soil measurements. Reprinted from Publication II.

The JIM snow model parametrizations driven with three microstructure models (SNICAR, SNTHERM and MOSES) provides grain size estimates, which are compared with manual measurements in Figure 12. The difference originating from the microstructure models is larger than the difference originating from JIM parametrization. Variability that originated from JIM parametrization was larger for the second winter than the first, which could be again related to the formation of MF grains in early winter (Figure 6). The measured traditional grain size was larger than any of the modelling results. On average, the measured optical grain size was between SNTHERM and SNICAR results. The difference between the measured optical grain size and the simulated grain size varied between -53 to $+45 \%$. SNTHERM had the smallest bias of $0.12 \mathrm{~mm}$ for the first winter, and SNICAR had the smallest bias of $-0.14 \mathrm{~mm}$ for the second winter, which means percentage values of $+32 \%$ and $-31 \%$ respectively. 
To summarize, the measured and the SNOWPACK-simulated traditional grain sizes were larger than the measured optical grain size and all the other simulated grain sizes. The optical grain size observations were larger than simulations with SNICAR and MOSES and smaller than the simulations with SNOWPACK and SNTHERM. However, SNOWPACK simulations for traditional and optical grain size were closer to the measured traditional grain size than the other simulations. Bias was smaller for the first winter than the second for SNOWPACK and SNTHERM. Bias was smaller for the second winter than the first for SNICAR and MOSES. The result is that the representation of microstructure in the models should be improved, especially where microstructure is described only with a size parameter. However, SNOWPACK has reasonable accuracy for microstructure simulations because it describes microstructure also with the shape parameters.

The accuracy of the simulations relies on representative input data and correctly modeled snow physics, which is challenging due to the complex nature of snow. As Rutter and others (2009) have demonstrated, different physical snow models produce large differences with the same input data due to a differing description of snow physics and layer structure. Other studies have been published on validation of different models for macrostructural properties; there have been studies for SNOWPACK (Groot Zwaaftink and others, 2013; Hirashima and others, 2008; Huang and others, 2012; Langlois and others, 2012; Lehning and others, 2001; Rasmus and others, 2007), and for SNTHERM and SNICAR (Huang and others, 2012). The general conclusion is that accuracy of the models is dependent on season, year, and location.

Other studies have also compared SNOWPACK-simulated microstructure with measurements (e.g. Groot Zwaaftink and others, 2013; Kontu and others, 2017; Lehning and others, 2001; Rasmus and others, 2007). The studies demonstrated varying agreement scores between the simulated and the observed grain sizes, depending on year and location, for example. Similarly, this work demonstrated annual variability for the model accuracies. Therefore, scaling of the simulation results with annually varying scaling factors could be implemented prior to further applications. The novel aspects of this work was to use SSA for optical grain size derivation in publication II and JIM configuration with three microstructure models in publication III. 

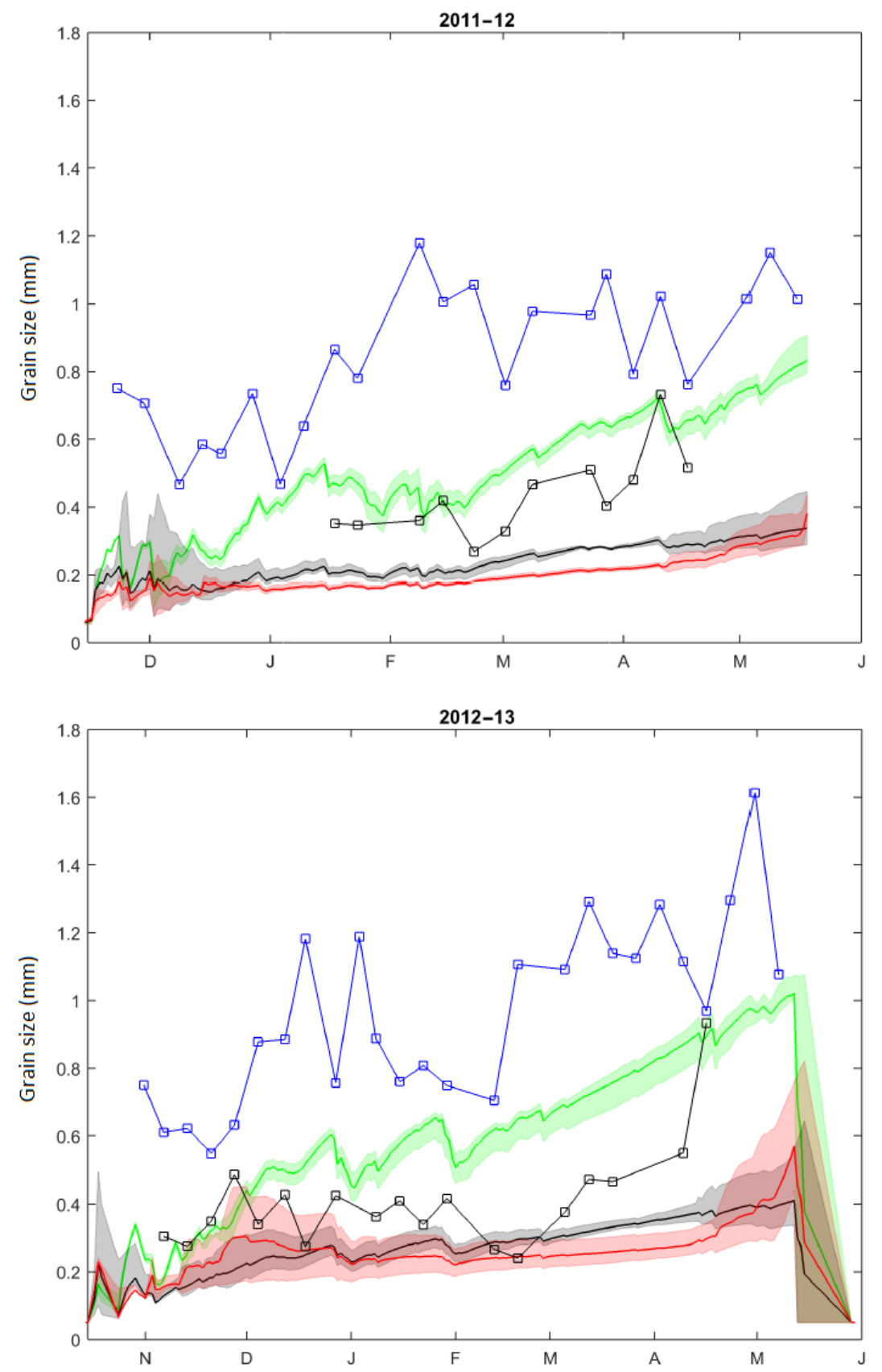

Figure 12. Measured traditional grain size (blue o), optical grain size (black o), SNTHERM (green line), SNICAR (grey line), and MOSES (red line)-modelled grain size with spread from different JIM parametrizations. Simulations are driven with meteorological, radiation, and soil measurements. Modified from Publication III. 
Model simulations of snow macrostructural properties are employed for several purposes such as avalanche forecasts (e.g. Bartelt and Lehning, 2002; Brun and others, 1992; Hirashima and others, 2008) and energy and mass balance studies (Carroll and others, 2006; Rutter and others, 2008). In addition, physical snow models can be coupled with climate models to predict snow macro-physical properties for different future climate scenarios (Marty and others, 2017). In the future, simulations could be beneficial for the retrieval of microwave remote sensing observations because the simulated macro-physical parameters have the potential to be used for driving the retrieval algorithms. In addition, simulated microstructural parameters could be potentially used as input parameters in the microwave emission models to increase the accuracy of the SWE retrievals (Kontu and others, 2017).

\subsection{Comparison of measured and simulated brightness temperatures}

The observed microwave brightness temperatures were compared to the emission model simulations in Publications III and IV. Publication III compared HUT, MEMLS, and DMRT-ML emission models driven with JIM snow cover states for 2011-2013, and Publication IV compared HUT and MEMLS models by using a data set that was collected during the ASMEx in 2013-2015. Only dry snow simulations were used in the studies. Air temperature, snow depth, and stratigraphy are presented in Figures 5 and 6 for the winters when the JIM snow model was applied for the natural snowpack.

In Publication III, simulations were made with the three microwave emission models that were driven with the three microstructure models and the 63 configurations of JIM model, which produced 1323 different brightness temperature simulations per day. There was varying physical complexity of the applied microwave emission models. The semi-empirical HUT model uses a simplified single-stream approach for describing the propagation of electromagnetic waves in snow; only the forward-propagating wave is considered. The semi-empirical MEMLS applies a two-flux model that considers both the forward and backward propagating emissions; moreover, scattering and absorption parameters are derived by considering propagation in six orthogonal directions. The theoretical DMRT-ML is the most physically complex of the models and has no limit for directions of energy propagation. Different representations of the scattering coefficients were applied: three extinction coefficient equations for HUT, an empirical representation and the improved Born approximation for MEMLS, and both "very sticky" and

"less sticky" approximations of stickiness for DMRT-ML (see Section 3.2). The optical grain size was assumed to be identical in microstructure models coupled with JIM, DMRT-ML, and HUT. The assumption might be poor for HUT because the model was developed by using traditional grain size. The exponential correlation length for MEMLS was calculated by using equation (3). 
Brightness temperatures simulated with MEMLS had the largest range of variability, while brightness temperatures simulated with HUT had the smallest range of variability from different representations and configurations for all frequencies. The range of simulated values generally covered the observed brightness temperatures, with some exceptions. The largest errors were in the winter of 2012-2013, which might originate from deeper depth hoar layers or crust layers middle of the snowpack (Figure 6). During the comparison of the coupled model simulations with observations, no model combination resulted in clearly superior results to other models for all frequency and polarization combinations (Figure 13a). Scaling factors applied to the grain size were calculated for the simulated microstructural parameters to achieve an optimal fit. In general for all microwave emission models, SNICAR simulations needed only small scaling, MOSES results needed little scaling up, and SNTHERM predictions required scaling down. Accordingly, Section 5.2 presents that SNICAR simulations were lower than measured optical grain size, MOSES had the lowest grain size values, and SNTHERM grain size simulations had larger values than the measured optical grain size. Generally, the difference in scaling factors were larger between the microstructure models than the emission models. The difference in the scaling factors between the microstructure models were 2.5 for DMRT-ML, 1.2 for MEMLS, and 2.6 for HUT, on average, and the difference in the scaling factors between the microwave emission models were 0.8 for SNTHERM, 2.1 for MOSES, and 1.7 for SNICAR, on average. When the scaling factors were used for the microstructure in simulations, RMSE values improved for most of the frequencies and polarizations, as is visible in Figure 13b. The study identified the need for better description of microstructure in the microwave emission models, which could reduce RMSE values for all frequencies and polarizations.

Manual observations from the snow slabs at the ASMEx were used to drive the HUT and MEMLS model predictions to the radiometric observations in Publication IV. The study used the single layer HUT model with the extinction coefficient from Kontu and Pulliainen (2010) and MEMLS with the improved Born approximation (Mätzler and Wiesmann, 1999) (Section 3.2). The snow microstructure was applied with the macro-photography-based traditional grain size in the HUT model and with the correlation length derived from equation (2) in MEMLS. The subnivean layer was simulated either as an absorbing base or a reflecting base with near perfect properties (99\% absorber or reflector respectively). The snow slabs were only 5-15 cm in depth, which affected the simulation accuracy of the HUT model at the reflecting base because the model only simulates the radiation propagating from the ground to the surface, so that the simulation for the experimental situation was not correctly modelled. 
a

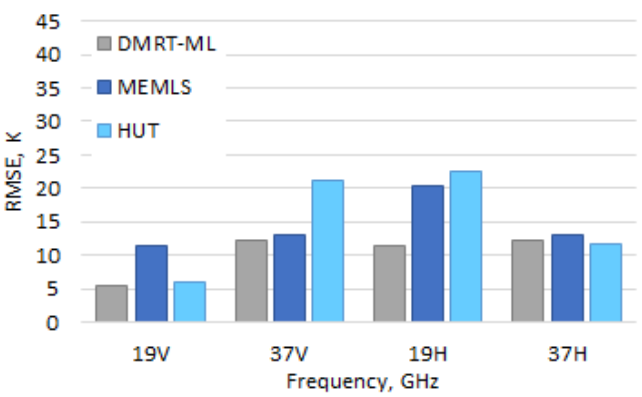

b

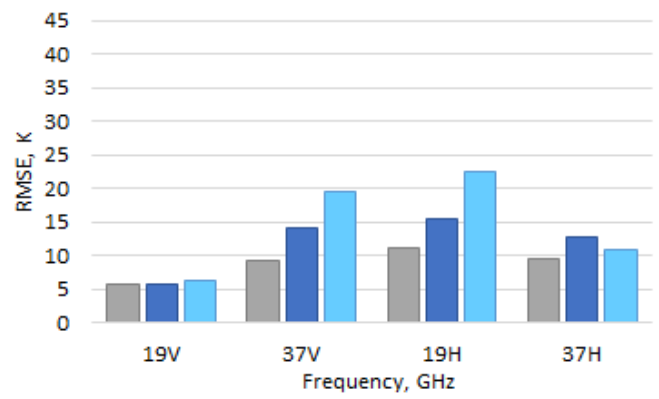

2012-2013

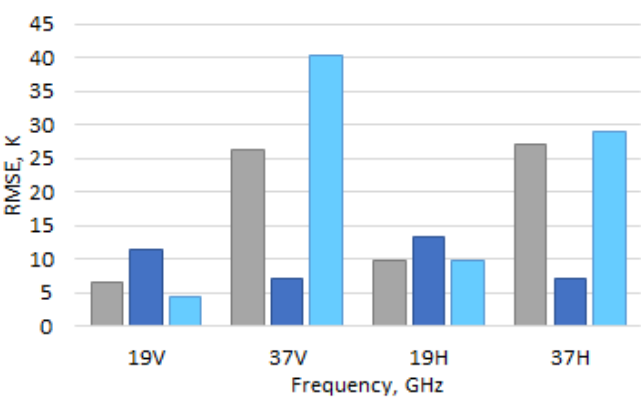

2012-2013

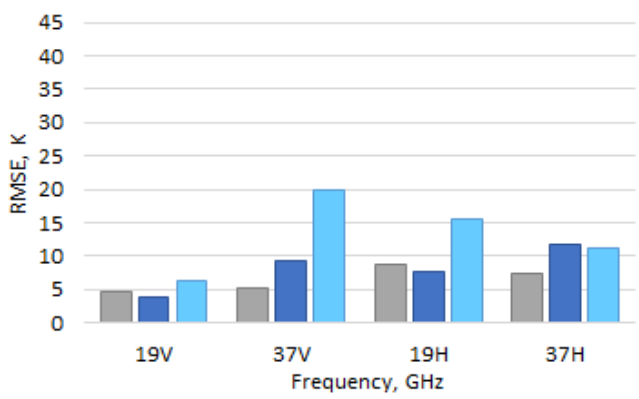

Figure 13. Average RMSE of observed and simulated brightness temperature with a) simulated microstructure and b) fitted microstructure for the natural snowpack. Horizontal $(H)$ and vertical (V) polarizations are simulated with three models: DMRT-ML (grey), MEMLS (dark blue), and HUT (light blue). Microwave emission model simulations were driven with JIM outputs (temperature, density, layer depth, and optical grain size). Equation (3) was applied to derive correlation length for MEMLS from the optical grain size. For soil permittivity, DMRT-ML and HUT was adapted to use Fresnel reflectivity for a smooth soil surface and to output the soil reflectivity for use in MEMLS. 

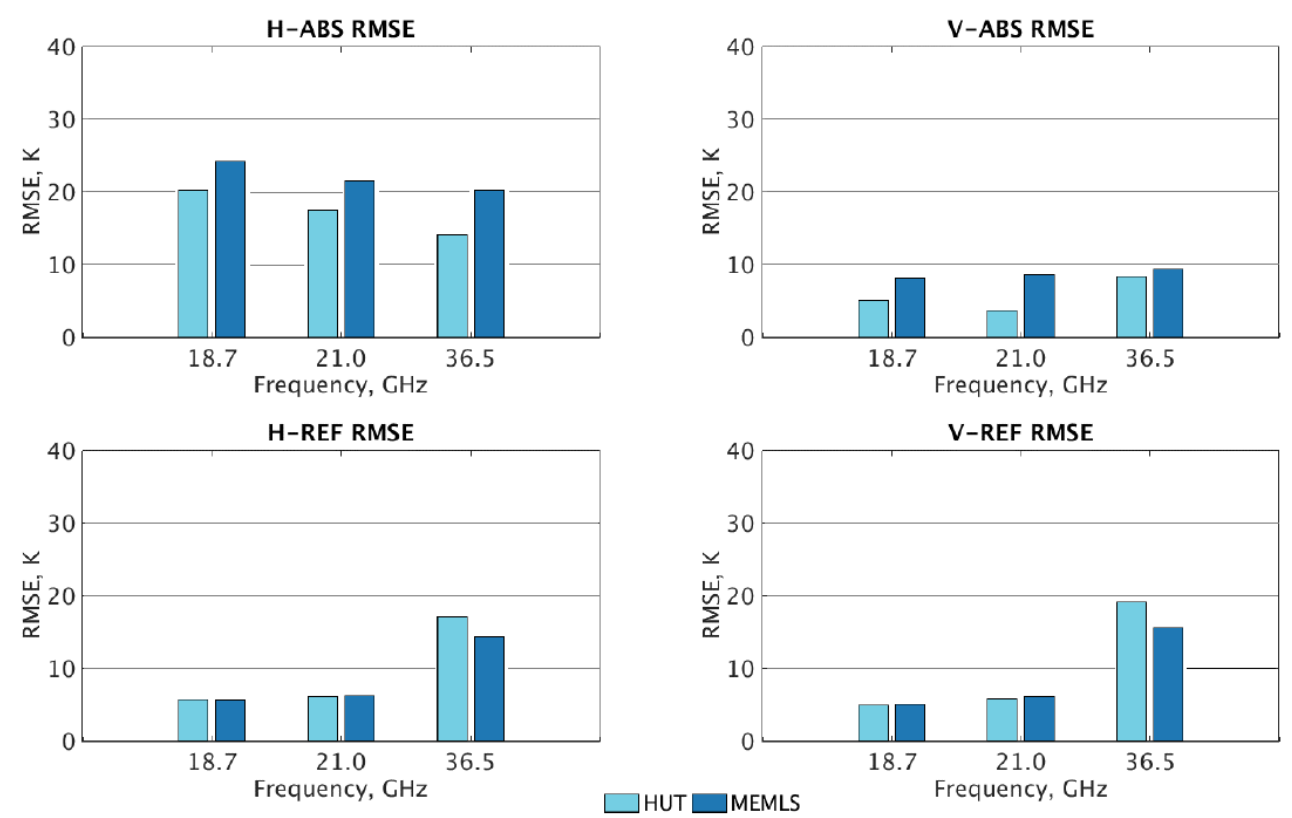

Figure 14. RMSE of observed brightness temperature and simulated with HUT (light blue) and MEMLS (dark blue) models for slab measurements. Horizontal $(H)$ and vertical $(V)$ polarizations with absorbing base (ABS) and reflecting base (REF) were simulated. Simulations were driven with measured snow density, temperature, and slab thickness with traditional grain size for HUT and SSA for MEMLS. Equation (2) was applied to derive correlation length for MEMLS from the SSA. The ground layer of the models was modified to simulate the reflecting properties of absorbing and reflecting bases. Modified from Publication IV.

Figure 14 depicts the RMSE between simulations and observations. The HUT model simulations depict smaller RMSE than MEMLS for the absorbing base case, but for both of the models, the horizontal polarization simulations had a larger RMSE than the vertical polarization simulations. The reflecting base simulations indicated similar RMSE for both models, with the exception of $36.5 \mathrm{GHz}$, where the HUT had larger RMSE with both of the polarizations. The conclusion is that microwave emission models should be improved by using SSA, for example, instead of traditional grain size in the description of the snow microstructure.

Several other studies have compared microwave emission model simulations with brightness temperature observations and resulted in RMSE values between observed and simulated brightness temperatures that are comparable to those of Publications III and IV. Other studies suggested to use multilayer models (Santi and others, 2017; Tedesco and Kim, 2006), 
quantitative microstructure measurements (Pan and others, 2016; Roy and others, 2016; Tedesco and Kim, 2006), scaled SSA (Roy and others, 2013; Royer and others, 2017) and ice lenses (Roy and others, 2016) in the models to produce simulation results closer to the observations. Other studies have also compared brightness temperature observations and microwave emission model simulations coupled with physical snow models (e.g., Brucker and others, 2011; Huang and others, 2012; Kontu and others, 2017; Langlois and others, 2012). These studies demonstrated that coupled models could improve the SWE retrievals, although either appropriate scaling of simulation results or model improvements would be needed. Löwe and Picard (2015) demonstrated that the scaling factor depends on preceding metamorphism, which indicates that the application of constant scaling factor is not adequate. As an advancement on those studies, Publication III used the simulation results of several microstructure models as the input for the emission models. Publication IV had the experimental set-up for the observations, where many novel in-situ measurement methods were used in addition to the multi-frequency microwave observations.

Based on Publications III, IV, and the other studies, it is hypothesized that the RMSE between the measured and the simulated brightness temperatures originates from poorly described multiple scattering (Tse and others, 2007) in the models. Microwave emission modeling could be improved by using a microstructural parameter that is measured with advanced technologies such as micro-CT instead of traditional grain size; this style of measurement could represent better microstructure for microwave radiation. Based on ASMEx, the improved extinction coefficient model that was based on optical grain size derived from SSA was introduced by Maslanka and others (2019). The new extinction coefficient model improved simulation results compared to simulations made with traditional grain size. However, SSA might not be the most appropriate microstructural parameter for the microwave radiation because it describes incomplete scattering at microwave wavelengths by describing the correlation function only at the origin (Proksch and others, 2015). Outside of the origin, the exponential correlation function is also related to grain size dispersity and grain shape (Krol and Löwe, 2016). Generally, in the collection of snow grains with a range of different sizes, the contribution of larger grains to scattering at microwave wavelengths is larger than the contribution of smaller grains (Picard and others, 2013). Instead, a set of parameters describing the whole correlation function could be applied (Picard and others, 2018). The improvements could lead to better SWE retrievals from the satellite observations in the future. However, only traditional grain size and optical grain size were used in the applied models. Thus, this study did not arrive at a conclusion on the applicability of the other parameters based on measurements with advanced technologies such as micro-CT. 


\subsection{Temporal and spatial variability of snow macrostructural properties}

Publication $\mathrm{V}$ provides a detailed overview of the manual snow measurement methods performed in Sodankylä. Based on the manually measured data set, the temporal and spatial variability of snow depth and SWE were analyzed. The natural variability of snow properties limit the feasible accuracy of the passive microwave observations.

The temporal variability of the snow depth in Sodankylä is depicted in Figure 15, which depicts a 100-year time series from 1915-2014. The maximum snow depth value is $119 \mathrm{~cm}$ from 6 April 2000. There has been an 87-day difference between the earliest (1998) and the latest (2000) onset of persistent cover, and there has been a 52-day difference between the earliest (1937) and the latest (1911) total snow melt. There is no visible increasing or decreasing trend for the annual maximum snow depth. Other studies on the temporal variability of the snow cover in Finland have been conducted. Luomaranta and others (2019) demonstrated that variations in the maximum snow depth and length of snow cover period during the last decades have been small in northern Finland, while the values have been clearly decreasing in southern and western Finland. However, the risk of heavy snow loads has been increasing in Sodankylä as in the whole of Finland from the 1960s to 1990s (Gregow and others, 2008). The temporal variability of snow macrostructural properties is important for long-term climatological research due to the sensitivity of the snow properties to air temperature (Brown and Mote, 2009). 

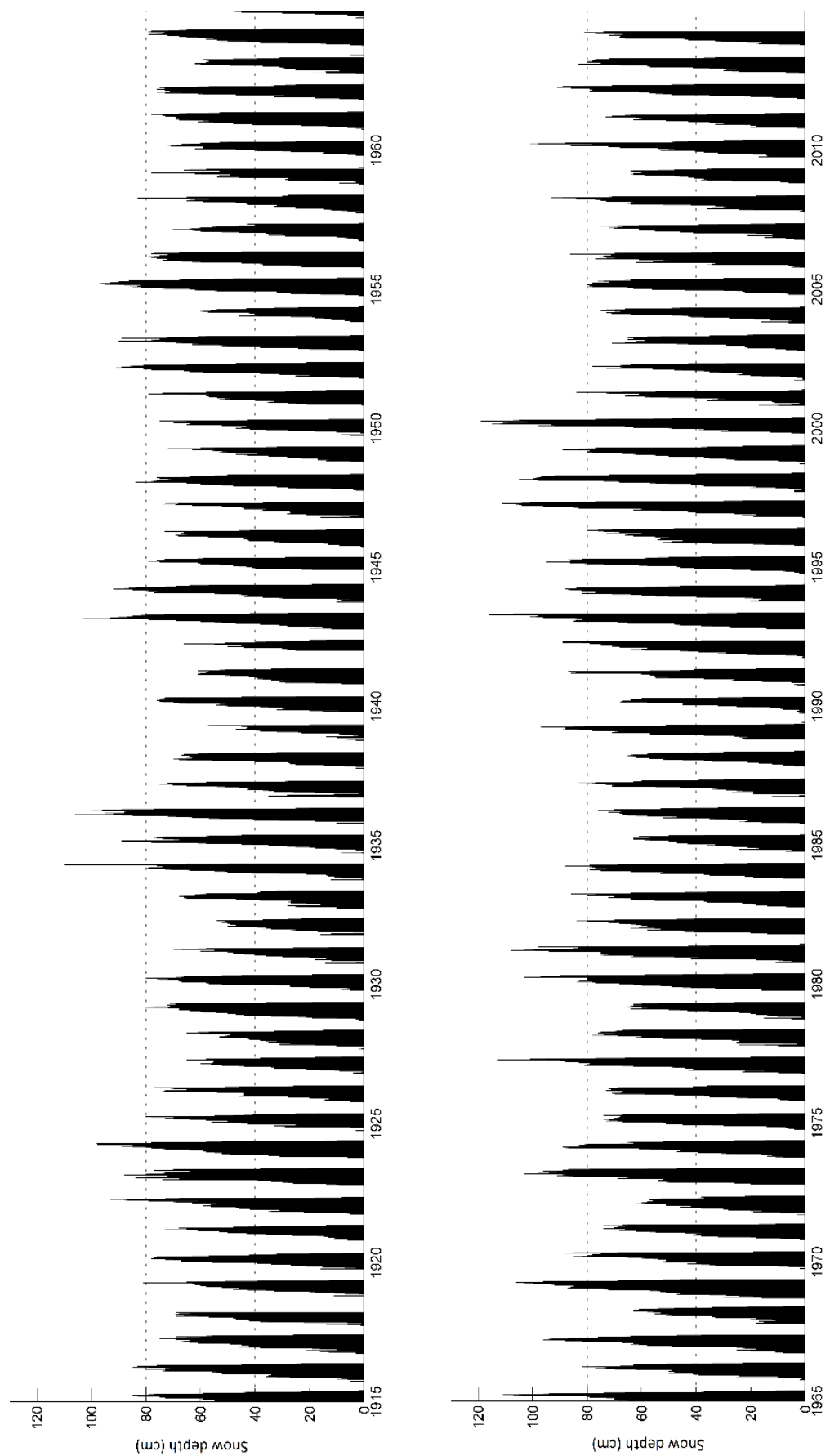

Figure 15. Time series of snow depth for 1915-2014. Modified from Publication V. 
Figure 16 depicts the spatial variability of snow depth and SWE in IOA (forest opening), a bog, and over lake ice from 2009-2014. The values are the largest for the IOA and are the smallest for the lake ice. In the data set observed between 1972-2015, the measurements at the forest site ( $500 \mathrm{~m}$ from IOA) are $9 \mathrm{~cm}$ higher than at the open site (at airport) on average. However, SWE values are similar in both sites, and therefore snow is denser at the open site. That is not visible as clearly as in Figure 16, where in the most cases, higher snow depth at IOA (average bias between IAO and bog is $15 \mathrm{~cm}$ for 2009-2014) also indicated higher SWE (average bias between IOA and bog $30 \mathrm{~mm}$ for 2009-2014). Generally, spatial variability between the sites was larger than the average bias between the simulations and the measurements presented in Section 5.2.

There are several studies of spatial variability of snow density, snow depth and SWE. It has been argued that snow depth is typically lower and snow density is typically larger for open areas and lake ice than for forested areas (Hannula and others, 2016). In addition, in the short scale, variability of snow depth and SWE has been argued to be larger at forested sites than at open or lake ice sites due to slopes and vegetation (Hannula and others, 2016; Zheng and others, 2016). The assumption has been that the variability of SWE in the forested sites originates from the variability of snow depth, and variability in the open or lake ice sites originates from density variations (Derksen and others, 2009). Similar variability of the snow properties as presented in this study could be expected in boreal forest zone in northern Finland when the variability inside a satellite observation is considered. 


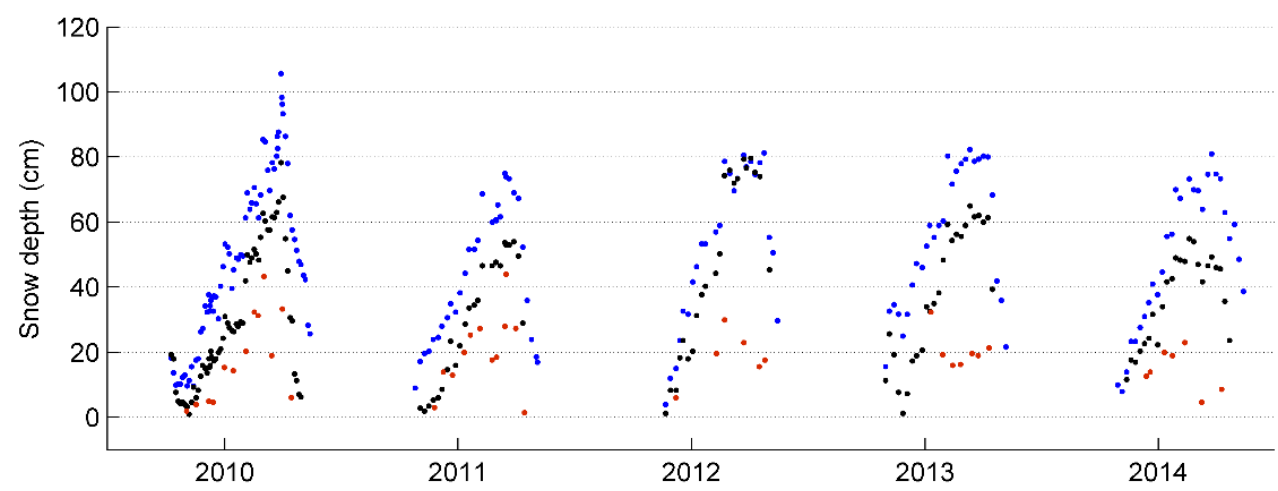

b

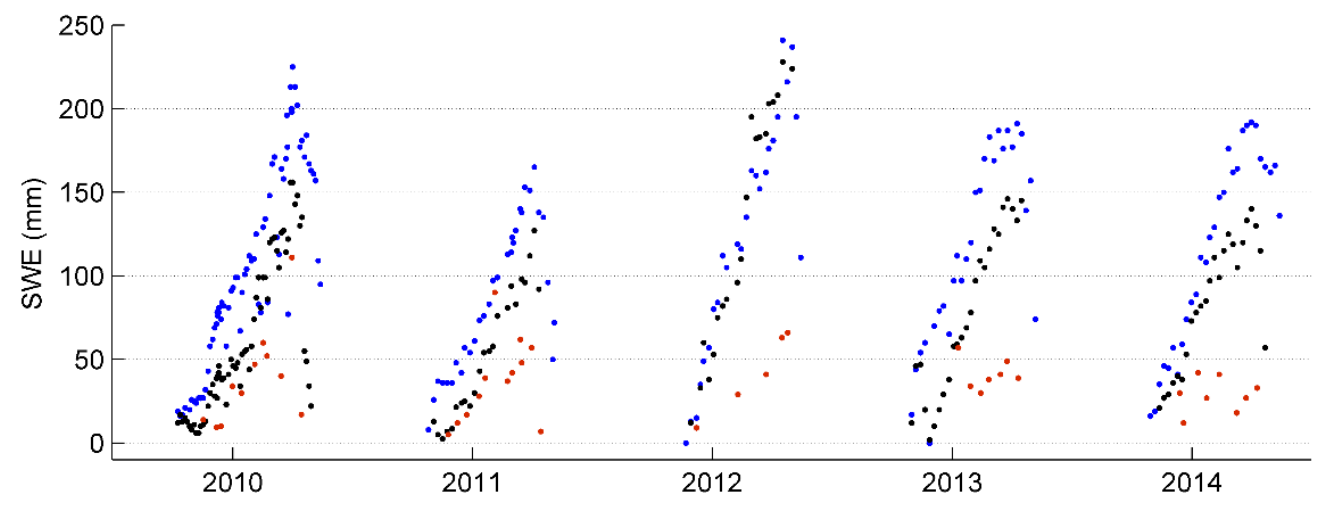

Figure 16. Time series for a) snow depth and b) SWE from snow pit sites IOA (blue), bog (black) and Lake Orajärvi (red). Modified from Publication V. 


\section{Conclusions}

This thesis studies the measurement methods and modelling of the snow characteristics that will serve improving the interpretation of passive microwave observations. Passive microwave remote sensing is a method to monitor SWE that is a widely used parameter for many climatological and hydrological applications, including long-term climate monitoring and river discharge forecasting. The challenges in the interpretation of the observations are the natural spatial variability of the snow characteristics, the availability of reliable input data, and the expression of the snow microstructure in the retrieval algorithms. The extensive measurement sets of taiga snow characteristics, brightness temperatures, and meteorological data used in this study, were collected at the Arctic Space Centre of Finnish Meteorological Institute (FMI-ARC) experiment sites in Sodankylä (67.367 N, 26.629 E) in northern Finland.

The main contributions of the study are as follows:

1) A novel portable optical spectrometer, QST, was tested for contact spectral reflectance measurements of snow profiles with findings:

- A reflectance-based index, derived from QST measurements, had a linear empirical relationship with SSA derived from the IceCube measurements.

- The QST measurements and $Q$-index have the potential to be utilized for the SSA measurements in the future.

2) The evolution of the snow characteristics was simulated with the physical snow models (SNOWPACK and JIM coupled with MOSES, SNTHERM, and SNICAR) that were driven with meteorological, radiation, and soil data. The simulations were validated with the snow pit measurements.

- Accuracy of the models in taiga snow conditions is dependent on season and year.

- The description of the snow microstructure in the physical snow models could be improved, especially where microstructure is described only with a size parameter. However, SNOWPACK has reasonable accuracy for microstructure simulations because it describes microstructure also with the shape parameters.

- The simulations scaled with annually varying scaling factors have the potential to be utilized in SWE retrieval. 
3) The measured and modelled snow characteristics were used for driving the microwave emission models (HUT, MEMLS and DMRT-ML) to simulate the microwave brightness temperature. The simulations were validated with the radiometric measurements.

- There was variable accuracy of applied models for different polarizations, frequencies, and measurement configurations. None of the microwave emission models that were driven with measured or modelled snow characteristics resulted in clearly superior results against other model configurations when compared to brightness temperature observations.

- The scaling factors applied to the grain size minimizes errors between the simulations and the observations. Generally, grain size in the three emission models needed less variable scaling factors than grain size in the three microstructure models to minimize errors to the observations.

- The microwave emission model improvements are needed, especially related to the description of the extinction in the snowpack, which is closely related to better representation of the snow microstructure.

4) The spatial variability of bulk snow properties were demonstrated around the field site.

- Snow depth had approximately $15 \mathrm{~cm}$ and SWE had approximately $30 \mathrm{~mm}$ spatial variability within the scale of $\mathrm{km}$ in the FMI-ARC field sites.

- Such spatial variability of snow properties can be expected as a minimum for satellite observation of a coarse spatial resolution in the case of boreal forest zone.

In the future, accuracy of the SWE retrievals could be improved with two methods related to the microwave emission modelling. First, the description of radiative transfer in the snowpack could be improved (Picard and others, 2018). Second, the quality of driving data could be better (e.g., Pan and others, 2016).

Absorption and scattering of the microwave radiation could be presented more adequately in the models, which is clear from the results of this thesis. Improving that presentation would require improved description of the snow microstructure. Consequently, the data set from the ASMEx was used for a new semi-empirical extinction coefficient model based on SSA which was presented by Maslanka and others (2019) to be coupled with the HUT microwave emission model. The semi-empirical extinction coefficient model improved simulations compared to the simulations made with the traditional grain size. However, microwave emission models could be improved in the future by using a microstructural parameter or set of parameters, which better describes the whole correlation function of the structural properties of snow, but this study did not arrive at a conclusion on the applicability of those microstructural parameters. Moreover, QST measurements and the presented $Q$-index have the potential for easy and rapid 
microstructure observations, which could support the improvement and validation of the microwave emission models. However, this would require a larger data set of QST measurements for the future algorithm development.

On the other hand, microstructure measurements are not available at the global scale for driving SWE retrievals. The microstructure simulations could be coupled with the microwave emission models to produce more accurate SWE inversions from the brightness temperature observations (Kontu and others, 2017). However, improvements of the representation of microstructure in physical snow models are required to produce adequate results. Also, global SWE retrieval presented by Takala and others (2011) uses the interpolation of snow depth measurements as input parameters. However, the interpolation could lack the spatial and temporal resolution of the in-situ measurements. The snow model simulations of snow depth could complement or replace the field measurements. On a global scale, the physical snow model simulations could be forced with a meteorological reanalysis product, which is based on the data assimilation of numerical models and field measurements. However, the applied physical snow model should be simple for global use, which on the other hand could reduce the accuracy of the retrieval. The physical snow models applied in this study were excessively complex for global use; therefore, validation should also be conducted for simpler physical snow models.

On the other hand, the natural spatial variability of the snow characteristics is another challenge in the interpretation of the passive microwave observations. Accuracy of spaceborne observations is limited by natural spatial variability regardless of microstructure presentation in the retrieval algorithms. Nevertheless, in the scale of a satellite observation, the influence of microstructure is somewhat averaged.

The results of this work improve the measurements and modelling of the snow microstructure. In addition, the improved understanding of the influence of snow microstructure to microwave emission from snow advances the interpretation of passive microwave observations. Thus, the results obtained here will potentially contribute to a more accurate SWE retrieval from spaceborne passive microwave remote sensing, a topic important for monitoring the climate and hydrological processes. 


\section{References}

Anttila, K. (2019) Seasonal snow surface roughness and albedo. Finnish Meteorological Institute Contributions 149.

Arnaud, L., Picard, G., Champollion, N., Domine, F., Gallet, J. C., Lefebvre, E., Fily, M., and Barnola, J. M. (2011) Measurement of vertical profiles of snow specific surface area with a $1 \mathrm{~cm}$ resolution using infrared reflectance: instrument description and validation. J. Glaciol., 57(201), 17-29.

Armstrong, R. and Brun, E. (2008) Snow and climate: physical processes, surface energy exchange and modeling, Cambridge Univ. Pr.

Armstrong, R. L., Chang, A., Rango, A., and Josberger, E. (1993) Snow depths and grain-size relationships with relevance for passive microwave studies. Ann. Glaciol., 17, 171-176.

Barnett, T. P., Adam, J. C., and Lettenmaier, D. P. (2005) Potential impacts of a warming climate on water availability in snow-dominated regions. Nature, 438(7066), 303.

Bartelt, P., and Lehning, M. (2002) A physical SNOWPACK model for the Swiss avalanche warning: Part I: numerical model. Cold Reg. Sci. Technol., 35(3), 123-145.

Baunach, T., Fierz, C., Satyawali, P. K., and Schneebeli, M. (2001) A model for kinetic grain growth. Ann. Glaciol., 32, 1-6.

Bentley W. A. and Humphreys W. J. (1931) Snow crystals, McGraw-Hill, New York.

Breiling, M., and Charamza, P. (1999) The impact of global warming on winter tourism and skiing: a regionalised model for Austrian snow conditions. Reg. Environ. Change, 1(1), 4-14.

Brown, R. D., and Robinson, D. A. (2011) Northern Hemisphere spring snow cover variability and change over 1922-2010 including an assessment of uncertainty. The Cryosphere, 5(1), 219-229.

Brown, R.D. and Mote, P.W. (2009) The response of Northern Hemisphere snow cover to a changing climate. J. Clim. 22, 2124-2145.

Brown, R. D., and Braaten, R. O. (1998) Spatial and temporal variability of Canadian monthly snow depths, 1946-1995. Atmos. Ocean, 36(1), 37-54.

Brucker, L., Royer, A., Picard, G., Langlois, A., and Fily, M. (2011) Hourly simulations of the microwave brightness temperature of seasonal snow in Quebec, Canada, using a coupled snow evolution-emission model. Remote Sens. Environ., 115(8), 1966-1977. 
Brun, E. (1989) Investigation on wet-snow metamorphism in respect of liquid-water content. Ann. Glaciol., 13, 22-26.

Brun, E., David, P., Sudul, M., and Brunot, G. (1992) A numerical model to simulate snow-cover stratigraphy for operational avalanche forecasting, J. Glaciol., 38, 13-22.

Brunauer S., Emmett P.H., and Teller E. (1938) Adsorption of gases in multimolecular layers. J. Am. Chem. Soc., 60(2), 309-319.

Brutel-Vuilmet, C., Ménégoz, M., and Krinner, G. (2013) An analysis of present and future seasonal Northern Hemisphere land snow cover simulated by CMIP5 coupled climate models. The Cryosphere, 7(1).

Calonne, N., Flin, F., Geindreau, C., Lesaffre, B., and Rolland du Roscoat, S. (2014) Study of a temperature gradient metamorphism of snow from 3-D images: time evolution of microstructures, physical properties and their associated anisotropy. The Cryosphere, 8(6), 2255-2274.

Carroll, T., Cline, D., Olheiser, C., Rost, A., Nilsson, A., Fall, G., Bovitz, C., and Li, L. (2006) NOAA's national snow analyses. In Proceedings of the 74th annual meeting of the western snow conference (Vol. 74, p. 13).

Chandrasekhar, S. (1960) Radiative transfer. Dover publications. New York.

Chang, A. T. C., Foster, J. L., and Hall, D. K. (1987) Nimbus-7 SMMR derived global snow cover parameters. Ann. Glaciol., 9, 39-44.

Cohen, J., Lemmetyinen, J., Pulliainen, J., Heinilä, K., Montomoli, F., Seppänen, J., and Hallikainen, M. T. (2015) The effect of boreal forest canopy in satellite snow mapping-A multisensor analysis. IEEE T. Geosci. Remote., 53(12), 6593-6607.

Colbeck, S. C. (1997) A Review of Sintering in Seasonal Snow (No. CRREL-97-10). Cold Regions Research and Engineering Lab Hanover $\mathrm{NH}$.

Colbeck, S. C. (1983) Theory of metamorphism of dry snow. J. Geophys. Res. Oceans, 88(C9), 5475-5482.

Colbeck, S. C. (1982) An overview of seasonal snow metamorphism. Geophys. Rev., 20(1), 4561.

Colbeck, S. C. (1980) Thermodynamics of snow metamorphism due to variations in curvature. J. Glaciol., 26(94), 291-301. 
Colbeck, S. C. (1973) Theory of metamorphism of wet snow. CRREL Res. Rep. 313.

Coleou, C., Lesaffre, B., Brzoska, J. B., Ludwig, W., and Boller, E. (2001) Three-dimensional snow images by X-ray microtomography. Ann. Glaciol., 32, 75-81.

Cotton, W. R., Tripoli, G. J., Rauber, R. M., and Mulvihill, E. A. (1986) Numerical simulation of the effects of varying ice crystal nucleation rates and aggregation processes on orographic snowfall. Journal of climate and applied meteorology, 25(11), 1658-1680.

Derksen, C., and Brown, R. (2012) Spring snow cover extent reductions in the 2008-2012 period exceeding climate model projections. Geophys. Res. Lett., 39(19).

Derksen, C., Sturm, M., Liston, G. E., Holmgren, J., Huntington, H., Silis, A., and Solie, D. (2009) Northwest territories and Nunavut snow characteristics from a subarctic traverse: Implications for passive microwave remote sensing, J. Hydrometeorol., 10, 448-463.

Derksen, C., Walker, A., and Goodison, B. (2005) Evaluation of passive microwave snow water equivalent retrievals across the boreal forest/tundra transition of western Canada. Remote Sens. Environ., 96(3-4), 315-327.

van Dijk, A. I., Renzullo, L. J., Wada, Y., and Tregoning, P. (2014) A global water cycle reanalysis (2003-2012) merging satellite gravimetry and altimetry observations with a hydrological multimodel ensemble. Hydrol. Earth Syst. Sci., 18(8), 2955-2973.

Domine, F., Salvatori, R., Legagneux, L., Salzano, R., Fily, M., and Casacchia, R. (2006) Correlation between the specific surface area and the short wave infrared (SWIR) reflectance of snow. Cold Reg. Sci. Technol., 46(1), 60-68.

Dong C. (2018) Remote sensing, hydrological modeling and in situ observations in snow cover research: A review. J. Hydrol., 561, 573-583.

Dozier, J., Davis, R. E., and Perla, R. (1987) On the objective analysis of snow microstructure. Avalanche Formation, Movement and Effects, 162, 46-59.

Debye, P., Anderson, Jr H.R. and Brumberger, H. (1957) Scattering by an inhomogeneous solid. II. The correlation function and its application. J. Appl. Phys., 28(6), 679-683.

Essery, R., Morin, S., Lejeune, Y., and Ménard, C. B. (2013) A comparison of 1701 snow models using observations from an alpine site, Adv. Water Res., 55, 131-148.

Essery, R., Best, M., and Cox, P. (2001) MOSES 2.2 Technical Documentation, Tech. rep., Hadley Centre, Met Office, UK, Hadley Centre technical note 30, 31 pp. 
Fierz, C., Armstrong, R. L., Durand, Y., Etchevers, P., Greene, E., McClung, D. M., Nishimura, K., Satyawali, P. K., and Sokratov, S. A. (2009) The International Classification for Seasonal Snow on the Ground, IHP-VII Technical Documents in Hydrology N 83, IACS Contribution N 1, UNESCOIHP, Paris.

Flanner, M. G. and Zender, C. S. (2006) Linking snowpack microphysics and albedo evolution, J. Geophys. Res., 111, D12208.

Foster, J. L., Hall, D. K., Chang, A. T. C., and Rango, A. (1984) An overview of passive microwave snow research and results. Geophys. Rev., 22(2), 195-208.

Gallet, J.-C., Domine, F., Zender, C. S., and Picard, G. (2009) Measurement of the specific surface area of snow using infrared reflectance in an integrating sphere at 1310 and $1550 \mathrm{~nm}$, The Cryosphere, 3, 167-182.

Goodison, B. E., and Walker, A. E. (1993) Use of snow cover derived from satellite passive microwave data as an indicator of climate change. Ann. Glaciol., 17, 137-142.

Granberg, H. B. (1985) Distribution of grain sizes and internal surface area and their role in snow chemistry in a sub-Arctic snow cover. Ann. Glaciol., 7, 149-152.

Gregow, H., Puranen, U., Venäläinen, A., Peltola, H., Kellomäki, S., and Schultz, D. (2008) Temporal and spatial occurrence of strong winds and large snow load amounts in Finland during 1961-2000. Silva Fennica, 42(4), 515-534.

Grenfell, T.C. and Warren S.G. (1999) Representation of a nonspherical ice particle by a collection of independent spheres for scattering and absorption of radiation. J. Geophys. Res. Atmos. 104(D24), 31697-31709.

Groot Zwaaftink, C. D., Cagnati, A., Crepaz, A., Fierz, C., Macelloni, G., Valt, M., and Lehning, M. (2013) Event-driven deposition of snow on the Antarctic Plateau: analyzing field measurements with SNOWPACK. The Cryosphere, 7(1), 333-347.

Haberkorn, A. (2019) European Snow Booklet - an Inventory of Snow Measurements in Europe. EnviDat.

Hagenmuller, P., Chambon, G., Flin, F., Morin, S., and Naaim, M. (2014) Snow as a granular material: assessment of a new grain segmentation algorithm. Granular Matter, 16(4), 421-432.

Hallikainen, M., Ulaby, F., and Van Deventer, T. (1987) Extinction Behavior of Dry Snow in the 18-to 90- GHz Range, IEEE T. Geosci. Remote., GE-25, 737-745. 
Hallikainen, M. T., and Jolma, P. A. (1986) Retrieval of the water equivalent of snow cover in Finland by satellite microwave radiometry. IEEE T. Geosci. Remote., (6), 855-862.

Hamlet, A. F., and Lettenmaier, D. P. (2007) Effects of 20th century warming and climate variability on flood risk in the western US. Water Resour. Res., 43(6).

Hancock, S., Baxter, R., Evans, J., and Huntley, B. (2013) Evaluating global snow water equivalent products for testing land surface models, Remote Sens. Environ., 128, 107-117.

Hannula, H. R., Lemmetyinen, J., Kontu, A., Derksen, C., and Pulliainen, J. (2016) Spatial and temporal variation of bulk snow properties in northern boreal and tundra environments based on extensive field measurements. Geosci. Instrum., Meth. Data Syst., 5(2), 347-363.

Hardy, J. P., Groffman, P. M., Fitzhugh, R. D., Henry, K. S., Welman, A. T., Demers, J. D., Fahey, T. J., Driscoll, C. T., Tierney, G. L., and Nolan, S. (2001) Snow depth manipulation and its influence on soil frost and water dynamics in a northern hardwood forest, Biogeochemistry, 56, 151-174.

Hedstrom, N. R., and Pomeroy, J. W. (1998) Measurements and modelling of snow interception in the boreal forest. Hydrological Processes, 12(10-11), 1611-1625.

Heggli, M., Frei, M., and Schneebeli, M. (2009) Snow replica method for three-dimensional Xray microtomography imaging, J. Glaciol., 55, 631-639.

Helmert, J., Şensoy Şorman, A., Alvarado Montero, R., De Michele, C., de Rosnay, P., Dumont, M., Finger, D., Lange, M., Picard, G., Popotova, V., Pullen, S., Vikhamar-Schuler, D., Arslan, A. (2018) Review of Snow Data Assimilation Methods for Hydrological, Land Surface, Meteorological and Climate Models: Results from a COST HarmoSnow Survey. Geosciences, $8(12), 489$.

Hirashima, H., Nishimura, K., Yamaguchi, S., Sato, A., and Lehning, M. (2008) Avalanche forecasting in a heavy snowfall area using the snowpack model. Cold Reg. Sci. Technol., 51(2-3), 191-203.

Hu, B., Chen, S., Hu, J., Xia, F., Xu, J., Li, Y., and Shi, Z. (2017) Application of portable XRF and VNIR sensors for rapid assessment of soil heavy metal pollution. PLoS ONE, 12, e0172438.

Huang, C., Margulis, S. A., Durand, M. T., and Musselman, K. N. (2012) Assessment of snow grainsize model and stratigraphy representation impacts on snow radiance assimilation: Forward modeling evaluation. IEEE T. Geosci. Remote., 50(11), 4551-4564. 
Hyvärinen, T., and Lammasniemi, J. (1985) Infrared measurement of grain size and melting degree of snow. In Infrared Technology XI (Vol. 572, pp. 158-166). International Society for Optics and Photonics.

Jordan, R. (1991) A One-Dimensional Temperature Model for a Snow Cover: Technical Documentation for SNTHERM.89, Cold Regions Research and Engineering Laboratory (U.S.), Engineer Research and Development Center (U.S.), Special Report 91-16.

Kelly, R. (2009) The AMSR-E Snow Depth Algorithm: Description and Initial Results, Journal of The Remote Sensing Society of Japan, 29, 307-317.

Kelly, R. E., and Chang, A. T. (2003). Development of a passive microwave global snow depth retrieval algorithm for Special Sensor Microwave Imager (SSM/I) and Advanced Microwave Scanning Radiometer-EOS (AMSR-E) data. Radio Sci., 38(4).

Kim, E., Gatebe, C., Hall, D., Newlin, J., Misakonis, A., Elder, K., Marshall, H.P., Heimstra, C., Brucker, L., and De Marco, E. (2017) Overview of SnowEx Year 1 Activities. SnowEx Workshop; 8-10 Aug. 2017, Longmont, CO, United States.

Kinar, N. J., and Pomeroy, J. W. (2015) Measurement of the physical properties of the snowpack. Geophys. Rev., 53(2), 481-544.

Kokhanovsky, A.A., and Zege, E.P. (2004) Scattering optics of snow. Appl. Optics, 43(7), 15891602.

Kontu, A. (2018) Effect of snow microstructure and subnivean water bodies on microwave radiometry of seasonal snow. Finnish Meteorological Institute Contributions 144.

Kontu, A., Lemmetyinen, J., Vehviläinen, J., Leppänen, L., and Pulliainen, J. (2017) Coupling SNOWPACK-modeled grain size parameters with the HUT snow emission model. Remote Sens. Environ., 194, 33-47.

Kontu, A. and Pulliainen, J. (2010) Simulation of spaceborne microwave radiometer measuremetns of snow cover using in situ data and brightness temperature modeling, IEEE T. Geosci. Remote., 48, 1031-1044.

Korhonen, J. (2019) Long-term changes and variability of the winter and spring season hydrological regime in Finland. Finnish Environment Institute.

Krol, Q., and Löwe, H. (2016) Relating optical and microwave grain metrics of snow: the relevance of grain shape. The Cryosphere, 10(EPFL-ARTICLE-225444), 2847-2863. 
Kunzi, K. F., Fisher, A. D., Staelin, D. H., and Waters, J. W. (1976) Snow and ice surfaces measured by the Nimbus 5 microwave spectrometer. J. Geophys. Res., 81(27), 4965-4980.

Kry, P. R. (1975) Quantitative stereological analysis of grain bonds in snow. J. Glaciol., 14(72), 467-477.

LaChapelle, E. R. (1969) Field guide to snow crystals, The University of Washington Press, 101 pp.

Langlois, A., Royer, A., Derksen, C., Montpetit, B., Dupont, F., and Goïta, K. (2012) Coupling the snow thermodynamic model SNOWPACK with the microwave emission model of layered snowpacks for subarctic and arctic snow water equivalent retrievals. Water Resour. Res., 48(12).

Langlois, A., Royer, A., Montpetit, B., Picard, G., Brucker, L., Arnaud, L., Harvey-Collard, P., Fily, M., and Goïta, K. (2010) On the relationship between snow grain morphology and in-situ near infrared calibrated reflectance photographs. Cold Reg. Sci. Technol., 61(1), 34-42.

Legagneux, L., Cabanes, A., and Dominé, F. (2002) Measurement of the specific surface area of 176 snow samples using methane adsorption at 77 K. J. Geophys. Res. Atmos., 107(D17).

Lemmetyinen, J., Kontu, A., Pulliainen, J., Vehviläinen, J., Rautiainen, K., Wiesmann, A., Mätzler, C., Werner, C., Rott, H., Nagler, T., Schneebeli, M., Proksch, M., Schüttemeyer, D. Kern, M., Davidson, M. W. J. (2016) Nordic snow radar experiment. Geosci. Instrum., Meth. Data Syst., 5(2), 403-415.

Lemmetyinen, J., Pulliainen, J., Rees, A., Kontu, A., Qiu, Y., and Derksen, C. (2010) Multiple-layer adaptation of HUT snow emission model: comparison with experimental data, IEEE T. Geosci. Remote, 48, 2781-2794.

Lemmetyinen, J., Derksen, C., Pulliainen, J., Strapp, W., Toose, P., Walker, A., Tauriainen, S., Pihlflyckt, J., Kärnä, J.-P., and Hallikainen, M. T. (2009) A comparison of airborne microwave brightness temperatures and snowpack properties across the boreal forests of Finland and Western Canada. IEEE T. Geosci. Remote., 47(3), 965-978.

Lehning, M., Bartelt, P., Brown, B., Fierz, C., and Satyawali, P. (2002a) A physical SNOWPACK model for the Swiss avalanche warning. Part II: snow microstructure. Cold Reg. Sci. Technol., 35(3), 147-167.

Lehning, M., Bartelt, P., Brown, B., and Fierz, C. (2002b) A physical SNOWPACK model for the Swiss avalanche warning: Part III: Meteorological forcing, thin layer formation and evaluation. Cold Reg. Sci. Technol., 35(3), 169-184. 
Lehning, M., Fierz, C., and Lundy, C. (2001) An objective snow profile comparison method and its application to SNOWPACK. Cold Reg. Sci. Technol., 33(2-3), 253-261.

Leppänen, L., Kontu, A., and Pulliainen, J. (2018) Automated Measurements of Snow on the Ground in Sodankylä. Geophysica, 53(1), 43-62.

Li, Q., Kelly, R., Leppänen, L., Vehviläinen, J., Kontu, A., Lemmetyinen, J., and Pulliainen, J. (2019) The Influence of Thermal Properties and Canopy-Intercepted Snow on Passive Microwave Transmissivity of a Scots Pine. IEEE T. Geosci. Remote.

Liston, G. E., and Elder, K. (2006) A distributed snow-evolution modeling system (SnowModel). J. Hydrometeorol., 7(6), 1259-1276.

Lundberg, A., and Koivusalo, H. (2003) Estimating winter evaporation in boreal forests with operational snow course data. Hydrol. Process., 17(8), 1479-1493.

Luomaranta, A., Aalto, J., and Jylhä, K. (2019) Snow cover trends in Finland over 1961-2014 based on gridded snow depth observations. Int. J. Climatol., 39(7), 3147-3159.

Löwe, H., and Picard, G. (2015) Microwave scattering coefficient of snow in MEMLS and DMRT$M L$ revisited: the relevance of sticky hard spheres and tomography-based estimates of stickiness. The Cryosphere, 9(6), 2101-2117.

Marty, C., Schlögl, S., Bavay, M., and Lehning, M. (2017). How much can we save? Impact of different emission scenarios on future snow cover in the Alps. The Cryosphere, 11(1), 517-529.

Maslanka W., Sandells, M., Gurney, R., Lemmetyinen J., Leppänen, L., Kontu, A., Matzl, M., Rutter, N., Watts, T., and Kelly R. (2019) Derivation and Evaluation of a New Extinction Coefficient for use with the n-HUT Snow, IEEE T. Geosci. Remote., ISSN 0196-2892.

Matzl, M. and Schneebeli, M. (2006) Measuring specific surface area of snow by near-infrared photography. J. Glaciol., 52(179), 558-564.

Montpetit, B., Royer, A., Roy, A., Langlois, A., and Derksen, C. (2013) Snow microwave emission modeling of ice lenses within a snowpack using the microwave emission model for layered snowpacks. IEEE T. Geosci. Remote., 51(9), 4705-4717.

Montpetit, B., Royer, A., Langlois, A., Cliche, P., Roy, A., Champollion, N., Picard, G., Domine, F., and Obbard, R. (2012) New shortwave infrared albedo measurements for snow specific surface area retrieval. J. Glaciol., 58(211), 941-952. 
Mätzler, C. (2002) Relation between grain-size and correlation length of snow, J. Glaciol., 48, 461-466.

Mätzler, C. (1998) Microwave properties of ice and snow. In Solar System Ices (pp. 241-257). Springer, Dordrecht.

Mätzler, C. (1994) Passive microwave signatures of landscapes in winter. Meteorol. Atmos. Phys., 54(1-4), 241-260.

Mätzler, C. (1987) Applications of the interaction of microwaves with the natural snow cover. Remote sensing reviews, 2(2), 259-387.

Mätzler, C., and Wiesmann, A. (1999) Extension of the microwave emission model of layered snowpacks to coarse-grained snow. Remote Sens. Environ., 70(3), 317-325.

Nakaya, U. (1954) Snow Crystals, Natural and Artifical. Harvard University Press, Cambridge, 510pp.

Niittynen, P., Heikkinen, R. K., and Luoto, M. (2018) Snow cover is a neglected driver of Arctic biodiversity loss. Nature Climate Change, 1.

Nitu R., Roulet Y.-A., Wolff M., Earle M., Reverdin A., Smith C., Kochendorfer J., Morin S., Rasmussen R., Wong K., Alastrué J., Arnold L., Baker B., Buisán S., Collado J. L., Colli M., Collins B., Gaydos A., Hannula H.-R., Hoover J., Joe P., Kontu A., Laine T., Lanza L., Lanzinger E., Lee G.W., Lejeune Y., Leppänen L., Mekis E,. Panel J.-M., Poikonen A., Ryu S., Sabatini F., Theriault J., Yang D., Genthon C., van den Heuvel F., Hirasawa N., Konishi H., Nishimura K., Senese A. (2018) Solid Precipitation Intercomparison Experiment 2012-2015, WMO Instruments and Observing Methods Report No. 131.

Norrman, J., Eriksson, M., and Lindqvist, S. (2000) Relationships between road slipperiness, traffic accident risk and winter road maintenance activity. Clim. Res., 15(3), 185-193.

Painter, T. H., Molotch, N. P., Cassidy, M., Flanner, M., and Steffen, K. (2007) Contact spectroscopy for determination of stratigraphy of snow optical grain size. J. Glaciol., 53(180), 121-127.

Pan, J., Durand, M., Sandells, M., Lemmetyinen, J., Kim, E. J., Pulliainen, J., Kontu, A., and Derksen, C. (2016) Differences Between the HUT Snow Emission Model and MEMLS and Their Effects on Brightness Temperature Simulation. IEEE T. Geosci. Remote., 54(4), 2001-2019. 
Peng, J., Ji, W., Ma, Z., Li, S., Chen, S., Zhou, L., and Shi, Z. (2016) Predicting total dissolved salts and soluble ionconcentrations in agricultural soils using portable visible near-infrared and midinfrared spectrometers. Biosyst. Eng., 152, 94-103.

Picard, G., Sandells, M., and Löwe, H. (2018) SMRT: an active-passive microwave radiative transfer model for snow with multiple microstructure and scattering formulations ( 1.0$)$. Geosci. Model Dev., 11(7), 2763-2788.

Picard, G., Brucker, L., Roy, A., Dupont, F., Fily, M., Royer, A., and Harlow, C. (2013) Simulation of themicrowave emission of multi-layered snowpacks using the densemedia radiative transfer theory: theDMRT-ML model. Geosci. Model Dev. 6 (4), 1061-1078.

Pirazzini, R., Leppänen, L., Picard, G., Lopez-Moreno, J., Marty, C., Macelloni, G., Kontu, A., von Lerber, A., Tanis, C. M., Schneebeli, M., de Rosnay, P., and Arslan, A. N. (2018) European In-Situ Snow Measurements: Practices and Purposes. Sensors, 18(7), 2016.

Pirinen, P., Simola, H., Aalto, J., Kaukoranta, J.-P., Karlsson, P., and Ruuhela, R. (2012) Climatological statistics of Finland 1981-2010, Finnish Meteorological Institute reports.

Proksch, M., Löwe, H., and Schneebeli, M. (2015) Density, specific surface area, and correlation length of snow measured by high-resolution penetrometry. J. Geophys. Res. Earth Surf., 120(2), 346-362.

Pulliainen, J. (2006) Mapping of snow water equivalent and snow depth in boreal and sub-arctic zones by assimilating space-borne microwave radiometer data and ground-based observations. Remote Sens. Environ., 101(2), 257-269.

Pulliainen, J., Grandell, J., and Hallikainen, M. (1999) HUT snow emission model and its applicability to snow water equivalent retrieval. IEEE T. Geosci. Remote., 37(3), 1378-1390.

Qu, X., and Hall, A. (2014) On the persistent spread in snow-albedo feedback. Clim. Dynam., 42(1-2), 69-81.

Rasmus (2005) Snow pack structure characteristics in Finland-measurements and modelling, REPORT SERIES IN GEOPHYSICS No 48, University of Helsinki.

Rasmus, S., Grönholm, T., Lehning, M., Rasmus, K., and Kulmala, M. (2007) Validation of the SNOWPACK model in five different snow zones in Finland. Boreal Environ. Res., 12, 467-488.

Rautiainen, K., Lemmetyinen, J., Pulliainen, J., Vehvilainen, J., Drusch, M., Kontu, A., Kainulainen, J., and Seppänen, J. (2012) L-band radiometer observations of soil processes in boreal and subarctic environments. IEEE T. Geosci. Remote., 50(5), 1483-1497. 
Rees, W. G. (2005) Remote sensing of snow and ice. CRC press.

Romanovsky, V. E., Smith, S. L., and Christiansen, H. H. (2010) Permafrost thermal state in the polar Northern Hemisphere during the international polar year 2007-2009: a synthesis. Permafrost and Periglacial processes, 21(2), 106-116.

de Rosnay, P., Balsamo, G., Albergel, C., Muñoz-Sabater, J., and Isaksen, L. (2014) Initialisation of land surface variables for numerical weather prediction, Surv. Geophys., 35, 607-621.

Roy, A., Royer, A., St-Jean-Rondeau, O., Montpetit, B., Picard, G., Mavrovic, A., Marchand, N., and Langlois, A. (2016) Microwave snow emission modeling uncertainties in boreal and subarctic environments. The Cryosphere, 10(2), 623-638.

Roy, A., Picard, G., Royer, A., Montpetit, B., Dupont, F., Langlois, A., Derksen, C., and Champollion, N. (2013) Brightness temperature simulations of the Canadian seasonal snowpack driven by measurements of the snow specific surface area. IEEE T. Geosci. Remote., 51(9), 46924704.

Roy, V., Goita, K., Royer, A., Walker, A., and Goodson, B. (2004) Snow Water Equivalent Retrieval in a Canadian Boreal Environment from Microwave Measurements using the HUT Snow Emission Model, IEEE T. Geosci. Remote., 42, 1850-1859.

Royer, A., Roy, A., Montpetit, B., Saint-Jean-Rondeau, O., Picard, G., Brucker, L., and Langlois, A. (2017) Comparison of commonly-used microwave radiative transfer models for snow remote sensing. Remote Sens. Environ., 190, 247-259.

Rutter, N., Sandells, M., Derksen, C., Toose, P., Royer, A., Montpetit, B., Langlois, A., Lemmetyinen, J., and Pulliainen, J. (2014) Snow stratigraphic heterogeneity within groundbased passive microwave radiometer footprints: Implications for emission modeling. J. Geophys. Res. Earth Surf. 119 (3), 550-565.

Rutter, N., Essery, R., Pomeroy, J., Altimir, N., Andreadis, K., Baker, I., Barr, A., Bartlett, P., Boone, A., Deng, H., Douville, H., Dutra, E., Elder, K., Ellis, C., Feng, X., Gelfan, A., Goodbody, A., Gusev, Y., Gustafsson, D., Hellström, R., Hirabayashi, Y., Hirota, T., Jonas, T., Koren, V., Kuragina, A., Lettenmaier, D., Li, W.-P., Luce, C., Martin, E., Nasonova, O., Pumpanen, J., Pyles, R. D., Samuelsson, P., Sandells, M., Schädler, G., Shmakin, A., Smirnova, T. G., Stähli, M., Stöckli, R., Strasser, U., Su, H., Suzuki, K., Takata, K., Tanaka, K., Thompson, E., Vesala, T., Viterbo, P., Wiltshire, A., Xia, K., Xue, Y., and Yamazaki, T. (2009) Evaluation of forest snow processes models (SnowMIP2), J. Geophys. Res., 114, D06111. 
Rutter, N., Cline, D., and Li, L. (2008) Evaluation of the NOHRSC snow model (NSM) in a onedimensional mode. J. Hydrometeorol., 9(4), 695-711.

Salminen, M., Pulliainen, J., Metsämäki, S., Kontu, A., and Suokanerva, H. (2009) The behaviour of snow and snow-free surface reflectance in boreal forests: Implications to the performance of snow covered area monitoring. Remote Sens. Environ., 113(5), 907-918.

Santi, E., Paloscia, S., Pampaloni, P., Pettinato, S., Brogioni, M., Xiong, C., and Crepaz, A. (2017) Analysis of Microwave Emission and Related Indices Over Snow using Experimental Data and a Multilayer Electromagnetic Model. IEEE T. Geosci. Remote., 55(4), 2097-2110.

Schneebeli, M., Pielmeier, C., and Johnson, J. B. (1999) Measuring snow microstructure and hardness using a high resolution penetrometer, Cold Reg. Sci. Technol., 30, 101-114.

Schneebeli, M., and Johnson, J. B. (1998) A constant-speed penetrometer for high-resolution snow stratigraphy. Ann. Glaciol., 26, 107-111.

Sihvola, A. and Tiuri, M. (1986) Snow fork for field determination of the density and wetness profiles of a snow pack, IEEE T. Geosci. Remote., GE-24, 717-721.

Sommerfeld, R. A., and LaChapelle, E. (1970). The classification of snow metamorphism. J. Glaciol., 9(55), 3-18.

Stamnes, K., Tsay, S. C., Wiscombe, W., and Laszlo, I. (2000). DISORT, a general-purpose Fortran program for discrete-ordinate-method radiative transfer in scattering and emitting layered media: documentation of methodology (p. 112). Tech. rep., Dept. of Physics and Engineering Physics, Stevens Institute of Technology, Hoboken, NJ 07030.

Stiles, W. H., and Ulaby, F. T. (1980) The active and passive microwave response to snow parameters: 1. Wetness. J. Geophys. Res. Oceans, 85(C2), 1037-1044.

Strasser, U. (2008) Snow loads in a changing climate: new risks?. Natural hazards and Earth System Science, 8(1), 1-8.

Sturm, M. (2015) White water: Fifty years of snow research in WRR and the outlook for the future. Water Resour. Res., 51(7), 4948-4965.

Sturm, M., and Benson, C. S. (1997) Vapor transport, grain growth and depth-hoar development in the subarctic snow. J. Glaciol., 43(143), 42-59.

Stogryn, A. (1986) A Study of the Microwave Brightness Temperature of Snow from the Point of View of Strong Fluctuation Theory, IEEE T. Geosci. Remote., GE-24, 220-231. 
Taillandier, A. S., Domine, F., Simpson, W. R., Sturm, M., Douglas, T. A., and Severin, K. (2006) Evolution of the snow area index of the subarctic snowpack in central Alaska over a whole season. Consequences for the air to snow transfer of pollutants. Environ. Sci. Technol., 40(24), 7521-7527.

Takala, M. (2018) Microwave remote sensing of snow and environment. Finnish Meteorological Institute Contributions 151.

Takala, M., Luojus, K., Pulliainen, J., Derksen, C., Lemmetyinen, J., Kärnä, J.P., Koskinen, J., and Bojkov, B. (2011) Estimating northern hemisphere snow water equivalent for climate research through assimilation of space-borne radiometer data and ground-based measurements. Remote Sens. Environ., 115(12), 3517-3529.

Tedesco, M., and Jeyaratnam, J. (2016) A new operational snow retrieval algorithm applied to historical AMSR-E brightness temperatures. Remote Sensing, 8(12), 1037.

Tedesco, M., and Kim, E. J. (2006) Intercomparison of electromagnetic models for passive microwave remote sensing of snow. IEEE T. Geosci. Remote., 44(10), 2654-2666.

Toure, A., Goite, K., Royer, A., Mätzler, C., and Schneebeli, M. (2008) Near-infrared digital photography to estimate snow correlation length for microwave emission modelling, Appl. Optics, 48, 1-11.

Tsang, L., Chen, C.-T., Chang, A., Guo, J., and Ding, K.-H. (2000) Dense media radiative transfer theory based on quasicrystalline approximation with application to passive microwave remote sensing of snow, Radio Sci., 35, 731-749.

Tse, K. K., Tsang, L., Chan, C. H., Ding, K. H., and Leung, K. W. (2007) Multiple scattering of waves by dense random distributions of sticky particles for applications in microwave scattering by terrestrial snow. Radio Sci., 42(05), 1-14.

Turunen, M. T., Rasmus, S., Bavay, M., Ruosteenoja, K., and Heiskanen, J. (2016) Coping with difficult weather and snow conditions: Reindeer herders' views on climate change impacts and coping strategies. Climate Risk Management, 11, 15-36.

Ulaby, F. T., Moore, R. K., and Fung, A. K. (1981) Microwave remote sensing: Active and passive. Volume 1 -Microwave remote sensing fundamentals and radiometry.

Vallese, F., and Kong, J. A. (1981) Correlation function studies for snow and ice. J. Appl. Phys., 52(8), 4921-4925. 
Vaughan, D. G., Corr, H. F., Bindschadler, R. A., Dutrieux, P., Gudmundsson, G. H., Jenkins, A., Newman, T., Vornberger, P., and Wingham, D. J. (2012) Subglacial melt channels and fracture in the floating part of Pine Island Glacier, Antarctica. J. Geophys. Res. Earth Surf., 117(F3).

Vionnet, V., Brun, E., Morin, S., Boone, A., Faroux, S., Le Moigne, P., Martin, E., and Willemet, J.M. (2012) The detailed snowpack scheme Crocus and its implementation in SURFEX v7.2, Geosci. Model Dev., 5, 773-791.

Warren, S.G. (1982) Optical properties of snow. Geophys. Rev., 20(1), 67-89.

Wiesmann, A. and Mätzler, C. (1999) Microwave Emission Model of Layered Snowpacks, Remote Sens. Environ. 70, 307-316.

Wiesmann, A., Mätzler, C., and Weise, T. (1998) Radiometric and structural measurements of snow samples, Radio Sci., 33, 273-289.

Wiscombe, W. J., and Warren, S. G. (1980) A model for the spectral albedo of snow. I: Pure snow. J. Atmos. Sci., 37(12), 2712-2733.

Wolley, J. (1858) Report of the British Association, part II, pp. 40-41, London. https://www.biodiversitylibrary.org/item/96162\#page/468/mode/1up (accessed 25 November 2019)

Zheng, Z., Kirchner, P. B., and Bales, R. C. (2016) Topographic and vegetation effects on snow accumulation in the southern Sierra Nevada: a statistical summary from lidar data. The Cryosphere, 10(1), 257-269. 

Publication I 

Article

\title{
Analysis of QualitySpec Trek Reflectance from Vertical Profiles of Taiga Snowpack
}

\section{Leena Leppänen *(D) and Anna Kontu}

Finnish Meteorological Institute, Space and Earth Observation Centre, Tähteläntie 62, 99600 Sodankylä, Finland; anna.kontu@fmi.fi

* Correspondence: leena.leppanen@fmi.fi; Tel.: +358-40-670-7133

Received: 20 September 2018; Accepted: 1 November 2018; Published: 6 November 2018

\begin{abstract}
Snow microstructure is an important factor for microwave and optical remote sensing of snow. One parameter used to describe it is the specific surface area (SSA), which is defined as the surface-area-to-mass ratio of snow grains. Reflectance at near infrared (NIR) and short-wave infrared (SWIR) wavelengths is sensitive to grain size and therefore also to SSA through the theoretical relationship between SSA and optical equivalent grain size. To observe SSA, the IceCube measures the hemispherical reflectance of a $1310 \mathrm{~nm}$ laser diode from the snow sample surface. The recently developed hand-held QualitySpec Trek (QST) instrument measures the almost bidirectional spectral reflectance in the range of $350-2500 \mathrm{~nm}$ with direct contact to the object. The geometry is similar to the Contact Probe, which was previously used successfully for snow measurements. The collected data set includes five snow pit measurements made using both IceCube and QST in a taiga snowpack in spring 2017 in Sodankylä, Finland. In this study, the correlation between SSA and a ratio of $1260 \mathrm{~nm}$ reflectance to differentiate between $1260 \mathrm{~nm}$ and $1160 \mathrm{~nm}$ reflectances is researched. The correlation coefficient varied between 0.85 and 0.98 , which demonstrates an empirical linear relationship between SSA and reflectance observations of QST.
\end{abstract}

Keywords: near-infrared reflectance; specific surface area; spectrometer; snow microstructure

\section{Introduction}

The microstructure of snow is an important parameter for the modelling of microwave emission and optical reflectance [1-3], and it is therefore also important for remote sensing applications. However, a parameter describing all snow properties, including size, shape, bonding, and the orientation of snow grains, is not simple to define. The parameters most often used for that purpose are traditional grain size [4], correlation length [3,5], optical grain size [6,7], and specific surface area (SSA) $[8,9]$. Several methods exist to measure these directly or indirectly, but this study concentrates only on the reflectance-derived, in-situ methods.

Snow reflectance at near infrared (NIR) and short-wave infrared (SWIR) wavelengths, especially over $1000 \mathrm{~nm}$, is dominated by grain size [6]. Optical effective grain size is defined as the diameter of spheres having equal optical properties compared with the original grains [6,10]. SSA is defined as the surface area of the air-ice interface per unit mass (unit $\mathrm{m}^{2} \mathrm{~kg}^{-1}$ ) $[9,11]$. Optical grain size and SSA are related by Equation (1):

$$
S S A=\frac{6}{\rho_{\text {ice }} D_{0}}
$$

where $\rho_{\text {ice }}$ is the density of ice and $D_{0}$ is the optical grain size, which is derived based on equations in $[9,12]$ as presented by [13]. Grain shape has been shown to affect the reflectance-derived SSA in many wavelengths $[10,14,15]$, and [16] presented a modelling study concerning the influence of grain shape on albedo-derived SSA, resulting in $20-25 \%$ error. 
DUal Frequency Integrating Sphere for Snow SSA (DUFISSS) was presented by [13]. It uses 1310 $\mathrm{nm}$ and $1550 \mathrm{~nm}$ lasers and an integrating sphere to measure hemispherical reflectance from the snow sample surface, which was converted to SSA $[13,17]$. The error of the SSA measurement was $10 \%$ based on [13]. The measurement method is similar to that of the IceCube, which is described in Section 2.2. The Profiler of Snow Specific Surface area Using SWIR reflectance Measurement (POSSSUM) and the Alpine Snow Specific Surface Area Profiler (ASSSAP) [18] are also based on the same principle. A contact spectroscopy method is presented by [7] to observe the optical grain diameter from a vertical profile of snowpack based on reflectance measurements of a band near $1030 \mathrm{~nm}$ by using a FieldSpec FR and attached modified Contact Probe (ASD Inc., Longmont, CO, USA). The derivation of optical grain size was based on an ice absorption model by [2]. The optical grain size and traditional grain size had poor correlation with less robust results for rounded grains, which is assumed to relate to the effect of grain shape. A review of past field experiments, where reflectance or albedo is compared to some of those parameters describing snow microstructure, is presented next.

Near infrared photography at $850-1000 \mathrm{~nm}$ is a method to observe SSA from reflectance as presented by [19]. The correlation between reflectance and SSA was reported to be 0.9 and the inaccuracy of SSA 15\%. A clear correlation between hemispherical reflectance derived from measured nadir SWIR spectral reflectance of snow from FiedSpec FR 350-2500 nm (ASD Inc., Longmont, CO, USA) and SSA measured with Brunauer Emmett Teller (BET) analysis [9,20] was presented by [8]. Additionally, they did not find any effect from grain shape on the results. A correlation between grain size and a ratio of $1160 \mathrm{~nm}$ and $1260 \mathrm{~nm}$ hemispherical reflectance is showed by [21]. The accuracy of average grain size estimation was presented to be $\pm 0.2 \mathrm{~mm}$. Spectral albedo was measured with the Autosolexs instrument (400-1050 nm) to estimate SSA [22]. The accuracy of SSA depended on the solar zenith angle and the leveling of the instrument, and error was presented to be $15 \%$. The SSA derived from Autosolexs had poor correlation with ASSSAP measurements; however, the wavelength and vertical resolutions of the instruments were different. The Automatic Spectro-Goniometer is presented for hemispherical-directional reflectance measurements [23]. The measurements were compared with Discrete Ordinates Radiative Transfer Program for a Multi-Layered Plane-Parallel Medium (DISORT)-modelled reflectance by using spheres with radii equal to the surface-area-to-volume ratio derived from stereological analysis, resulting in model underestimation with a maximum mean root-mean-square error (RMSE) of $0.09 \%$ for $1300 \mathrm{~nm}$. A study where albedo was modelled with DISORT based on SSA measured with DUFISSS resulted in $1.1 \%$ difference to measured albedo with FieldSpec pro JR (ASD Inc., Longmont, CO, USA) [24]. It is estimated that $1 \%$ error in albedo corresponds approximately with $15 \mathrm{~m}^{2} \mathrm{~kg}^{-1}$ error in SSA [16]. In addition, the optical diameter of snow grains with data derived from near infrared photography or FieldSpec (ASD Inc., Longmont, CO, USA) spectral albedo or reflectance observations is researched by [25-29]. Grain size or size distribution was measured traditionally or from image-processing of microphotography.

The presented methods from previous studies are primarily intended for measuring reflectance from the surface of the snowpack, and they are not suitable for measuring vertical profiles except for contact spectroscopy with the Contact Probe and near-infrared photography. Since solar radiation is subject to variability, originating from, for example, zenith angle and cloud cover, it is beneficial that the instrument used includes an internal light source for stable illumination. A newly developed instrument, QST (ASD Inc., Longmont, CO, USA), was tested for performing rapid measurements of vertical snow profiles. The hand-held instrument measures almost bidirectional reflectance with similar optical geometry to that of the Contact Probe. The instrument was tested on taiga snowpack in the Arctic Space Centre of the Finnish Meteorological Institute in Sodankylä in northern Finland. QST has been used previously for other purposes such as the detection of ion concentrations in soil [30] and heavy metal pollution in soil [31]. Snow measurements are more challenging due to the deeper penetration depth of the radiation, the fragile structure of the snowpack, and melting of the snow.

Previous results of SSA measurements from a taiga snowpack in Sodankylä include the comparison of SSA and optical grain size to modelling results. The optical grain size derived from SSA 
measurements of IceCube was compared to SNOWPACK [32-34] modelled optical grain size in [35,36]. SNTHERM [37,38], SNICAR [39], and MOSES [40] modelled optical grain sizes were compared to IceCube-derived optical grain size by [37]. Moreover, the spectral reflectance of a taiga snowpack has previously been measured with a portable Field Spec pro JR spectrometer in the Sodankylä area and a similar mast-based spectrometer located at the same area as the measurements performed for this study [41,42]. In addition, measurements of bidirectional reflectance factor have been performed with a goniospectropolariphotometer $[43,44]$.

The aim of this study was to test the suitability of the QST instrument for measuring the reflectance of snow, and the main conclusion of the study was that an empirical relationship between SSA and QST reflectance exists. The paper has the following structure: Section 2 presents field measurements and methods, results are presented in Section 3, and discussion is made in Section 4.

\section{Materials and Methods}

Snow measurements have been performed at the Intensive Observation Area (IOA) in Sodankylä in northern Finland since 2006 (Figure 1) for the calibration, validation, and development of remote sensing instruments and interpretation algorithms. Vegetation in the cleared area among sparse pine forests consists of lichen, moss, heather, crowberry, and lingonberry, whose growth rate is approximately $0.4 \mathrm{~cm}$ per year in the snow pit area [45]. Typically, the average maximum snow depth $(\sim 80 \mathrm{~cm})$ occurs in late March. The average air temperature is below $0{ }^{\circ} \mathrm{C}$ from November to April, and the average wind speed is low $\left(1-2 \mathrm{~m} \mathrm{~s}^{-1}\right)$ in the area as described in [35]. Several automated instruments measuring snow, soil, radiation, and meteorological parameters are installed in the IOA, in addition to manually recorded snow pit measurements [35]. The data set for this study was taken from snow pit measurements made in spring 2017 (22 February, 7 March, 16 March, 21 March, and 3 April) with clear or partially cloudy sky conditions.

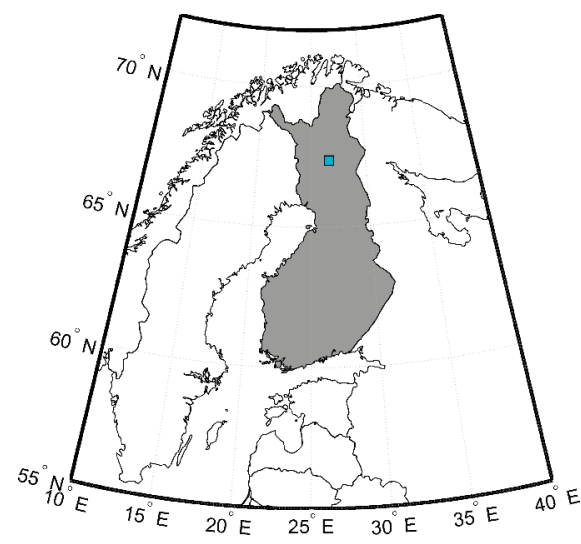

(a)

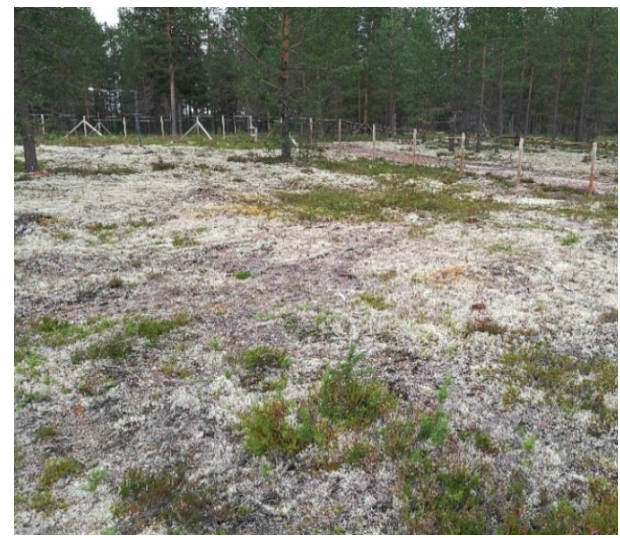

(b)

Figure 1. (a) Location of Sodankylä in northern Finland; (b) snow pit measurement site in Sodankylä.

\subsection{Layers, Traditional Grain Size, and Density}

Horizontal layers of the snowpack were defined manually with a brush and toothpicks. Layers were defined according to visual appearance, grain type, grain size, hardness, and wetness. Macrophotography-based, traditional grain size, the largest extent of an average grain [4], was estimated from macro-photographs taken against a $1 \mathrm{~mm}$ reference grid. The density profile was measured every $5 \mathrm{~cm}$ with a $10 \mathrm{~cm} \times 10 \mathrm{~cm} \times 5 \mathrm{~cm}$ rectangular sampler and digital scale with $\pm 1 \mathrm{~g}$ accuracy. More detailed information of the methods is presented by [35]. 


\subsection{SSA with IceCube}

The reflectance and SSA was observed with IceCube manufactured by A2 Photonic Sensors, Grenoble, France. IceCube measures the hemispherical reflectance of a $1310 \mathrm{~nm}$ laser from the snow sample surface (Figure 2a). A photodiode observes diffuse radiation from the integrating sphere originating from the laser and reflected from the sample. The snow sample is collected with a spatula (or a specific tool), packed into the sample holder to reach a minimum density of $200 \mathrm{~kg}$ $\mathrm{m}^{-3}$, and the surface is levelled (Figure $2 \mathrm{~b}$ ). The sample holder is $2.5 \mathrm{~cm}$ high and $6 \mathrm{~cm}$ in diameter. Software provided by the manufacturer converts the observed voltage value to reflectance using the calibration results. The instrument is calibrated for every measurement occasion using reference plates of different reflectivity. The calibration curve is fitted to the six calibration measurements. Determination of SSA from the reflectance is based on DISORT modelling and depends also on optical parameters of the integrating sphere [13]. In this study, the SSA samples were taken in $3 \mathrm{~cm}$ intervals from the vertical profile of the snowpack. A more detailed description of the IceCube measurement procedure is presented in [35] and a discussion on measurement errors is presented in [46].

Additional testing of the measurement accuracy occurred on 21 March 2017. The measurement of each sample from the profile was repeated three times with IceCube by rotating the sample in the azimuth direction between measurements. In addition, three samples were taken from both the surface layer and the depth hoar layer to test the effect of the sampling procedure and packing density. Those samples were also weighed to determine the sample density.

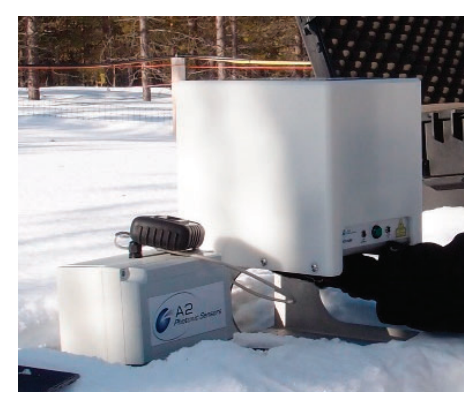

(a)

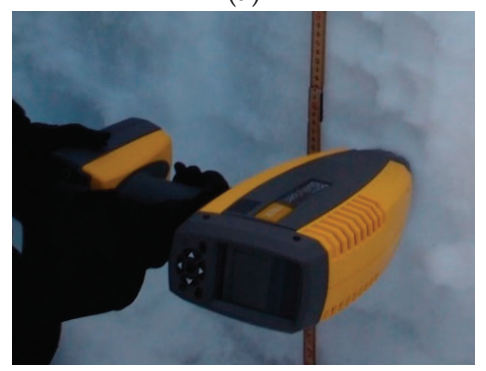

(c)

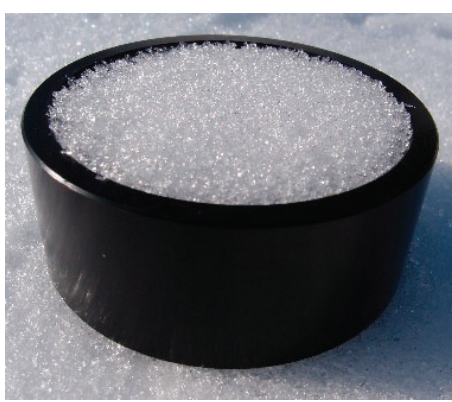

(b)

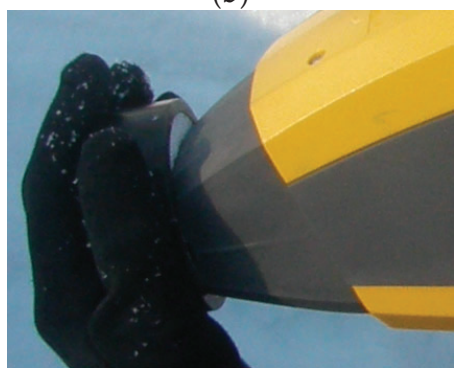

(d)

Figure 2. (a) The IceCube measurement; (b) the IceCube sample; (c) the QualitySpec Trek (QST) measurement from the snowpack vertical profile; (d) the QST measurement from sampled snow.

\subsection{Reflectance with QualitySpec Trek}

QST is a portable spectrometer manufactured by ASD Inc., Longmont, CO, USA (Figure 2c,d). QST measures the almost bidirectional reflectance of NIR and SWIR radiation at 350-2500 nm wavelengths with a spectral resolution of $9.8 \mathrm{~nm}$ at $1400 \mathrm{~nm}$. The instrument has three detectors: 350-1000 nm (512-element silicon array), 1001-1785 nm (InGaAs photodiode), and 1786-2500 nm (InGaAs photodiode). The instrument also has an internal light source and internal gray scale reference 
for optimization and wavelength calibration. The light source is a Quartz Tungsten Halogen bulb with a color temperature of $2870 \mathrm{~K} \pm 33 \mathrm{~K}$. Illumination and viewing geometry is presented in Figure 3. The window of QST is approximately $1 \mathrm{~cm}$ in diameter, and the whole window is illuminated by the internal light source. The window and materials inside the instrument are designed to minimize specular reflections. The angle from the instrument window to the light source is $55^{\circ}$ and the angle to the fiber optic is $78^{\circ}$. The fiber optic cable has a field of view of $25^{\circ}$, which means that the field of view is $0.82 \mathrm{~cm}$ on the window of the instrument. The Contact Probe [7] has the same measurement geometry as QST. Additional calibration is made before every measurement occasion with a separate white reference plate. The reference plate is attached in front of the instrument window with magnetic plugs. It is important that the white reference plate is clean and that the manufacturer provides information for cleaning and replacing the plate. Full-spectrum dark reference is measured also during the start-up with an internal shutter, the light source is turned off, and the white reference is plugged. The dark reference (background) value is subtracted from raw data prior to the reflectance calculation. The sample count averaging time can be set to $1,2,5$, or $10 \mathrm{~s}$. The instrument scans the entire wavelength range 10 times per second and produces an average of those. The sample is set to physical contact with the instrument window (Figure 2c,d and Figure 3), so cleaning of the window between the measurements is therefore required. A measurement is stored by pushing a trigger button. Sound signals for starting and finishing the measurement notes when the instrument needs to be in stationary position with the (snow) sample. The most recent data is shown on the screen. Audio note recording is possible after the measurement. The instrument also stores coordinates and elevation from the internal GPS for each sample. Automatic and manual data storage options are available. The resulting reflectance is absolute reflectance (reflectance normalized with reference reflectance). Since the instrument is commercial, calibration data and data from the single spectrums before averaging are not available.

The measurement procedure included a white reference measurement, instrument setup (choosing how many times the wavelength range is scanned for averaging), and snow measurement (repeated). Cleaning of the window was rarely needed. Automatic data storage was used. The integration time for a measurement was set to 1 or $2 \mathrm{~s}$. A longer integration time meant more averaged spectrums and therefore less noise for an acquisition. On the other hand, the instrument remained steadier in snow with a shorter integration time. Two procedures related to how the instrument can be used are (1) vertical reflectance profile from the snowpack of the snow pit wall and (2) reflectance from the snow surface without digging a snow pit. The measurements were made with the first procedure from the snowpack profile by pushing the instrument window steadily against the snow pit wall during the measurement (Figure 2c). The window had physical contact to the snow so that the distance between the snow and fiber optic cable was always constant and the measurement configuration did not change. The measurements were made at approximately $2-5 \mathrm{~cm}$ intervals from the vertical profile. Some of the IceCube samples were also measured with QST by pushing the window against the snow in the middle of the sample surface (Figure 2d). 


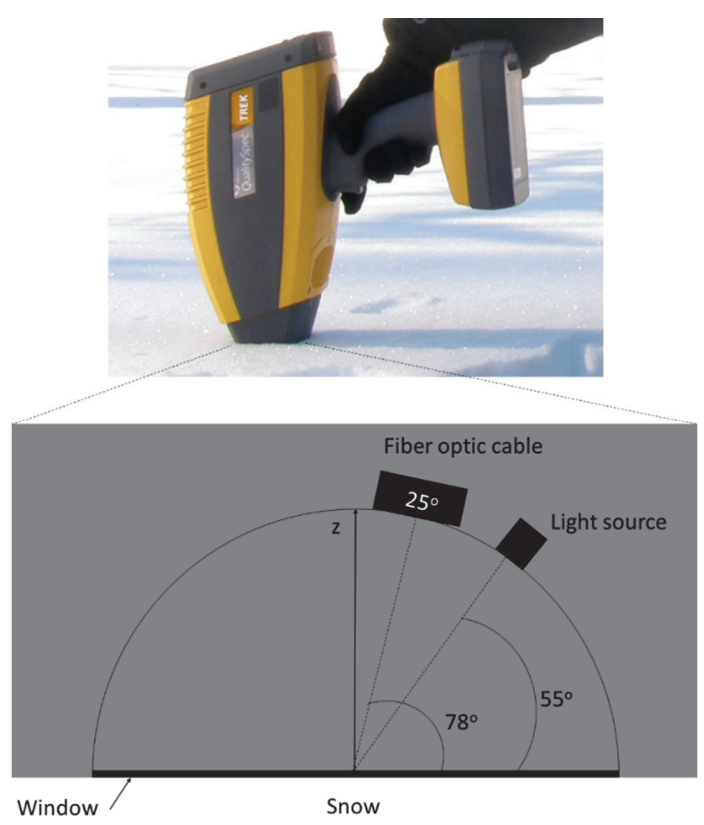

Figure 3. Illumination and viewing configuration. Fiber optic and light source have the same azimuth angle. Fiber optic cable has $25^{\circ}$ field of view. Diameter of the window is approximately $1 \mathrm{~cm}$.

\subsection{Methods for Comparison of QST and IceCube Measurements}

Reflectance profiles were measured with QST from both the snowpack and the sampled snow on 21 March and 3 April 2017. The two profiles were measured with different height intervals, and therefore both profiles were linearly interpolated for every centimeter (no extrapolation). A comparison presented in Section 3.3 was made only for the heights where both interpolated reflectance values existed.

The empirical relationship between SSA and reflectance was studied with 1160 and $1260 \mathrm{~nm}$ reflectance-dependent coefficient $Q$, which is the ratio of reflectance at the bottom of the ice absorption feature and the reflectance change in the ice absorption feature. The absorption coefficient of ice is larger at $1260 \mathrm{~nm}$ than at $1160 \mathrm{~nm}$. Q is calculated with Equation (2) as

$$
Q=\frac{R_{1260}}{R_{1160}-R_{1260}}
$$

where $R_{1160}$ is reflectance at $1160 \mathrm{~nm}$ and $R_{1260}$ is reflectance at $1260 \mathrm{~nm}$.

Similarly, interpolation was also needed to compare SSA and reflectance-derived $Q$ from the same heights of snow. Linear interpolation without extrapolation was made for SSA when the reflectance profiles from the snowpack were studied. For 21 March, the values from the first of the three SSA measurements of the same sample were used. The comparison presented in Section 3.4 was made with interpolated SSA values from the same heights as the original reflectance profile measurements from the snowpack. Interpolation was not needed in the case of the reflectance profile from sampled snow because the same samples were measured with both instruments.

Clearly erroneous reflectance values measured with QST were removed from the analysis ( $>0.1$ difference to the closest value without fitting to other values around). One of those was from the snowpack profile in 16 March ( $63 \mathrm{~cm}$ height), another one was from the snowpack profile in 21 March (70 cm height), and the two last ones were from the sampled snow in 21 March (48 and $51 \mathrm{~cm}$ height). 


\section{Results}

The data set includes vertical profile measurements of reflectance, SSA, macrophotography-based traditional grain size, and density from various snow types with varying grain size and density in a taiga snowpack. The snow height of $0 \mathrm{~cm}$ was set to the ground surface. The height of the snow and air temperature for spring 2017 are presented in Figure 4. An overview of all data used in the study is presented in Figure 5.

\subsection{Snowpack Properties}

The height of snow increased before 21 March and melting had already started in 3 April, as shown in Figure 4. The air temperature was close to zero or positive (in ${ }^{\circ} \mathrm{C}$ ) on $16 \mathrm{March}, 21 \mathrm{March}$, and 3 April. Layer properties had temporal variations; however, there were some lasting similarities. The hard crust layer at approximately $30 \mathrm{~cm}$ height (red in Figure 5c) was observed in all snow pits. The traditional grain size was larger below than above that layer, which is typical, because grain growth is largest at the bottom due to the higher temperature gradient. Between $30-40 \mathrm{~cm}$ height of snow, the grain shape changed from round (pink in Figure 5c) to faceted (light blue in Figure 5c), and grain size increased simultaneously. In mid-winter, the bottom layers consisted of smaller grains than in the layers above those. Typically, traditional grain size was larger in faceted crystal and depth hoar layers than layers with rounded grains, as expected based on the temperature gradient. Density was lowest in the top $5-15 \mathrm{~cm}$ of the snowpack. Maximum density was found in the 5-15 cm bottom layer of the snowpack, and in the crust layer around $30-40 \mathrm{~cm}$ height. Based on those observations, the reflectance and SSA measurements were made at differing air temperatures and snow conditions with variating grain size, grain type, and density.

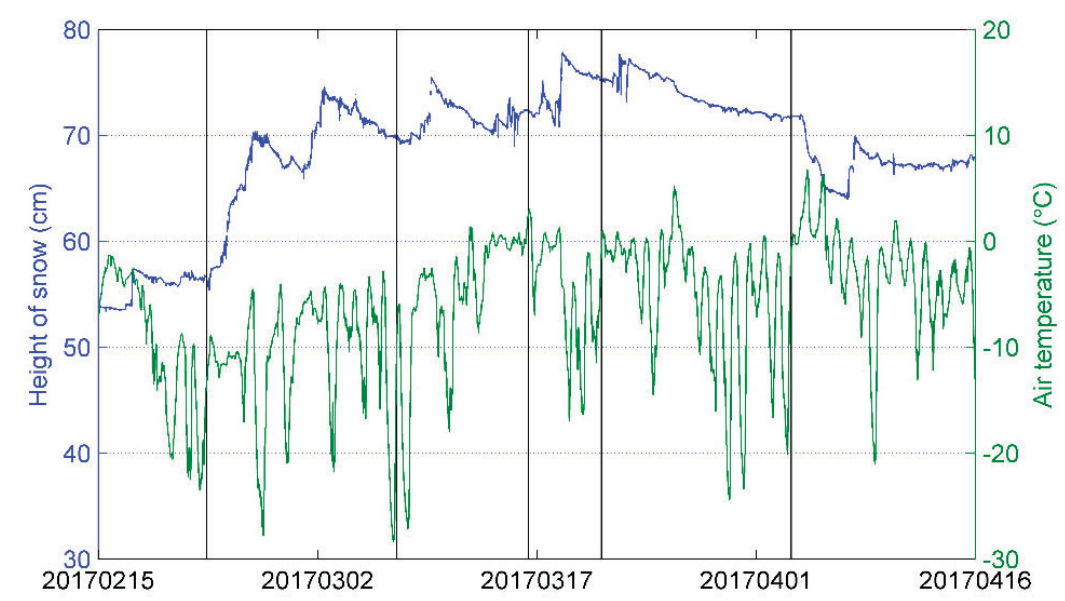

Figure 4. The height of snow (blue) and air temperature (green) measured at the Intensive Observation Area (IOA). Vertical black lines indicate the measurements made with QST. 

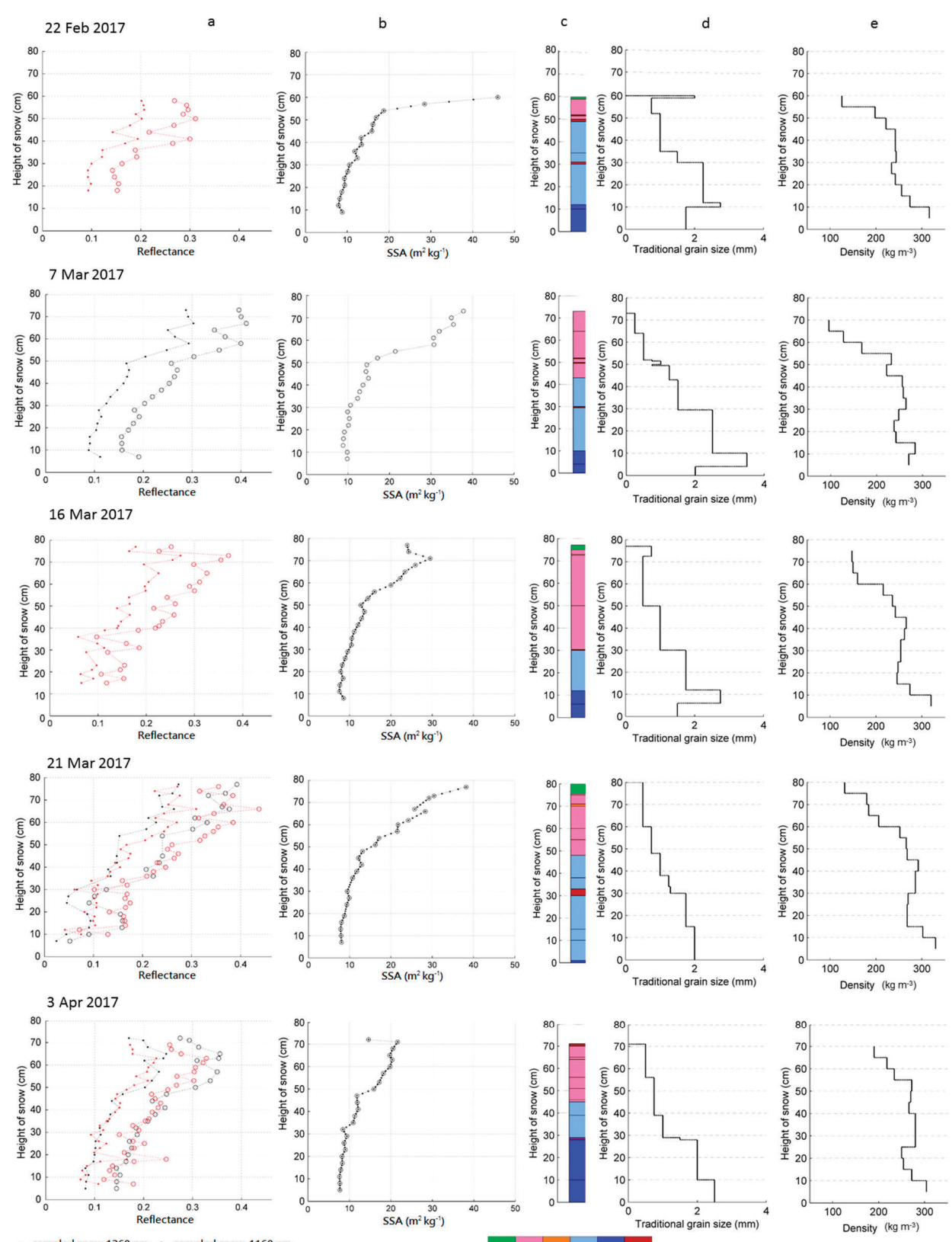

- sampled snow $1260 \mathrm{~nm} \circ$ sampled snow $1160 \mathrm{n}$

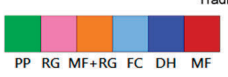

Figure 5. Reflectance from QST, specific surface area (SSA) from IceCube, grain type, macrophotography-based traditional grain size, and density profiles of snow are plotted in columns (a-e) for all dates. Original SSA data are marked with circles and interpolated values with dots in column (b). SSA for 21 March 2017 is plotted from the first measurement of three for every height. Grain type abbreviations are described in [4]. 


\subsection{Repeatability of SSA Measurements}

Repeatability of the SSA measurements with IceCube was tested to confirm the reliability of observations for the following analysis. First, the measurement method was tested by repeating measurements with the same sample; then, sampling was tested by sampling snow to different densities. The repeatability of the IceCube measurement method was tested on 21 March 2017. Every sample from the profile was measured three times with IceCube. The mean standard deviation of the SSA was $0.34 \mathrm{~m}^{2} \mathrm{~kg}^{-1}$, which means a relative standard deviation (RSD) of $2.0 \%$. RSD is calculated by Equation (3)

$$
R S D=100 \sigma / \mu
$$

where $\sigma$ is the standard deviation and $\mu$ is the average. The repeatability of IceCube sampling was also tested on 21 March 2017. Precipitation particles in the surface layer and faceted crystals in the bottom of the snowpack were both sampled three times. The samples were taken next to each other so that snow was as homogenous as possible for all the samples. The samples were packed to different densities, measured with IceCube and weighed for density calculation. The average standard deviation was 0.65 and RSD was $2.85 \%$ (Table 1$)$. Since the total RSD was low $(<5 \%)$, SSA is relied on as a truthful value in the subsequent analysis.

Table 1. The SSA from three samples of precipitation particles at the surface and faceted crystals in the bottom of the snowpack. Standard deviations (STD) and relative standard deviations (RSD) from Equation (3) are calculated for both surface and bottom.

\begin{tabular}{ccccc}
\hline & Density $\left(\mathrm{kg} \mathrm{m}^{-3}\right)$ & SSA $_{\left(\mathbf{m}^{\mathbf{2}} \mathbf{~ k g}^{-\mathbf{1}}\right)}$ & STD & RSD (\%) \\
\hline \multirow{3}{*}{ Surface } & 225.0 & 39.8 & & \\
& 309.9 & 41.6 & 1.04 & 2.53 \\
& 352.4 & 41.6 & & \\
Bottom & 338.2 & 7.9 & & \\
& 409.0 & 8.2 & 0.25 & 3.17 \\
\hline Average & 394.9 & 7.7 & & \\
\hline
\end{tabular}

\subsection{Comparison of QST Reflectance Profiles}

Reflectance profiles were measured with QST from both the snowpack and the sampled snow in 21 March and 3 April 2017. Both profiles were made next to each other at the same snow pit. The reflectance profiles were compared with three wavelengths $(1160,1260$, and $1310 \mathrm{~nm})$, which are used later in the study.

The comparison results showed a strong correlation between the reflectance profiles directly from the snowpack and the sampled snow with a correlation coefficient of 0.92-0.94 (Table 2), as was expected. Bias varied from -0.020 to 0.016 and RMSE varied from 0.022 to 0.040 (Table 2). According to the results, IceCube sampling had only a small effect on the reflective properties of snow (microstructure) at 1160, 1260, and $1310 \mathrm{~nm}$ wavelengths.

Table 2. Bias, root-mean-square error (RMSE) and correlation coefficient $(R)$ for QST reflectances from the snowpack profile and the sampled snow.

\begin{tabular}{ccccc}
\hline Date & Wavelength $(\mathbf{n m})$ & Bias & RMSE & $\boldsymbol{R}$ \\
\hline \multirow{3}{*}{ 21 March 2017 } & 1160 & -0.0204 & 0.040 & 0.92 \\
& 1260 & -0.0202 & 0.031 & 0.94 \\
& 1310 & -0.0230 & 0.034 & 0.93 \\
\hline \multirow{3}{*}{ 3 April 2017 } & 1160 & 0.0160 & 0.033 & 0.92 \\
& 1260 & 0.0055 & 0.022 & 0.92 \\
& 1310 & 0.0068 & 0.023 & 0.92 \\
\hline
\end{tabular}




\subsection{Empirical Relationship between SSA and Reflectance}

Previously shown relationships between snow microstructural parameters and albedo or hemispherical reflectance are described in the Section 1. Similarly, we hypothesized that reflectance measured with QST could have an empirical connection to the SSA. The empirical relationship between SSA and reflectance was studied with 1160 and $1260 \mathrm{~nm}$ reflectance-dependent coefficient $\mathrm{Q}$ (see Section 2.4). Examples of the measured reflectance are presented in Figure 6, where the upper part of an ice absorption feature was located close to $1160 \mathrm{~nm}$ and bottom of it close to $1260 \mathrm{~nm}$. The correlation between SSA and Q was high with correlation coefficients between 0.85 and 0.98 (Table 3). Linear fits are presented for measurements from the snowpack and the sampled snow in Figure 7. The fit is better for the QST measurements from the snowpack (Figure 7a). Single outliers existed for observations in 21 March from sampled snow, which are visible in the scatter plot of Figure 7b. There is approximately 0.2 bias in the linear fits between QST measurements from the snowpack and from the sampled snow. The results prove that an empirical relationship between SSA and reflectance exists, although measurement of light, new snow and fragile depth hoar is challenging.

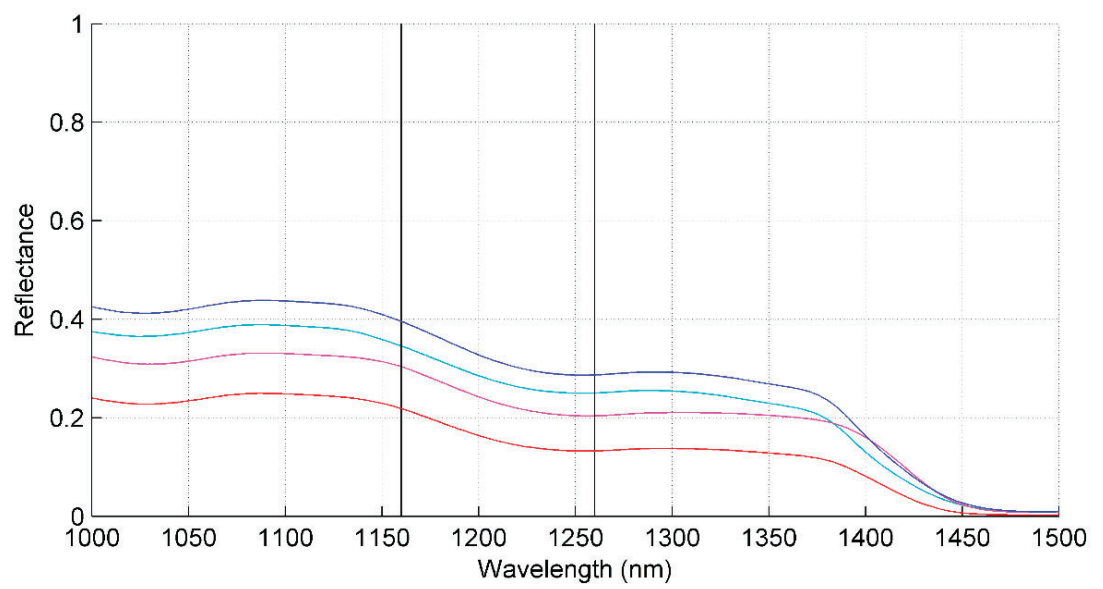

Figure 6. Example of reflectances measured on 7 March 2017 at heights of $73 \mathrm{~cm}$ (blue), $64 \mathrm{~cm}$ (cyan), $52 \mathrm{~cm}$ (magenta), and $34 \mathrm{~cm}$ (red). Vertical lines indicate wavelengths $1160 \mathrm{~nm}$ and $1260 \mathrm{~nm}$.

Table 3. Correlation coefficient $(R)$ between SSA and Q for the QST measurements from the snowpack profile and profile of the sampled snow.

\begin{tabular}{ccc}
\hline Date & Profile & $\boldsymbol{R}$ \\
\hline 22 February 2017 & Snowpack & 0.95 \\
7 March 2017 & Sampled Snow & 0.98 \\
16 March 2017 & Snowpack & 0.89 \\
21 March 2017 & Sampled Snow & 0.89 \\
21 March 2017 & Snowpack & 0.94 \\
3 April 2017 & Sampled Snow & 0.96 \\
3 April 2017 & Snowpack & 0.85 \\
\hline
\end{tabular}




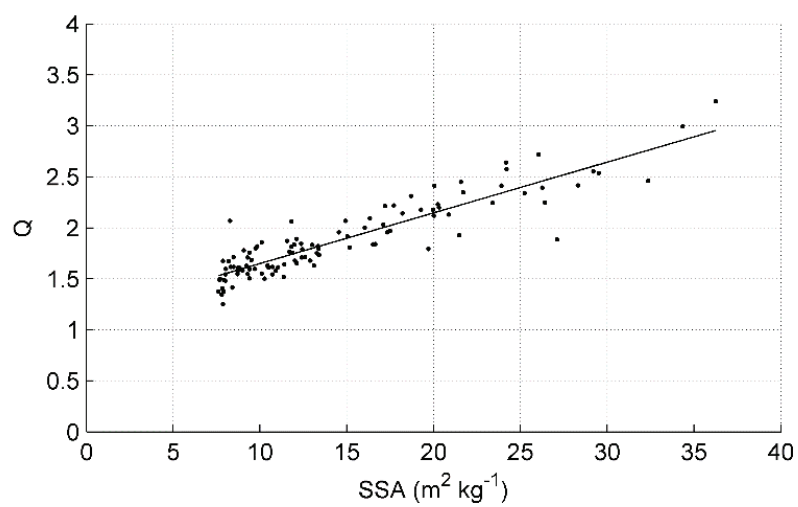

(a)

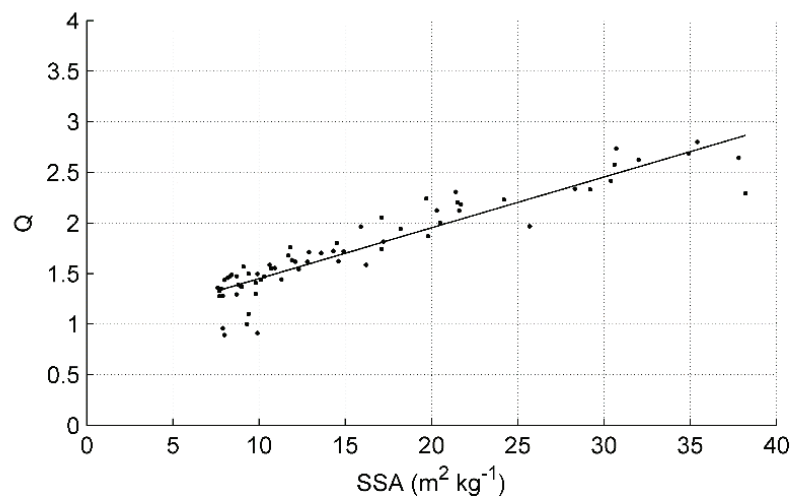

(b)

Figure 7. Scatter plot of Q with Equation (2) ( $y$-axis) and SSA ( $x$-axis) from the QST measurements made (a) directly from the snowpack profile and $(\mathbf{b})$ the measurements from the sampled snow. Lines fitted to the points are marked.

\section{Discussion}

Snow microstructure is an important parameter for microwave and optical remote sensing of snow. Field observations are needed in the development and validation of retrieval algorithms. Therefore, simple and accurate novel measurement methods are required. In this study, the newly developed QST instrument for reflectance measurements was tested on taiga snow, and the empirical relationship between QST reflectance and the microstructural parameter SSA was defined.

We tested the measurement accuracy of SSA to confirm the repeatability of the measurement method. The accuracy was tested by repeating IceCube measurements (several measurements from the same sample) and repeating IceCube sampling (several samples from the same height of snow). The first one resulted in an error (relative standard deviation) of $2.0 \%$ and the second one resulted in an error of $2.9 \%$. However, the repeated sampling was made for two of the most difficult types of snow to measure with IceCube with a relatively small set of observations. The total error was below $5 \%$, and measurements are therefore considered repeatable in the taiga snow conditions. We hypothesized that snow sampling for IceCube measurements might change the microstructure of snow. However, the correlation of the two QST reflectance profiles (one directly from the snowpack and one from the sampled snow) was high, with correlation coefficients of 0.92-0.94. Based on this result, we assume that the IceCube sampling procedure does not remarkably affect the optical properties and microstructure of the snow in the sample. Analysis made from the IceCube and the QST measurements resulted in a 
strong correlation between SSA and $\mathrm{Q}$, where $\mathrm{Q}$ is the ratio of reflectance at the bottom of the absorption feature $(1260 \mathrm{~nm})$ and the reflectance change in the absorption feature (between 1160 and $1260 \mathrm{~nm}$ ). The reflectance profiles measured from both the snowpack and the sampled snow were used to calculate the correlation coefficients, which had values $0.85-0.98$. In Section 1, the presented correlations of instruments measuring reflectance or albedo to SSA measurements are around 0.9. Compared to those values, the correlation between SSA and Q is approximately similar or better. Lower values of $\mathrm{Q}$ from the sampled snow compared to observations from the snowpack (bias of 0.2) originate likely from absorption by the black sample holder. The outlier values of the sampled snow on 21 March originate most likely from the melting of the snow samples due the longer measurement procedure, since the samples were measured first three times with IceCube, then weighed and finally measured with QST. Typically, the sampled snow was measured with QST directly after one IceCube measurement.

The QST measurements contain error arising from instrument metrics, the observer, and the environmental conditions. As a heavy instrument $(2.5 \mathrm{~kg})$, QST is difficult to hold stably in a stationary position with physical contact to the snow when it is not possible to lean the instrument on snow. This is the case with newly fallen surface snow with a low density (around $100 \mathrm{~kg} \mathrm{~m}^{-3}$ ) and depth hoar layer snow, which is coarse and therefore fragile. This could be avoided by using an appropriate, assembled tripod or another support structure. On the other hand, adjusting the height of the tripod between each measurement of a profile might slow down the measurements. Physical contact to the snow is required so this needs to be confirmed when using external support. However, dense and compact snow (rounded grains or faceted crystals with traditional grain size $<1.25 \mathrm{~mm}$ and density $>200 \mathrm{~km} \mathrm{~m}^{-3}$ ) had no such problems. In surface snow, solar radiation penetrates the snowpack and possibly causes some degree of error in the measurements. This could be avoided by covering the snowpack, as presented in $[7,19]$. The sampled snow measurements with QST were made mostly in the shade of the snow pit. The effect of different external illumination conditions was not studied. Warming of the instrument window and plastic casing causes some melting of the snow, and probably some inaccuracy to the measurements, especially during clear skies and positive air temperature conditions. Definition of the exact point of measurement in the snow profile is difficult, with the accuracy being approximately $\pm 2 \mathrm{~cm}$. The instrument size limits its ability to perform measurements close to the ground, so that the bottom of the snowpack below approximately $10 \mathrm{~cm}$ is difficult to measure. The clearly erroneous reflectance measurements, which were removed from the analysis, were expected to originate from the wetness of the snow or scattering of the radiation to outside of the field of view.

QST has similar optical geometry to the Contact Probe, and it uses the same range of wavelengths. However, QST is a compact, hand-held instrument while the Contact Probe is attached to a spectrometer. The hand-held instrument has no external spectrometer, laptop, and connecting cables, so QST is therefore fast and simple to use compared to the Contact Probe. In addition, audio notes are possible to record with QST. However, the Contact Probe has less direct contact with snow and the light source is further from the snow, which may reduce additional warming and melting of the snow. Reflectance from the Contact Probe is successfully used for calculation of optical grain size with the Nolin-Dozier model [7]. Therefore, we assume that derivation of optical grain size or SSA from the QST reflectance could be possible with a lookup table in the future, since the empirical relationship between SSA and reflectance has been found. However, it would require a more comprehensive set of observations and proper testing of the penetration depth of radiation and the lost portion of scattered radiation, where field experiments with both QST and the Contact Probe would be beneficial.

Author Contributions: Conceptualization, L.L. and A.K.; Formal analysis, L.L.; Investigation, L.L.; Methodology, L.L. and A.K.; Visualization, L.L.; Writing一original draft, L.L.; Writing一review \& editing, L.L. and A.K.

Funding: Work of Leena Leppänen has been partly undertaken with funding from the Vilho, Yrjö and Kalle Väisälä Foundation of the Finnish Academy of Science and Letters. 
Acknowledgments: We thank the personnel of Arctic Space Centre of Finnish Meteorological Institute for performing the manual snow measurements. We thank ASD Goetz instrument support program for the availability of the QualitySpec Trek instrument.

Conflicts of Interest: The authors declare no conflict of interest.

\section{References}

1. Pulliainen, J.; Grandell, J.; Hallikainen, M. HUT snow emission model and its applicability to snow water equivalent retrieval. IEEE Trans. Geosci. Remote Sens. 1999, 37, 1378-1390. [CrossRef]

2. Nolin, A.W.; Dozier, J. A hyperspectral method for remotely sensing the grain size of snow. Remote Sens. Environ. 2000, 74, 207-216. [CrossRef]

3. Mätzler, C. MATLAB functions for Mie scattering and absorption, version 2. IAP Res. Rep. 2002, 8, 1-24.

4. Fierz, C.; Armstrong, R.L.; Durand, Y.; Etchevers, P.; Greene, E.; McClung, D.M.; Nishimura, K.; Satyawali, P.K.; Sokratov, S.A. The International Classification for Seasonal Snow on the Ground; IHP-VII Technical Documents in Hydrology N ${ }^{\circ} 83$, IACS Contribution N ${ }^{\circ}$; UNESCO-IHP: Paris, France, 2009.

5. Debye, P.; Anderson, H.R.; Brumberger, H. Scattering by an inhomogeneous solid. II. The correlation function and its application. J. Appl. Phys. 1957, 28, 679-683. [CrossRef]

6. Warren, S.G. Optical properties of snow. Rev. Geophys. 1982, 20, 67-89. [CrossRef]

7. Painter, T.H.; Molotch, N.P.; Cassidy, M.; Flanner, M.; Steffen, K. Contact spectroscopy for determination of stratigraphy of snow optical grain size. J. Glaciol. 2007, 53, 121-127. [CrossRef]

8. Domine, F.; Salvatori, R.; Legagneux, L.; Salzano, R.; Fily, M.; Casacchia, R. Correlation between the specific surface area and the short wave infrared (SWIR) reflectance of snow. Cold Reg. Sci. Technol. 2006, 46, 60-68. [CrossRef]

9. Legagneux, L.; Cabanes, A.; Dominé, F. Measurement of the specific surface area of 176 snow samples using methane adsorption at 77 K. J. Geophys. Res. Atmos. 2002, 107. [CrossRef]

10. Grenfell, T.C.; Warren, S.G. Representation of a nonspherical ice particle by a collection of independent spheres for scattering and absorption of radiation. J. Geophys. Res. Atmos. 1999, 104, 31697-31709. [CrossRef]

11. Dominé, F.; Cabanes, A.; Taillandier, A.S.; Legagneux, L. Specific surface area of snow samples determined by $\mathrm{CH} 4$ adsorption at $77 \mathrm{~K}$ and estimated by optical microscopy and scanning electron microscopy. Environ. Sci. Technol. 2001, 35, 771-780. [CrossRef] [PubMed]

12. Kokhanovsky, A.A.; Zege, E.P. Scattering optics of snow. Appl. Opt. 2004, 43, 1589-1602. [CrossRef] [PubMed]

13. Gallet, J.C.; Domine, F.; Zender, C.S.; Picard, G. Measurement of the specific surface area of snow using infrared reflectance in an integrating sphere at 1310 and $1550 \mathrm{~nm}$. Cryosphere 2009, 3, 167-182. [CrossRef]

14. Neshyba, S.P.; Grenfell, T.C.; Warren, S.G. Representation of a nonspherical ice particle by a collection of independent spheres for scattering and absorption of radiation: 2. Hexagonal columns and plates. J. Geophys. Res. Atmos. 2003, 108. [CrossRef]

15. Grenfell, T.C.; Neshyba, S.P.; Warren, S.G. Representation of a nonspherical ice particle by a collection of independent spheres for scattering and absorption of radiation: 3. Hollow columns and plates. J. Geophys. Res. Atmos. 2005, 110. [CrossRef]

16. Picard, G.; Brucker, L.; Fily, M.; Gallée, H.; Krinner, G. Modeling time series of microwave brightness temperature in Antarctica. J. Glaciol. 2009, 55, 537-551. [CrossRef]

17. Gallet, J.C.; Domine, F.; Dumont, M. Measuring the specific surface area of wet snow using $1310 \mathrm{~nm}$ reflectance. Cryosphere 2014, 8, 1139-1148. [CrossRef]

18. Arnaud, L.; Picard, G.; Champollion, N.; Domine, F.; Gallet, J.-C.; Lefebvre, E.; Fily, M.; Barnola, J.-M. Measurement of vertical profiles of snow specific surface area with a $1 \mathrm{~cm}$ resolution using infrared reflectance: Instrument description and validation. J. Glaciol. 2011, 57, 17-29. [CrossRef]

19. Matzl, M.; Schneebeli, M. Measuring specific surface area of snow by near-infrared photography. J. Glaciol. 2006, 52, 558-564. [CrossRef]

20. Brunauer, S.; Emmett, P.H.; Teller, E. Adsorption of gases in multimolecular layers. J. Am. Chem. Soc. 1938, 60, 309-319. [CrossRef]

21. Hyvärinen, T.; Lammasniemi, J. Infrared Measurement of Grain Size and Melting Degree of Snow; Infrared Technology XI; International Society for Optics and Photonics: San Diego, CA, USA, 1985; Volume 572, pp. 158-166. 
22. Picard, G.; Libois, Q.; Arnaud, L.; Verin, G.; Dumont, M. Development and calibration of an automatic spectral albedometer to estimate near-surface snow SSA time series. Cryosphere 2016, 10, 1297-1316. [CrossRef]

23. Painter, T.H.; Dozier, J. Measurements of the hemispherical-directional reflectance of snow at fine spectral and angular resolution. J. Geophys. Res. Atmos. 2004, 109. [CrossRef]

24. Carmagnola, C.M.; Dominé, F.; Dumont, M.; Wright, P.; Strellis, B.; Bergin, M.; Dibb, J.; Picard, G.; Libois, Q.; Arnaud, L.; et al. Snow spectral albedo at Summit, Greenland: Measurements and numerical simulations based on physical and chemical properties of the snowpack. Cryosphere 2013, 7, 1139-1160. [CrossRef]

25. Langlois, A.; Royer, A.; Montpetit, B.; Picard, G.; Brucker, L.; Arnaud, L.; Harvey-Collardard, P.; Fily, M.; Goïta, K. On the relationship between snow grain morphology and in-situ near infrared calibrated reflectance photographs. Cold Reg. Sci. Technol. 2010, 61, 34-42. [CrossRef]

26. Aoki, T.; Aoki, T.; Fukabori, M.; Hachikubo, A.; Tachibana, Y.; Nishio, F. Effects of snow physical parameters on spectral albedo and bidirectional reflectance of snow surface. J. Geophys. Res. Atmos. 2000, 105, 10219-10236. [CrossRef]

27. Pirazzini, R.; Räisänen, P.; Vihma, T.; Johansson, M.; Tastula, E.M. Measurements and modelling of snow particle size and shortwave infrared albedo over a melting Antarctic ice sheet. Cryosphere 2015, 9, 2357-2381. [CrossRef]

28. Tanikawa, T.; Aoki, T.; Hori, M.; Hachikubo, A.; Abe, O.; Aniya, M. Monte Carlo simulations of spectral albedo for artificial snowpacks composed of spherical and nonspherical particles. Appl. Opt. 2006, 45, 5310-5319. [CrossRef] [PubMed]

29. Tanikawa, T.; Aoki, T.; Hori, M.; Hachikubo, A.; Aniya, M. Snow bidirectional reflectance model using non-spherical snow particles and its validation with field measurements. EARSeL eProc. 2006, 5, 137-145.

30. Peng, J.; Ji, W.; Ma, Z.; Li, S.; Chen, S.; Zhou, L.; Shi, Z. Predicting total dissolved salts and soluble ion concentrations in agricultural soils using portable visible near-infrared and mid-infrared spectrometers. Biosyst. Eng. 2016, 152, 94-103. [CrossRef]

31. Hu, B.; Chen, S.; Hu, J.; Xia, F.; Xu, J.; Li, Y.; Shi, Z. Application of portable XRF and VNIR sensors for rapid assessment of soil heavy metal pollution. PLoS ONE 2017, 12, e0172438. [CrossRef] [PubMed]

32. Bartelt, P.; Lehning, M. A physical SNOWPACK model for the Swiss avalanchewarning: Part I: Numerical model. Cold Reg. Sci. Technol. 2002, 35, 123-145. [CrossRef]

33. Lehning, M.; Bartelt, P.; Brown, B.; Fierz, C.; Satyawali, P. A physical SNOWPACK model for the Swiss avalanche warning. Part II: Snow microstructure. Cold Reg. Sci. Technol. 2002, 35, 147-167. [CrossRef]

34. Lehning, M.; Bartelt, P.; Brown, B.; Fierz, C. A physical SNOWPACK model for the Swiss avalanche warning: Part III: Meteorological forcing, thin layer formation and evaluation. Cold Reg. Sci. Technol. 2000, 35, 169-184. [CrossRef]

35. Leppänen, L.; Kontu, A.; Hannula, H.-R.; Sjöblom, H.; Pulliainen, J. Sodankylä manual snow survey program. Geosci. Instrum. Methods Data Syst. 2016, 5, 163-179. [CrossRef]

36. Kontu, A.; Lemmetyinen, J.; Vehviläinen, J.; Leppänen, L.; Pulliainen, J. Coupling SNOWPACK-modeled grain size parameters with the HUT snow emission model. Remote Sens. Environ. 2017, 194, 33-47. [CrossRef]

37. Sandells, M.; Essery, R.; Rutter, N.; Wake, L.; Leppänen, L.; Lemmetyinen, J. Microstructure representation of snow in coupled snowpack and microwave emission models. Cryosphere 2017, 11, 229. [CrossRef]

38. Jordan, R. A One-Dimensional Temperature Model for a Snow Cover: Technical Documentation for SNTHERM.89; Special Report 91-16; Cold Regions Research and Engineering Laboratory (U.S.): Hanover, NH, USA; Engineer Research and Development Center (U.S.): Vicksburg, MS, USA, 1991.

39. Flanner, M.G.; Zender, C.S. Linking snowpack microphysics and albedo evolution. J. Geophys. Res. 2006, 111, D12208. [CrossRef]

40. Essery, R.; Best, M.; Cox, P. MOSES 2.2 Technical Documentation; Technical Report, Hadley Centre Technical Note 30; Hadley Centre, Met Office: Exeter, UK, 2001; p. 31.

41. Salminen, M.; Pulliainen, J.; Metsämäki, S.; Kontu, A.; Suokanerva, H. The behaviour of snow and snow-free surface reflectance in boreal forests: Implications to the performance of snow covered area monitoring. Remote Sens. Environ. 2009, 113, 907-918. [CrossRef]

42. Meinander, O.; Kazadzis, S.; Arola, A.; Riihelä, A.; Räisänen, P.; Kivi, R.; Kontu, A.; Kouznetsov, R.; Sofiev, M.; Svensson, J.; et al. Spectral albedo of seasonal snow during intensive melt period at Sodankylä, beyond the Arctic Circle. Atmos. Chem. Phys. 2013, 13, 3793-3810. [CrossRef] 
43. Peltoniemi, J.I.; Kaasalainen, S.; Näränen, J.; Matikainen, L.; Piironen, J. Measurement of directional and spectral signatures of light reflectance by snow. IEEE Trans. Geosci. Remote Sens. 2005, 43, 2294-2304. [CrossRef]

44. Peltoniemi, J.; Hakala, T.; Suomalainen, J.; Puttonen, E. Polarised bidirectional reflectance factor measurements from soil, stones, and snow. J. Quant. Spectrosc. Radiat. 2009, 110, 1940-1953. [CrossRef]

45. Leppänen, L.; Leinss, S.; Suokanerva, H. Growth of Forest Floor Vegetation Observed from Snow Depth Measurements in Sodankylä, Finland, Snow an Ecological Phenomenon, Smolenice, Slovakia, 19-21 September 2017. Available online: http://www.sbks.sk/smolenice/Leppanen\%20et\%20al.pdf (accessed on 5 November 2018).

46. Leppänen, L.; Kontu, A.; Vehviläinen, J.; Lemmetyinen, J.; Pulliainen, J. Comparison of traditional and optical grain-size field measurements with SNOWPACK simulations in a taiga snowpack. J. Glaciol. 2015, 61, 151-162. [CrossRef]

(C) 2018 by the authors. Licensee MDPI, Basel, Switzerland. This article is an open access article distributed under the terms and conditions of the Creative Commons Attribution (CC BY) license (http://creativecommons.org/licenses/by/4.0/). 

Publication II 



\title{
Comparison of traditional and optical grain-size field measurements with SNOWPACK simulations in a taiga snowpack
}

\author{
L. LEPPÄNEN, A. KONTU, J. VEHVILÄINEN, J. LEMMETYINEN, J. PULLIAINEN \\ Arctic Research Centre, Finnish Meteorological Institute, Sodankylä, Finland \\ Correspondence: L. Leppänen <leena.leppanen@fmi.fi>
}

\begin{abstract}
Knowledge of snow microstructure is relevant for modelling the physical properties of snow cover and for simulating the propagation of electromagnetic waves in remote-sensing applications. Characterization of the microstructure in field conditions is, however, a challenging task due to the complex, sintered and variable nature of natural snow cover. A traditional measure applied as a proxy of snow microstructure, which can also be determined in field conditions, is the visually estimated snow grain size. Developing techniques also allow measurement, for example, of the specific surface area (SSA) of snow, from which the optical-equivalent grain size can be derived. The physical snow model SNOWPACK simulates evolution of snow parameters from meteorological forcing data. In this study we compare an extensive experimental dataset of measurements of traditional grain size and SSA-derived optical grain size with SNOWPACK simulations of grain-size parameters. On average, a scaling factor of $\mathbf{1 . 2}$ is required to match traditional grain-size observations with the corresponding SNOWPACK simulation; a scaling factor of 2.1 was required for the optical equivalent grain size. Standard deviations of scaling factors for the winters of 2011/12 and 2012/13 were 0.36 and 0.42 , respectively. The largest scaling factor was needed in early winter and under melting conditions.
\end{abstract}

KEYWORDS: remote sensing, snow, snow metamorphosis, snow physics

\section{INTRODUCTION}

In the Northern Hemisphere, observation of seasonal snow cover is essential to, for example, climate change monitoring, flood forecasting and avalanche warning systems (e.g. Martinec and Rango, 1986; Brown, 2000; Mognard, 2003; Shaffrey and others, 2009). Snow microstructure is important for physical modelling of snow evolution and remote-sensing algorithms. Grain size is a critical parameter in the analysis of snowpack development and metamorphism (Colbeck, 1982). It is also used as a proxy of snow microstructure in many remote-sensing applications (Tsang and others, 1985; Pulliainen and others, 1999).

Global mapping of snow cover is possible with optical and microwave satellite instruments (e.g. Hall and others, 2002). The extent of the snow-covered area can be observed by using visual and near-infrared wavelengths (e.g. Hall and others, 1995; Maurer and others, 2003), and snow water equivalent (SWE) can be determined from passive microwave measurements (e.g. Chang and others, 1982; Pulliainen and Hallikainen, 2001). Radiative transfer models are used to simulate microwave radiation from experimental measurements, and model inversion can be applied in retrieval of snow parameters from microwave observations. Among other snow parameters, snow emission models use grain size (Tsang and others, 1985; Pulliainen and others, 1999) or correlation length (Tsang and Kong, 1981; Stogryn, 1986; Wiesmann and others, 1998; Wiesmann and Mätzler, 1999) to describe the effect of snow microstructure on microwaves. The models are very sensitive to changes in the parameter describing the microstructure; thus its parameterization has a direct impact on the accuracy of the inverted SWE (e.g. Grenfell and Warren, 1999; Mätzler and Wiesmann, 1999; Roy and others, 2004).

Natural snowpacks consist of morphologically different layers (Colbeck, 1991); layers have typically distinct grain size, grain type, density, hardness and wetness. Several methods of defining the snow microstructure have been presented. The physical size of snow grains $(E)$ is traditionally defined visually as the largest diameter $(\mathrm{mm})$ of a typical particle (Colbeck and others, 1990; Fierz and others, 2009). However, an acknowledged problem concerning $E$ is that it is difficult to define and measure with good repeatability in field conditions (e.g. Domine and others, 2006). Baunach and others (2001) present a comparison of $E$ estimations made by several experts; the difference in estimation of $E$ varied between 0.25 and $1.25 \mathrm{~mm}$. Estimations were closest when grains were at an early stage of metamorphosis, i.e. grains were quite small and round. Other measures of individual grains more descriptive of the microwave behavior have been proposed by, for example, Mätzler (2002).

The optical grain size $\left(D_{0}\right)$, on the other hand, is defined as the diameter of independent spheres that have the same optical hemispherical reflectance properties as the snow, and which are proportional to the volume-surface ratio of the grains (Giddings and LaChapelle, 1961; Wiscombe and Warren, 1980; Dozier and others, 1987; Grenfell and Warren, 1999). Therefore, $D_{0}$ is not the same as $E$ of a particle, with the exception of material consisting of perfect spheres (Wiscombe and Warren, 1980). Theoretical correlation length, on the other hand, describes the distribution of scattered radiation, and is related to grain size, shape and volumetric distribution of snow grains (e.g. Debye and others, 1957; Jin, 1993). However, three-dimensional measurements of the correlation length are difficult.

The physical snow evolution model SNOWPACK (Lehning and others, 2002a) can be used to simulate the evolution of different characteristics of snow. Simulation of $E$ is not a simple process, because the physical processes are variable and the shapes of snow crystals are complex; therefore, several equations and semi-empirical parameterizations are 
needed. In the non-dendritic case, when grains are not branched, $D_{0}$ is dependent on $E$. Independent equations are applied for the dendritic branched grains.

$D_{0}$ can be derived from specific surface area (SSA) measurements. SSA is a geometrical characteristic of porous sintered materials such as snow, and is related to chemical, physical and electromagnetic properties of the medium (Grenfell and Warren, 1999; Domine and others, 2008; Matzl and Schneebeli, 2010). SSA can be measured by stereology (e.g. Matzl and Schneebeli, 2010), X-ray computed microtomography (Flin and others, 2005; Chen and Baker, 2010), the methane adsorption method (Domine and others, 2001; Legagneux and others, 2002) and optical methods (Matzl and Schneebeli, 2006; Painter and others, 2007; Gallet and others, 2009; Langlois and others, 2010; Arnaud and others, 2011). Reflectance, and therefore optically measured SSA, also depends on grain shape (Picard and others, 2009). In this study, SSA was measured with the optical reflectance method presented by Gallet and others (2009).

The aim of the presented research was to: (1) compare in situ measured values to those modelled using the SNOWPACK thermodynamic snow model and (2) investigate the source and magnitude of measurement errors related to these parameters.

\section{THEORY AND MEASUREMENT METHODS}

\section{Grain growth}

The shape and size of ice particles (referred to as snow grains from now on) change throughout the winter. Growth of snow grains is caused by changes in ambient physical conditions (Adams and Brown, 1982; Colbeck, 1982); the strongest effects are caused by changes in temperature and density.

Temperature differences in the snowpack are related to differences in air temperature, thermal conductivity of snow, terrain, vegetation, elevation and the amount of sunlight. Land-cover type affects the structure of the snowpack (e.g. an ice layer over a bog forms a different base for the snowpack than dry ground). Furthermore, even if the ambient temperature remains stable, the snowpack exhibits a vertical temperature gradient in conditions where the ambient and subnivean temperatures differ because of the low thermal conductivity of snow. Changes in snow density are also induced by temperature changes; however, the snowpack also compacts at constant temperatures, new snow increases the pressure in the older snow, and density of the snow increases.

Changes in temperature and density affect the state of grain metamorphism in the snowpack. Generally, metamorphism drives the formation of different grain shapes (Fierz and others, 2009). Colbeck (1982) describes grain shape changes through the winter; grains can form again several times, and a rule of thumb is that the average size of snow grains increases with age and depth of snowpack.

\section{Snow class definitions}

Snow grains can be classified by shape. In this paper, definitions following Fierz and others (2009) are used: grain classifications include precipitation particles (PP), decomposing and fragmented precipitation particles (DF), rounded grains (RG), faceted crystals (FC), depth hoar (DH), melt forms (MF) and ice formations (IF).
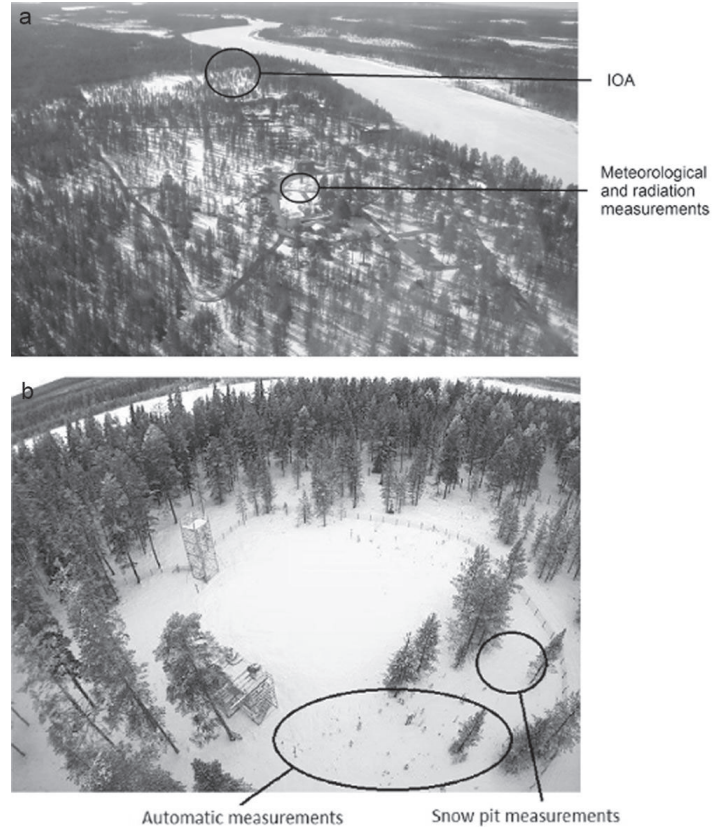

Fig. 1. (a) Aerial photograph of the Sodankylä facilities. IOA is the intensive operation area. Meteorological and radiation measurements, used to force the SNOWPACK model, were made $500 \mathrm{~m}$ from IOA in a similar environment. (b) The measurement field covered with snow on a natural forest floor.

\section{Measurement site}

Snow profiles were measured at the Arctic Research Centre of the Finnish Meteorological Institute (FMI), Sodankylä, northern Finland, $\left(67.368^{\circ} \mathrm{N}, 26.633^{\circ} \mathrm{E}\right)$ over two snow seasons. Measurements were made between January 2012 and April 2013. The measurement site (IOA (intensive observation area)) was located in a clearing surrounded by a sparse pine forest (Fig. 1). The site hosted several automated measurements (e.g. snow temperature profile, soil temperature profile, soil moisture and SWE). The meteorological and radiation data used for modelling were measured at a distance of $500 \mathrm{~m}$ from the IOA, where surroundings were similar to the IOA.

Snow cover at the site persists on average for 200 days, between the end of October and the end of May (Pirinen and others, 2012). The thermal winter, when the daily average temperature falls below zero, typically begins near the end of September and ends near the end of May. The maximum amount of snow is, on average, $80 \mathrm{~cm}$ in March, followed by a snowmelt period lasting until May. For the two winter seasons (2012 and 2013) used in this research, the measured snow depth and temperature profiles are presented in Figure 2.

The seasonal snowpack in Sodankylä has large variations in grain size and density, and impurities from, for example, tree litter and inorganic soot. Vertical layering caused by weather effects is inherent in snowpacks; however, natural snow also exhibits a high degree of horizontal variability in layering and snow structure caused by wind, vegetation and terrain effects (Sturm and others, 1998). In the case of new snow, the surface of the 


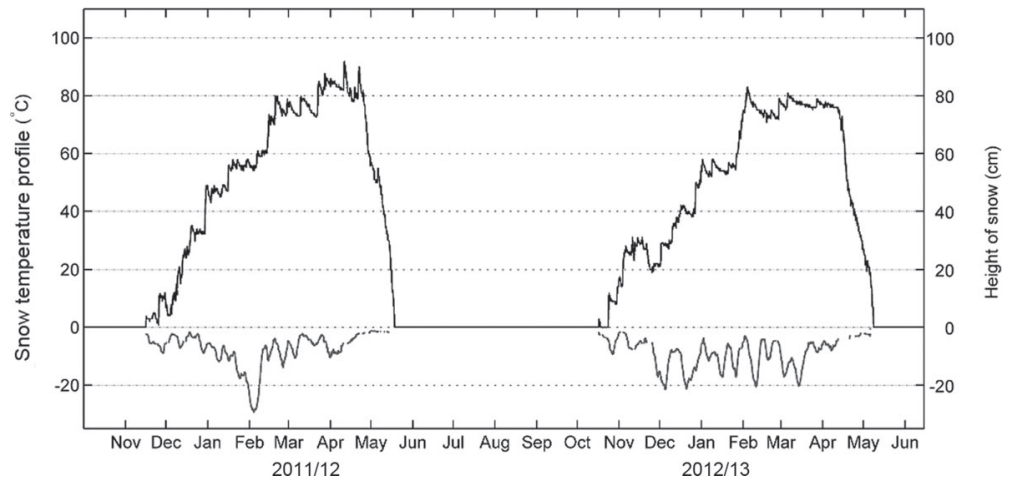

Fig. 2. Height of snow (upper, black curves) and temperature profile (difference of temperature at surface and base) of snowpack (lower, grey curves) during winters 2011/12 and 2012/13.

snowpack is typically light, and new snowflakes are large and dendritic. For older snowpacks, densification typically increases towards the bottom layers. In the middle of the snowpack, snow grains are smaller and rounder than in the surface layers. Grain size further increases towards the ground; near the ground, snow consists of grains with a large range of different sizes. During winter, the thickness of the bottom layer (mostly $\mathrm{DH}$ crystals) increases, the proportion of small and large grains changes, and the proportion in the layer increases near ground. The structure of the snowpack varies annually, in particular as a function of the temperature gradient over the snowpack (between air and soil temperatures).

The most common grain shapes in Sodankylä are PP, DF, RG, FC, DH and MF. Occasionally over the winter, SH crystals occur. Melting and recrystallization of the surface snow during a warm period, followed by a cold period, creates a hard crust layer, which is classified as MFcr or sometimes as IF.

The average grain-size value for the whole snowpack was considered appropriate when analysing the time series of snowpack evolution. As snow pits are forcibly made at a different location each time, the dataset at hand encompassed both temporal and spatial variations in snow structure, which are difficult to separate from one another. A weighted average was calculated to alleviate the effects of spatial (horizontal) variability of grain size in the snowpack. As the propagation of electromagnetic radiation in snow is closely related to the SWE (depth $\times$ density), weighting with SWE gives a better proxy of the relative weight of the grain size in each layer in terms of microwave interactions, compared to simple depth-weighted averaging. Other methods include weighing the grain size of each layer by the assumed optical depth of respective overlying layers (e.g. Tedesco and Kim, 2006).

\section{Snow-pit measurements}

The research was based on manual snow-pit measurements made over the 2011/12 and 2012/13 winter seasons. The collected data include estimates of $E$ as well as SSA measurements. SSA was measured with a commercial IceCube instrument (Gallet and others, 2009). Grain-size measurements of $E$ were performed by visually analysing macro-photographs of grain samples against a reference grid. Automated meteorological and radiation data from the test site were used to drive the SNOWPACK model; model estimates of $E$ and $D_{0}$, given as $E_{\mathrm{spi}}$ and $D_{0 \mathrm{sp}}$, aggregated over the snowpack to improve comparability, were analysed against the in situ measurements. The different grain-size parameters are presented in Table 1.

The collected dataset includes 35 snow-pit measurements, made over the two winters. Typically, the snow pits were measured at 1 week intervals. However, several extra measurements were arranged. Due to the destructive nature of the measuring process, the exact location of the snow pit changed each time; new pits were made at a minimum distance of $1 \mathrm{~m}$ from previous pits to avoid changes in snow structure caused by previous pit measurements. The data thus also include the effect of small-scale spatial variability, in addition to temporal variability caused by weather events and snow metamorphism.

All measurements from a snow pit were taken from a vertical cut of $\sim 50 \mathrm{~cm}$ width made in the snowpack. Layers were determined manually from the snow-pit wall by changes in snow structure (e.g. density, hardness, grain size and shape). The measured snow-pit data include snow layer thicknesses, $E$ for each layer, temperature profile (every $10 \mathrm{~cm}$ ), density profile measured by weighting a snow sample (every $5 \mathrm{~cm}$ ), and SSA measurements (every $3 \mathrm{~cm}$ ). However, reliable density and SSA measurements from $5-10 \mathrm{~cm}$ above ground level were not always possible due to hard packed or very coarse-grained snow.

Table 1. Grain-size definitions

\begin{tabular}{|c|c|c|}
\hline Grain size & Symbol & Description \\
\hline Traditional & $E$ & $\begin{array}{l}\text { The classical grain size of a snow } \\
\text { layer is the average size of its grains. } \\
\text { The largest extension of a grain is } \\
\text { measured in } \mathrm{mm} \text {. }\end{array}$ \\
\hline Optical & $D_{0}$ & $\begin{array}{l}\text { Diameter of optically equivalent ice } \\
\text { spheres which have the same } \\
\text { optical properties (surface-to-volume } \\
\text { ratio) as original particles. Derived } \\
\text { from the reflectance measurements } \\
\text { made with the IceCube instrument. }\end{array}$ \\
\hline SNOWPACK traditional & $E_{\mathrm{sp}}$ & Simulated with SNOWPACK model. \\
\hline SNOWPACK optical & $D_{\text {osp }}$ & Simulated with SNOWPACK model. \\
\hline
\end{tabular}



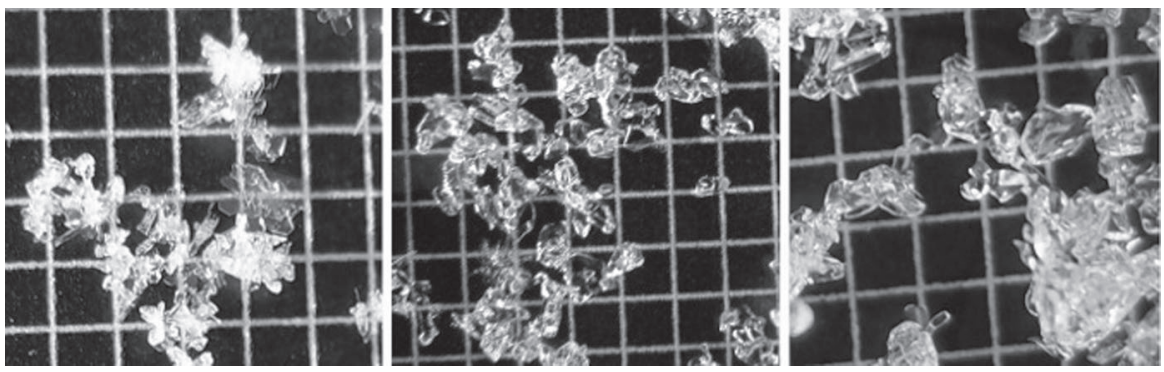

Fig. 3. Macro-photographs taken against a $1 \mathrm{~mm}$ reference grid in Sodankylä. Examples of dendritic (left) and non-dendritic (middle) grains. Grain shape in the left panel is PPsd, in the middle panel RGxf and in the right panel right FCxr. Grain size exhibits large variability in the right panel, likely causing observer-related bias. Grain size is more uniform in the other two photographs.

E was estimated visually for each snow layer by comparing snow grains to a $1 \mathrm{~mm}$ reference grid. The methodology differed from the traditional measurement (Fierz and others, 2009), because estimation was made during post-processing from macro-photographs. Occasionally, layers contained very hard snow and grains, and could not be distinguished without breaking the snow structure. Some of the photographs were also of low quality, so the grain-size estimation could not be made. Only one snow sample was taken from each layer, so errors in the definition of snow layers may have affected the representativity of the results. $E$ was recorded to the nearest $0.25 \mathrm{~mm}$. Photographs of different types of grains are presented in Figure 3. The snow type was determined visually from the same macro-photographs.

\section{SSA measurements}

A novel method of measuring $D_{0}$, the diameter of opticalequivalent ice spheres, is to derive it from measurements of reflectance (Gallet and others, 2009). SSA $\left(\mathrm{m}^{2} \mathrm{~kg}^{-1}\right)$ is defined as the surface area of particles per unit mass:

$$
\mathrm{SSA}=S / M=S /\left(\rho_{\mathrm{i}} V\right),
$$

where $S$ is surface area, $M$ is mass of the sample, $\rho_{\mathrm{i}}$ is the density of ice $\left(917 \mathrm{~kg} \mathrm{~m}^{-2}\right)$ and $V$ is volume of the sample (Legagneux and others, 2002). The optical diameter of ice spheres is presented by Kokhanovsky and Zege (2004) as

$$
D_{0}=6 \mathrm{~V} / \mathrm{S} \text {. }
$$

The theoretical relation between $D_{0}$ and SSA from Eqns (1) and (2) is

$$
D_{0}=6 /(\rho \mathrm{SSA}) \text {. }
$$

The SSA decreases with increasing grain size, as there is more empty space between large grains than between smaller grains.

For SSA measurements, we used the IceCube manufactured by A2 Photonic Sensors, France, which is a commercial single-frequency instrument similar to DUFISSS (Gallet and others, 2009). The instrument measures the hemispherical infrared reflectance of the snow samples, which can be linked to SSA (e.g. Domine and others, 2006; Matzl and Schneebeli, 2006). The whole snowpack was sampled at $3 \mathrm{~cm}$ intervals; the measurements were made from the same cut in the snowpack (i.e. pit) as the $E$ estimations.

IceCube measurements consisted of calibration measurements and measurements of snow samples. The surface of the sample had to be smooth for the measurement to succeed; ice layers and very hard snow layers were difficult to measure, and several measurements were omitted as a result. Moreover, large crystals at the bottom of the snowpack proved difficult to sample correctly, so these measurements may carry additional errors. The sample also had to be compacted in the sample holder to avoid absorption of radiation at the bottom of the holder, which obscures reflections from the snow sample. For clustered grains (e.g. $\mathrm{MFcl}$ or MFpc), the SSA value was smaller, because grains were closer to each other than free grains of the same size would be (Dozier and Painter, 2004). During the measurement the sample holder was set below the instrument. Calibration measurements of the IceCube were made before and after every measurement occasion. The calibration result depended on, for example, the laser temperature, the cleanness of the spectralon surfaces and the mechanics of the instrument. The IceCube was calibrated by measuring the reflectances of six different spectralon plates and the background radiation. A least-squares polynomial was fitted to these seven measurements, and the success of the calibration was determined from the fit. The programme gives the user an estimate of the quality of the calibration from the success of the curve fit, by using a scale of very poor, poor, good and excellent. Error estimation of calibration is important, because the success of the calibration was not seen during measurement and some of the calibration measurements were often of poor quality. Errors may have originated from any single calibration measurement or multiple calibration measurements. Theoretically, it was also possible for all calibration measurements to be shifted systematically to the same direction to indicate good calibration, but the magnitude of the result (signal-toreflectance relationship) would then be erroneous.

\section{Snowpack model}

SNOWPACK is a one-dimensional (1-D) physically based finite-element model developed at the WSL Institute for Snow and Avalanche Research SLF, Switzerland. The characteristics of the numerical set-up, the microstructure and the initial and driving parameters of the model are described by Lehning and others $(2002 a, b)$. The number of individual layers in the model is not restricted, and increases in response to snow precipitation.

SNOWPACK simulates three types of snow metamorphism: equilibrium metamorphism, temperature gradient metamorphism and wet snow metamorphism. Only the first two metamorphism simulations were investigated in this study. 
The snow grains are parameterized using size parameters (grain size and bond size) and shape parameters (dendricity and sphericity). The sphericity describes the ratio of rounded versus faceted shapes, and the dendricity describes the part of original grain shapes that remain in a snow layer. Both parameters vary from 0 to 1 . The dendricity and sphericity were set to 1 and 0.5 , respectively, for new snow. In old rounded snow grains, the dendricity decreases to zero. The shape parameters are based on the French snow model Crocus. Further details can be found in, for example, Brun and others (1992).

Grain growth and thus grain size $\left(E_{\mathrm{sp}}\right)$ is defined by several equations in the SNOWPACK model depending on the physical conditions in the snowpack. The grain growth during equilibrium metamorphism, as the temperature gradient is small, is based on a mixture theory model described by Brown and others $(1999,2001) . E_{\mathrm{sp}}$ during equal temperature metamorphism is the diameter of a sphere. The grain growth rate $\left(r_{\mathrm{g}}\right)$ is presented by Lehning and others (2002b) in the equal temperature metamorphism as

$$
\dot{r}_{\mathrm{g}}(T, t)=s\left(A_{1}+\frac{A_{2}}{r_{\mathrm{g}}}\right) \mathrm{e}^{A_{3}\left(1 / T_{\mathrm{R}}-1 / T\right)},
$$

where $T$ is temperature, $t$ is time, $s$ is sphericity, $A_{1}, A_{2}$ and $A_{3}$ are coefficients, $r_{\mathrm{g}}$ is grain size, and $T_{\mathrm{R}}$ is reference temperature $(273.15 \mathrm{~K})$. The temperature gradient metamorphism used in SNOWPACK is described by Baunach and others (2001). It assumes that snow grains grow as plates, while the thickness of the plate stays constant. The length of a side of these plates is the temperature gradient metamorphism grain size in SNOWPACK. The grain growth rate is presented by Lehning and others (2002b) in the temperature gradient metamorphism as

$$
\dot{r}_{\mathrm{g}}(T)=\frac{\mathrm{a}^{2}\left(J_{\mathrm{L}}(t)-\frac{a^{3}(t)}{\Delta z} \Delta /_{\mathrm{L} 2 \mathrm{~L}}(t)\right)}{2 f_{\mathrm{gg}} \rho_{\mathrm{i}} r_{\mathrm{g}}(0) r_{\mathrm{g}}(t)},
$$

where $r_{\mathrm{g}}(0)$ is initial grain size, $\rho_{\mathrm{i}}$ is density of pure ice, $f_{\mathrm{gg}}$ is the adjustable geometrical factor for better approximation of the real grain shape (Baunach and others, 2001; Lehning and others, 2002b), $J_{\mathrm{L}}$ is interlayer mass, $J_{\mathrm{L} 2 \mathrm{~L}}$ is layer-to-layer mass, $r_{\mathrm{g}}(t)$ is actual growing grain size, $a$ is lattice constant and $z$ is snow height. Grain-size simulation of SNOWPACK has been fitted to grain-size measurements by adjusting model parameters empirically with cold laboratory experiments.

The optical grain size $\left(D_{0 \text { sp }}\right)$, which is simulated with SNOWPACK, is presented in Vionnet and others (2012) in the dendritic case as

$$
D_{0 \text { sp }}=10^{-4}[d+(1-d)(4-s)]
$$

and in the non-dendritic case as

$$
D_{0 \mathrm{sp}}=E_{\mathrm{sp}}(1-s) \max \left(4 \times 10^{-4}, \frac{E_{\mathrm{sp}}}{2}\right),
$$

where $D_{\text {Osp }}(\mathrm{m})$ is the SNOWPACK optical grain size, $d$ is dendricity, $s$ is sphericity and $E_{\mathrm{sp}}(\mathrm{m})$ is SNOWPACK traditional grain size. Thus the $D_{0 s p}$ in the non-dendritic grains depends on $E_{\mathrm{sp}}$.

In this study, version 3.1.0 of SNOWPACK was used to simulate $E_{\mathrm{sp}}$ and $D_{\text {osp }}$ for winters 2011/12 and 2012/13. Air temperature, relative humidity, wind speed and direction, incoming and outgoing shortwave radiation and snow depth observations were collected from an operational weather station (WMO code 02836) operated by the FMI at the
Table 2. Summary of automated measurements used to drive the SNOWPACK model

Measurements in Sodankylä Unit Distance from IOA*

$\mathrm{m}$

$\begin{array}{lcr}\text { Air temperature } & { }^{\circ} \mathrm{C} & 500 \\ \text { Air relative humidity } & \% & 500 \\ \text { Incoming shortwave radiation } & \mathrm{W} \mathrm{m}^{-2} & 500 \\ \text { Outgoing shortwave radiation } & \mathrm{W} \mathrm{m}^{-2} & 500 \\ \text { Snow depth } & \mathrm{Cm}^{\circ} & 500 \\ \text { Snow temperature profile } & { }^{\circ} \mathrm{C} & 0 \\ \text { Soil temperature profile } & { }^{\circ} \mathrm{C} & 0 \\ \text { Wind speed } & \mathrm{m} \mathrm{s}^{-1} & 500 \\ \text { Wind direction } & \circ & 500\end{array}$

*Intensive operation area.

Sodankylä Arctic Research Centre. These observations were augmented with automatic ground temperature observations and snow temperature observations close to the operational station. Incoming and outgoing longwave radiation observations were available, but the longwave radiation data contained gaps preventing their application in simulations. Therefore, only shortwave radiation data were used. In simulations for this study, SNOWPACK was driven by snow depth observations instead of precipitation data. Density of new snow was determined following Lehning and others (2002a). The data used to drive the model have $30 \mathrm{~min}$ intervals, and the data used for the simulations are listed in Table 2 and in the Appendix. The SNOWPACK model outputs the parameters of snow profiles at $60 \mathrm{~min}$ intervals.

SNOWPACK grain size has been compared to measured grain size and grain type in several recent studies (Schweizer and others, 2006; Rasmus and others, 2007; Hirashima and others, 2008). Rasmus and others (2007) calculated agreement scores for measured and simulated grain sizes in Finland; agreement was generally good in northern Finland, where the snowpack was more stable. On the other hand, Schweizer and others (2006) compared measured and simulated grain size for each grain type, finding no large differences between measured and simulated grain sizes. Langlois and others (2012) compared the correlation length derived from $D_{0}$ measured by InfraRed Integrating Sphere (Montpetit and others, 2012) and SNOWPACK model results, and scaled $D_{0}$ lower to fit measurements to simulations. Huang and others (2012) researched grain sizes predicted by different models. Their result was that SNOWPACK predictions for $E$ and $D_{0}$ are as good as predicted by using two other models (Flanner-Zender Grain Size Model (Flanner and Zender, 2006) and Jordan Grain Size Model (Sun and others, 1999)) which both predict the size parameters well.

\section{RESULTS}

\section{Comparison of experimental and snowpack modelled grain sizes}

Time series of $E, D_{O}$ and density profiles in Sodankylä snowpack

Profiles of $E$ and $D_{0}$ are presented in Figure 4 for a single snow pit in February. The layered structure of the snowpack was visible in both the $E$ and $D_{0}$ profiles. Generally, the magnitude of $E$ was larger than the magnitude of $D_{0}$. 


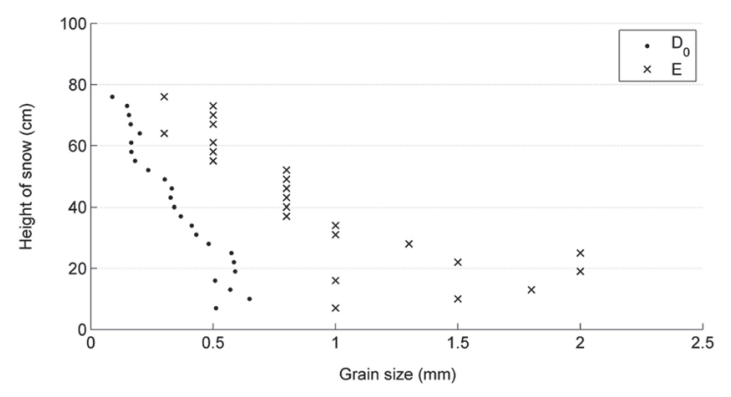

Fig. 4. $E$ (crosses) and $D_{0}$ (dots) compared using measurements made at $3 \mathrm{~cm}$ intervals for a single snow pit.

Nevertheless, both measures indicated a similar trend of increasing grain size towards the bottom snow layers. Both methods indicated relatively small variation in grain size above a snow height of $20 \mathrm{~cm}$. However, in lower layers the grain-size variability increased significantly.

Density, $E_{\mathrm{sp}}$ and $D_{0 \text { sp }}$ were modelled with SNOWPACK from meteorological and radiation data as described above and in Table 2 and the Appendix. Manual density measurements are compared to SNOWPACK simulations in Figure 5.

The bias in snow thickness between manually measured and automatic observations, used as forcing for SNOWPACK simulations, was $\sim 5 \mathrm{~cm}$ during the dry snow season (Fig. 5). Both measured and simulated density values exhibit an increasing trend from snow surface towards the ground, from $50-150$ to $300-500 \mathrm{~g} \mathrm{~cm}^{-3}$ in simulated and $50-200$ to $250-450 \mathrm{~g} \mathrm{~cm}^{-3}$ for typical measured values in top and bottom layers, respectively. During the dry snow season, average densities for the 2011/12 winter were 208 and $175 \mathrm{~g} \mathrm{~cm}^{-3}$ and for the 2012/13 winter were 187 and $217 \mathrm{~g} \mathrm{~cm}^{-3}$ for measurements and simulations, respectively. During the melt season, density increased by up to $50 \%$ in both simulated and measured values. Some differences were apparent between two winter seasons: For instance, during the $2011 / 12$ winter, density was notably large during the melt season, with measured values reaching $470 \mathrm{~g} \mathrm{~cm}^{-3}$. However, for the 2012/13 winter, the maximum measured densities during the melt season were $400 \mathrm{~g} \mathrm{~cm}^{-3}$, although the density in bottom layers was larger during the dry-snow season than for the 2011/12 season.

Time series of $E, E_{\mathrm{sp}}, D_{0}$ and $D_{0 \mathrm{sp}}$ profiles are presented in Figures 6 and 7 . The range of values for $E$ was $0.25-2.75$, for $E_{\mathrm{sp}}$ was $0-2.5$, for $D_{0}$ was $0-1.25 \mathrm{~mm}$ and for $D_{0 \text { sp }}$ was $0-$ $1.5 \mathrm{~mm}$. Typically, grain growth towards the bottom of the snowpack was apparent both in SNOWPACK simulations and measured data. The simulated layering profile can be compared to manually determined layering structure based on Figure 6; the measured $E$ for manually determined layers is marked on the upper edge of the respective layer. Typically, SNOWPACK simulated more layers (up to $>40$ ) than could be determined by the snow-pit observation (typically not more than ten layers). In order to allow intercomparison of $E, E_{\mathrm{sp}}, D_{0}$ and $D_{0 \mathrm{sp}}$ in a consistent fashion, $E_{\mathrm{sp}}$ and $D_{0 \text { sp }}$ were weighted with the SWE of each layer. A similar method was applied for in situ data. This was seen as a necessary process due to ambiguities in relating the many simulated layers to the relatively few layers apparent in manual observations. Furthermore, as described earlier, snow-pit observations do not represent temporal

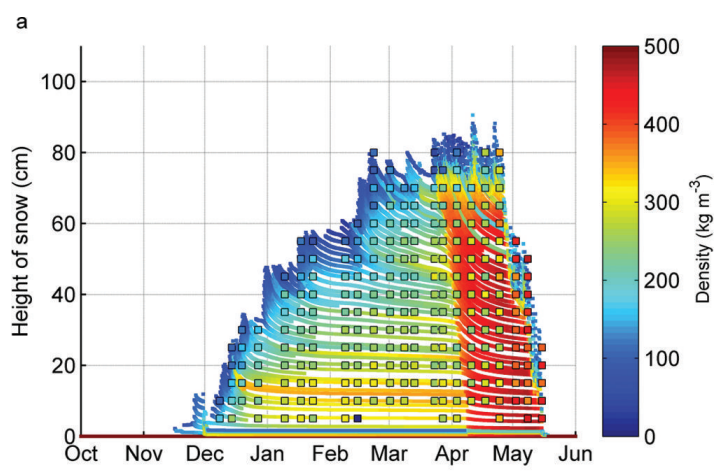

b

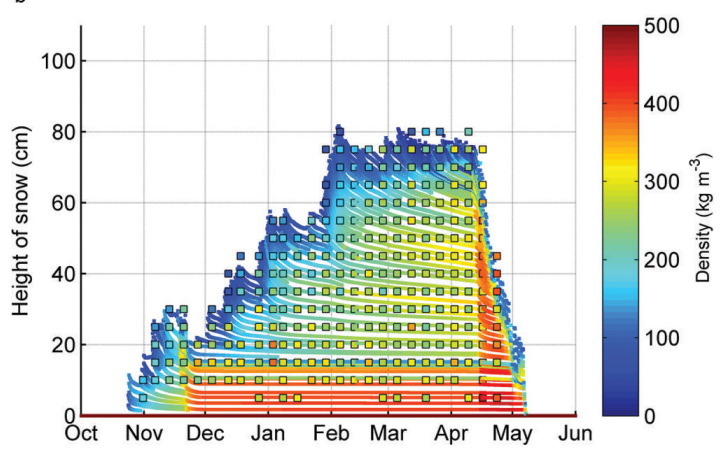

Fig 5. Snow density simulated with SNOWPACK compared to manual density measurements. Coloured boxes represent manually measured values; solid lines represent SNOWPACK simulations: (a) 2011/12; (b) 2012/13.

evolution of a discrete location but also contain the effect of spatial variability in the natural snowpack.

\section{Averaged time series of $E$ and $D_{O}$ in Sodankylä snowpack}

The time series of both manually measured and simulated $E$ and $D_{0}$ are presented in Figure 8. Root-mean-square (rms) errors, unbiased rms errors, biases and correlation coefficients $\left(R^{2}\right)$ of datasets are presented in Table 3. For the time series of $E$ and $E_{\mathrm{sp}}$ in winter $2011 / 12, R^{2}$ was 0.56 and the bias $0.12 \mathrm{~mm}$. For winter 2012/13 the variations were larger (with a bias of $0.26 \mathrm{~mm}$ ) and the $R^{2}$ was $0.36 . R^{2}$ during January-March was 0.91 and 0.28 during the first and second winters, respectively. $R^{2}$ was 0.14 and 0.54 in October-December, and 0.20 and 0.32 in the melt season of the same two seasons respectively.

$D_{0 \text { sp }}$ and $D_{0}$ trends were similar for both winters, and $R^{2}$ for the whole season was 0.75 for both seasons. During January-March 2012, $R^{2}$ was 0.42 , and during JanuaryMarch 2013, 0.76. $R^{2}$ was 0.27 and 0.94 respectively in the melting seasons and 0.79 in October-December 2012. However, $D_{0 \text { sp }}$ was constantly larger than $D_{0}$. Therefore, the bias and rms error between $D_{0}$ and $D_{0 \text { sp }}$ were larger than between $E$ and $E_{\mathrm{sp}}$.

A linear scaling factor $\beta_{\mathrm{sp}}$ describing the ratio between measured and simulated grain size can be defined so that

$$
D=\beta_{\mathrm{sp}} D_{\mathrm{sp}},
$$

where $D$ is measured grain size and $D_{\mathrm{sp}}$ is simulated grain 
a

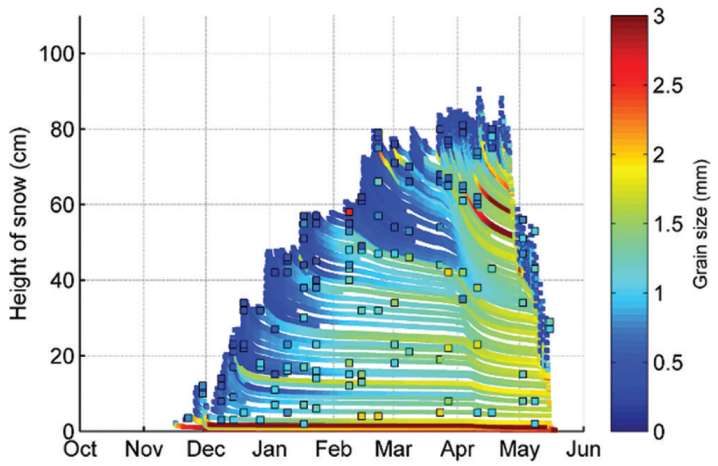

b

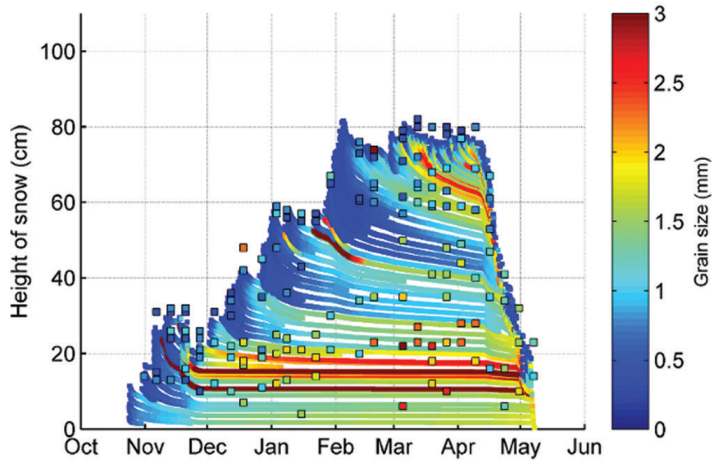

Fig. 6. SNOWPACK simulation of $E_{\mathrm{sp}}$ compared to manual measurements of $E$. Coloured boxes represent manually measured values; solid lines represent SNOWPACK simulations: (a) 2011/12; (b) $2012 / 13$.

size. Values for $\beta_{\mathrm{sp}}$ and standard deviations are presented in Table 4 and Figure 9 for the two snow seasons. Average scaling factors between the two years were within 0.1 of each other on average. Considering both winters, the scaling factor, $\beta_{D 0 \text { sp }}$, between measured $D_{0}$ and simulated $D_{0 \text { sp }}$ was 2.1 , and $\beta_{\text {Esp }}$ between measured $E$ and simulated $E_{\mathrm{sp}}$ was 1.2.

Table 3. Correlation coefficient $\left(R^{2}\right)$, bias, rms error and unbiased rms error between measured and SNOWPACK simulated grain sizes. Grain sizes are defined in Table 1

\begin{tabular}{lcc}
\hline & $E_{\text {sp }}$ & $D_{\text {osp }}$ \\
\hline$R^{2}$ & & \\
$E$ & 0.47 & 0.38 \\
$D_{0}$ & 0.69 & 0.74 \\
Bias & & \\
$E(\mathrm{~mm})$ & 0.19 & 0.01 \\
$D_{0}(\mathrm{~mm})$ & 0.71 & 0.50 \\
rms error & & \\
$E(\mathrm{~mm})$ & 0.37 & 0.38 \\
$D_{0}(\mathrm{~mm})$ & 0.72 & 0.53 \\
Unbiased rms error & & \\
$E(\mathrm{~mm})$ & 0.32 & 0.38 \\
$D_{0}(\mathrm{~mm})$ & 0.14 & 0.16 \\
\hline
\end{tabular}

a

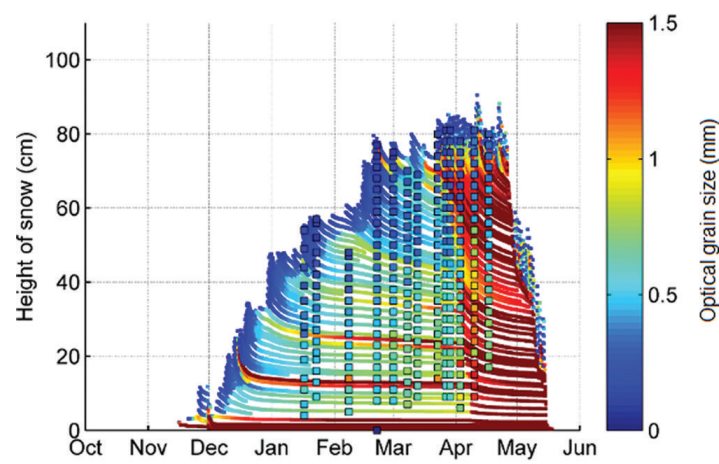

b

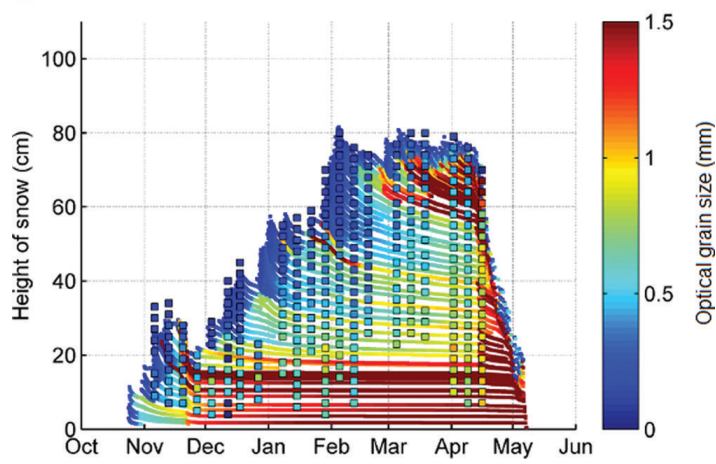

Fig. 7. SNOWPACK simulation of $D_{\text {Osp }}$ compared to manual measurements of $D_{0}$ for snow pit 14 February 2013. Coloured boxes represent manually measured values; solid lines represent SNOWPACK simulations: (a) 2011/12; (b) 2012/13,

The standard deviations were 0.42 and 0.36 respectively. $\beta_{\text {Esp }}$ varied between 0.8 and 2.1 over both winters. $\beta_{\text {Esp }}$ was more stable during the first winter than the second, with values in the range $0.9-2.3$ compared to $0.8-1.8$ for the first and second winters, respectively. $\beta_{E s p}$ was largest during October-December and the late melting season, reaching

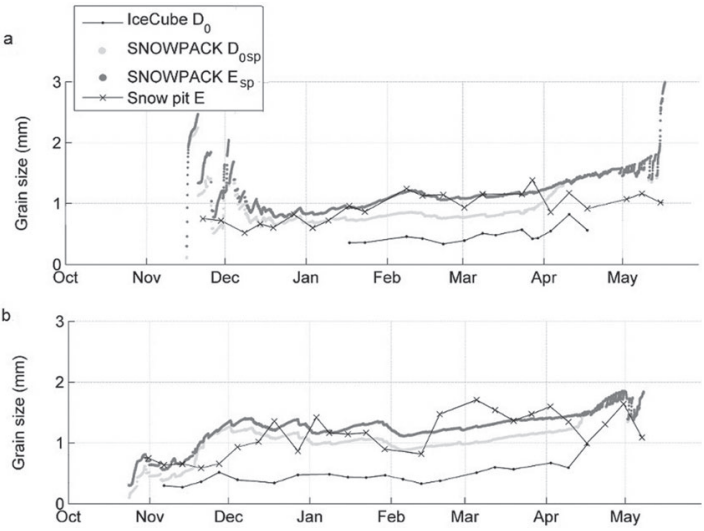

Fig. 8. Time series of measured $E$ and $D_{0}$ and SNOWPACK simulated $E_{\text {sp }}$ and $D_{\text {osp. }}$ (a) $2011 / 12$; (b) 2012/13. 

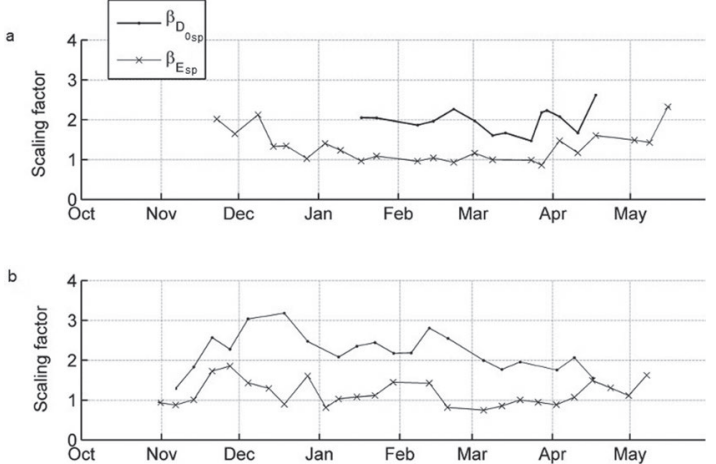

Fig. 9. Time series of scaling factors $\beta_{E s p}$ and $\beta_{D 0 s p}$ between measured $E$ and $D_{0}$ and SNOWPACK simulated $E_{\mathrm{sp}}$ and $D_{0 \mathrm{sp}}$ : (a) $2011 / 12$; (b) $2012 / 13$.

values up to 2.3. In January-March, $\beta_{\text {Esp }}$ was 1.1 on average. Also $\beta_{D 0 \text { sp }}$ was more variable during the second winter (range 1.3-3.2) than the first (range 1.8-2.8). For $\beta_{D 0 \text { sp }}$, there was no clear seasonally related trend, but measurements in December 2012 required the largest $\beta_{D 0 \text { sp }}$ (average 3.1) while measurements in the 2013 melting season required the smallest $\beta_{D 0 \text { sp }}$ (average 1.75). In January-March, $\beta_{D 0 \text { sp }}$ was $\sim 2$.2. It can also be noticed that trends of $\beta_{D 0 \text { sp }}$ and $\beta_{E s p}$ were similar during the second winter.

\section{Sources of measurement errors}

Several factors contribute to the uncertainty of estimates of $E$, including random errors arising from preparation of the snow sample, and systematic errors arising from the estimation process itself. Errors are mainly caused by layer definition in the field, placing grains in the reference plate from the snowpack, unsuccessful photographing, failure to distinguish the single grains in the macro-photograph, failure to measure the size of a grain using a $1 \mathrm{~mm}$ reference scale or choosing the typical average grain in the macro-photograph. Other contributions to the error may be made by (1) the snow structure being disturbed when a sample of grains is placed on the reference plate, and (2) separation of the grain boundaries in the macrophotographs not always being clear.

Determining the layered stratification of the snowpack was an important aspect of the snow-pit measurement, because $E$ may vary both horizontally and vertically. However, the process was also subject to observer error.

Table 4. The scaling factor beta between measured and SNOWPACK simulaled grain sizes. $\beta_{E s p}$ is for traditional grain size $E$, and $\beta_{D 0 \text { sp }}$ is for optical grain size $D_{0}$. Standard deviations (std) are also presented

$2011-13$

$2011 / 12$

$2012 / 13$

\begin{tabular}{llll}
\hline$\beta_{E s p}$ & 1.24 & 1.16 & 1.3 \\
$\operatorname{std}\left(\beta_{E s p}\right)$ & 0.36 & 0.31 & 0.39 \\
$\beta_{D 0 \text { sp }}$ & 2.11 & 2.21 & 1.97 \\
$\operatorname{std}\left(\beta_{D 0 \text { sp }}\right)$ & 0.42 & 0.47 & 0.30 \\
\hline
\end{tabular}

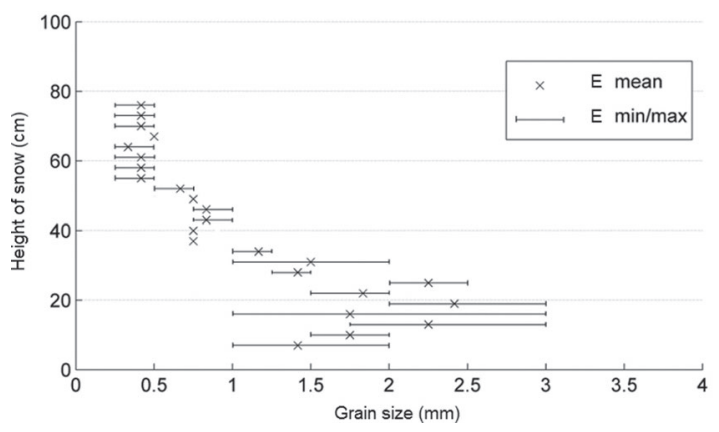

Fig. 10. An example of observer-related errors in $E$ estimations. The macro-photographs taken by $3 \mathrm{~cm}$ intervals were analysed separately by three observers; the mean value of $E$ (crosses) is marked with error bars between minimum and maximum values.

The method applied for manual layer definition has been described above. Separation of layers was occasionally difficult because differences between the layers were not always clear. An alternative instrument for the definition of snow layer boundaries is the Snow Micro Penetrometer (SMP) (Pielmeier and Schneebeli, 2003), which may allow more objective separation of the layering structure.

An example of comparison for $E$ estimations made by three observers from the same photographs is determined in Figure 10. Estimation of $E$ was made from samples taken at intervals of $3 \mathrm{~cm}$, in order to acquire more samples for comparison, and on the other hand, in order to compare with $D_{0}$ from the same snow sample. The snow pit chosen for comparison included several layers and snow types. The difference between estimations was largest at the bottom of the snowpack, where the sample contained a large scale of different grain sizes (Fig. 3). Even if all the grains in the photograph were almost the same size, there was a potential error of up to $0.25 \mathrm{~mm}$ (the precision of our estimation). More comparative data are needed for a more complete error analysis of $E$.

The errors in the IceCube measurement were a sum of random errors originating from the sampling process as well as systematic errors in instrument calibration. Preparation of the samples for the IceCube instrument involved several uncertainties caused by the compaction level of the snow in the sample holder (reflection from the bottom of the sample holder) and the sample surface smoothness (reflection from the sample surface). The errors in instrument calibration were caused by the cleanness of calibration spectralons (shade of the spectralons) and the descent temperature of the instrument and laser (power of the laser). Additional errors were caused by instrument properties. For example, scattering from grains below the sample surface resulted in underestimation of the reflectance, which appeared to be reduced by the limited field of view (Gallet and others, 2009). Moreover, the radiation penetration depth depends on snow density, which was usually $\sim 1 \mathrm{~cm}$; however, radiation did not penetrate the calibration spectralon plates as porous snow, which increased the amount of reflected radiation and worsened the accuracy of the calibration.

A total of 27 measurements included IceCube calibration data before and after the measurement. The average 
difference in $D_{0}$ between two calibrations was $0.044 \mathrm{~mm}$. The reflectance data of the largest and smallest differences between calibrations were used to derive $D_{0}$ in Figure 11. The largest difference (average from pit) was $0.113 \mathrm{~mm}$ on 10 April 2012, and the smallest average difference (average from pit) was $0.001 \mathrm{~mm}$ on 12 March 2013. Root-meansquare errors between these calibrations were $0.121 \mathrm{~mm}$ and $0.0025 \mathrm{~mm}$ respectively. Contrary to expectation, the largest differences in $D_{0}$ were between very poor and good calibrations, and the smallest were between good and poor calibrations, when the above scale is used. The average difference between $D_{0}$ of two calibrations made on the same day was still $<0.05 \mathrm{~mm}$

\section{DISCUSSION}

The magnitude of $E$ was clearly larger than $D_{0}$ in both the measured and simulated cases. However, the magnitude difference between $E_{\mathrm{sp}}$ and $D_{0 \mathrm{sp}}$ was not as large as between $E$ and $D_{0}$. Underestimation of $D_{0}$ may result partly from a lack of measurements from the bottom of the snowpack. Previous results also scaled $D_{\text {osp }}$ lower than in this study (Langlois and others, 2012). The best correlation (from $R^{2}$, bias rms error and unbiased rms error) was between $D_{0}$ and $D_{\text {osp }}$ and then $E$ and $E_{\mathrm{sp}}$. The average scaling factor $\beta_{E \mathrm{sp}}$ varied $13 \%$ from one winter to another, and $\beta_{D 0 \text { sp }}$ was within $11 \%$. Standard deviations of yearly scaling factors were in the range $0.3-0.5$.

According to our results, SNOWPACK simulations of $E_{\mathrm{sp}}$ and $D_{0 \text { sp }}$ showed the best agreement with field measurements during January-March conditions. For early winter in November and the snowmelt season in April and May, $E_{\mathrm{sp}}$ and $D_{0 \text { sp }}$ varied most, and a clear disconnect from field measurements was also apparent. During October-December, only a few snow layers were identified in field measurements; thus the variability in individual observations of $E$ and $D_{0}$ affected the overall bulk average and the calculated average scaling factor. Overestimation of SNOWPACK density also affected the weak correlation of $E$ and $D_{0}$ measurements with simulations during the melt season. Furthermore, measurements of $E$ and $D_{0}$ also exhibit more uncertainties during the melt season in wet snow conditions.

Determination of layers, placing the grains in the reference plate and observer-related estimation causes the largest errors in $E$. Choosing the average $E$ from the macrophotograph is the most sensitive part for error estimation. A comparison of estimates from three observers of the same macro-photographs indicated errors up to $1 \mathrm{~mm}$. $D_{0}$, measured using the IceCube instrument, however, was less sensitive to observer-related errors than $E$ estimates, but several stages of the measurement process (sampling, calibration of original values, deriving $D_{0}$ from SSA) may still result in inaccuracies. The light newly fallen snow (density $\sim 50 \mathrm{~g} \mathrm{~L}^{-1}$ ) had to be compacted in the sample holder, and the quality of the sample was affected by different sampling techniques, smoothness of the sample surface, etc. The calibration-related error was relatively small (average $0.05 \mathrm{~mm}$; maximum $0.12 \mathrm{~mm}$ ). Error is very small because calibrations are made during the same measurement occasion. Calibration errors were further reduced by cleaning calibration spectralons, and stabilizing the instrument and laser temperatures before the calibration.

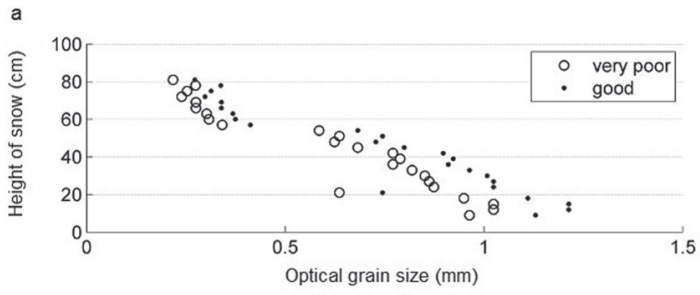

b

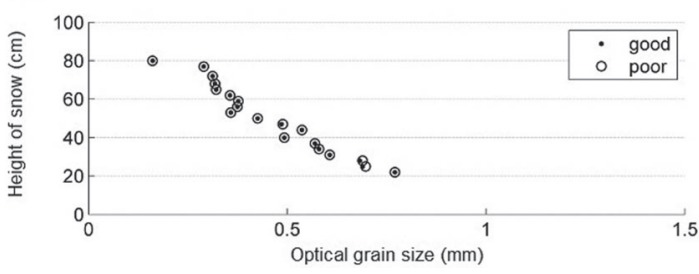

Fig. 11. The effect of repeated calibration of the SSA measurements on $D_{0}$. The same IceCube measurement is calibrated twice. On 10 April 2012, the mean difference between very poor (unfilled circles) and good (dots) calibrations of $D_{0}$ was $0.113 \mathrm{~mm}$; on 12 March 2013 the difference between good (dots) and poor (unfilled circles) calibrations of $D_{0}$ was $0.001 \mathrm{~mm}$.

\section{CONCLUSIONS}

A description of the snow microstructure is essential for physical snow models and radiative transfer models. A typical measure applied as a proxy indicator of snow microstructure has been the grain size $(E)$. However, there are several ambiguities related to defining and measuring $E$. An alternative parameter describing snow microstructure, the optical grain size $\left(D_{0}\right)$, can be derived from SSA measurements (Gallet and others, 2009). However, the definition of $D_{0}$ is based on optics, and its measurement is based on optical reflection from snow, which is not directly related, for example, to the scattering behaviour of radiation at microwave frequencies. On the other hand, empirical relations between $E$ and the propagation of microwaves have been established in the past (Hallikainen and others, 1987). Physical snow models such as SNOWPACK are important for global derivation of snow properties that are difficult to observe in the field (e.g. grain size), for remotesensing applications and hazard prediction systems. Therefore, a good correlation of manual measurements with the model is essential.

The main objective of the study was to compare $E$ and $D_{0}$ to $E_{\mathrm{sp}}$ and $D_{0 \mathrm{sp}}$. Another objective was to define measurement errors of $E$ and $D_{0}$. The measurements were made during the 2011/12 and 2012/13 winters in Sodankylä.

Layers simulated with SNOWPACK were not directly comparable with the manually determined layering structure, as simulation typically produced more layers with also a differing density profile. Furthermore, collected field data also exhibited the effects of spatial variability in natural snow. Therefore, averaged and weighted values for the whole snowpack were used in this study for intercomparison of measured and simulated values.

The temporal variation of measured and simulated values was similar in the time series (Fig. 8); however, in the first winter the average correlation was better. The largest difference between measured and simulated values occurred 
in October-December and during the melting season in April and May. The magnitude of $D_{0 \text { sp }}$ was approximately twice as large as $D_{0}$, while the magnitude of $E$ was almost the same for measured and simulated values (Table 3; Fig. 9). Calculated $R^{2}$ values were best between the same respective measured and simulated parameters, even though the magnitude of $D_{0 \text { sp }}$ was closer to $E$ than $D_{0}$ (Table 4).

The largest uncertainties in both $E$ estimations and $D_{0}$ measurements were estimated to occur in the bottom layer of the snowpack, where the grains were large and loose. The IceCube calibration error was $0.05 \mathrm{~mm}$ on average. The effect of other errors (sampling method, sample surface smoothness and observer) on $D_{0}$ was $<0.1 \mathrm{~mm}$ in our preliminary unpublished results. $E$ for an average grain was estimated to the nearest $0.25 \mathrm{~mm}$. The magnitude of error in $E$ was suspected to be in the millimetre range (Fig. 11).

This study suggests that SNOWPACK was able to simulate with reasonable accuracy the magnitude and trend of traditional grain-size profiles for boreal forest/taiga snow in midwinter. In the case of optical grain size, SNOWPACK simulations exhibited a notably large bias compared to measured values; however, the correlation between measured and simulated values exceeded that of the classical grain size.

\section{ACKNOWLEDGEMENTS}

We thank the WSL Institute for Snow and Avalanche Research SLF and especially Mathias Bavay and Martin Schneebeli for the opportunity to use the SNOWPACK model. We also thank the staff of FMI Arctic Research Centre in Sodankylä for performing the in situ measurements.

\section{REFERENCES}

Adams EE and Brown RL (1982) A model for crystal development in dry snow. Geophys. Res. Lett., 9(11), 1287-1289 (doi: 10.1029/ GL009i011p01287)

Arnaud L and 7 others (2011) Measurement of vertical profiles of snow specific surface area with a $1 \mathrm{~cm}$ resolution using infrared reflectance: instrument description and validation. J. Glaciol., 57(201), 17-29 (doi: 10.3189/002214311795306664)

Baunach T, Fierz C, Satyawali PK and Schneebeli M (2001) A model for kinetic grain growth. Ann. Glaciol., 32, 1-6 (doi: 10.3189/172756401781819427)

Brown RD (2000) Northern Hemisphere snow cover variability and change, 1915-97. J. Climate, 13(7), 2339-2355 (doi: 10.1016/ S0165-232X(01)00032-5)

Brown RL, Edens MQ and Barber M (1999) Mixture theory of mass transfer based upon microstructure. Defence Sci. J., 49(5), 393-409

Brown RL, Satyawali PK, Lehning M and Bartelt P (2001) Modeling the changes in microstructure during metamorphism. Cold Reg. Sci. Technol., 33(2-3), 91-101 (doi: 10.1016/S0165-232X(01) 00032-5)

Brun E, David P, Sudul M and Brunot G (1992) A numerical model to simulate snow-cover stratigraphy for operational avalanche forecasting. J. Glaciol., 38(128), 13-22

Chang ATC, Foster JL, Hall DK, Rango A and Hartline BK (1982) Snow water equivalent estimation by microwave radiometry. Cold Reg. Sci. Technol., 5(3), 259-267 (doi: 10.1016/0165232X(82)90019-2)

Chen S and Baker I (2010) Evolution of individual snowflakes during metamorphism. J. Geophys. Res., 115(D21), D21114 (doi: 10.1029/2010JD014132)
Colbeck SC (1982) An overview of seasonal snow metamorphism. Rev. Geophys. Space Phys., 20(1), 45-61 (doi: 10.1029/ RG020i001p00045)

Colbeck SC (1991) The layered character of snow covers. Rev. Geophys., 29(1), 81-96 (doi: 10.1029/90RG02351)

Colbeck SC and 7 others (1990) The international classification for seasonal snow on the ground. International Commission on Snow and Ice, International Association of Scientific Hydrology, Wallingford

De Vries DA (1963) Thermal properties of soils. In Van Wijk WR ed. Physics of plant environment. North-Holland Publishing Co., Amsterdam

Debye P, Anderson HR and Brumberger H (1957) Scattering by an inhomogeneous solid II. The correlation function and its application. J. Appl. Phys., 28(6), 679-683 (doi: 10.1063/ $1.1722830)$

Domine F, Cabanes A, Taillandier AS and Legagneux L (2001) Specific surface area of snow samples determined by $\mathrm{CH}_{4}$ adsorption at $77 \mathrm{~K}$ and estimated by optical microscopy and scanning electron microscopy. Environ. Sci. Technol., 35(4), 771-780 (doi: 10.1021/es001168n)

Domine F, Salvatori R, Legagneux L, Salzano R, Fily $M$ and Casacchia R (2006) Correlation between the specific surface area and the short wave infrared (SWIR) reflectance of snow. Cold Reg. Sci. Technol., 46(1), 60-68 (doi: 10.1016/j.coldregions. 2006.06.002)

Domine $\mathrm{F}$ and 7 others (2008) Snow physics as relevant to snow photochemistry. Atmos. Chem. Phys., 8(2), 171-208 (doi: 10.5194/acp-8-171-2008)

Dozier J and Painter TH (2004) Multispectral and hyperspectral remote sensing of alpine snow properties. Annu. Rev. Earth Planet. Sci., 32, 465-494 (doi: 10.1146/annurev.earth.32. 101802.120404)

Dozier J, Davis RE and Perla R (1987) On the objective analysis of snow microstructure. IAHS Publ. 162 (Symposium at Davos 1986 - Avalanche Formation, Movement and Effects), 49-59

Fierz C and 8 others (2009) The international classification for seasonal snow on the ground. (IHP Technical Documents in Hydrology 83) UNESCO-International Hydrological Programme, Paris

Flanner MG and Zender CS (2006) Linking snowpack microphysics and albedo evolution. J. Geophys. Res., 111(D12), D12208 (doi: 10.1029/2005JD006834)

Flin F and 9 others (2005) Adaptive estimation of normals and surface area for discrete 3-D objects: application to snow binary data from x-ray tomography. IEEE Trans. Image Process., 14(5), 585-596 (doi: 10.1109/TIP.2005.846021)

Gallet J-C, Domine F, Zender CS and Picard G (2009) Measurement of the specific surface area of snow using infrared reflectance in an integrating sphere at 1310 and $1550 \mathrm{~nm}$. Cryosphere, 3(2), 167-182 (doi: 10.5194/tc-3-167-2009)

Giddings JC and LaChapelle E (1961) Diffusion theory applied to radiant energy distribution and albedo of snow. J. Geophys. Res., 66(1), 181-189 (doi: 10.1029/JZ066i001p00181)

Grenfell TC and Warren SG (1999) Representation of a nonspherical ice particle by a collection of independent spheres for scattering and absorption of radiation. J. Geophys. Res., 104(D24), 31 697-31 709 (doi: 10.1029/2005JD005811)

Hall DK, Riggs GA and Salomonson VV (1995) Development of methods for mapping global snow cover using Moderate Resolution Imaging Spectroradiometer (MODIS) data. Remote Sens. Environ., 54(2), 127-140 (doi: 10.1016/0034-4257(95) 00137-P)

Hall DK, Riggs GA, Salomonson VV, DiGirolamo N and Bayr KJ (2002) MODIS snow-cover products. Remote Sens. Environ., 83(1-2), 181-194 (doi: 10.1016/S0034-4257(02)00095-0)

Hallikainen MT, Ulaby FT and Van Deventer TE (1987) Extinction behavior of dry snow in the 18 - to $90-\mathrm{GHz}$ range. IEEE Trans. Geosci. Remote Sens., 25(6), 737-745 (doi: 10.1109/ TGRS.1987.289743) 
Hirashima H, Nishimura K, Yamaguchi S, Sato A and Lehning M (2008) Avalanche forecasting in a heavy snowfall area using the snowpack model. Cold Reg. Sci. Technol., 51(2-3), 191-203 (doi: 10.1016/j.coldregions.2007.05.013)

Huang C, Margulis SA, Durand MT and Musselman KN (2012) Assessment of snow grain-size model and stratigraphy representation impacts on snow radiance assimilation: forward modeling evaluation. IEEE Trans. Geosci. Remote Sens., 50(11), 4551-4564 (doi: 10.1109/TGRS.2012.2192480)

Jin Y-Q (1993) Electromagnetic scattering modelling for quantitative remote sensing. World Scientific, Singapore

Kokhanovsky AA and Zege EP (2004) Scattering optics of snow. Appl. Opt., 43(7), 1589-1602 (doi: 10.1364/AO.43.001589)

Langlois A and 8 others (2010) On the relationship between snow grain morphology and in-situ near infrared calibrated reflectance photographs. Cold Reg. Sci. Technol., 61(1), 34-42 (doi: 10.1016/j.coldregions.2010.01.004)

Langlois A, Royer A, Derksen C, Montpetit B, Dupont F and Goïta K (2012) Coupling the snow thermodynamic model SNOWPACK with the microwave emission model of layered snowpacks for subarctic and arctic snow water equivalent retrievals. Water Resour. Res., 48(12), W12524 (doi: 10.1029/2012WR012133)

Legagneux L, Cabanes A and Domine F (2002) Measurement of the specific surface area of 176 snow samples using methane adsorption at 77 K. J. Geophys. Res., 107(D17), 4335 (doi: 10.1029/2001JD001016)

Lehning M, Bartelt P, Brown B, Fierz C and Satyawali P (2002a) A physical SNOWPACK model for the Swiss avalanche warning. Part II: snow microstructure. Cold Reg. Sci. Technol., 35(3), 147-167 (doi: 10.1016/S0165-232X(02)00072-1)

Lehning M, Bartelt P, Brown B and Fierz C (2002b) A physical SNOWPACK model for the Swiss avalanche warning. Part III: meteorological forcing, thin layer formation and evaluation. Cold Reg. Sci. Technol., 35(3), 169-184 (doi: 10.1016/S0165232X(02)00072-1)

Martinec J and Rango A (1986) Parameter values for snowmelt runoff modelling. J. Hydrol., 84(3-4), 197-219 (doi: 10.1016/ 0022-1694(86)90123-X)

Matzl M and Schneebeli M (2006) Measuring specific surface area of snow by near-infrared photography. J. Glaciol., 52(179), 558-564 (doi: 10.3189/172756506781828412)

Matzl M and Schneebeli M (2010) Stereological measurement of the specific surface area of seasonal snow types: comparison to other methods, and implications for $\mathrm{mm}$-scale vertical profiling. Cold Reg. Sci. Technol., 64(1), 1-8 (doi: 10.1016/j.coldregions.2010.06.006)

Mätzler C (2002) Relation between grain-size and correlation length of snow. J. Glaciol., 48(162), 461-466 (doi: 10.3189/ 172756502781831287)

Mätzler C and Wiesmann A (1999) Extension of the microwave emission model of layered snowpacks to coarse-grained snow. Remote Sens. Environ., 70(3), 317-325 (doi: 10.1016/S00344257(99)00047-4)

Maurer EP, Rhoads JD, Dubayah RO and Lettenmaier D (2003) Evaluation of the snow-covered area data product from MODIS. Hydrol. Process., 17(1), 59-71 (doi: 10.1002/hyp.1193)

Mognard NM (2003) Global snow-cover evolution from twenty years of satellite passive microwave data. In Proceedings of International Geoscience and Remote Sensing Symposium (IGARSS 2003), 21-25 July 2003, Toulouse, France, Vol. 4. Institute of Electrical and Electronics Engineers, Piscataway, NJ, 2838-2840

Montpetit B and 8 others (2012) New shortwave infrared albedo measurements for snow specific surface area retrieval. J. Glaciol., 58(211), 941-952 (doi: 10.3189/2012JoG11J248)

Painter TH, Molotch NP, Cassidy M, Flanner M and Steffen K (2007) Contact spectroscopy for determination of stratigraphy of snow optical grain size. J. Glaciol., 53(180), 121-127 (doi: 10.3189/172756507781833947)

Picard G, Arnaud L, Domine F and Fily M (2009) Determining snow specific surface area from near-infrared reflectance measurements: numerical study of the influence of grain shape. Cold Reg. Sci. Technol., 56(1), 10-17 (doi: 10.1016/ j.coldregions.2008.10.001)

Pielmeier C and Schneebeli M (2003) Stratigraphy and changes in hardness of snow measured by hand, rammsonde and snow micro penetrometer; a comparison with planar sections. Cold Reg. Sci. Technol., 37(3), 393-405 (doi: 10.1016/S0165-232X (03)00079-X)

Pirinen P, Simola H, Aalto J, Kaukoranta J-P, Karlsson P and Ruuhela R (2012) Climatological statistics of Finland 19812012. (Report No. 2012-1) Finnish Meteorological Institute, Helsinki

Pulliainen J and Hallikainen M (2001) Retrieval of regional snow water equivalent from space-borne passive microwave observations. Remote Sens. Environ., 75(1), 76-85 (doi: 10.1016/ S0034-4257(00)00157-7)

Pulliainen JT, Grandell J and Hallikainen MT (1999) HUT snow emission model and its applicability to snow water equivalent retrieval. IEEE Trans. Geosci. Remote Sens., 37(3), 1378-1390 (doi: 10.1109/36.763302)

Rasmus S, Gronholm S, Lehning T, Rasmus M and Kulmala M (2007) Validation of the SNOWPACK model in five different snow zones in Finland. Boreal Environ. Res., 12(4), 467-488

Roy V, Goïta K, Royer R, Walker AE and Goodison BE (2004) Snow water equivalent retrieval in a Canadian boreal environment from microwave measurements using the HUT snow emission model. IEEE Trans. Geosci. Remote Sens., 42(9), 1850-1859 (doi: 10.1109/TGRS.2004.832245)

Schweizer J, Bellaire S, Fierz C, Lehning M and Pielmeier C (2006) Evaluating and improving the stability predictions of the snow cover model SNOWPACK. Cold Reg. Sci. Technol., 46(1), 52-59 (doi: 10.1016/j.coldregions.2006.05.007)

Shaffrey LC and 25 others (2009) U.K. HiGEM: the new UK highresolution global environment model - model description and basic evaluation. J. Climate, 22(8), 1861-1896 (doi: 10.1175/ 2008JCLI2508.1)

Stogryn A (1986) A study of the microwave brightness temperature of snow from the point of view of the strong fluctuation theory. IEEE Trans. Geosci. Remote Sens., 24(2), 220-231 (doi: 10.1109/TGRS.1986.289641)

Sturm M, Morris K and Massom R (1998) The winter snow cover of the West Antarctic pack ice: its spatial and temporal variability. In Jeffries MO ed. Antarctic sea ice: physical processes, interactions and variability. (Antarctic Research Series 74) American Geophysical Union, Washington, DC, 1-18

Sun S, Jin J and Xue Y (1999) A simple snow-atmosphere-soil transfer model. J. Geophys. Res., 104(D16), 19 587-19597 (doi: 10.1029/1999JD900305)

Tedesco M and Kim EJ (2006) Intercomparison of electromagnetic models for passive microwave remote sensing of snow. IEEE Trans. Geosci. Remote Sens., 44(10), 2654-2666 (doi: 10.1109/ TGRS.2006.873182)

Tsang $L$ and Kong JA (1981) Scattering of electromagnetic waves from random media with strong permittivity fluctuations. Radio Sci., 16, 303-320 (doi: 10.1029/RS016i003p00303)

Tsang L, Kong JA and Shin RT (1985) Theory of microwave remote sensing. Wiley, New York

Vionnet V and 7 others (2012) The detailed snowpack scheme Crocus and its implementation in SURFEX v7.2. Geosci. Model Dev., 5(3), 773-791 (doi: 10.5194/gmd-5-773-2012)

Wiesmann A and Mätzler C (1999) Microwave emission model of layered snowpacks. Remote Sens. Environ., 70(3), 307-316 (doi: 10.1016/S0034-4257(99)00046-2)

Wiesmann A, Mätzler C and Weise T (1998) Radiometric and structural measurements of snow samples. Radio Sci., 33(2), 273-289 (doi: 10.1029/97RS02746)

Wiscombe WJ and Warren SG (1980) A model for the spectral albedo of snow. I. Pure snow. J. Atmos. Sci., 37(12), 2712-2733 (doi: 10.1175/1520-0469(1980)037<2712:AMFTSA>2.0.CO;2) 


\section{APPENDIX}

Table 5. SNOWPACK.ini file parameters

\begin{tabular}{|c|c|c|}
\hline Data step length & $30 \mathrm{~min}$ & \\
\hline Calculation step length & $15 \mathrm{~min}$ & \\
\hline Height of meteo values & $2.0 \mathrm{~m}$ & \\
\hline Height of wind value & $22.0 \mathrm{~m}$ & \\
\hline $\begin{array}{l}\text { Enforce measured snow } \\
\text { heights }\end{array}$ & True & \\
\hline SW mode & 2 & $\begin{array}{c}\text { Incoming and reflected } \\
\text { shortwave radiation are both } \\
\text { measured }\end{array}$ \\
\hline Neutral & 1 & $\begin{array}{l}\text { Force Monin-Obukhov } \\
\text { formulation to assume neutral } \\
\text { conditions }\end{array}$ \\
\hline Canopy & False & Open area \\
\hline Measure TSS & False & $\begin{array}{l}\text { Measured surface temperature } \\
\text { not available }\end{array}$ \\
\hline Change BC & False & \\
\hline Incoming longwave & False & \\
\hline Snow redistribution & True & \\
\hline SNP SOIL & True & Soil layers defined \\
\hline Soil flux & False & \\
\hline Geo heat & 0.06 & \\
\hline Advanced settings & $\begin{array}{l}\text { Default variant, } \\
\text { default settings }\end{array}$ & \\
\hline
\end{tabular}

Table 6. SNOWPACK.sno file parameters

\begin{tabular}{|c|c|c|}
\hline Latitude & 7571768 & Sodankylä, northern Finland \\
\hline Longitude & 484270 & \\
\hline Altitude & $180 \mathrm{~m}$ & \\
\hline Slope Angle & $0.0^{\circ}$ & \\
\hline Slope Azi & $0.0^{\circ}$ & \\
\hline nSoilLayerData & 1 & $\begin{array}{c}\text { Soil homogeneous at least } \\
\text { the first } 1.5 \mathrm{~m}\end{array}$ \\
\hline nSnowLayerData & 0 & \\
\hline Bare Soil z0 & 0.02 & \\
\hline Soil Albedo & 0.2 & \\
\hline CanopyHeight & $10.0 \mathrm{~m}$ & \\
\hline CanopyLeafArealndex & 0.0 & \\
\hline $\begin{array}{l}\text { CanopyDirect- } \\
\text { Throughfall }\end{array}$ & 0.0 & \\
\hline WindScalingFactor & 1.0 & \\
\hline Profiledate & 01.08 .2011 & \\
\hline Soil layer thickness & $1.5 \mathrm{~m}$ & \\
\hline Volume fraction ice & 0.00 & \\
\hline Volume fraction water & 0.15 & $\begin{array}{l}\text { Calculated from automatic } \\
\text { soil moisture measurements }\end{array}$ \\
\hline Volume fraction void & 0.15 & \\
\hline Volume fraction soil & 0.7 & \\
\hline Soil density & $1700 \mathrm{~kg} \mathrm{~m}^{-3}$ & Soil approximated as \\
\hline Soil heat conductivity & $1.5 \mathrm{~W} \mathrm{~m}^{-1} \mathrm{~K}^{-1}$ & compact sandy soil. Values \\
\hline Soil specific heat & $1200 \mathrm{~J} \mathrm{~kg}^{-1} \mathrm{~K}^{-1}$ & $\begin{array}{l}\text { estimated according to the } \\
\text { volumetric fraction of water } \\
\text { after de Vries (1963) }\end{array}$ \\
\hline
\end{tabular}


Publication III

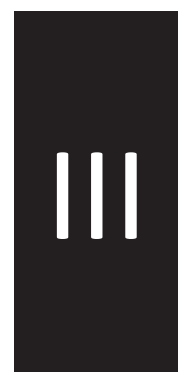





\title{
Microstructure representation of snow in coupled snowpack and microwave emission models
}

\author{
Melody Sandells ${ }^{1}$, Richard Essery ${ }^{2}$, Nick Rutter ${ }^{3}$, Leanne Wake ${ }^{3}$, Leena Leppänen ${ }^{4}$, and Juha Lemmetyinen ${ }^{5}$ \\ ${ }^{1}$ CORES Science and Engineering Limited, Burnopfield, UK \\ ${ }^{2}$ University of Edinburgh, Edinburgh, UK \\ ${ }^{3}$ Northumbria University, Newcastle-upon-Tyne, UK \\ ${ }^{4}$ Finnish Meteorological Institute, Arctic Research Centre, Sodankylä, Finland \\ ${ }^{5}$ Finnish Meteorological Institute, Helsinki, Finland
}

Correspondence to: Melody Sandells (melody.sandells@ coresscience.co.uk)

Received: 17 July 2016 - Published in The Cryosphere Discuss.: 26 July 2016

Revised: 3 November 2016 - Accepted: 19 December 2016 - Published: 27 January 2017

\begin{abstract}
This is the first study to encompass a wide range of coupled snow evolution and microwave emission models in a common modelling framework in order to generalise the link between snowpack microstructure predicted by the snow evolution models and microstructure required to reproduce observations of brightness temperature as simulated by snow emission models. Brightness temperatures at 18.7 and $36.5 \mathrm{GHz}$ were simulated by 1323 ensemble members, formed from 63 Jules Investigation Model snowpack simulations, three microstructure evolution functions, and seven microwave emission model configurations. Two years of meteorological data from the Sodankylä Arctic Research Centre, Finland, were used to drive the model over the 2011-2012 and 2012-2013 winter periods. Comparisons between simulated snow grain diameters and field measurements with an IceCube instrument showed that the evolution functions from SNTHERM simulated snow grain diameters that were too large (mean error 0.12 to $0.16 \mathrm{~mm}$ ), whereas MOSES and SNICAR microstructure evolution functions simulated grain diameters that were too small (mean error -0.16 to $-0.24 \mathrm{~mm}$ for MOSES and -0.14 to $-0.18 \mathrm{~mm}$ for SNICAR). No model (HUT, MEMLS, or DMRT-ML) provided a consistently good fit across all frequencies and polarisations. The smallest absolute values of mean bias in brightness temperature over a season for a particular frequency and polarisation ranged from 0.7 to $6.9 \mathrm{~K}$.

Optimal scaling factors for the snow microstructure were presented to compare compatibility between snowpack model microstructure and emission model microstructure. Scale factors ranged between 0.3 for the SNTHERM-
\end{abstract}

empirical MEMLS model combination (2011-2012) and 3.3 for DMRT-ML in conjunction with MOSES microstructure (2012-2013). Differences in scale factors between microstructure models were generally greater than the differences between microwave emission models, suggesting that more accurate simulations in coupled snowpack-microwave model systems will be achieved primarily through improvements in the snowpack microstructure representation, followed by improvements in the emission models. Other snowpack parameterisations in the snowpack model, mainly densification, led to a mean brightness temperature difference of $11 \mathrm{~K}$ at $36.5 \mathrm{GHz} \mathrm{H}$-pol and $18 \mathrm{~K}$ at V-pol when the Jules Investigation Model ensemble was applied to the MOSES microstructure and empirical MEMLS emission model for the 2011-2012 season. The impact of snowpack parameterisation increases as the microwave scattering increases. Consistency between snowpack microstructure and microwave emission models, and the choice of snowpack densification algorithms should be considered in the design of snow mass retrieval systems and microwave data assimilation systems.

\section{Introduction}

Global observations of the snow cover extent from optical and microwave satellite observations combined with in situ data have shown a reduction in the spring snow cover (Brown et al., 2010; Brown and Robinson, 2011). Observed decline in snow cover extent during 2008-2011 exceeded that predicted by climate models (Derksen and Brown, 2012). Ob-

Published by Copernicus Publications on behalf of the European Geosciences Union. 
servations also indicate that duration of snow cover is also reducing, but they cannot determine whether mass or volume of snow has changed.

Microwave, altimetry, or coarser-scale gravity satellite sensors offer the only feasible way to measure snow mass or depth on a global scale, with microwave observations spanning the longest timescale of these. However, microwave algorithms such as those developed by Chang et al. (1987) and Kelly (2009) can result in large errors because of the high sensitivity of applied forward models to parameterization of the snow microstructure (Davenport et al., 2012). In particular, the assumption of a fixed snow scatterer radius in the Chang et al. (1987) algorithm does not reflect the naturally changing snowpack structure. Errors in snow mass products derived from these algorithms mean that the products are difficult to use for evaluation of snow mass in climate models (Clifford, 2010) and unsuitable for assimilation into land surface models for streamflow forecasts (Andreadis and Lettenmaier, 2006). Development of the assimilation-based technique in GlobSnow allows changes in the snow microstructure to be taken into account through inversion of groundbased observations of snow depth and coinciding microwave brightness temperatures (Takala et al., 2011). Although more accurate than other global products, some errors remain, and the GlobSnow accuracy relies on the proximity and representativity of the ground stations (Hancock et al., 2013). In addition, the intermediate retrieval of the snow "grain size" in GlobSnow is a parameter that also incorporates other land surface features, so is not a true representation of the snow effective diameter (Lemmetyinen et al., 2015).

Snowpack evolution models offer a way to estimate temporal changes in snow microstructural parameters and stratigraphy (e.g. Lehning et al., 2002; Brun et al., 1992). Intercomparison studies have shown large differences between snow evolution models driven by the same forcing data (Rutter et al., 2009). Given that the mass inputs were the same for the 33 snow models considered in the SNOWMIP2 study of Rutter et al. (2009), it is differences in the internal snow physics and model structure (layering assumptions) that result in the wide range of simulated depth and snow mass. Temperature, temperature gradient, and density drive changes in the snow microstructure (e.g. Flanner and Zender, 2006), so it is likely that different snow physics assumptions in a coupled snowpack and emission model result in different thermal structures, microstructure parameterisations, and ultimately different microwave extinction behaviour.

Theoretical differences between specific electromagnetic models have been examined in Löwe and Picard (2015), Pan et al. (2015), and other intercomparisons carried out by Tedesco and Kim (2006). These studies are useful for interpreting differences in electromagnetic model outputs for a snapshot profile of the snowpack properties. Given the dependence of microwave scattering on snow microstructure, a satellite retrieval system needs some quantification of microstructure. Snowpack evolution modelling offers a means to quantify the metamorphic changes in snow microstructure. Indeed, snowpack evolution models have been coupled with microwave emission models to demonstrate the potential of this approach for snow remote sensing applications (Langlois et al., 2012; Andreadis and Lettenmaier, 2012; Brucker et al., 2011; Picard et al., 2009). These studies all examined the accuracy of a single snowpack model coupled with a single microwave emission model.

The purpose of this study is to inform future design of retrieval and assimilation systems where snowpack evolution models may be used to provide microstructural parameters for microwave emission models, by examining how particular snowpack and emission model choices lead to a variation in simulated brightness temperatures throughout the winter period, and evaluate how the simulated values compare to observations. The Jules Investigation Model (JIM; Essery et al., 2013) has been coupled with three widely used microwave emission models: the Dense Media Radiative Transfer Multi-Layer model (DMRT-ML; Picard et al., 2013), the Microwave Emission Model of Multi-Layer Snow (MEMLS; Wiesmann and Mätzler, 1999), and the Helsinki University of Technology (HUT) multi-layer model (Lemmetyinen et al., 2010; Pulliainen et al., 1999). Snowpack microstructure metamorphism is represented here by three different options with differing complexity for grain diameter evolution (or equivalently the specific surface area, SSA). These models are the grain growth models of SNTHERM (SNT; Jordan, 1991), SNICAR (SNI; Flanner and Zender, 2006), and MOSES (MOS; Essery et al., 2001). This allowed quantification of the seasonal variation in uncertainty in brightness temperature simulations from 1323 coupled snowpackemission model systems, as evaluated against ground-based observations of brightness temperature.

The study approach, model descriptions, and field measurements are given in Sect. 2. Comparisons between simulations and between simulations and observations are presented in Sect. 3, and the implications for future approaches to the remote sensing of snow mass are discussed in Sect. 4.

\section{Models and methods}

This study builds on the work of Essery et al. (2013), who incorporated many published snow model parameterisations within a single model framework, the JIM, which is described in Sect. 2.1. As this earlier study did not incorporate snow microstructure changes, JIM was coupled with three microstructure evolution functions for this study, described in Sect. 2.2, and three distinct snow emission models, detailed in Sect. 2.3. Steps necessary to form the model ensemble, including assumptions about the representation of the soil, are given in Sect. 2.4. A description of the field site, driving, and evaluation data for the simulations in this paper are presented in Sect. 2.5. 
Table 1. Equations for options governing the representation of processes in the JIM model subset.

\begin{tabular}{rll}
\hline Option & Description & Model parameterization \\
\hline Compaction: 0 & Physical & $\frac{1}{\rho_{\mathrm{s}}} \frac{\mathrm{d} \rho_{\mathrm{s}}}{\mathrm{d} t}=\frac{M_{\mathrm{s}} g}{\eta}+c_{1} \exp \left[-c_{2}\left(T_{\mathrm{m}}-T_{\mathrm{S}}\right)-c_{3} \max \left(0, \rho_{\mathrm{s}}-\rho_{0}\right)\right]$ \\
1 & Empirical & $\rho_{\mathrm{S}}(t+\delta t)=\rho_{\max }+\left[\rho_{\mathrm{s}}(t)-\rho_{\max }\right] \exp \left(-\delta t / \tau_{\rho}\right)$ \\
2 & Constant & $\rho_{\mathrm{s}}=250 \mathrm{~kg} \mathrm{~m}^{-3}$ \\
\hline Fresh snow density: 0 & Empirical & $\rho_{\mathrm{f}}=\max \left[a_{\mathrm{f}}+b_{\mathrm{f}}\left(T_{\mathrm{a}}-T_{\mathrm{m}}\right)+c_{\mathrm{f}} U_{\mathrm{a}}^{1 / 2}, \rho_{\min }\right]$ \\
1 & Empirical & $\rho_{\mathrm{f}}=\rho_{\min }+\max \left[d_{\mathrm{f}}\left(T_{\mathrm{a}}-T_{\mathrm{m}}+e_{\mathrm{f}}\right)^{3 / 2}, 0\right]$ \\
2 & Constant & $\rho_{\mathrm{f}}=100 \mathrm{~kg} \mathrm{~m}^{-3}$ \\
\hline Thermal conductivity: 0 & Empirical & $\lambda_{\mathrm{s}}=\lambda_{\mathrm{a}}+\left(a_{\lambda} \rho_{\mathrm{s}}+b_{\lambda} \rho_{\mathrm{s}}^{2}\right)\left(\lambda_{\mathrm{i}}-\lambda_{\mathrm{a}}\right)$ \\
1 & Empirical & $\lambda_{\mathrm{s}}=c_{\lambda}\left(\frac{\rho_{\mathrm{s}}}{\rho_{\mathrm{w}}}\right)^{n_{\lambda}}$ \\
2 & Constant & $\lambda_{\mathrm{s}}=0.265 \mathrm{Wm}^{-1} \mathrm{~K}^{-1}$ \\
\hline Maximum liquid water: 0 & Empirical & $\frac{\gamma_{\mathrm{w}, \max }}{\rho_{\mathrm{s}}}=r_{\min }+\left(r_{\max }-r_{\min }\right) \max \left(1-\frac{\rho_{\mathrm{s}}}{\rho_{\mathrm{r}}}, 0\right)$ \\
1 & Constant & $\gamma_{\mathrm{w}, \max }=\rho_{\mathrm{W}}\left(1-\frac{\gamma_{\mathrm{i}}}{\rho_{\mathrm{i}}}\right) S_{\mathrm{wi}}$ \\
2 & None & $\gamma_{\mathrm{w}, \max }=0 \mathrm{~kg} \mathrm{~m}^{-3}$ \\
\hline
\end{tabular}

JIM variables are snow density $\rho_{\mathrm{s}}$, overlying snow mass $M_{\mathrm{S}}$, snow temperature $T_{\mathrm{s}}$, air temperature $T_{\mathrm{a}}$, wind speed $U_{\mathrm{a}}$, snow effective thermal conductivity $\lambda_{\mathrm{s}}$, partial density of liquid water $\gamma_{\mathrm{w}}$, and partial density of ice $\gamma_{\mathrm{i}}$. Other symbols represent constants, given in Essery et al. (2013).

\subsection{Snow model parameterisation}

Essery et al. (2013) developed the JIM, a system of 1701 snowpack evolution models to provide a systematic method and common framework to examine how the range of snowpack parameterisations used in land surface models impacts the simulation of snow parameters. Based on this work, a more computationally efficient version, a factorial snowpack model has been developed (Essery, 2015) that allows for 32 model configurations. JIM is based on an Eulerian grid scheme (fixed layer structure), which requires mass redistribution between layers with precipitation events. An alternative approach is a Lagrangian grid scheme: a deforming layer structure that retains much of the same snow material throughout the season (e.g. Jordan, 1991; Brun et al., 1992; Lehning et al., 2002). For this paper, a subset of the original JIM members was selected as these were expected to influence the parameters important for microwave modelling. The subset includes variation in the representation of compaction, the density of newly deposited snow, thermal conductivity, and liquid-water flow (snow hydrology). Table 1 summarises the different approaches taken. Note that a variable fresh snow density (options 0 and 1) cannot be used when the snowpack has fixed density (compaction option 2), so there are only 63 model configurations in the model subset rather than 81 . For all other snowpack parameterisations, option "1" from Essery et al. (2013) were used for albedo, surface exchange, and snow fraction representations to form the JIM subset.

\subsection{Microstructure evolution}

JIM subset outputs were used to drive three microstructure models of differing complexity. SNT (Jordan, 1991) growth of snow grain diameter $d$ is based on the rate of vapour transport through the snow (and therefore temperature gradient), which leads to the microstructure evolution function of dry snow in SNT as

$\frac{\partial d}{\partial t}=\frac{g_{1}}{d} D_{\mathrm{eos}}\left(\frac{1000}{P_{\mathrm{a}}}\right)\left(\frac{T_{\mathrm{s}}}{T_{\mathrm{m}}}\right)^{6} C_{k T_{\mathrm{s}}}\left|\frac{\partial T_{\mathrm{s}}}{\partial z}\right|$,

where $g_{1}$ and $D_{\text {eos }}$ are empirical constants, $P_{\mathrm{a}}$ is the atmospheric pressure, $C_{k T_{\mathrm{s}}}$ is the variation of saturation vapour pressure with snow temperature $T_{\mathrm{s}}, T_{\mathrm{m}}=273.15 \mathrm{~K}$, and $\frac{\partial T_{\mathrm{s}}}{\partial z}$ is the temperature gradient. Grain growth under wet conditions is more rapid, with empirical constant $g_{2}$ and is dependent on the liquid fractional volume, $f_{1}$ by

$\begin{array}{ll}\frac{\partial d}{\partial t}=\frac{g_{2}}{d}\left(f_{1}+0.05\right) & f_{1}<0.09, \\ \frac{\partial d}{\partial t}=\frac{g_{2}}{d}(0.14) & f_{1} \geq 0.09 .\end{array}$

SNI microstructure evolution is a computationally efficient approximation to a model based on physics that uses a lookup table for empirical parameters $\tau$ and $\kappa$, as described in Flanner and Zender (2006). These parameters are dependent on the snow density, temperature, and temperature gradient. The equation of microstructure evolution in SNI is based on snow SSA:

$\operatorname{SSA}(t)=\operatorname{SSA}_{0}\left(\frac{\tau}{t+\tau}\right)^{1 / \kappa}$. 
SSA per unit mass of ice $\left(\mathrm{m}^{2} \mathrm{~kg}^{-1}\right)$ can then be converted to grain diameter with $D=6 /\left(\rho_{\mathrm{i}} \mathrm{SSA}\right)$ (Mätzler, 2002; Montpetit et al., 2012).

A third microstructure model, MOS, parameterises snow evolution as a function of grain radius $r$ and snow age:

$r(t+\Delta t)=\left[r(t)^{2}+\frac{G_{\mathrm{r}}}{\pi} \Delta t\right]^{1 / 2}-\left[r(t)-r_{0}\right] \frac{S_{\mathrm{f}} \Delta t}{d_{0}}$,

where $G_{\mathrm{r}}$ is an empirical temperature-dependent grain area growth rate, $S_{\mathrm{f}}$ is the snowfall rate in time interval $\Delta t$, and $d_{0}$ is a constant representing the mass of fresh snow required to reset the snow albedo to its maximum value.

Other microstructure parameterisations are available, namely the Crocus (Vionnet et al., 2012) and SNOWPACK (Lehning et al., 2002) microstructure evolution functions. It is not currently possible to couple these with the JIM model due to the Eulerian grid structure of JIM. Mass transfer between layers allows numerical averaging of concepts such as grain diameter and SSA, but not shape-dependent concepts such as dendricity and sphericity. Therefore the Crocus and SNOWPACK functions have not been included in this study.

\subsection{Microwave emission models}

The microwave models chosen for this application span a range of physical complexity in their representation of the snow. The HUT model (Lemmetyinen et al., 2010) is a semiempirical model based on strong forward scattering assumptions, the MEMLS model (Wiesmann and Mätzler, 1999) is of intermediate complexity and contains the improved Born approximation (Mätzler, 1998), and the DMRT-ML model (Picard et al., 2013) is the most physically complex and is based on quasi-crystalline approximation with coherent potential (QCA-CP). Many other microwave emission models have been developed, such as Mie scattering approach of Boyarskii and Tikhonov (2000), Chang et al. (1976), and Eom et al. (1983), strong fluctuation theory (Stogryn, 1986; Song and Zhang, 2007), distorted Born approximation (Tsang et al., 2000), the quasi-crystalline approximation (Grody, 2008), other QCA-CP models (Rosenfeld and Grody, 2000; Jin, 1997), or the numerical method of Maxwell's equations in 3-D (Xu et al., 2012). These references are not exhaustive but do give an illustration of the range of models available. Here, we restrict the comparison to widely available multilayer models that span a range of complexity and whose computational efficiency is such that entire seasons can be simulated rapidly.

Of the models chosen, all are multiple layer and broadly require the same information; i.e. they use layered information on snow temperature, density, and layer thickness as input but differ in their representation of the microstructure. They are all based on radiative transfer theory, which is gov- erned by the following general equation:

$$
\begin{gathered}
\mu \frac{\partial \boldsymbol{T}_{\mathrm{B}}\left(\theta_{\mathrm{s}}, \phi_{\mathrm{s}}, z\right)}{\partial z}=\kappa_{\mathrm{a}} T(z)+\frac{1}{4 \pi} \int_{4 \pi} \Psi\left(\theta_{\mathrm{s}}, \phi_{\mathrm{s}} ; \theta_{\mathrm{i}}, \phi_{\mathrm{i}}\right) \\
\cdot \boldsymbol{T}_{\mathrm{B}}\left(\theta_{\mathrm{i}}, \phi_{\mathrm{i}}, z\right) \mathrm{d} \Omega_{\mathrm{i}}-\kappa_{\mathrm{e}} \cdot \boldsymbol{T}_{\mathrm{B}}\left(\theta_{\mathrm{s}}, \phi_{\mathrm{s}}, z\right),
\end{gathered}
$$

where $\theta$ and $\phi$ are the zenith and azimuth angles, $\mu=\cos \theta$, $\boldsymbol{T}_{\mathrm{B}}$ is the brightness temperature vector, which we will assume here to consist of horizontally and vertically polarised brightness temperature only, $\kappa_{\mathrm{a}}$ is the absorption coefficient, and $\kappa_{\mathrm{e}}$ is the extinction coefficient, which is a sum of the absorption coefficient and the scattering coefficient $\kappa_{\mathrm{s}}$. The models differ in which two coefficients determine the third. In HUT, the derived coefficient is $\kappa_{\mathrm{s}}$, whereas $\kappa_{\mathrm{e}}$ is derived in MEMLS and $\kappa_{\mathrm{a}}$ in DMRT-ML. Other differences between models include the representation of the phase function (single-stream model with separate up- and downwelling components in HUT, six-stream in MEMLS and multiple streams in DMRT-ML), specification of the absorption coefficient and the numerical techniques applied to solve the radiative transfer equation (Lemmetyinen et al., 2010; Wiesmann and Mätzler, 1999; Picard et al., 2013; Mätzler and Wiesmann, 1999; Pan et al., 2015). Differences between models are not restated here, but options chosen within each model leading to different model versions are stated in the following subsections.

\subsubsection{DMRT-ML}

DMRT-ML is based on a sticky hard spheres representation of the microstructure so that the scattering coefficient given by the QCA-CP is given as

$\kappa_{\mathrm{S}}=\frac{2}{9} k_{0}^{4} a^{3} f\left|\frac{\epsilon_{\mathrm{s}}-\epsilon_{\mathrm{b}}}{1+\frac{\epsilon_{\mathrm{s}}-\epsilon_{\mathrm{b}}}{3 E_{\mathrm{eff}}}(1-f)}\right|^{2} \frac{(1-f)^{4}}{(1+2 f-t f(1-f))^{2}}$,

where $k_{0}=2 \pi / \lambda$ is the wave number, a is the radius of the spheres, $f$ is the fractional volume of scatterers, $\epsilon_{\mathrm{S}}$ is the permittivity of the scatterers, $\epsilon_{\mathrm{b}}$ is the permittivity of the background, and $E_{\text {eff }}$ is the effective permittivity of the medium. $t$ is related to the stickiness factor $\tau$ governing the potential of particles to coalesce. For non-sticky particles $t=0$ but for sticky particles, it is given by the largest of the two solutions to the quadratic equation:

$\frac{f}{12} t^{2}-\left(\tau+\frac{f}{1-f}\right) t+\frac{1+f / 2}{(1-f)^{2}}=0$.

Whilst Löwe and Picard (2015) have shown that it may be possible to determine stickiness from micro-CT measurements of the snow, an appropriate value of stickiness is not known for the field observations used in this paper. Roy et al. (2013) and Löwe and Picard (2015) showed that non-sticky representation in DMRT-ML is inappropriate. For this model ensemble, two DMRT-ML configurations have been chosen 
to capture the range of brightness temperatures simulated: "DMRT less sticky" ( $\tau=0.2)$ and "DMRT very sticky" ( $\tau=$ 0.1 ). These two values represent reasonable values used by others (e.g. Tsang et al., 2007; Shih et al., 1997).

\subsubsection{MEMLS}

Within MEMLS there are a suite of options for the calculation of the scattering coefficient. Two of the options within MEMLS were selected for this study to cover both empirical and theoretical approaches: "MEMLS empirical" and "MEMLS IBA". The empirical version of MEMLS used gives the scattering coefficient as

$\kappa_{\mathrm{S}}=\left(9.2 p_{\mathrm{ec}}-1.23 \rho+0.54\right)^{2.5}(v / 50)^{2.5}$,

where the correlation length $p_{\mathrm{ec}}$ is in $\mathrm{mm}$, density $\rho$ is in $\mathrm{gcm}^{-3}$, and frequency $v$ is in GHz. This is suitable for correlation lengths $0.05<p_{\mathrm{ec}}<0.3 \mathrm{~mm}$ and density $0.1<\rho<$ $0.4 \mathrm{~g} \mathrm{~cm}^{-3}$.

MEMLS IBA uses the improved Born approximation theory given in Mätzler (1998) and Mätzler and Wiesmann (1999), where the scattering coefficient is given by the integral of the phase function for polarisation angle $\chi$

$\kappa_{\mathrm{s}}=\frac{1}{4 \pi} \int_{4 \pi} f(1-f)\left(\epsilon_{\mathrm{s}}-\epsilon_{\mathrm{b}}\right)^{2} K^{2} I k_{0}^{4} \sin ^{2} \chi \mathrm{d} \Omega$.

One further assumption applied to distinguish this MEMLS IBA configuration is that oblate grains are used rather than small spherical scatterers or thin spherical shells. This assumption governs the representation of the mean square field ratio, $K^{2}$, as detailed in Mätzler and Wiesmann (1999). The microstructure length information is contained in $I$ :

$I=\frac{2 p_{\mathrm{ec}}}{\left(1+4 \epsilon_{\mathrm{eff}} k_{0}^{2} \sin ^{2}(\theta / 2) p_{\mathrm{ec}}^{2}\right)^{2}}$.

It should be noted that the choice of oblate grains also affects the effective permittivity in $I$, represented by an empirical, density-dependent effective permittivity (Wiesmann and Mätzler, 1999, Eqs. 45-47) for this case.

\subsubsection{HUT}

HUT has three options for the extinction coefficient. These are nominally suited to different grain diameter $\left(d_{0}\right)$ ranges, with some overlap between them. All three versions (termed HUT H87, HUT R04, HUT K10) have been included in this version of the model ensemble. HUT H87 is based on the work of Hallikainen et al. (1987):

$\kappa_{\mathrm{e}}=0.0018 v^{2.8} d_{0}^{1.9}$.

This is nominally appropriate for frequency range $v=18$ $60 \mathrm{GHz}$ and $d_{0}<1.6 \mathrm{~mm}$.
The extinction coefficient in HUT H04, with a validity range of $1.3<d_{0}<4 \mathrm{~mm}$ was derived by Roy et al. (2004):

$\kappa_{\mathrm{e}}=2 v^{0.8} d_{0}^{1.2}$.

Kontu and Pulliainen (2010) gave the extinction coefficient for maritime snow, used here in the HUT K10 simulations as

$\kappa_{\mathrm{e}}=0.08 v^{1.75} d_{0}^{1.8}$.

Scaling of the grain diameter by the relationship recommended in Kontu and Pulliainen (2010) has not been applied here as it was developed for snow microstructure observations rather than simulated snowpack microstructure.

\subsection{Model framework}

Interfacing of the various model inputs and outputs was enabled through the development of the ensemble framework, via a combination of shell script and Octave/MATLAB code. The DMRT-ML model was run from the shell script, which subsequently calls an Octave/MATLAB script to run HUT and MEMLS. HUT and MEMLS run alternately in this framework as the soil parameters (common between DMRT-ML and HUT) are used to calculate soil reflectivity in HUT, which is then used as the lower boundary condition in MEMLS. Internal parallelisation of the MATLAB code of HUT-MEMLS means that a season-long simulation of one HUT-MEMLS combination with one grain scaling factor takes 9 min over eight cores. For the DMRT-ML FORTRAN code, external bash shell parallelisation reduces execution time from 16 to ca. $2 \mathrm{~h}$ for one grain scale factor and two parameterisations of stickiness. Over 29 million individual brightness temperatures were simulated for this study.

For the purposes of this study, the effective sphere size in JIM, DMRT-ML, and HUT is assumed to be identical i.e. $d_{\mathrm{HUT}}=2 \times r_{\mathrm{DMRT}}=d_{\mathrm{JIM}}$. This may not be a good assumption as the empirical extinction coefficient model used in HUT was based on observations of the maximum grain extent rather than effective diameter, which was almost impossible to measure at the time of the original work. The exponential correlation length in MEMLS (in mm) is calculated from the theoretical relationship to the effective grain diameter from JIM (in $\mu \mathrm{m}$ ) as Montpetit et al. (2013) and Mätzler (2002):

$p_{\mathrm{ec}}=\frac{2}{3}\left(1-\frac{\rho_{\mathrm{s}}}{\rho_{\mathrm{i}}}\right) \frac{d_{\mathrm{JIM}}}{1000}$.

Figure 1 illustrates the flow of information in the model ensemble. Meteorological data are used to drive the 189 configurations of JIM (3 microstructural models for each of the 63 snowpack parameterisations). The outputs from JIM are then reformatted for each of the three electromagnetic models. Table 2 gives a summary of the main differences in inputs 


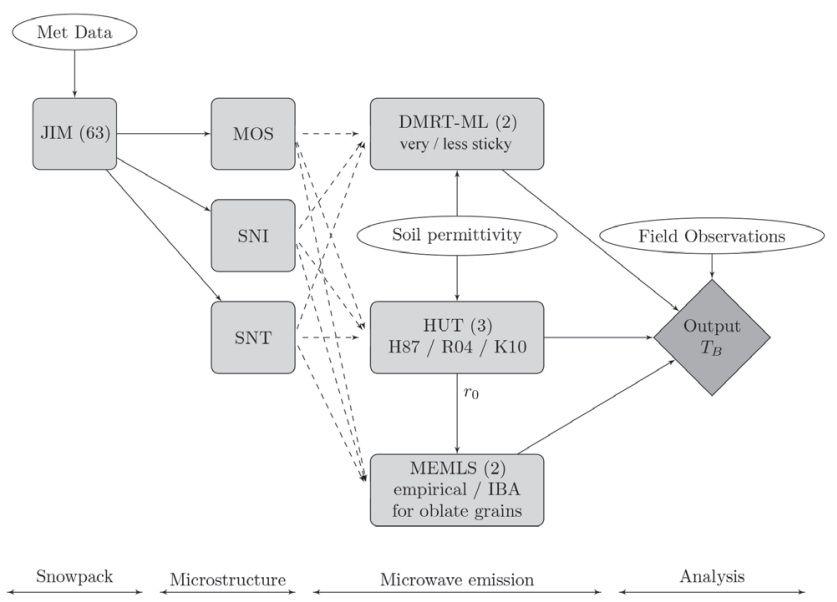

Figure 1. Flowchart showing flow of information from JIM snow evolution model outputs to outputs from the various microwave emission models.

Table 2. Electromagnetic model inputs, as a function of JIM snowpack model outputs.

\begin{tabular}{|c|c|c|c|c|}
\hline & $\begin{array}{l}\text { JIM } \\
\text { output }\end{array}$ & $\begin{array}{l}\text { DMRT-ML } \\
\text { input }\end{array}$ & $\begin{array}{l}\text { MEMLS } \\
\text { input }\end{array}$ & $\begin{array}{l}\text { HUT } \\
\text { input }\end{array}$ \\
\hline Temperature & $T_{\mathrm{JIM}}[\mathrm{K}]$ & $T_{\mathrm{JIM}}[\mathrm{K}]$ & $T_{\mathrm{JIM}}[\mathrm{K}]$ & $T_{\mathrm{JIM}}-273.15\left[{ }^{\circ} \mathrm{C}\right]$ \\
\hline Density & $\rho_{\text {JIM }}\left[\mathrm{kg} \mathrm{m}^{-3}\right]$ & $\rho_{\mathrm{JIM}}\left[\mathrm{kg} \mathrm{m}^{-3}\right]$ & $\rho_{\mathrm{JIM}}\left[\mathrm{kg} \mathrm{m}^{-3}\right]$ & $\frac{\rho_{\mathrm{IIM}}}{1000}\left[\mathrm{~g} \mathrm{~cm}^{-3}\right]$ \\
\hline Layer size & $\Delta z_{\mathrm{JIM}}[\mathrm{m}]$ & $\Delta z_{\mathrm{JIM}}[\mathrm{m}]$ & $\frac{\Delta z_{\mathrm{JIM}}}{100}[\mathrm{~cm}]$ & $\rho_{\mathrm{JIM}} \Delta z_{\mathrm{JIM}}\left[\mathrm{mm}_{\mathrm{swe}}\right]$ \\
\hline Microstructure & $d_{\mathrm{JIM}}[\mu \mathrm{m}]$ & $d_{\mathrm{JIM}}[\mu \mathrm{m}]$ & $\frac{2}{3}\left(1-\frac{\rho_{\mathrm{s}}}{\rho_{\mathrm{i}}}\right) \frac{d_{\mathrm{JIM}}}{1000}[\mathrm{~mm}]$ & $\frac{d_{\mathrm{IIM}}}{1000}[\mathrm{~mm}]$ \\
\hline Layer number & $1=$ base & $1=$ base & $1=$ base & $1=$ top \\
\hline Soil permittivity & - & $\epsilon_{\mathrm{obs}}$ & $r_{0, \mathrm{HUT}}$ & $\epsilon_{\mathrm{obs}}$ \\
\hline
\end{tabular}

between models. The electromagnetic model inputs are then used to drive the two DMRT-ML model versions $(\tau=0.1$, $\tau=0.2$ ), the two MEMLS model versions (empirical, IBA with oblate grains), and the three HUT versions (three different extinction coefficient models). Meteorological and field data used to drive and evaluate the ensemble are described in the following section.

\subsection{Data}

Model runs for this study were performed for the Intensive Observation Area (IOA) of the Finnish Meteorological Institute Arctic Research Centre (FMI-ARC). The site provides a wealth of forcing and evaluation data, including automated soil, snow and meteorological observations, ground-based microwave radiometry, and a programme of manual snow profile observations. Air temperature, solar ra- diation, and precipitation observations from this site for the two seasons of simulations are shown in Fig. 2. November rain events occurred in both years, as well as in early December in 2011-2012. Layers with melt-freeze polycrystals and other melt forms were detected in snow observations during both seasons. Metadata and details on the meteorological instruments are given in Essery et al. (2016). Dual polarisation microwave radiometers, including at frequencies of 18.7 and $36.5 \mathrm{GHz}$, are situated on a $4 \mathrm{~m}$ tower pointing inwards on the edge of a large clearing surrounded by a mainly pine forest. Further details about the IOA site are given in Lemmetyinen et al. (2016). Details on the manual snow profile observation programme are given by Leppänen et al. (2016).

Simulations were carried out for the winters of 2011-2012 and 2012-2013 as there were 49 approximately bi-weekly snow pit observations over these 2 years available for snow- 

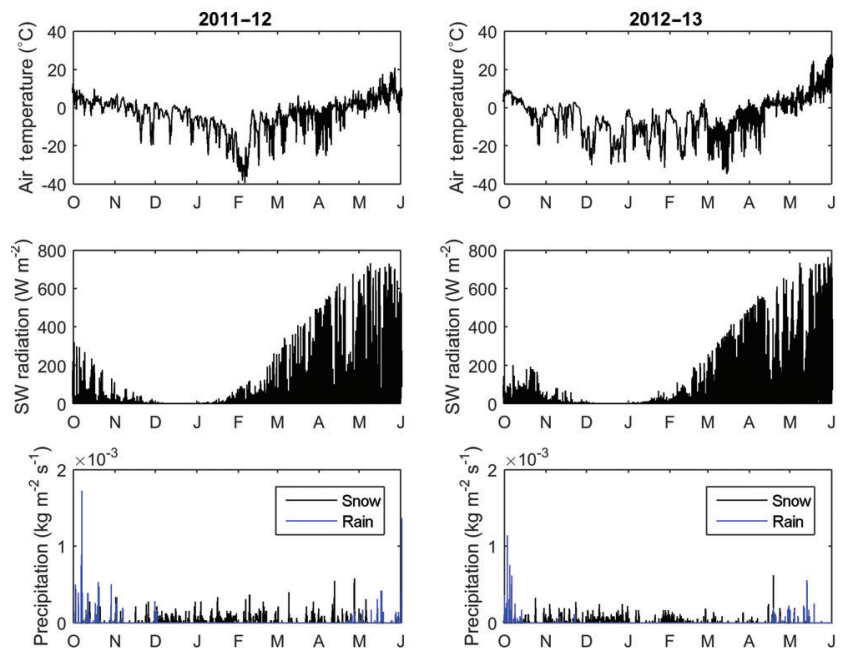

Figure 2. Air temperature, solar radiation, and precipitation data measured at the Sodankylä site, used as inputs for the JIM simulations.

pack model evaluation. Snow samples from 31 of these pits were extracted and used to measure profiles of the SSA with the IceCube instrument (Zuanon, 2013). A bulk grain diameter was calculated for the analysis from the snow water equivalent (SWE)-weighted mean SSA, excluding layers without observations. For these two seasons, the real component of the soil permittivity measurements were available at $100 \mathrm{MHz}$, measured at three locations in the observation area with Delta-T devices ML2x sensors, installed horizontally at a depth of approximately $2 \mathrm{~cm}$ beneath the organic surface layer. Mean measurements from the stable winter period (1 December-31 March) were chosen as representative for the entire season, which resulted in values of soil permittivity of 4.4 in 2011-2012 and 4.6 in 2012-2014. For the JIM simulations in this paper, a scaling factor of 1.11 was applied to the 2011-2012 precipitation data, and a scaling factor of 1.06 was applied to the 2012-2013 data to match the measured snow accumulation on the ground better. These factors differ slightly from the values used in the 7-year consolidated data set of Essery et al. (2016).

\subsection{Simulation methodology}

Choices in the snowpack evolution parameterisations made here lead to 189 unique JIM snowpack models. Modelled snowpack profiles of layer thickness, temperature, density, and grain diameter were output daily at noon for this study. These were then applied to the seven microwave emission model combinations, resulting in 1323 sets of brightness temperature simulations per day.

In order to illustrate and analyse the effects of assumptions regarding snowpack evolution and microwave scattering on simulated brightness temperatures over the course of the winter season, the remainder of the paper will do the following:

1. Present the range of brightness temperatures expected for any generic combination of snowpack and emission model.

2. Apply a range of scaling factors $(0.1 \leq \Phi \leq 5.0)$ to simulated JIM snowpack diameters $\left(d_{\text {optimal }}=\Phi d_{\text {JIM }}\right)$ and calculate the degree of misfit between simulated and observed brightness temperatures using the following cost function $(\mathrm{CF})$ :

$\mathrm{CF}=\sum^{\text {ndays }} \sum^{\nu} \sum^{\text {pol }}\left(\frac{T_{\mathrm{B}_{\text {sim }}}-T_{\mathrm{B}_{\mathrm{obs}}}}{2}\right)^{2}$.

The cost function term is summed over the two polarisations ( $\mathrm{H}$ - and V-pol) for the two frequencies (18.7 and $36.5 \mathrm{GHz}$ ) over the number of days (ndays) when observations and simulations are both available. Due to the observation schedule at the Sodankylä site, the noon "observations" for comparison with the simulations were determined as the mean of the $10 \mathrm{am}$ and $2 \mathrm{pm}$ observations. If observations were missing from either or both of these times, the brightness temperature for that day was excluded from the CF calculation. Optimal $\Phi$ were found from the minimisation of the $C F$.

3. Isolate the effect of snowpack parameterisations on simulated brightness temperature by presenting simulation results grouped by parameterisations of densification, liquid-water flow, initial snow density, and thermal conductivity. This will determine which factors govern the 

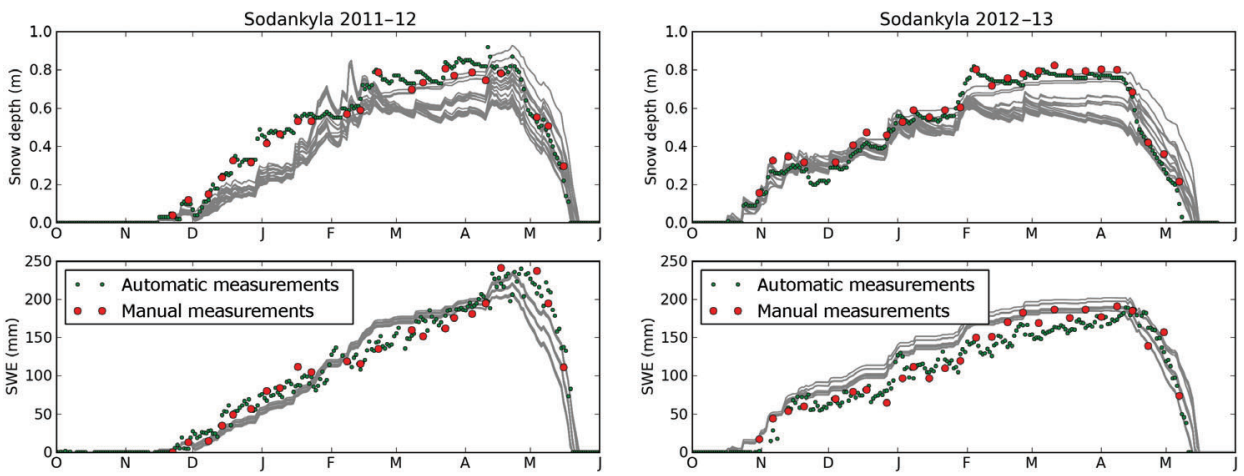

Figure 3. Snow depth and water equivalent simulated by the Jules Investigation Model subset used in this study. Grey lines indicate individual JIM subset member simulations. Note that erroneous positive SWE observation points have been removed at the end of the season when snow depth is zero, as this is a sensor artifact related to soil moisture changes.

spread in brightness temperature and are therefore important for the design of snow retrieval assimilation systems.

\section{Results}

Snow depth and SWE simulated by the JIM is shown in Fig. 3. There is a small difference between the automatic measurements and the manual field observations attributable to the spatial variability of the snow and difference in measurement location. Ultrasonic snow depth measurements were on average $12 \mathrm{~mm}$ deeper than the snow pit observations in 2011-2012 but were $29 \mathrm{~mm}$ shallower than snow pit measurements in 2012-2013. SWE measured automatically by the gamma ray sensor had a mean value of $3.6 \mathrm{~mm} \mathrm{SWE}$ greater than the pit observations in 2011-2012 but $5.9 \mathrm{~mm}$ less in 2012-2013.

Although the precipitation inputs were scaled due to known sensor undercatch problems, in 2011-2012 the SWE was underestimated until the end of January, then overestimated until the melt period. Compared with snow pit observations, the SWE bias prior to 1 February was $-14.2 \mathrm{~mm}$. Between 1 February and 31 March, the SWE bias was $19.1 \mathrm{~mm}$. From 1 April until the end of the season, the bias was $-24.5 \mathrm{~mm}$ water equivalent. In 2012-2013, simulated SWE was overestimated for most of the season, with a mean bias of $13.7 \mathrm{~mm}$ compared with the snow pit observation. Simulated SWE is relatively insensitive to the snow parameterisation in the accumulation period, but three distinct model groups emerge in the melt period, which are due to the three different representations of the liquid-water flow. The snowpack model parameterisations have a greater impact on the snow depth, which is to be expected as this is directly affected by the representation of densification and initial snow density.
Figure 4 demonstrates the impact of the snow model parameterisations on snow grain diameter growth, as simulated with the MOS, SNI, and SNT microstructure evolution functions. Each microstructure model results in a spread of bulk grain diameter due to the 63 snowpack parameterisations, but in general the difference between microstructure models is greater than the difference due to snowpack parameterisations. The simulation range is greatest at the start and at the end of the season, when the snowpacks can be subject to the largest temperature gradients or liquid-water dependent growth. In both years of simulation, the mid-season bulk grain diameter is smallest with MOS and largest with SNT. MOS and SNI are similar in magnitude, but SNT bulk grain diameters were approximately twice as large on average, with a mean ratio over the season of 1.9-2.2, as shown in Table 3. SNT bulk grain diameter was up to 3.2 times larger than MOS bulk grain diameter. Visual estimation of the snow grain diameter gave values that were always larger than all of the simulations. Measured SSA-derived bulk grain diameters generally lay in between the SNT simulations and the simulations with SNI and MOS. The mean absolute error and mean relative difference for these simulations are presented in Table 4. SNT had the lowest bias $(0.12 \mathrm{~mm})$ in 2011-2012, whereas SNI had the lowest bias $(-0.14 \mathrm{~mm})$ in $2012-2013$. Bulk grain diameter simulated by the microstructure models led to a mean difference of between -53 and $+45 \%$ relative to the observations.

Simulation of mean and range of brightness temperature from the three emission models driven by all snowpack and microstructure model combinations is shown in Fig. 5. Note that excessively low brightness temperatures on 1 November 2011 were excluded from this figure as the snowpack for some JIM members was extremely thin with an unphysically high snow density. In general, HUT with three representations of extinction coefficient showed the smallest range of 

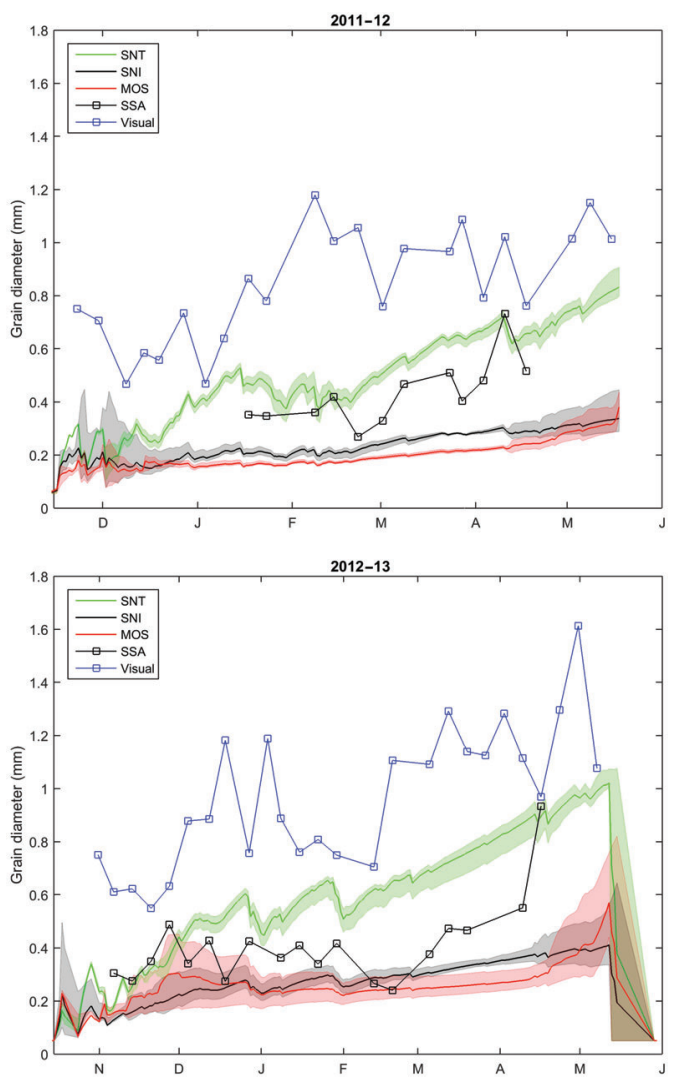

Figure 4. Bulk grain diameter evolution for the MOS, SNT, and SNI microstructure evolution models and the spread in model results. Observations of bulk diameter were derived from macrophotography (Visual) and from SSA measurements from the IceCube instrument.

Table 3. Comparison of grain diameters simulated by different microstructure models. The mean and max ratio between pairs of models is given in columns. Where the 2012-2013 values differ, these are given in parentheses.

\begin{tabular}{lll}
\hline & Mean & Max \\
\hline SNI / MOS & $1.2(1.1)$ & $1.4(1.3)$ \\
SNT / MOS & 2.2 & $3.1(3.2)$ \\
SNT / SNI & $1.9(2.0)$ & 2.5 \\
\hline
\end{tabular}

brightness temperature, whereas DMRT-ML (covering both very sticky and less sticky assumptions) had a much greater range, which was nearly as large as MEMLS (empirical representation and improved Born approximation with oblate grains). This is demonstrated by the ratio between the seasonal mean ranges of brightness temperature presented in Ta-
Table 4. Mean absolute error ( $\mathrm{mm}$ ) between bulk grain diameter simulated with the microstructure models compared with observations derived from SSA measurements with IceCube. Smallest bias for each year is shown in bold. Percentages are given in parentheses.

\begin{tabular}{lrr}
\hline & $2011-2012$ & $2012-2013$ \\
\hline MOS & $-0.24(-53 \%)$ & $-0.16(-34 \%)$ \\
SNI & $-0.18(-40 \%)$ & $-\mathbf{0 . 1 4}(-31 \%)$ \\
SNT & $\mathbf{0 . 1 2}(32 \%)$ & $0.16(45 \%)$ \\
\hline
\end{tabular}

Table 5. Ratio of mean brightness temperature ranges simulated by two microwave emission models. The mean and max ratio between pairs of models is given in columns.

\begin{tabular}{|c|c|c|c|c|}
\hline & $19 \mathrm{~V}$ & $19 \mathrm{H}$ & $37 \mathrm{~V}$ & $37 \mathrm{H}$ \\
\hline \multicolumn{5}{|c|}{ 2011-2012 } \\
\hline DMRTML/HUT & 1.6 & 1.2 & 3.8 & 3.1 \\
\hline MEMLS/HUT & 3.7 & 1.9 & 4.5 & 3.2 \\
\hline MEMLS/DMRTML & 2.4 & 1.5 & 1.2 & 1.0 \\
\hline \multicolumn{5}{|c|}{ 2012-2013 } \\
\hline DMRTML/HUT & 2.0 & 1.6 & 3.3 & 3.0 \\
\hline MEMLS/HUT & 3.9 & 2.4 & 3.9 & 3.2 \\
\hline MEMLS/DMRTML & 2.0 & 1.5 & 1.2 & 1.1 \\
\hline
\end{tabular}

ble 5, where the ranges compared with HUT had a ratio of greater than 1. MEMLS had a larger range than DMRT-ML, although at $37 \mathrm{GHz}$ the difference was small. As illustrated in Fig. 5, at $19 \mathrm{GHz}$, the mean of DMRT-ML simulations were highest and the mean of MEMLS simulations were generally lowest (with the exception of $19 \mathrm{H}$ in 2011-2012). At $37 \mathrm{GHz}$, horizontal and vertical polarisation, HUT gives the highest mean brightness temperature in both years, although the mean DMRT-ML brightness temperature is within $3 \mathrm{~K}$ of HUT at horizonal polarisation (both years). MEMLS mean brightness temperatures are the lowest at $37 \mathrm{GHz}$ at both horizontal and vertical polarisation in both years. All ranges exhibit a distinctive "wedge" shape, where the ranges generally increase throughout the season until the collapse of the range in the melt period.

Compared with the brightness temperature observations, no model gives a consistently better performance across both frequencies and both polarisations. This is illustrated in Table 6, where mean bias and root mean square error (RMSE) for each season has been presented for each frequency and polarisation combination. The lowest bias was less than $7 \mathrm{~K}$ in magnitude, whereas the lowest RMSE for each frequency/polarisation was less than $13 \mathrm{~K}$. For both years, DMRT-ML gave the lowest bias at $19 \mathrm{H}$ and MEMLS gave the lowest bias at $37 \mathrm{GHz}(\mathrm{V}$ and $\mathrm{H})$. At 19V DMRTML had the lowest bias in 2011-2012 whereas HUT had the lowest bias in 2012-2013. Figure 5 shows that the observed brightness temperature is generally within the range simu- 

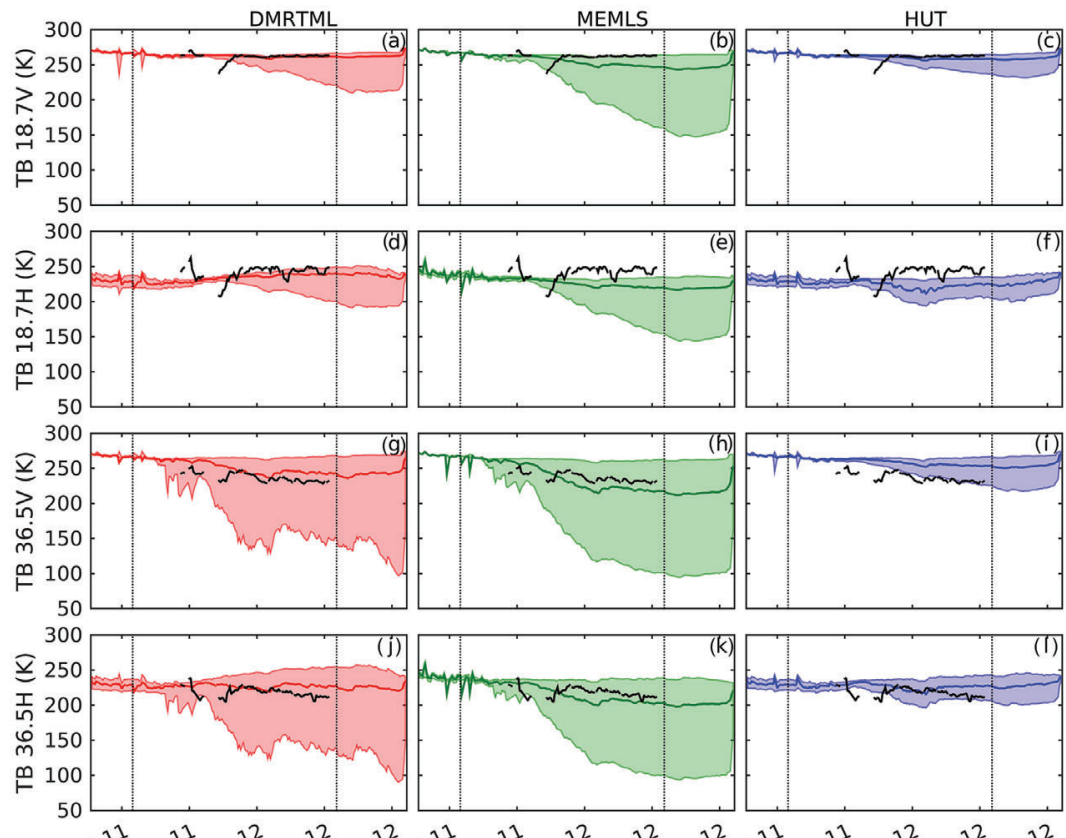

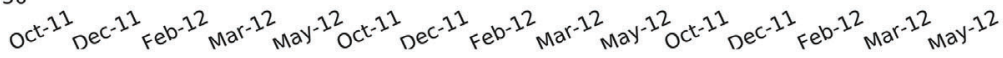
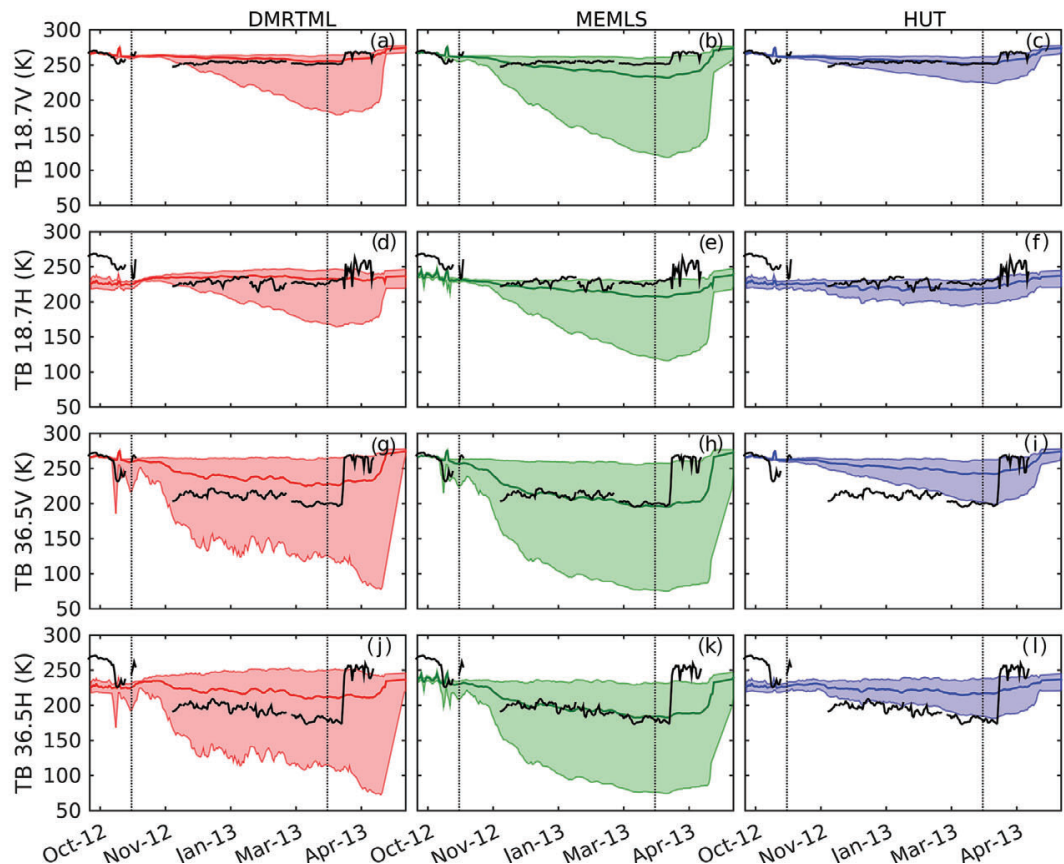

Figure 5. Range and mean of brightness temperature over the two winter seasons as simulated with the DMRT-ML, MEMLS, and HUT models, driven by $63 \mathrm{JIM}$ outputs and 3 microstructure evolution models. Black lines indicate the observed brightness temperatures. Vertical dashed lines enclose the period of analysis (1 November-31 March). 
Table 6. Mean bias and RMSE in brightness temperature (K) simulated by DMRT-ML (very sticky and less sticky), MEMLS (empirical and IBA oblate), and HUT (H87, R04, and K10) forced by 189 JIM-microstructure model combinations. Only days in the period from 1 November to $31 \mathrm{March}$, where all four frequency/polarisation measurements were available, were included in the analysis. Bold values indicate the lowest bias/RMSE for each frequency/polarisation.

\begin{tabular}{|c|c|c|c|c|c|}
\hline & & $19 \mathrm{~V}$ & $19 \mathrm{H}$ & $37 \mathrm{~V}$ & $37 \mathrm{H}$ \\
\hline \multicolumn{6}{|c|}{ 2011-2012 } \\
\hline \multirow{3}{*}{ Bias } & DMRTML & 0.7 & -5.4 & 10.4 & 8.7 \\
\hline & MEMLS & -7.8 & -16.3 & -6.9 & -6.2 \\
\hline & HUT & -1.3 & -18.8 & 20.6 & 7.6 \\
\hline \multirow{3}{*}{ RMSE } & DMRTML & 5.5 & 11.4 & 12.2 & 12.2 \\
\hline & MEMLS & 11.3 & 20.4 & 13.0 & 13.1 \\
\hline & HUT & 6.1 & 22.4 & 21.1 & 11.7 \\
\hline \multicolumn{6}{|c|}{ 2012-2013 } \\
\hline \multirow{3}{*}{ Bias } & DMRTML & 5.6 & 6.9 & 25.2 & 24.5 \\
\hline & MEMLS & -9.3 & -11.4 & -0.9 & 1.5 \\
\hline & HUT & 2.9 & -8.0 & 39.2 & 26.4 \\
\hline \multirow{3}{*}{ RMSE } & DMRTML & 6.4 & 9.8 & 26.2 & 27.0 \\
\hline & MEMLS & 11.4 & 13.2 & 7.0 & 7.0 \\
\hline & HUT & 4.2 & 9.8 & 40.2 & 28.9 \\
\hline
\end{tabular}

Table 7. Optimal microwave microstructure scale factors dependent on snow microstructure evolution function, based on minimisations of cost function between 1 November and 31 March in each year.

\begin{tabular}{|c|c|c|c|c|c|c|c|}
\hline & \multicolumn{2}{|c|}{ DMRTML } & \multicolumn{2}{|c|}{ MEMLS } & \multicolumn{3}{|c|}{ HUT } \\
\hline & less & very & IBA & EMP & H87 & R04 & K10 \\
\hline \multicolumn{8}{|c|}{ 2011-2012 } \\
\hline SNT & 1.1 & 0.6 & 0.5 & 0.3 & 0.9 & 0.5 & 0.7 \\
\hline MOS & 3.3 & 1.6 & 1.7 & 1.0 & 2.6 & 1.4 & 2.2 \\
\hline SNI & 2.5 & 1.3 & 1.2 & 0.8 & 1.9 & 1.1 & 1.7 \\
\hline \multicolumn{8}{|c|}{ 2012-2013 } \\
\hline SNT & 1.3 & 0.7 & 0.7 & 0.5 & 1.2 & 1.1 & 1.1 \\
\hline MOS & 3.1 & 1.7 & 1.6 & 1.1 & 3.2 & 2.7 & 2.9 \\
\hline SNI & 2.8 & 1.5 & 1.5 & 1.1 & 2.9 & 2.3 & 2.6 \\
\hline
\end{tabular}

A value of 1.0 indicates that the snow grain diameter simulated by a particular form of the snow model may be used directly in the microwave model to give the best agreement with measured brightness temperature.

lated by each of the three microwave emission models, with the exception of 19H in 2011-2012 (MEMLS and HUT) and 37H/V in 2012-2013 (HUT). End of season brightness temperature observations are not replicated in the simulations as the liquid-water content of the snowpack model is currently decoupled from the electromagnetic snow model, so the simulations only represent dry snow brightness temperature.
Table 8. Mean bias and RMSE in brightness temperature (K) simulated by DMRT-ML (sticky and non-sticky), MEMLS (empirical and IBA oblate), and HUT (H87, R04, and K10) forced by 189 JIM-microstructure model combinations, with optimal microstructure scale factors from Table 7 applied. Only days in the period from 1 November to 31 March, where all four frequency/polarisation measurements were available, were included in the analysis. Bold values indicate the lowest bias/RMSE for each frequency/polarisation.

\begin{tabular}{|c|c|c|c|c|c|}
\hline & & $19 \mathrm{~V}$ & $19 \mathrm{H}$ & $37 \mathrm{~V}$ & $37 \mathrm{H}$ \\
\hline \multicolumn{6}{|c|}{$2011-2012$} \\
\hline \multirow{3}{*}{ Bias } & DMRTML & 1.0 & -5.1 & 6.6 & 5.6 \\
\hline & MEMLS & -0.3 & -11.3 & 13.1 & 10.5 \\
\hline & HUT & -1.3 & -18.8 & 19.1 & 6.2 \\
\hline \multirow{3}{*}{ RMSE } & DMRTML & 5.6 & 11.2 & 9.3 & 9.5 \\
\hline & MEMLS & 5.7 & 15.5 & 14.0 & 12.7 \\
\hline & HUT & 6.1 & 22.4 & 19.5 & 10.7 \\
\hline \multicolumn{6}{|c|}{$2012-2013$} \\
\hline \multirow{3}{*}{ Bias } & DMRTML & 3.7 & 5.6 & -0.3 & 1.4 \\
\hline & MEMLS & -1.2 & -5.1 & 6.0 & 9.1 \\
\hline & HUT & -4.4 & -14.3 & 18.0 & 7.5 \\
\hline \multirow{3}{*}{ RMSE } & DMRTML & 4.7 & 8.8 & 5.2 & 7.5 \\
\hline & MEMLS & 3.9 & 7.6 & 9.3 & 11.7 \\
\hline & HUT & 6.2 & 15.4 & 19.8 & 11.2 \\
\hline
\end{tabular}

Table 7 indicates scaling factors that would need to be applied to the grain diameter in order to allow a particular microstructure evolution function to minimise the $\mathrm{CF}$ given in Eq. (16), i.e. the best agreement with observed brightness temperature for all four frequency and polarisation combinations. A scale factor of 1 suggests a perfect fit between snowpack microstructure and microwave microstructure. A scale factor of less than 1 indicates a snowpack grain diameter overestimate, whereas a scale factor of greater than 1 is an underestimate. For SNT microstructure, a scale factor of less than 1 was required in 2011-2012 for all emission models with the exception of the less sticky $(\tau=0.2)$ application of DMRT-ML. This indicates that the SNT microstructure resulted in grain diameters larger than that required by the emission models for that year. In 2012-2013 SNT microstructure required slight scaling to increase the grain diameter for HUT and for less sticky DMRT-ML, but downscaling for very sticky hard spheres in DMRT-ML and for MEMLS. With the exception of the application to empirical MEMLS in 2011-2012, the SNI and MOS grain diameters were too small and required scaling upwards. A CF minimum was achieved for empirical MEMLS driven by MOS microstructure with no scaling whatsoever in 2011-2012. The pattern is consistent between years, with the greatest interannual difference in scale factor for HUT. 


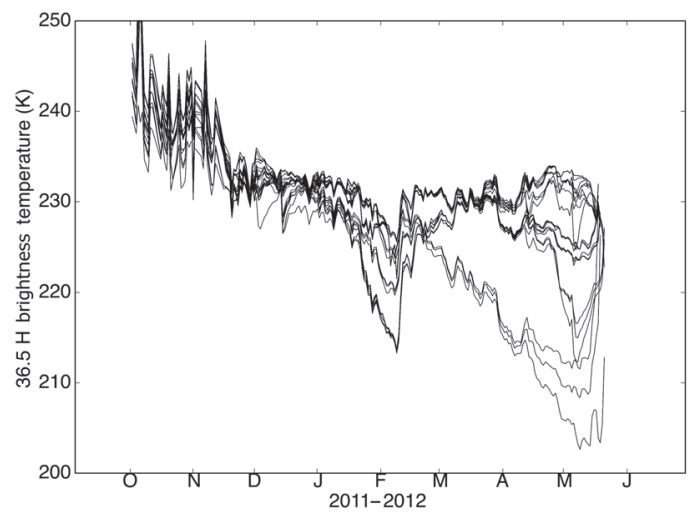

Figure 6. Variability in brightness temperature simulated with empirical MEMLS, driven by the MOSES microstructure model and 63 JIM snowpack outputs (no scaling of microstructure was required).

Once the microstructure differences have been isolated through application of the optimal scale factor, as shown in Table 8, DMRT-ML bias and RMSE improved, with the exception of the small increase in $19 \mathrm{~V}$ bias in 20112012. For MEMLS, improvements in bias and RMSE at the lower frequency were at the expense of the higher frequency in both years. The opposite occurred for HUT in 20122013, whereas in 2011-2012 the bias and RMSE decreased at all frequencies and polarisations apart from a marginal $(<0.04 \mathrm{~K})$ increase in RMSE at $19 \mathrm{~V}$.

Differences in brightness temperature also exist in the simulations due to the snowpack parameterisation (i.e. $63 \mathrm{JIM}$ combinations). Empirical MEMLS with MOS microstructure in the 2011-2012 season was chosen as a test case to illustrate the effects of snowpack parameterisation on the brightness temperature because of the equivalence of snowpack and emission model microstructure (no scaling required). This subset of 63 simulations for $37 \mathrm{H}$ brightness temperature in 2011-2012 is shown in Fig. 6. There is a seasonal dependence in the range, with model divergence from mid-January onwards. 1 February and 1 May were chosen for cluster analysis to determine which parameterisations caused the split in simulations, as shown in Fig. 7.

Clear groupings of simulations in Fig. 7, upper left, indicate that the snowpack densification parameterisation has a distinguishable effect on the simulation of brightness temperature. A physical representation of densification (parameterization $=0$ ) gave the lowest brightness temperatures on the 1 February, but the highest by 1 May. In contrast, where no compaction is simulated, i.e. snow density is constant throughout the season (parameterization $=2$ ), the opposite is true. An empirical representation of densification (parameterization $=1$ ) results in brightness temperatures generally between those of the physical, and of no densification. Ther- mal conductivity has no effect on the simulation of brightness temperature, whereas subtle differences are attributable to the fresh snow density value and to the representation of snow hydrology. There is no discernible difference between fresh snow density parameterisation schemes 0 and 1 , whereas 2 gives a different set of brightness temperatures. Snow hydrology has very little effect in the early season but can lead to differences in the melt period. Overall, the snowpack parameterisations with MOSES microstructure and empirical MEMLS lead to a mean difference in the $36.5 \mathrm{GHz}$ brightness temperature of $11 \mathrm{~K}$ at $\mathrm{H}$-pol and $18 \mathrm{~K}$ at V-pol. The maximum difference in $36.5 \mathrm{GHz}$ brightness temperature was $33 \mathrm{~K}$ at $\mathrm{H}$-pol and $54 \mathrm{~K}$ at V-pol for the 2011-2012 season. The maximum difference between $\mathrm{H}$ and $\mathrm{V}$ polarisation for all unscaled microstructure-electromagnetic model combinations is demonstrated in Table 9. Large differences in the maximum brightness temperature difference as a result of the 63 snowpack configurations occurred for the SNT microstructure. Except for DMRT-ML less sticky and HUT with MOS or SNI microstructure, the V-pol difference is greater than the H-pol difference.

\section{Discussion}

The biggest difference to obtaining accurate simulations would be made by improving the microstructure evolution models within snowpack models because the optimal scale factors are generally larger between microstructure models than between emission models. SNTHERM grains tend to be too large for the emission models and generally require scaling down to smaller values. SNICAR grains are in the mid-range and require a small amount of scaling, generally upwards to larger grains. MOSES grains are the smallest and generally require higher scale factors than SNICAR. These patterns are consistent, regardless of the electromagnetic radiative transfer model used. Differences between microstructure evolution models are so large because they were developed in models with different purposes. MOSES is a large-scale land surface model, requiring snow grain size for albedo calculations (Essery et al., 2001). SNICAR is a snow albedo model (Flanner and Zender, 2006). SNTHERM, in contrast, was developed to predict surface temperature and uses grain diameter in the simulation of liquid-water flow as well as albedo (Jordan, 1991). SNICAR and MOSES grain sizes are closer to the SSA-derived grain diameter as a result. SNTHERM simulates a grain size that is closer in concept to the visual estimates of grain diameter than the other two models. The large spread when coupling snowpack evolution and microwave models, due to the differences in the modelling of snow microstructure, is consistent with the wide range of studies that have investigated how to link snowpack observations of microstructure to the microstructure parameter required in electromagnetic models (e.g Kendra et al., 1998; Du et al., 2005; Tedesco et al., 2006; Liang et al., 2008; 

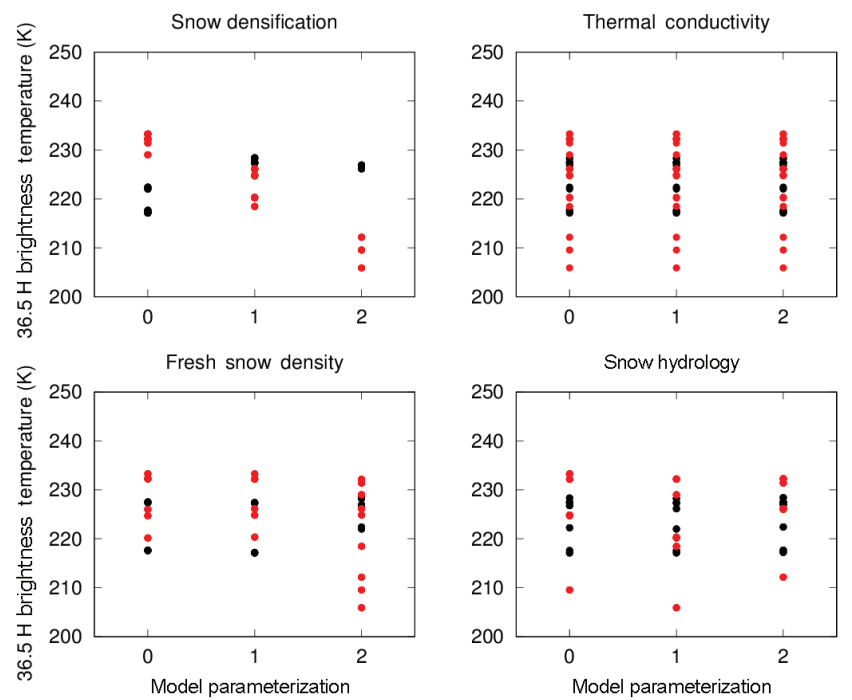

Figure 7. Cluster analysis of brightness temperature simulated by MOSES microstructure and empirical MEMLS for 1 February 2012 (black dots) and 1 May 2012 (red dots) according to model parameterization choices. Brightness temperature simulations are split according to the different representations for each process representation. Values 0, 1, 2 relate to parameterisations given in Essery et al. (2013) and as described in Sect. 2.1. Where distinct clusters occur that differ between parameterisations, this indicates sensitivity to the parameterization.

Table 9. Maximum difference in brightness temperature in $\mathrm{K}(\mathrm{H}-\mathrm{pol} / \mathrm{V}-\mathrm{pol})$ due to 63 snowpack parameterisations for each unscaled snow microstructure evolution function (2011-2012 season).

\begin{tabular}{|c|c|c|c|c|c|c|c|}
\hline & \multicolumn{2}{|c|}{ DMRTML } & \multicolumn{2}{|c|}{ MEMLS } & \multicolumn{3}{|c|}{ HUT } \\
\hline & less & very & IBA & EMP & H87 & R04 & K10 \\
\hline SNT & $50 / 63$ & $148 / 169$ & $88 / 113$ & $126 / 153$ & $27 / 34$ & $26 / 33$ & $28 / 36$ \\
\hline MOS & $22 / 15$ & $41 / 45$ & $24 / 25$ & $33 / 54$ & $20 / 9$ & $21 / 14$ & $20 / 11$ \\
\hline SNI & $22 / 15$ & $59 / 67$ & $24 / 43$ & $55 / 77$ & $20 / 13$ & $21 / 18$ & $20 / 15$ \\
\hline
\end{tabular}

Durand et al., 2008; Brucker et al., 2011; Xu et al., 2012; Montpetit et al., 2013; Roy et al., 2013; Rutter et al., 2014; Picard et al., 2014).

Nevertheless there are differences between microwave emission models for a particular microstructure evolution model and even differences within the same family of emission models. "Improvement" in the microstructure for a particular model combination may lead to less accurate simulations at some frequencies and polarisations, which highlights that there is more to understand. In part, this may be due to the methodology of this study as the CF is calculated per microstructure-electromagnetic model configuration, yet the bias and RMSE are presented for each electromagnetic model family. An individual contribution can influence the group in a non-intuitive way.

Here, the lowest bias and RMSE for unscaled microstructure simulations were -6.9 to $+6.9 \mathrm{~K}$ and 4.2 to $12.2 \mathrm{~K}$, respectively, but depended on microwave model, frequency, and polarisation. In an attempt to put these results into context, there are a number of studies that have quantified brightness temperature simulation errors for these models. These fall into different categories, depending on sensor characteristics, the source of the evaluation data (ground-based, airborne, satellite) and presence of ice lenses (Derksen et al., 2012), the treatment of the snow microstructure (Picard et al., 2014), snow type, observation angle, and the specific electromagnetic model (Tedesco and Kim, 2006), and the underlying substrate (Lemmetyinen et al., 2009; Derksen et al., 2014). Examples of unscaled field observations of microstructure compared with ground-based observations include the HUT simulations of Derksen et al. (2012), who found an RMSE of 10-34 K, and Rutter et al. (2014), who found a bias of $34-68 \mathrm{~K}$ that was reduced to $<0.6 \mathrm{~K}$ upon application of grain scale factors of 2.6-5.3. Scaling, or best-fit, relationships were used by Durand et al. (2008) (mean absolute error 3.1 K at V-pol and 9.3 K at H-pol), Montpetit et al. 
(2013) (RMSE 8-20 K), Brucker et al. (2011) (RMSE 1.5 K), Picard et al. (2014) (RMSE 1-11 K), and Roy et al. (2013) (RMSE 12-16 K). However, in some cases the frequencydependent results have been combined and in others kept separate.

For DMRT-ML, consideration of the stickiness is imperative. Two constant values were considered here: extremely cohesive or less sticky particles. Löwe and Picard (2015) have made progress in understanding stickiness from microCT data. There are theoretical limits, based on snow density (Löwe and Picard, 2015, Eqs. 35-36), but in general stickiness is independent of diameter and of density and a constant value should not be used, as was done here. Further research is needed in this regard.

For the HUT radiative transfer model, the optimum combinations of snowpack and microwave model are dependent on both models and, therefore, the end application. The SNT microstructure is most closely matched to the microstructure of the Hallikainen et al. (1987) extinction model. Both were developed with a similar concept of microstructure. With MOS or SNI microstructure, Roy et al. (2004) would be most appropriate. Kontu and Pulliainen (2010) is more broadly applicable as the scale factor always lies between R04 and H87, regardless of the microstructure model. Therefore K10 may be better choice if a range of microstructure models is considered in a data assimilation retrieval scheme but with only one observation operator.

In the case of MEMLS, there are some differences between the empirical model and IBA, but the microstructure model really matters. IBA is a more appropriate model for the larger SNT grains and endorses the recommendation of Mätzler and Wiesmann (1999) for IBA in the simulation of larger grains. The microstructural concept of MOS matches the microstructure of empirical MEMLS very well, with no scaling required in 2011-2012, although SNI is equally appropriate in 2012-2013.

There is little variation between years for the DMRT-ML (sticky) and MEMLS models, and a consistent pattern for HUT. Other studies have investigated the microstructural link between snowpack and microwave models. Wiesmann et al. (2000) found that the scale factor between exponential correlation length in MEMLS and grain diameter in SNTHERM for the Weissfluhjoch site in Davos, Switzerland, was 0.16. Applying Eq. (15) for snow of density $250 \mathrm{~kg} \mathrm{~m}^{-3}$, the scale factor to relate the grain diameter of SNTHERM to the exponential length in MEMLS for the Sodankylä site would be 0.24 for IBA and 0.15 for empirical MEMLS for the 20112012 data set. This is entirely consistent with the Wiesmann et al. (2000) study, in spite of the different locations and snowpack conditions.

Wiesmann et al. (2000) also reported a relationship for Crocus simulations, as did Brucker et al. (2011). At this stage it is not possible to make comparisons of this work with those studies because the Crocus evolution model has not been included in this study due to the difficulty of ap- plying these models to the Eulerian frame snowpack model scheme used here. These two studies are, however, consistent with each other. Wiesmann et al. (2000) found a snow-typedependent scale factor of 0.3-0.4 between MEMLS correlation length and Crocus grain diameter, whereas the range in Brucker et al. (2011) was $0.4-0.25$ for snow density between 100 and $400 \mathrm{~kg} \mathrm{~m}^{-3}$. The scaling factor between the SNOWPACK-derived correlation length and the correlation length of MEMLS was found to be 0.1 (Langlois et al., 2012) but, again, a comparison with this work is not possible as the SNOWPACK grain evolution model has similar requirements to the Crocus microstructure model as they have a common origin.

When isolating the spread in brightness temperature due to snowpack parameterisations, this spread is largely due to the snowpack model representation of the densification process, with a variable impact throughout the season. After the microstructure model, snow compaction must be considered carefully in the design of a coupled snowpack-microwave model. Liquid-water flow representation in the snowpack model may become important in the melt period, particularly for a snowpack with mid-winter melt periods or if the snowpack model is used to provide information on SWE during melt when microwave observations cannot. If fresh snow is assumed to have a constant density in a retrieval or assimilation system then that value will have an impact but is less important than compaction. Thermal conductivity has no discernable impact on the brightness temperature simulations so the choice of its representation is largely irrelevant for snow mass retrieval and assimilation systems.

Although empirical MEMLS driven by MOSES was chosen as an example to demonstrate the impact of parameterisations, this was purely because of the apparent consistency between the MOSES grain diameter converted to exponential correlation length and MEMLS simulations for 2011-2012 at this site. This is not a general endorsement of empirical models, as those based on physics are expected to be more universally applicable, but the specific application of these models will dictate the balance of accuracy versus simplicity. Extending the analysis beyond this example, snow parameterisations affect other unscaled model combinations to varying degrees. Microstructure scaling factors in Table 7 can be used as a proxy for the degree of scattering in the unscaled simulations. A higher scale factor acts to increase the simulated scattering, so for a scale factor $<1$ too much scattering occurs in the unscaled simulations. Snowpack parameterisations have a greater impact for a higher degree of scattering, larger at V-pol than H-pol. This is because scattering is already greater at $\mathrm{H}$-pol so the spread in $\mathrm{H}$-pol simulations as a result of snowpack parameterisations is suppressed by the existing level of scattering. The converse applies for high scaling factors (e.g. MOS with less sticky DMRT-ML).

Although the differences in scale factors between microstructure models are larger than the differences in scale factors between microwave models, this does not negate the 
need for developments in the microwave models. This is highlighted by the treatment of field observations of SSA to derive optical diameter as even these require some form of scaling (e.g. Montpetit et al., 2013; Picard et al., 2014; Rutter et al., 2014). Use of scale factors can improve brightness temperature accuracy at some frequency and polarisations but may decrease the accuracy at others. The necessity of scale factors indicate the need for a deeper understanding in the role of microstructure in the microwave models. Much of this is discussed from a theoretical perspective by Löwe and Picard (2015). With a sticky hard sphere model of the microstructure, even if the stickiness is known, Löwe and Picard (2015) showed that a scale factor to relate the measured optical diameter to microwave diameter depends on the type of metamorphism the snow has been subjected to. Indeed, here, constant scale factors have been applied with no attempt to assess how these may change over the season. They do not account for the anisotropic nature of the snow, which adds to the complexity both in the modelling of the snowpack (Löwe et al., 2013) and in microwave scattering (Leinss et al., 2016). Some of the fundamental questions on how to relate snowpack and microwave microstructure may be addressed with a better microstructure descriptor of the snowpack rather than a single length scale and would benefit from easy interchangeability between different microwave models and different snowpack evolution models. Ultimately a consistent microstructural treatment will be needed in both snowpack evolution and microwave models.

\section{Conclusions}

Future snow mass and depth retrievals systems may rely on snowpack models to provide snow microstructural parameters. To improve accuracy in seasonal simulations of brightness temperature, the largest gains will be achieved by improving the microstructural representation within snowpack models, followed by improvements in the emission models to use accurate microstructural information and reduce bias and RMSE at all frequencies and polarisations simultaneously. For the design of retrieval systems with current capabilities, particular model combinations may be more suitable than others, and careful consideration must be given to snow compaction processes. Snow process representation becomes increasingly important as the snowpack scatters more. The future lies in a better and consistent treatment of snow microstructure in both snowpack and emission model developments.

\section{Code availability}

Code to analyse the data is available on GitHub: https:// github.com/mjsandells/TC_Sandells_2017.

\section{Data availability}

Data are available at the repository doi:10.6084/m9.figshare.4552822 (Sandells et al., 2017). These include JIM outputs, the non-scaled grain diameter and optimal grain diameter brightness temperature simulations, and observations of brightness temperature and grain size. The full brightness temperature data set (all scaling factors) is too large to place in a repository but can be made available upon request.

Competing interests. The authors declare that they have no conflict of interest.

Acknowledgements. This work was funded in part by the NERC National Centre for Earth Observation, and supported by the European Space Agency projects "Technical assistance for the deployment of an X- to Ku-band scatterometer during the NoSREx experiment" (ESA ESTEC contract 22671/09/NL/JA/ef) and "Microstructural origin of electromagnetic signatures in microwave remote sensing of snow" (ESA ESTEC contract 4000112698/14/NL/LvH). We thank the staff of FMI Arctic Research Centre in Sodankylä for performing the in situ measurements. We thank G. Picard and an anonymous reviewer for their comments to improve this paper.

Edited by: M. Tedesco

Reviewed by: G. Picard and one anonymous referee

\section{References}

Andreadis, K. M. and Lettenmaier, D. P.: Assimilating remotely sensed snow observations into a macroscale hydrology model, Adv. Water Resour., 29, 872-886, doi:10.1016/j.advwatres.2005.08.004, 2006.

Andreadis, K. M. and Lettenmaier, D. P.: Implications of Representing Snowpack Stratigraphy for the Assimilation of Passive Microwave Satellite Observations, J. Hydrometeorol., 13, 14931506, doi:10.1175/JHM-D-11-056.1, 2012.

Boyarskii, D. and Tikhonov, V.: The Influence of Stratigraphy On Microwave Radiation From Natural Snow Cover, J. Electromagnet. Wave., 14, 1265-1285, doi:10.1163/156939300X01201, 2000.

Brown, R., Derksen, C., and Wang, L.: A multi-data set analysis of variability and change in Arctic spring snow cover extent, 1967-2008, J. Geophys. Res., 115, D16111, doi:10.1029/2010JD013975, 2010.

Brown, R. D. and Robinson, D. A.: Northern Hemisphere spring snow cover variability and change over 1922-2010 including an assessment of uncertainty, The Cryosphere, 5, 219-229, doi:10.5194/tc-5-219-2011, 2011.

Brucker, L., Royer, A., Picard, G., Langlois, A., and Fily, M.: Hourly simulations of the microwave brightness temperature of seasonal snow in Quebec, Canada, using a coupled snow evolution-emission model, Remote Sens. Environ., 115, 19661977, doi:10.1016/j.rse.2011.03.019, 2011. 
Brun, E., David, P., Sudul, M., and Brunot, G.: A numerical model to simulate snow-cover stratigraphy for operational avalanche forecasting, J. Glaciol., 38, 13-22, 1992.

Chang, A. T. C., Gloersen, P., Schmugge, T., Wilheit, T. T., and Zwally, H. J.: Microwave emission from snow and glacier ice, J. Glaciol., 16, 23-39, 1976.

Chang, A. T. C., Foster, J. L., and Hall, D. K.: Nimbus-7 SMMR Derived Global Snow Cover Parameters, Ann. Glaciol., 9, 3944, 1987.

Clifford, D.: Global estimates of snow water equivalent from passive microwave instruments: history, challenges and future developments, Int. J. Remote Sens., 31, 3707-3726, doi:10.1080/01431161.2010.483482, 2010.

Davenport, I., Sandells, M., and Gurney, R.: The effects of variation in snow properties on passive microwave snow mass estimation, Remote Sens. Environ., 118, 168-175, doi:10.1016/j.rse.2011.11.014, 2012.

Derksen, C. and Brown, R.: Spring snow cover extent reductions in the 2008-2012 period exceeding climate model projections, Geophys. Res. Lett., 39, L19504, doi:10.1029/2012GL053387, 2012.

Derksen, C., Toose, P., Lemmetyinen, J., Pulliainen, J., Langlois, A., Rutter, N., and Fuller, M.: Evaluation of passive microwave brightness temperature simulations and snow water equivalent retrievals through a winter season, Remote Sens. Environ., 117, 236-248, doi:10.1016/j.rse.2011.09.021, 2012.

Derksen, C., Lemmetyinen, J., Toose, P., Silis, A., Pulliainen, J., and Sturm, M.: Physical properties of Arctic versus subarctic snow: Implications for high latitude passive microwave snow water equivalent retrievals, J. Geophys. Res.-Atmos., 119, 72547270, doi:10.1002/2013JD021264, 2014.

Du, J., Shi, J., and Wu, S.: A comparison of a second-order snow model with field observations, in: Geoscience and Remote Sensing Symposium, 2005, IGARSS '05, Proceedings, 2005 IEEE International, 4, p. 2649, 2005.

Durand, M., Kim, E., and Margulis, S.: Quantifying Uncertainty in Modeling Snow Microwave Radiance for a Mountain Snowpack at the Point-Scale, Including Stratigraphic Effects, IEEE T. Geosci. Remote, 46, 1753-1767, doi:10.1109/TGRS.2008.916221, 2008.

Eom, H. J., Lee, K. K., and Fung, A. K.: Microwave emission from an irregular snow layer, Remote Sens. Environ. 13, 423-437, doi:10.1016/0034-4257(83)90011-1, 1983.

Essery, R.: A factorial snowpack model (FSM 1.0), Geosci. Model Dev., 8, 3867-3876, doi:10.5194/gmd-8-3867-2015, 2015.

Essery, R., Best, M., and Cox, P.: MOSES 2.2 Technical Documentation, Tech. rep., Hadley Centre, Met Office, UK, Hadley Centre technical note 30, 31 pp., 2001.

Essery, R., Morin, S., Lejeune, Y., and Ménard, C. B.: A comparison of 1701 snow models using observations from an alpine site, Adv. Water Res., 55, 131-148, 2013.

Essery, R., Kontu, A., Lemmetyinen, J., Dumont, M., and Ménard, C. B.: A 7-year dataset for driving and evaluating snow models at an Arctic site (Sodankylä, Finland), Geosci. Instrum. Method. Data Syst., 5, 219-227, doi:10.5194/gi-5-219-2016, 2016.

Flanner, M. G. and Zender, C. S.: Linking snowpack microphysics and albedo evolution, J. Geophys. Res., 111, D12208, doi:10.1029/2005JD006834, 2006.
Grody, N.: Relationship between snow parameters and microwave satellite measurements: Theory compared with Advanced Microwave Sounding Unit observations from 23 to $150 \mathrm{GHz}$, J. Geophys. Res., 113, D22108, doi:10.1029/2007JD009685, 2008.

Hallikainen, M., Ulaby, F., and Van Deventer, T.: Extinction Behavior of Dry Snow in the 18-to 90- GHz Range, IEEE T. Geosci. Remote, GE-25, 737-745, doi:10.1109/TGRS.1987.289743, 1987.

Hancock, S., Baxter, R., Evans, J., and Huntley, B.: Evaluating global snow water equivalent products for testing land surface models, Remote Sens. Environ., 128, 107-117, 2013.

Jin, Y.-Q.: Simulation of a multi-layer model of dense scatterers for anomalous scattering signatures from SSM/I snow data, Int. J. Remote Sens., 18, 2531-2538, doi:10.1080/014311697217459, 1997.

Jordan, R.: A One-Dimensional Temperature Model for a Snow Cover: Technical Documentation for SNTHERM.89, Cold Regions Research and Engineering Laboratory (U.S.), Engineer Research and Development Center (U.S.), Special Report 91-16, 1991.

Kelly, R.: The AMSR-E Snow Depth Algorithm: Description and Initial Results, Journal of The Remote Sensing Society of Japan, 29, 307-317, doi:10.11440/rssj.29.307, 2009.

Kendra, J., Sarabandi, K., and Ulaby, F.: Radar measurements of snow: experiment and analysis, IEEE T. Geosci. Remote, 36, 864-879, doi:10.1109/36.673679, 1998.

Kontu, A. and Pulliainen, J.: Simulation of Spaceborne Microwave Radiometer Measurements of Snow Cover Using In Situ Data and Brightness Temperature Modeling, IEEE T. Geosci. Remote, 48, 1031-1044, doi:10.1109/TGRS.2009.2030499, 2010.

Langlois, A., Royer, A., Derksen, C., Montpetit, B., Dupont, F., and Goïta, K.: Coupling the snow thermodynamic model SNOWPACK with the microwave emission model of layered snowpacks for subarctic and arctic snow water equivalent retrievals, Water Resour. Res., 48, W12524, doi:10.1029/2012WR012133, 2012.

Lehning, M., Bartelt, P., Brown, B., Fierz, C., and Satyawali, P.: A physical SNOWPACK model for the Swiss avalanche warning: Part II. Snow microstructure, Cold Reg. Sci. Technol., 35, 147167, doi:10.1016/S0165-232X(02)00073-3, 2002.

Leinss, S., Löwe, H., Proksch, M., Lemmetyinen, J., Wiesmann, A., and Hajnsek, I.: Anisotropy of seasonal snow measured by polarimetric phase differences in radar time series, The Cryosphere, 10, 1771-1797, doi:10.5194/tc-10-1771-2016, 2016.

Lemmetyinen, J., Derksen, C., Pulliainen, J., Strapp, W., Toose, P., Walker, A., Tauriainen, S., Pihlflyckt, J., Kärnä, J., and Hallikainen, M.: A Comparison of Airborne Microwave Brightness Temperatures and Snowpack Properties Across the Boreal Forests of Finland and Western Canada, IEEE T. Geosci. Remote, 47, 965-978, doi:10.1109/TGRS.2008.2006358, 2009.

Lemmetyinen, J., Pulliainen, J., Rees, A., Kontu, A., Qiu, Y., and Derksen, C.: Multiple-Layer Adaptation of HUT Snow Emission Model: Comparison With Experimental Data, IEEE T. Geosci. Remote, 48, 2781-2794, doi:10.1109/TGRS.2010.2041357, 2010.

Lemmetyinen, J., Derksen, C., Toose, P., Proksch, M., Pulliainen, J., Kontu, A., Rautiainen, K., Seppänen, J., and Hallikainen, M.: Simulating seasonally and spatially varying snow cover brightness temperature using HUT snow emission model and retrieval of a microwave effective grain size, Remote Sens. Environ. 156, 71-95, doi:10.1016/j.rse.2014.09.016, 2015. 
Lemmetyinen, J., Kontu, A., Pulliainen, J., Vehviläinen, J., Rautiainen, K., Wiesmann, A., Mätzler, C., Werner, C., Rott, H., Nagler, T., Schneebeli, M., Proksch, M., Schüttemeyer, D., Kern, M., and Davidson, M. W. J.: Nordic Snow Radar Experiment, Geosci. Instrum. Method. Data Syst., 5, 403-415, doi:10.5194/gi-5-403-2016, 2016.

Leppänen, L., Kontu, A., Hannula, H.-R., Sjöblom, H., and Pulliainen, J.: Sodankylä manual snow survey program, Geosci. Instrum. Method. Data Syst., 5, 163-179, doi:10.5194/gi-5-1632016, 2016.

Liang, D., Xu, X., Tsang, L., Andreadis, K., and Josberger, E.: The Effects of Layers in Dry Snow on Its Passive Microwave Emissions Using Dense Media Radiative Transfer Theory Based on the Quasicrystalline Approximation (QCA/DMRT), IEEE T. Geosci. Remote, 46, 3663-3671, doi:10.1109/TGRS.2008.922143, 2008.

Löwe, H. and Picard, G.: Microwave scattering coefficient of snow in MEMLS and DMRT-ML revisited: the relevance of sticky hard spheres and tomography-based estimates of stickiness, The Cryosphere, 9, 2101-2117, doi:10.5194/tc-9-2101-2015, 2015.

Löwe, H., Riche, F., and Schneebeli, M.: A general treatment of snow microstructure exemplified by an improved relation for thermal conductivity, The Cryosphere, 7, 1473-1480, doi:10.5194/tc-7-1473-2013, 2013.

Mätzler, C.: Improved Born approximation for scattering of radiation in a granular medium, J. Appl. Phys., 83, 6111-6117, doi:10.1063/1.367496, 1998.

Mätzler, C.: Relation between grain-size and correlation length of snow, J. Glaciol., 48, 461-466, doi:10.3189/172756502781831287, 2002.

Mätzler, C. and Wiesmann, A.: Extension of the Microwave Emission Model of Layered Snowpacks to Coarse-Grained Snow, Remote Sens. Environ., 70, 317-325, doi:10.1016/S00344257(99)00047-4, 1999.

Montpetit, B., Royer, A., Langlois, A., Cliche, P., Roy, A., Champollion, N., Picard, G., Domine, F., and Obbard, R.: New shortwave infrared albedo measurements for snow specific surface area retrieval, J. Glaciol., 58, 941-952, doi:10.3189/2012JoG11J248, 2012.

Montpetit, B., Royer, A., Roy, A., Langlois, A., and Derksen, C.: Snow Microwave Emission Modeling of Ice Lenses Within a Snowpack Using the Microwave Emission Model for Layered Snowpacks, IEEE T. Geosci. Remote, 51, 4705-4717, doi:10.1109/TGRS.2013.2250509, 2013.

Pan, J., Durand, M., Sandells, M., Lemmetyinen, J., Kim, E., Pulliainen, J., Kontu, A., and Derksen, C.: Differences Between the HUT Snow Emission Model and MEMLS and Their Effects on Brightness Temperature Simulation, IEEE T. Geosci. Remote, 54, 2001-2019, doi:10.1109/TGRS.2015.2493505, 2015.

Picard, G., Brucker, L., Fily, M., Gallée, H., and Krinner, G.: Modeling time series of microwave brightness temperature in Antarctica, J. Glaciol., 55, 537-551, doi:10.3189/002214309788816678, 2009.

Picard, G., Brucker, L., Roy, A., Dupont, F., Fily, M., Royer, A., and Harlow, C.: Simulation of the microwave emission of multilayered snowpacks using the Dense Media Radiative transfer theory: the DMRT-ML model, Geosci. Model Dev., 6, 1061-1078, doi:10.5194/gmd-6-1061-2013, 2013.
Picard, G., Royer, A., Arnaud, L., and Fily, M.: Influence of meter-scale wind-formed features on the variability of the microwave brightness temperature around Dome $\mathrm{C}$ in Antarctica, The Cryosphere, 8, 1105-1119, doi:10.5194/tc-8-1105-2014, 2014.

Pulliainen, J., Grandell, J., and Hallikainen, M.: HUT snow emission model and its applicability to snow water equivalent retrieval, IEEE T. Geosci. Remote, 37, 1378-1390, doi:10.1109/36.763302, 1999.

Rosenfeld, S. and Grody, N.: Anomalous microwave spectra of snow cover observed from Special Sensor Microwave/Imager measurements, J. Geophys. Res., 105, 1491314925, doi:10.1029/1999JD900486, 2000.

Roy, A., Picard, G., Royer, A., Montpetit, B., Dupont, F., Langlois, A., Derksen, C., and Champollion, N.: Brightness Temperature Simulations of the Canadian Seasonal Snowpack Driven by Measurements of the Snow Specific Surface Area, IEEE T. Geosci. Remote, 51, 4692-4704, doi:10.1109/TGRS.2012.2235842, 2013.

Roy, V., Goita, K., Royer, R., Walker, A., and Goodison, B.: Snow water equivalent retrieval in a Canadian boreal environment from microwave measurements using the HUT snow emission model, IEEE T. Geosci. Remote, 42, 1850-1859, doi:10.1109/TGRS.2004.832245, 2004.

Rutter, N., Essery, R., Pomeroy, J., Altimir, N., Andreadis, K., Baker, I., Barr, A., Bartlett, P., Boone, A., Deng, H., Douville, H., Dutra, E., Elder, K., Ellis, C., Feng, X., Gelfan, A., Goodbody, A., Gusev, Y., Gustafsson, D., Hellström, R., Hirabayashi, Y., Hirota, T., Jonas, T., Koren, V., Kuragina, A., Lettenmaier, D., Li, W.-P., Luce, C., Martin, E., Nasonova, O., Pumpanen, J., Pyles, R. D., Samuelsson, P., Sandells, M., Schädler, G., Shmakin, A., Smirnova, T. G., Stähli, M., Stöckli, R., Strasser, U., Su, H., Suzuki, K., Takata, K., Tanaka, K., Thompson, E., Vesala, T., Viterbo, P., Wiltshire, A., Xia, K., Xue, Y., and Yamazaki, T.: Evaluation of forest snow processes models (SnowMIP2), J. Geophys. Res., 114, D06111, doi:10.1029/2008JD011063, 2009.

Rutter, N., Sandells, M., Derksen, C., Toose, P., Royer, A., Montpetit, B., Langlois, A., Lemmetyinen, J., and Pulliainen, J.: Snow stratigraphic heterogeneity within groundbased passive microwave radiometer footprints: Implications for emission modeling, J. Geophys. Res.-Earth, 119, 550-565, doi:10.1002/2013JF003017, 2014.

Sandells, M., Essery, R., Rutter, N., Wake, L., Leppänen, L., and Lemmetyinen, J.: The Cryosphere Sandells et al. 2017 Datafiles, figshare, doi:10.6084/m9.figshare.4552822.v1, retrieved: 17 January 2017.

Shih, S.-E., Ding, K.-H., Kong, J., Yang, Y., Davis, R., Hardy, J., and Jordan, R.: Modeling of millimeter wave backscatter of timevarying snow cover, J. Electromagnet. Wave., 11, 1289-1298, 1997.

Song, K. and Zhang, Y.: Snow-cover environmental monitoring and assessment in Northeast China using passive microwave emission models, Environ. Monit. Assess., 140, 223229, doi:10.1007/s10661-007-9862-4, 2007.

Stogryn, A.: A Study of the Microwave Brightness Temperature of Snow from the Point of View of Strong Fluctuation Theory, IEEE T. Geosci. Remote, GE-24, 220-231, doi:10.1109/TGRS.1986.289641, 1986. 
Takala, M., Luojus, K., Pulliainen, J., Derksen, C., Lemmetyinen, J., Kärnä, J.-P., Koskinen, J., and Bojkov, B.: Estimating northern hemisphere snow water equivalent for climate research through assimilation of space-borne radiometer data and groundbased measurements, Remote Sens. Environ., 115, 3517-3529, doi:10.1016/j.rse.2011.08.014, 2011.

Tedesco, M. and Kim, E.: Intercomparison of Electromagnetic Models for Passive Microwave Remote Sensing of Snow, IEEE T. Geosci. Remote, 44, 2654-2666, doi:10.1109/TGRS.2006.873182, 2006.

Tedesco, M., Kim, E. J., Cline, D., Graf, T., Koike, T., Armstrong, R., Brodzik, M. J., and Hardy, J.: Comparison of local scale measured and modelled brightness temperatures and snow parameters from the CLPX 2003 by means of a dense medium radiative transfer theory model, Hydrol. Process., 20, 657-672, doi:10.1002/hyp.6129, 2006.

Tsang, L., Chen, C.-T., Chang, A. T. C., Guo, J., and Ding, K.-H.: Dense media radiative transfer theory based on quasicrystalline approximation with applications to passive microwave remote sensing of snow, Radio Sci., 35, 731-749, doi:10.1029/1999RS002270, 2000.

Tsang, L., Pan, J., Liang, D., Li, Z., Cline, D., and Tan, Y.: Modeling Active Microwave Remote Sensing of Snow Using Dense Media Radiative Transfer (DMRT) Theory With MultipleScattering Effects, IEEE T. Geosci. Remote, 45, 990-1004, doi:10.1109/TGRS.2006.888854, 2007.
Vionnet, V., Brun, E., Morin, S., Boone, A., Faroux, S., Le Moigne, P., Martin, E., and Willemet, J.-M.: The detailed snowpack scheme Crocus and its implementation in SURFEX v7.2, Geosci. Model Dev., 5, 773-791, doi:10.5194/gmd-5-773-2012, 2012.

Wiesmann, A. and Mätzler, C.: Microwave Emission Model of Layered Snowpacks, Remote Sens. Environ. 70, 307-316, doi:10.1016/S0034-4257(99)00046-2, 1999.

Wiesmann, A., Fierz, C., and Mätzler, C.: Simulation of microwave emission from physically modeled snowpacks, Ann. Glaciol., 31, 397-405, doi:10.3189/172756400781820453, 2000.

Xu, X., Tsang, L., and Yueh, S.: Electromagnetic Models of $\mathrm{Co} /$ Cross Polarization of Bicontinuous/DMRT in Radar Remote Sensing of Terrestrial Snow at X- and Ku-band for CoReH2O and SCLP Applications, IEEE J. Sel. Top. Appl., 5, 1024-1032, doi:10.1109/JSTARS.2012.2190719, 2012.

Zuanon, N.: IceCube, a portable and reliable instruments for snow specific surface area measurement in the field, in: Proceedings, International Snow Science Workshop Grenoble - Chamonix Mont-Blance - 2013, 1020-1023, 2013. 
Publication IV

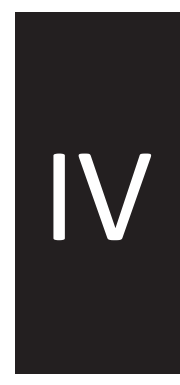





\title{
Arctic Snow Microstructure Experiment for the development of snow emission modelling
}

\author{
William Maslanka ${ }^{1}$, Leena Leppänen ${ }^{2}$, Anna Kontu ${ }^{2}$, Mel Sandells ${ }^{3}$, Juha Lemmetyinen ${ }^{2}$, Martin Schneebeli $^{4}$, \\ Martin Proksch ${ }^{4}$, Margret Matzl $^{4}$, Henna-Reetta Hannula ${ }^{2}$, and Robert Gurney ${ }^{1}$ \\ ${ }^{1}$ Department of Meteorology, University of Reading, Reading, UK \\ ${ }^{2}$ Finnish Meteorological Institute, Arctic Research Centre, Sodankylä, Finland \\ ${ }^{3}$ CORES Science and Engineering LTD, Burnopfield, UK \\ ${ }^{4}$ WSL Institute of Snow and Avalanche Research, SLF, Davos, Switzerland \\ Correspondence to: William Maslanka (w.maslanka@pgr.reading.ac.uk)
}

Received: 27 November 2015 - Published in Geosci. Instrum. Method. Data Syst. Discuss.: 18 December 2015

Revised: 24 March 2016 - Accepted: 30 March 2016 - Published: 14 April 2016

\begin{abstract}
The Arctic Snow Microstructure Experiment (ASMEx) took place in Sodankylä, Finland in the winters of 2013-2014 and 2014-2015. Radiometric, macro-, and microstructure measurements were made under different experimental conditions of homogenous snow slabs, extracted from the natural seasonal taiga snowpack. Traditional and modern measurement techniques were used for snow macroand microstructure observations. Radiometric measurements of the microwave emission of snow on reflector and absorber bases were made at frequencies 18.7, 21.0, 36.5, 89.0, and 150.0 GHz, for both horizontal and vertical polarizations. Two measurement configurations were used for radiometric measurements: a reflecting surface and an absorbing base beneath the snow slabs. Simulations of brightness temperatures using two microwave emission models, the Helsinki University of Technology (HUT) snow emission model and Microwave Emission Model of Layered Snowpacks (MEMLS), were compared to observed brightness temperatures. RMSE and bias were calculated; with the RMSE and bias values being smallest upon an absorbing base at vertical polarization. Simulations overestimated the brightness temperatures on absorbing base cases at horizontal polarization. With the other experimental conditions, the biases were small, with the exception of the HUT model $36.5 \mathrm{GHz}$ simulation, which produced an underestimation for the reflector base cases. This experiment provides a solid framework for future research on the extinction of microwave radiation inside snow.
\end{abstract}

\section{Introduction}

Snow is a vital component of the water cycle, and is critically important for meteorological and climatological studies due to its high albedo, high thermal emissivity, and thermal insulating properties (Cohen and Rind, 1991). In addition, over 1 billion people rely on snowmelt for their fresh water drinking supply (Barnett et al., 2005). To predict and monitor the evolution of potential snowmelt, continuous observations of key parameters such as snow water equivalent (SWE), height of snowpack (HS, as defined by Fierz et al., 2009), and snow extent (SE) are required throughout the year. While traditional snow pit and automatic weather station observations are important, remote sensing observations of snow with passive microwave radiometers are currently the only means in northern countries to provide vital global daily measurements of snow properties. As snow crystals act as scattering centres for upwelling microwave radiation, the size of the snow crystal, the radiation wavelength (and therefore its frequency), and the snow depth all play a role in dictating the amount of scattering present in a snowpack (Chang et al., 1987; Hallikainen et al., 1987).

Over the last 30 years, space-borne passive microwave observations have been used to estimate snow mass and SWE (Chang et al., 1987; Hollinger et al., 1990; Kelly et al., 2003; Takala et al., 2011). The basis of snow mass estimates (Chang et al., 1987) is based on comparison of the observed brightness temperature at a frequency where scattering by the snow crystals is dominant $(>25 \mathrm{GHz}, 37 \mathrm{GHz}$ 
is commonly used) with the observed brightness temperature at a frequency where scattering is not dominant $(<25 \mathrm{GHz}$, $19 \mathrm{GHz}$ is commonly used). Numerous empirical formulae were developed for estimating SWE from the passive microwave observations (Künzi et al., 1982; Chang et al., 1987; Hallikainen, 1989; Amlien, 2008); however, relying on rigid regression coefficients, these empirical approaches were often only valid for certain regional areas with poor interannual consistency (Derksen et al., 2003). Purely theoretical models for snow emission have also been developed (e.g. Tsang et al., 2000). However, these models tend to be very complex and due to the diversity of ancillary information required, their use in practical SWE retrieval from satellite observations is limited. Sitting between empirical and theoretical models are semi-empirical models; these combine radiative transfer theory with results from observations, adjusting key model components empirically. Two commonly used semi-empirical models are the Helsinki University of Technology (HUT) snow emission model (Pulliainen et al., 1999; Lemmetyinen et al., 2010) and the Microwave Emission Model of Layered Snowpacks (MEMLS, Wiesmann and Mätzler, 1999; Mätzler and Wiesmann, 1999).

Both the HUT snow emission model and MEMLS use snow parameters to describe the snowpack and snow microstructure. These parameters include physical temperature, density, and some form of microstructure parameter. This microstructure parameter (describing size, shape, orientation of snow grains) has a large effect on the observed brightness temperature (Foster et al., 1999; Armstrong et al., 1993) because the intensity of scattered microwave radiation is directly linked to snow microstructure (Chang et al., 1987). However, the amount of scattering, described by the scattering coefficient in both the HUT snow emission model and MEMLS, is empirically defined based on observations (Pulliainen et al., 1999; Wiesmann and Mätzler, 1999; Pan et al., 2015). However, MEMLS also includes an option to define the scattering coefficient purely on a physical basis (Mätzler and Wiesmann, 1999).

The Arctic Snow Microstructure Experiment (ASMEx) took place at the Arctic Research Centre of Finnish Meteorological Institute (FMI-ARC) in Sodankylä, Finland in the winter seasons of 2013-2014 and 2014-2015. During the ASMEx, macro-, microstructure, and radiometric measurements of homogeneous snow slabs were made. The snow slabs were extracted from the natural seasonal taiga snowpack. The radiometric measurements were made on two different bases: one assumed perfect absorber and one perfect reflector. Observations of snow macro- and microstructure were made after radiometric measurements. The observed parameters were fed into the HUT snow emission model and MEMLS to produce simulated brightness temperatures. Only homogeneous slabs of dry snow were considered for microwave emission simulation. This was to avoid using wet snow in the radiometric measurements, as the dielectric properties of dry and wet snow are very different. The real and imaginary parts of the dielectric constant of water are much greater than those of ice (Stiles and Ulaby, 1981), increasing the complexity of the behaviour of the dielectric properties of snow.

This paper uses both the HUT snow emission model and MEMLS to simulate the microwave emission of homogenous snow slabs extracted from the natural snowpack in FMI-ARC during ASMEx, and compares simulated and observed microwave emission from the snow slabs. The ultimate aim of ASMEx is to improve the understanding of the microwave extinction processes within the snowpack, and their relation to microstructural properties of natural snow cover. This will enable to improve the precision of future and existing snow emission models.

\section{Methods and models}

\subsection{Methods}

\subsubsection{Excavation of snow slabs}

The snow slabs were extracted from the natural snowpack in the intense observation area (IOA) of the FMI-ARC that is situated in the clearing of a sparse pine forest, in Sodankylä, Finland. A snow sample of size $80 \times 60 \mathrm{~cm}$ was mechanically removed from the snowpack. The thickness of these slabs varied typically between 14 and $19 \mathrm{~cm}$, with the exception of one slab, comprised of depth hoar, being approximately $5 \mathrm{~cm}$ thick. Snow slabs were taken from different depths within the snowpack, in order to capture a range of grain sizes and types. The snow slabs were taken at different periods during the two winters of ASMEx, to capture a wider range of grain sizes and types. Each of the snow slabs was extracted from a homogeneous layer, and its stratigraphy was manually assessed after the radiometric measurements.

The preparation and extraction of the snow slabs was a delicate process. Once a homogeneous layer of sufficient thickness was selected, the sample was prepared by pushing a metal plate (surrounded by a microwave transparent plastic sheet to avoid snow freezing to the metal plate, both at ambient temperature) into the snowpack and selecting the snow sample with a plastic frame as shown in Fig. 1. The plastic frame was also allowed to cool to the ambient temperature, in order to reduce the snow melt-freeze problem. Cuts were made to the surface snow, using metal plates and saws, parallel to the sides of the plastic frame. This allowed the frame to sink to the level of the embedded metal frame. All cuts were made outside to the plastic frame, in order to limit the disruption to the potential sample. Once the plastic frame was level with the metal plate, the entire sampling apparatus and snow sample were pulled out of the snowpack. Any snow above the slab sample and plastic frame was removed. The top of the snow sample was carefully smoothed with a metal plate as gently as possible without making artificial features 


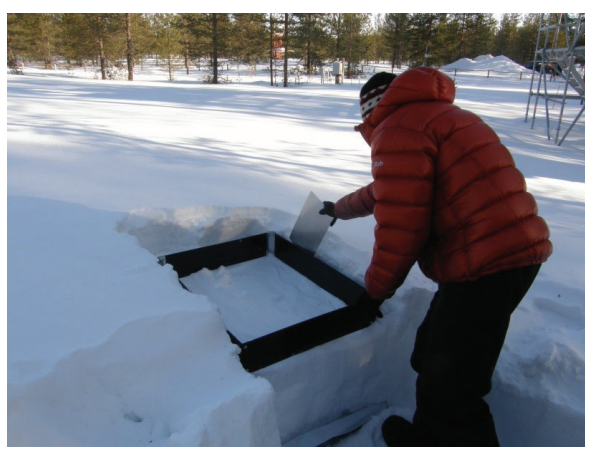

Figure 1. Snow sample was taken from snowpack with a plastic frame, a metal plate and a saw, and a metal bottom plate surrounded by a plastic sheet.

on the slab surface. Immediately after extraction, the slabs were placed in front of the radiometer for brightness temperature measurements. A total of 14 samples were extracted in that manner.

\subsubsection{Radiometric measurements}

The microwave radiometric measurements were made with two RPG-XCH-DP Dicke Switch radiometers, installed on top of the radiometric tower in the IOA. The experimental set up of radiometric measurements is described in Fig. 2. Five different frequencies $(18.7,21.0,36.5,89.0$, and $150.0 \mathrm{GHz})$ at both horizontal and vertical polarizations were used, although not all frequencies were working for all slabs. Tables 1 and 2 detail the radiometric data collected from the ASMEx slabs in 2014 and 2015, respectively. The radiometric measurements were made at an inclination angle of $50^{\circ}$. Equivalent sky brightness temperatures were also made to measure the intensity of the downwelling radiation.

Radiometric measurements followed a comparable procedure as in Wiesmann et al. (1998). The first measurement was made with the snow slab on top of the reflective metal base. The metal base acts as a perfect reflector by reflecting the downwelling emission of microwave radiation from the sky. Once the snow slab had been observed at all frequencies, sky measurements at an equivalent incidence angle were made. The metal plate was then carefully removed from the set up, so that the snow slab was upon the assumed perfect absorber. The radiometric measurements were then repeated. Emissivity tests of the absorbing material, using the experimental setup in Fig. 2 without the snow slab and metal plate, proved that the assumption of a near-perfect blackbody was valid for all slab experiments, with the exception of slabs B05 and B07. For these two slabs, the metal strips in the tape, used to hold the top-most piece of Styrofoam together, caused a reduction in brightness temperature at horizontal polarizations at different frequencies. A

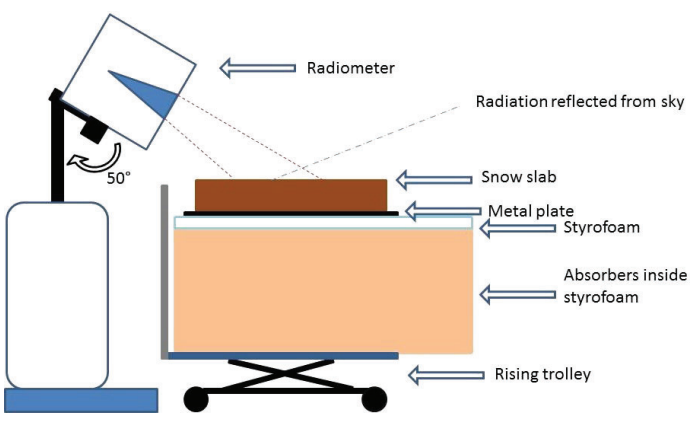

Figure 2. Setup for radiometer measurements with a $50^{\circ}$ inclination angle.

correction (none at $18.7 \mathrm{GHz},-1 \mathrm{~K}$ at $21.0 \mathrm{GHz},-2 \mathrm{~K}$ at $36.5 \mathrm{GHz},-8 \mathrm{~K}$ at $89.0 \mathrm{GHz}$, and $-15 \mathrm{~K}$ at $150.0 \mathrm{GHz}$ ) was applied to the absorbing base brightness temperature data for slabs B05 and B07.Throughout the radiometric measurements the physical temperatures of snow, air, and absorbing material were also measured for modelling purposes.

\subsubsection{Measurements of snow macro- and microstructure}

Once the radiometric measurements had been completed, the destructive sampling of the physical parameters of snow macro- and microstructure took place. Initially, the stratigraphy of the slab was observed using the SnowMicroPen (SMP; Schneebeli and Johnson, 1998 and Schneebeli et al., 1999). The SMP uses a sensitive piezoelectric force sensor on top of a penetrative rod, which is capable of detecting changes in penetrative resistance at a high resolution $(4 \mu \mathrm{m})$. A total of 12 SMP profiles were taken across each slab to assess the stratigraphy and homogeneity. The nominal locations of the SMP profiles, as well as all other macro- and microstructure measurements, are shown in Fig. 3. From the SMP profiles, it is possible to detect layers as well as produce profiles of density, correlation length, and specific surface area (SSA) of the snow (Proksch et al., 2015). For the purposes of this experiment, nine slabs (eight dry and one wet) could be considered homogeneous, with minimal horizontal and vertical features. The other five slabs exhibited significant vertically layered structures, and contained features such as ice crusts within the snow. These internal features would produce additional scattering and internal reflections that would be difficult to quantify in the models for simulation.

The SSA is defined as the ratio between the surface area of the ice and its mass (Legagneux et al., 2002). A new method for measuring the SSA is the IceCube instrument, which is a commercially available version of DUFISSS (Gallet et al., 2009). The IceCube instrument uses a $1310 \mathrm{~nm}$ infrared laser to measure the hemispherical reflectance from the sample. 
Table 1. Radiometric data measured from the 2014 ASMEx slabs. Brightness temperatures from reflective base $\left(T_{\mathrm{BM}}\right)$, sky after reflective base measurements $\left(T_{\mathrm{BM}, \mathrm{SKY}}\right)$, absorbing base $\left(T_{\mathrm{BA}}\right)$, and sky after absorbing base measurements $\left(T_{\mathrm{BA}, \mathrm{SKY}}\right)$ are presented. Horizontal (vertical) brightness temperatures are shown.

\begin{tabular}{|c|c|c|c|c|c|c|c|c|c|}
\hline \multirow[t]{2}{*}{ Sample } & \multirow{2}{*}{$\begin{array}{r}\text { Freq } \\
(\mathrm{GHz})\end{array}$} & \multicolumn{2}{|c|}{$T_{\mathrm{BM}}(\mathrm{K})$} & \multicolumn{2}{|c|}{$T_{\mathrm{BM}, \mathrm{SKY}}(\mathrm{K})$} & \multicolumn{2}{|c|}{$T_{\mathrm{BA}}(\mathrm{K})$} & \multicolumn{2}{|c|}{$T_{\mathrm{BA}, \mathrm{SKY}}(\mathrm{K})$} \\
\hline & & $\mathrm{H}$ pol & V pol & H pol & V pol & H pol & V pol & H pol & V pol \\
\hline A01 & 18.7 & 22.94 & 23.43 & 18.06 & 17.90 & 243.27 & 258.29 & 14.01 & 13.24 \\
\hline A01 & 21.0 & 30.42 & 30.87 & 24.11 & 24.01 & 238.51 & 257.81 & 18.59 & 18.74 \\
\hline A01 & 36.5 & 51.66 & 52.13 & 38.21 & 38.58 & 243.80 & 257.82 & 25.23 & 25.51 \\
\hline A02 & 21.0 & 46.41 & 54.53 & 15.22 & 15.83 & 152.52 & 217.99 & 14.39 & 14.85 \\
\hline $\mathrm{A} 02$ & 36.5 & 93.71 & 115.81 & 23.89 & 24.98 & 144.62 & 192.49 & 22.21 & 23.39 \\
\hline A03 & 18.7 & 37.28 & 35.96 & 19.57 & 19.83 & 255.18 & 272.08 & 19.57 & 19.83 \\
\hline A03 & 21.0 & 50.94 & 50.87 & 32.01 & 32.13 & 257.10 & 272.19 & 32.01 & 32.13 \\
\hline A04 & 18.7 & 77.45 & 79.14 & 19.30 & 19.16 & 221.22 & 254.11 & 19.30 & 19.16 \\
\hline A04 & 21.0 & 111.81 & 111.96 & 29.17 & 29.09 & 217.65 & 248.46 & 29.17 & 29.09 \\
\hline A05 & 18.7 & 47.95 & 48.96 & 19.43 & 17.84 & 225.19 & 262.16 & 19.79 & 18.51 \\
\hline A05 & 21.0 & 63.11 & 64.68 & 28.63 & 28.70 & 239.14 & 263.03 & 29.36 & 29.46 \\
\hline A05 & 89.0 & 180.79 & 201.66 & 54.13 & 53.37 & 193.85 & 202.99 & 65.79 & 65.02 \\
\hline A05 & 150.0 & 205.16 & 212.83 & 96.23 & 100.98 & 205.65 & 212.11 & 109.70 & 111.87 \\
\hline A06 & 18.7 & 28.54 & 31.80 & 7.40 & 9.11 & 228.19 & 256.50 & 8.29 & 9.87 \\
\hline A06 & 21.0 & 41.92 & 45.64 & 12.63 & 12.23 & 235.55 & 256.59 & 13.46 & 12.77 \\
\hline A06 & 89.0 & 177.19 & 192.06 & 29.48 & 27.36 & 185.05 & 198.34 & 29.58 & 27.76 \\
\hline A06 & 150.0 & 181.88 & 188.24 & 42.61 & 34.88 & 184.20 & 189.46 & 47.66 & 35.22 \\
\hline A07 & 18.7 & 27.34 & 27.94 & 9.78 & 10.20 & 229.06 & 258.48 & 10.58 & 11.00 \\
\hline A07 & 21.0 & 37.85 & 38.03 & 13.80 & 14.40 & 224.12 & 257.64 & 14.55 & 14.59 \\
\hline A07 & 89.0 & 165.43 & 183.30 & 30.17 & 30.54 & 168.96 & 186.30 & 30.17 & 30.54 \\
\hline A07 & 150.0 & 175.07 & 186.75 & 45.36 & 39.93 & 174.46 & 187.88 & 45.36 & 39.93 \\
\hline
\end{tabular}

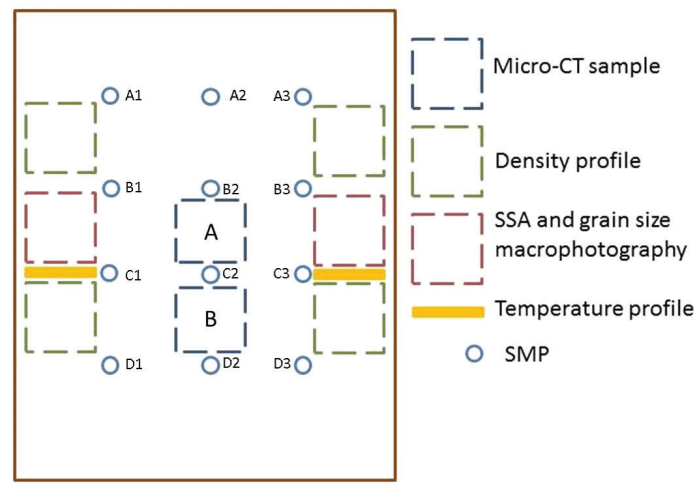

Figure 3. Approximate locations of the macro- and microstructure measurements in the snow slab. Individual SMP and micro-CT measurement locations are also depicted.

The SSA of the snow slab was measured at two different locations in a vertical profile with $3 \mathrm{~cm}$ intervals. The traditional grain size, $E$, is defined by Fierz et al. (2009) as largest extent of an average grain. In this study, post-processed visual estimation of traditional grain size was made from the macrophotographs to improve repeatability of the estimation. Snow grains from the SSA samples were collected and sep- arated upon a $1 \mathrm{~mm}$ reference grid for macrophotography, in order to have profiles of traditional grain size and SSA from the same location. Traditional grain size was estimated visually from macrophotographs with $0.25 \mathrm{~mm}$ resolution.

Snow samples were taken from the centre of the radiometer footprint to be scanned with microcomputed tomography (micro-CT) apparatus. The cast samples were analysed via three-dimensional x-ray tomography in WSL Institute of Snow and Avalanche Research, SLF, Switzerland, to produce a three dimensional image of the snow (Heggli et al., 2009). From this image, it is possible to measure many important microstructural parameters, especially a vertically highly resolved profile of density and correlation length.

In addition to the different number of microstructural measurements of the snow slab, vertical profiles of physical temperature and density took place in other locations within the slab with a vertical resolution of $5 \mathrm{~cm}$. The density profiles were made using a density cutter with a volume of $500 \mathrm{~cm}^{3}$.

\subsection{Models}

\subsubsection{Helsinki University of Technology snow emission model}

The Helsinki University of Technology (HUT) snow emission model (Pulliainen et al., 1999; Lemmetyinen et al., 2010) is a semi-empirical model, which uses the radiative 
Table 2. Radiometric data measured from the 2015 ASMEx slabs (horizontal/vertical polarization). Brightness temperatures from reflective base $\left(T_{\mathrm{BM}}\right)$, sky after reflective base measurements $\left(T_{\mathrm{BM}, \mathrm{SKY}}\right)$, absorbing base $\left(T_{\mathrm{BA}}\right)$, and sky after absorbing base measurements $\left(T_{\mathrm{BA}, \mathrm{SKY}}\right)$ are presented.

\begin{tabular}{|c|c|c|c|c|c|c|c|c|c|}
\hline \multirow[t]{2}{*}{ Sample } & \multirow{2}{*}{$\begin{array}{r}\text { Freq } \\
(\mathrm{GHz})\end{array}$} & \multicolumn{2}{|c|}{$T_{\mathrm{BM}}(\mathrm{K})$} & \multicolumn{2}{|c|}{$T_{\mathrm{BM}, \mathrm{SKY}}(\mathrm{K})$} & \multicolumn{2}{|c|}{$T_{\mathrm{BA}}(\mathrm{K})$} & \multicolumn{2}{|c|}{$T_{\mathrm{BA}, \mathrm{SKY}}(\mathrm{K})$} \\
\hline & & H pol & $\mathrm{V}$ pol & H pol & V pol & H pol & $\mathrm{V}$ pol & H pol & V pol \\
\hline B01 & 18.7 & 18.73 & 18.33 & 10.87 & 9.82 & 246.71 & 257.23 & 11.04 & 9.74 \\
\hline B01 & 21.0 & 28.69 & 28.69 & 17.92 & 17.49 & 245.98 & 258.02 & 17.83 & 17.46 \\
\hline B01 & 36.5 & 42.71 & 44.08 & 21.99 & 22.48 & 241.77 & 254.49 & 21.58 & 21.81 \\
\hline B02 & 18.7 & 20.60 & 19.30 & 8.66 & 8.21 & 229.52 & 251.64 & 7.51 & 6.49 \\
\hline B02 & 21.0 & 30.56 & 28.61 & 13.69 & 13.72 & 231.56 & 252.80 & 11.77 & 11.65 \\
\hline B02 & 36.5 & 54.75 & 54.55 & 24.00 & 24.27 & 228.46 & 247.58 & 19.49 & 19.86 \\
\hline B03 & 18.7 & 24.64 & 23.74 & 13.33 & 11.84 & 234.63 & 264.68 & 13.30 & 11.48 \\
\hline B03 & 21.0 & 37.70 & 36.85 & 24.79 & 23.76 & 243.67 & 265.30 & 24.15 & 23.13 \\
\hline B03 & 36.5 & 57.32 & 56.63 & 27.16 & 26.32 & 241.55 & 263.11 & 26.26 & 25.41 \\
\hline B04 & 18.7 & 24.78 & 22.95 & 10.38 & 9.12 & 229.91 & 261.78 & 9.64 & 9.03 \\
\hline B04 & 21.0 & 31.14 & 30.06 & 14.61 & 13.61 & 232.52 & 260.89 & 14.30 & 13.29 \\
\hline B04 & 36.5 & 64.69 & 63.53 & 23.54 & 21.80 & 229.18 & 255.05 & 23.21 & 21.67 \\
\hline B05 & 18.7 & 35.56 & 33.28 & 7.71 & 8.02 & 233.71 & 255.74 & 8.01 & 8.29 \\
\hline B05 & 21.0 & 43.27 & 41.96 & 13.73 & 12.75 & 242.98 & 257.92 & 15.28 & 13.40 \\
\hline B05 & 36.5 & 85.16 & 88.68 & 22.57 & 21.87 & 226.33 & 241.98 & 22.84 & 21.94 \\
\hline B05 & 89.0 & 162.60 & 161.70 & 42.60 & 33.90 & 178.50 & 175.20 & 43.50 & 36.00 \\
\hline B05 & 150.0 & 199.70 & 187.60 & 67.40 & 54.00 & 195.70 & 186.10 & 67.70 & 57.40 \\
\hline B06 & 18.7 & 22.89 & 22.31 & 9.02 & 8.43 & 238.45 & 260.81 & 9.11 & 8.27 \\
\hline B06 & 21.0 & 30.09 & 28.78 & 12.46 & 12.46 & 239.06 & 261.53 & 12.49 & 11.37 \\
\hline B06 & 36.5 & 63.62 & 62.54 & 21.83 & 21.34 & 236.89 & 258.01 & 21.95 & 21.39 \\
\hline B06 & 89.0 & 195.4 & 200.85 & 30.05 & 30.05 & 208.27 & 210.84 & 38.43 & 31.09 \\
\hline B06 & 150.0 & 201.43 & 194.45 & 44.46 & 44.46 & 202.49 & 193.59 & 60.18 & 43.68 \\
\hline B07 & 18.7 & 55.39 & 55.25 & 10.18 & 9.65 & 209.77 & 242.70 & 10.08 & 9.50 \\
\hline B07 & 21.0 & 62.84 & 64.10 & 12.72 & 12.22 & 214.42 & 243.58 & 12.23 & 11.74 \\
\hline B07 & 36.5 & 124.04 & 131.10 & 21.12 & 20.80 & 195.59 & 211.41 & 21.83 & 20.91 \\
\hline B07 & 89.0 & 167.92 & 165.34 & 37.24 & 29.18 & 167.85 & 165.21 & 35.02 & 27.93 \\
\hline B07 & 150.0 & 190.38 & 180.01 & 57.67 & 45.89 & 189.56 & 179.56 & 51.66 & 44.31 \\
\hline
\end{tabular}

transfer approach to model the microwave brightness temperature. It is capable of treating the snow as a single homogeneous layer (Pulliainen et al., 1999) or as a series of homogeneous layers (Lemmetyinen et al., 2010), with the layers being defined by its physical temperature, density, observed grain diameter, and SWE.

The model's basic assumption is that the microwave radiation is scattered mostly in the forward direction, which allows simplifying the radiative transfer equation to a single flux. Calculation of the absorption coefficient in the HUT model is based on empirical models by Mätzler (1987); while the total extinction coefficient (sum of absorption and scattering coefficients) was originally calculated by Hallikainen et al. (1987) from observations of natural snow slabs collected in southern Finland. The extinction coefficients calculated by Hallikainen et al. (1987) is valid between 18 and $90 \mathrm{GHz}$. Calculation of the total extinction coefficient was originally based on the mean observed grain size (Table 1, Hallikainen et al., 1987), which can be interpreted to be close to the traditional measure of grain size, $E$ (Fierz et al., 2009). However, an effective grain size $D_{\text {eff }}$, i.e. the grain size value that cor- responds to the total scattering effects from the snowpack, was later introduced by Kontu and Pulliainen (2010) to alleviate large errors arising from the use of $E$ in model simulations. According to Kontu and Pulliainen (2010), effective grain size and traditional grain size are related by

$D_{\mathrm{eff}}=\left(1-e^{-1.5 E}\right)$.

Other extinction coefficient relationships exist for the HUT model (Roy et al., 2004; Kontu and Pulliainen, 2010), but these have not been used here. A possible reason for discrepancies noted by both Kontu and Pulliainen (2010) as well as Roy et al. (2004) for coarse grained snow is that measured $E$ in the data set by Hallikainen et al. (1987) extended only up to $1.6 \mathrm{~mm}$. The extinction coefficient model may thus not hold for $E>1.6 \mathrm{~mm}$.

The HUT model uses up- and downwelling emissions, represented by single-flux approximations, to calculate the total emission at the top of the snowpack. Multiple reflections at layer interfaces are accounted. Separate modules were used to simulate the effect of vegetation and atmosphere to de- 
tected emission were published with the original model, but were not applied here.

\subsubsection{Microwave Emission Model of Layered Snowpacks}

MEMLS (Wiesmann and Mätzler, 1999; Mätzler and Wiesmann, 1999) is also based on radiative transfer theory, treating the snowpack as a stack of horizontal layers, with each layer being characterized by its depth, physical temperature, density, and exponential correlation length. Although exponential correlation length $P_{e x}$ was not directly measured, it can be calculated via measurements of density (Mätzler, 2002) and SSA (Toure et al., 2008), such that:

$P_{\text {ex }}=\frac{3\left(1-\frac{\rho_{\text {snow }}}{\rho_{\text {ice }}}\right)}{\text { SSA }}$

where $\rho_{\text {snow }}$ is the density of snow, and $\rho_{\text {ice }}$ is the density of ice $\left(917 \mathrm{~kg} \mathrm{~m}^{-3}\right)$.

These data are used to calculate absorption and scattering coefficients within the snow, as well as transmissivity and reflectivity between adjacent snow layers. A two-flux (up- and downwelling) model is used to calculate the emitted brightness temperature at the top of the snowpack. However, the absorption and scattering coefficients are adjusted with six flux coefficients (up- and downwelling, and four horizontal directions). The scattering coefficient was empirically defined from radiometric and macro- and microstructure measurements as laid out by Wiesmann et al. (1998) and it is valid between 10 and $100 \mathrm{GHz}$. An optional feature, originally implemented for coarse-grained snow with a large correlation length, is to use the improved Born approximation (Mätzler and Wiesmann, 1999) for the calculation of the scattering coefficient.

\section{Results}

\subsection{Macro- and microstructure observations}

Preliminary analyses of snow macro- and microstructure measurements include slab thickness, physical temperature, density, SSA, grain size $E$, and homogeneity. $E$ ranged from 0.5 to $2.0 \mathrm{~mm}$, average slab densities ranged from 130 to $340 \mathrm{~kg} \mathrm{~m}^{-3}$, and physical snow temperature ranged from -14 to $0^{\circ} \mathrm{C}$. The variability of snow characteristics and homogeneity from all 14 slabs are shown in Table 3. Bulk averages and standard deviations of micro-CT-derived SSA and density values are given in Table 4. Locally calibrated bulk averages and standard deviations of SMP-derived SSA and density values are given in Table 5 .

\subsection{Comparison of snow emission models}

The parameters from the eight dry homogeneous slabs in Table 3 were fed into both the single-layer HUT snow emis-

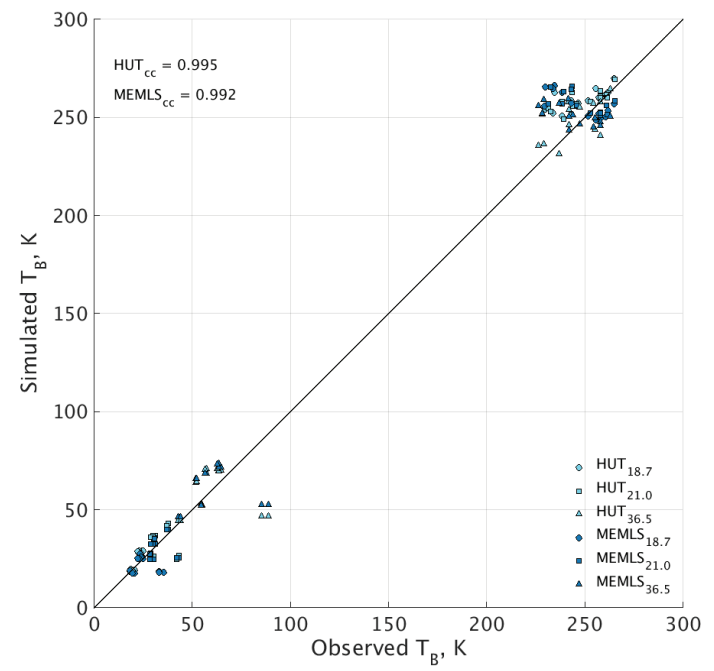

Figure 4. HUT (light blue) and MEMLS (dark blue) simulated brightness temperatures plotted against observed brightness temperatures at 18.7 (circle), 21.0 (square), and $36.5 \mathrm{GHz}$ (triangle). The correlation coefficients of the single-layer HUT model (HUT ${ }_{\mathrm{CC}}$ ) and MEMLS (MEMLS $\mathrm{CC}$ ) are also displayed.

sion model and into MEMLS to produce simulated brightness temperatures. The ground layer in both of the models was modified to simulate the absorbing and reflecting bases by altering the reflecting properties of the ground, to model the reflective properties of the metal plate $(r=1)$ and the absorbing base $(r=0)$. The absorbing and reflective bases were simulated assuming a near-perfect absorption and reflection at the snow-base interface. The directly measured downwelling sky contribution was applied as the downwelling flux in both models. The simulated brightness temperatures at $18.7,21.0$, and $36.5 \mathrm{GHz}$ were compared to the observed brightness temperatures, as shown in Fig. 4, and the 2-D correlation coefficient for each model was calculated. The RMSE and bias values were calculated for each base simulation, at both horizontal and vertical polarizations. The RMSE and bias at the two higher frequencies ( 89.0 and $150.0 \mathrm{GHz}$ ) were not calculated for this study. Figure 5 shows the RMSE values and Fig. 6 shows the bias values of the simulations.

The values in Fig. 5 show that for the absorbing base, the HUT model simulations tend to have smaller RMSE values than MEMLS, while for the reflective base simulations the RMSE values are comparable at 18.7 and $21.0 \mathrm{GHz}$. At $36.5 \mathrm{GHz}$ the HUT snow emission model produces larger RMSE values than MEMLS. The RMSE values for the absorbing base of vertical polarization (V-ABS) are the smallest.

It can be seen from Fig. 6 that the reflective base cases have the smallest bias, with 18.7 and $21.0 \mathrm{GHz}$ only having very 
Table 3. Averaged results from macro- and microstructure measurements. It should be noted that slab A03 was wet, so was not considered for model simulation.

\begin{tabular}{|c|c|c|c|c|c|c|c|c|c|c|c|c|}
\hline \multirow[t]{2}{*}{ Date } & \multirow[t]{2}{*}{$\begin{array}{l}\text { Slab } \\
\text { ref. }\end{array}$} & \multicolumn{2}{|c|}{$\begin{array}{c}\text { Temperature } \\
\left({ }^{\circ} \mathrm{C}\right)\end{array}$} & \multicolumn{2}{|c|}{$\begin{array}{c}\text { Density } \\
\left(\mathrm{kg} \mathrm{m}^{-3}\right)\end{array}$} & \multicolumn{2}{|c|}{$\begin{array}{c}\text { Grain size } \\
(\mathrm{mm})\end{array}$} & \multicolumn{2}{|c|}{$\begin{array}{c}\mathrm{SSA} \\
\left(\mathrm{m}^{2} \mathrm{~kg}^{-1}\right)\end{array}$} & \multicolumn{2}{|c|}{$\begin{array}{c}\text { Thickness } \\
(\mathrm{cm})\end{array}$} & \multirow[t]{2}{*}{ Homogenous } \\
\hline & & $\begin{array}{r}\text { Bulk } \\
\text { avg. }\end{array}$ & SD & $\begin{array}{l}\text { Bulk } \\
\text { avg. }\end{array}$ & $\mathrm{AD}$ & $\begin{array}{l}\text { Bulk } \\
\text { avg. }\end{array}$ & SD & $\begin{array}{c}\text { Bulk } \\
\text { avg. }\end{array}$ & SD & $\begin{array}{c}\text { Bulk } \\
\text { avg. }\end{array}$ & SD & \\
\hline 13 Jan 2014 & $\mathrm{~A} 01$ & -13.1 & 0.1 & 135.5 & 28.4 & 0.5 & 0.1 & 35.8 & 6.3 & 17.8 & 0.8 & Yes \\
\hline 14 Jan 2014 & $\mathrm{~A} 02$ & -22.2 & 0.4 & 264.2 & 21.6 & 0.7 & 0.2 & 15.4 & 5.6 & 15.6 & 0.4 & No \\
\hline 11 Feb 2014 & $\mathrm{~A} 03$ & -0.3 & 0.4 & 227.7 & 41.9 & 0.6 & 0.2 & 18.0 & 4.5 & 16.6 & 0.5 & Yes \\
\hline 13 Feb 2014 & A04 & -0.5 & 0.4 & 225.7 & 41.9 & 0.9 & 0.3 & 11.3 & 2.3 & 18.0 & 0.5 & No \\
\hline 3 Mar 2014 & A 05 & -0.8 & 0.1 & 286.7 & 36.5 & 0.9 & 0.2 & 15.8 & 3.7 & 15.6 & 0.4 & No \\
\hline 18 Mar 2014 & A06 & -7.6 & 0.7 & 280.0 & 14.9 & 0.8 & 0.2 & 17.5 & 2.7 & 14.8 & 0.7 & Yes \\
\hline 20 Mar 2014 & $\mathrm{~A} 07$ & -5.1 & 3.5 & 284.8 & 15.2 & 0.9 & 0.1 & 15.5 & 2.6 & 14.8 & 0.3 & No \\
\hline 2 Feb 2015 & B01 & -13.2 & 0.9 & 139.5 & 23.9 & 0.5 & 0.1 & 36.4 & 5.9 & 14.8 & 0.3 & Yes \\
\hline 5 Feb 2015 & B02 & -10.9 & 0.2 & 160.3 & 34.1 & 0.5 & 0.1 & 36.4 & 8.0 & 13.9 & 0.2 & Yes \\
\hline 19 Feb 2015 & B03 & -2.6 & 0.4 & 234.0 & 24.0 & 0.6 & 0.1 & 22.8 & 4.0 & 14.9 & 0.2 & Yes \\
\hline 11 Mar 2015 & B04 & -5.4 & 0.2 & 268.2 & 26.3 & 1.1 & 0.1 & 21.2 & 2.0 & 16.2 & 0.3 & Yes \\
\hline $12 \operatorname{Mar} 2015$ & B05 & -3.2 & 0.5 & 337.5 & 9.0 & 1.9 & 0.1 & 10.3 & 0.3 & 5.4 & 0.4 & Yes \\
\hline 24 Mar 2015 & B06 & -5.4 & 0.3 & 315.0 & 17.5 & 1.3 & 0.1 & 17.3 & 2.4 & 14.5 & 0.4 & Yes \\
\hline $25 \operatorname{Mar} 2015$ & B07 & -3.7 & 0.4 & 282.5 & 17.1 & 2.0 & 0.2 & 9.4 & 0.5 & 15.2 & 0.3 & No \\
\hline
\end{tabular}
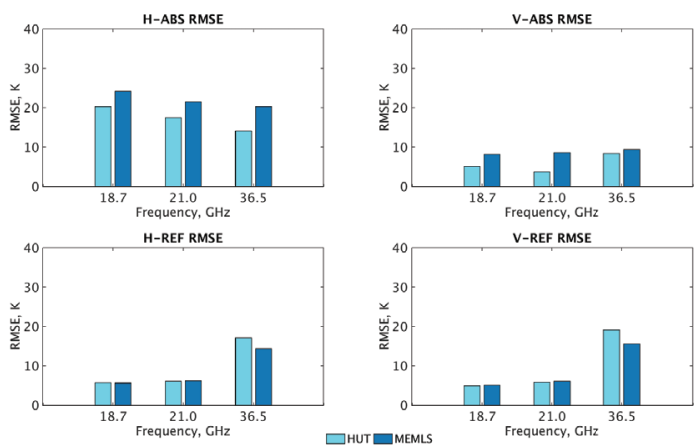

Figure 5. Simulated brightness temperature RMSE at horizontal $(\mathrm{H})$ and vertical $(\mathrm{V})$ polarizations for the absorber material base (ABS) and the reflective metal plate base (REF). Eight slabs were simulated at 18.7 and $21.0 \mathrm{GHz}$, while seven slabs were simulated at $36.5 \mathrm{GHz}$.

small magnitude $(<|2 \mathrm{~K}|)$ biases. At $36.5 \mathrm{GHz}$, the HUT model is negatively biased and MEMLS is slightly positively biased. It suggests that the HUT model underestimated the microwave emission while MEMLS slightly overestimated it at $36.5 \mathrm{GHz}$ on the reflective base cases. The bias for the absorbing base of horizontal polarization (H-ABS) was positive regardless of model or frequency. The bias for the VABS simulations $(<|6 \mathrm{~K}|)$ was negative for all frequencies with MEMLS, and with HUT model positive at 18.7 and $21.0 \mathrm{GHz}$, and slightly negative at $36.5 \mathrm{GHz}$.

The larger magnitude bias in the REF situations in the single-layer HUT simulations can be attributed to the way
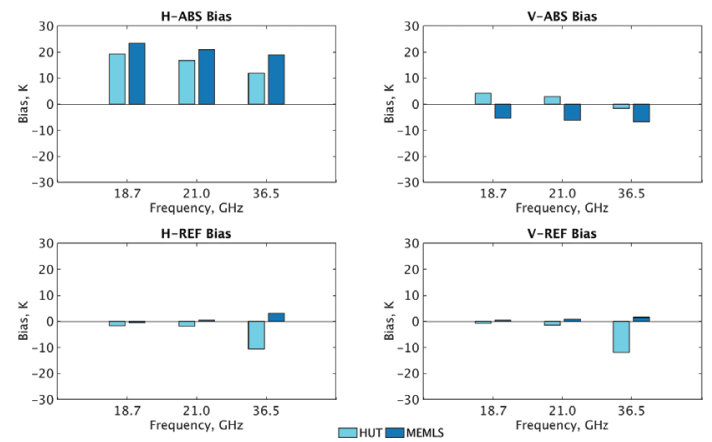

Figure 6. Simulated brightness temperature bias at horizontal $(\mathrm{H})$ and vertical $(\mathrm{V})$ polarizations for the absorber material base (ABS) and the reflective metal plate base (REF). Eight slabs were simulated at 18.7 and $21.0 \mathrm{GHz}$, while seven slabs were simulated at $36.5 \mathrm{GHz}$

which the simulated emission is calculated. The bias in HUT for both REF situations is largely reduced (bias $<|3 \mathrm{~K}|$ ), when the snow thickness is doubled. This doubling of snow depth mimics the doubling of the path length that the downwelling radiation must travel through when the ground is a near perfect reflector (as the downwelling radiation passes through the slab to the reflective plate, is reflected, then travels back through the snow slab). By not doubling the snow depth, the single-layer HUT snow emission model does not correctly model the experimental situation, as it only models the radiation propagating from the ground to the surface, thus underestimating the reflective simulations. 
Table 4. Micro-CT-derived bulk average and standard deviation values of SSA and density. The values for A and B correspond to positions A and B in Fig. 3. Micro-CT A02A was not analysed, thus values of SSA and density are not given.

\begin{tabular}{|c|c|c|c|c|c|c|c|c|}
\hline \multirow{3}{*}{$\begin{array}{l}\text { Position } \\
\text { Slab } \\
\text { ref. }\end{array}$} & \multicolumn{4}{|c|}{$\mathrm{SSA}\left(\mathrm{m}^{2} \mathrm{~kg}^{-1}\right)$} & \multicolumn{4}{|c|}{ Density $\left(\mathrm{kg} \mathrm{m}^{-3}\right)$} \\
\hline & \multicolumn{2}{|c|}{ A } & \multicolumn{2}{|c|}{ B } & \multicolumn{2}{|c|}{ A } & \multicolumn{2}{|c|}{ B } \\
\hline & $\begin{array}{c}\text { Bulk } \\
\text { avg. }\end{array}$ & SD & $\begin{array}{c}\text { Bulk } \\
\text { avg. }\end{array}$ & SD & $\begin{array}{c}\text { Bulk } \\
\text { avg. }\end{array}$ & SD & $\begin{array}{c}\text { Bulk } \\
\text { avg. }\end{array}$ & SD \\
\hline A01 & 29.3 & 4.3 & 29.9 & 4.3 & 95.6 & 40.7 & 91.3 & 35.9 \\
\hline A02 & X & X & 13.1 & 4.3 & X & X & 250.0 & 65.7 \\
\hline A03 & 16.2 & 5.2 & 16.6 & 5.5 & 202.4 & 48.5 & 198.6 & 45.6 \\
\hline A04 & 9.3 & 2.0 & 9.4 & 2.2 & 311.9 & 62.1 & 308.2 & 64.5 \\
\hline A05 & 9.9 & 3.7 & 9.8 & 2.4 & 285.0 & 62.7 & 283.4 & 47.6 \\
\hline A06 & 12.7 & 2.2 & 12.9 & 2.2 & 277.0 & 28.6 & 270.7 & 29.7 \\
\hline A07 & 10.6 & 2.2 & 10.9 & 1.2 & 288.6 & 86.8 & 270.1 & 25.4 \\
\hline B01 & 27.0 & 4.0 & 28.0 & 3.9 & 136.7 & 54.4 & 147.0 & 52.7 \\
\hline B02 & 24.7 & 3.6 & 26.0 & 3.7 & 189.3 & 62.5 & 176.5 & 60.2 \\
\hline B03 & 16.6 & 1.4 & 16.6 & 1.3 & 249.8 & 34.0 & 253.7 & 35.1 \\
\hline B04 & 16.2 & 2.4 & 15.8 & 2.3 & 267.8 & 40.4 & 272.2 & 39.7 \\
\hline B05 & 8.2 & 1.1 & 8.5 & 0.3 & 321.1 & 69.3 & 318.5 & 43.8 \\
\hline B06 & 12.7 & 1.0 & 12.8 & 1.0 & 319.1 & 32.5 & 318.7 & 24.0 \\
\hline B07 & 7.8 & 0.7 & 8.1 & 0.7 & 325.7 & 42.2 & 289.2 & 36.3 \\
\hline
\end{tabular}

Table 5. Locally calibrated SMP-derived bulk average and standard deviation values of SSA and density. The values for B2 and C2 correspond to positions $\mathrm{B} 2$ and $\mathrm{C} 2$ in Fig. 3.

\begin{tabular}{|c|c|c|c|c|c|c|c|c|}
\hline \multirow{3}{*}{$\begin{array}{l}\text { Position } \\
\text { Slab } \\
\text { ref. }\end{array}$} & \multicolumn{4}{|c|}{$\mathrm{SSA}\left(\mathrm{m}^{2} \mathrm{~kg}^{-1}\right)$} & \multicolumn{4}{|c|}{ Density $\left(\mathrm{kg} \mathrm{m}^{-3}\right)$} \\
\hline & \multicolumn{2}{|c|}{ B2 } & \multicolumn{2}{|c|}{$\mathrm{C} 2$} & \multicolumn{2}{|c|}{$\mathrm{B} 2$} & \multicolumn{2}{|c|}{$\mathrm{C} 2$} \\
\hline & $\begin{array}{l}\text { Bulk } \\
\text { avg. }\end{array}$ & SD & $\begin{array}{l}\text { Bulk } \\
\text { avg. }\end{array}$ & SD & $\begin{array}{l}\text { Bulk } \\
\text { avg. }\end{array}$ & SD & $\begin{array}{l}\text { Bulk } \\
\text { avg. }\end{array}$ & SD \\
\hline A01 & 38.0 & 4.8 & 39.0 & 5.6 & 147.2 & 35.4 & 144.1 & 37.9 \\
\hline A02 & 21.7 & 3.7 & 21.6 & 3.0 & 295.6 & 38.7 & 297.3 & 37.6 \\
\hline $\mathrm{A} 03$ & 28.2 & 4.3 & 28.5 & 3.9 & 201.2 & 30.1 & 198.6 & 26.5 \\
\hline A04 & 19.2 & 4.6 & 18.2 & 7.9 & 268.9 & 39.1 & 275.6 & 44.8 \\
\hline A05 & 21.9 & 4.6 & 21.7 & 5.4 & 255.3 & 36.8 & 246.6 & 32.9 \\
\hline A06 & 24.2 & 2.4 & 23.9 & 3.4 & 261.6 & 24.5 & 269.2 & 34.6 \\
\hline A07 & 24.6 & 2.2 & 24.7 & 1.4 & 254.3 & 20.9 & 253.9 & 14.7 \\
\hline B01 & 26.1 & 3.3 & 26.2 & 3.3 & 230.5 & 25.1 & 228.5 & 25.8 \\
\hline B02 & 27.8 & 2.3 & 27.9 & 2.9 & 216.7 & 23.1 & 217.7 & 26.8 \\
\hline B03 & 27.5 & 2.5 & 26.5 & 1.4 & 220.2 & 15.1 & 227.4 & 12.3 \\
\hline B04 & 26.3 & 5.2 & 26.7 & 5.9 & 230.1 & 45.9 & 225.8 & 47.6 \\
\hline B05 & 18.5 & 4.2 & 18.6 & 4.5 & 254.0 & 15.1 & 263.3 & 30.0 \\
\hline B06 & 20.8 & 1.5 & 21.1 & 1.9 & 289.7 & 16.2 & 285.3 & 21.2 \\
\hline B07 & 23.2 & 5.9 & 21.8 & 4.5 & 256.7 & 54.3 & 267.0 & 38.9 \\
\hline
\end{tabular}

The doubling of the snow thickness also reduces the errors introduced by slab B05 (initial thickness $5.4 \mathrm{~cm}$ ), as the small thickness is not enough for scattering to be correctly simulated. Additional errors will be introduced, due to the slight changes in the snow density and microstructural parameter that were not recorded by the traditional observations, due to the coarse resolution of the method (vertical profile of 3$5 \mathrm{~cm})$. There were variations in density and SSA that were recorded by the micro-CT and SMP observations, but were not recorded with the traditional observation techniques.

\section{Summary}

The Arctic Snow Microstructure Experiment (ASMEx) consisted of radiometric, macro-, and microstructure measurements of snow slabs upon absorbing and reflecting bases. 
Brightness temperatures of the homogeneous snow slabs were simulated with the HUT snow emission model and with MEMLS. Results of the comparison of simulations and observations are described in Sect. 3.2. The HUT model produced smaller RMSE across all three frequencies for the simulations upon an absorbing base. The reflective base simulations produced RMSE values that were comparable with the HUT model and MEMLS at 18.7 and $21.0 \mathrm{GHz}$. Both models overestimated the brightness temperature at $\mathrm{H}-\mathrm{ABS}$, and at V-ABS the single-layer HUT model slightly overestimated the brightness temperature while MEMLS underestimated it. Both models produced very small biases for the reflective base cases, with the exception of the HUT model at $36.5 \mathrm{GHz}$.

The RMSE and bias is influenced by internal extinction processes within the snow slabs, which are imperfectly simulated by the model physics. The relatively high errors, especially at $\mathrm{H}$ pol, considering the highly controlled measurement setup, highlight the requirement for further development of the models, as well as the need to better quantify the snow microstructural properties themselves. These preliminary brightness temperature simulations will be repeated in the future using the physical snow properties collected by the modern techniques including SMP and micro-CT measurements. Ultimately, a revised extinction model will be created for the HUT snow emission model, and implemented with the aim to improve the model inversions of SWE from radiometric measurements of microwave emission. This revised extinction coefficient, based on the data collected during the ASMEx campaign, will be a function of microstructural parameter and frequency.

Author contributions. Juha Lemmetyinen, Mel Sandells, and Martin Schneebeli planned the experiment with help of William Maslanka. William Maslanka had the main responsibility in organizing and carrying out the measurements. Leena Leppänen had the responsibility of organizing measurements as the local operator, including implementation of measurement setup and participation to measurement procedure. Anna Kontu and HennaReetta Hannula participated in the experimental measurements. William Maslanka conducted data processing and simulations. Margret Matzl provided the micro-CT data set. Martin Proksch provided the SMP analysis. William Maslanka and Leena Leppänen prepared the manuscript with contributions from all co-authors.

Acknowledgements. We thank the staff of FMI Arctic Research Centre in Sodankylä for performing the ground-based radiometer measurements and macro- and microstructure measurements. We also thank the staff of WSL Institute of Snow and Avalanche Research SLF for the SMP instrument and for the SMP and micro$\mathrm{CT}$ analyses of the snow samples. The manuscript preparation was supported by the EU 7th Framework Program project "EuropeanRussian Centre for cooperation in the Arctic and Sub-Arctic environmental and climate research" (EuRuCAS, Grant no. 295068).
Edited by: C. Ménard

\section{References}

Amlien, J.: Remote Sensing of Snow with Passive Microwave Radiometers - A review of current algorithms, Report 1019, Norsk Regnesentral, Oslo, 1-52, 2008.

Armstrong, A., Chang, A., Rango, A., and Josberger, E.: Snow depths and grain-size relationships with relevance for passive microwave studies, Ann. Glaciol., 17, 171-176, 1993.

Barnett, T. P., Adam, J. C., and Lettenmaier, D. P.: Potential Impacts of a Warming Climate on Water Availability in Snow-Dominated Regions, Nature, 438, 303-309, 2005.

Chang, A. T. C., Foster, J. L., and Hall, D. K.: Nimbus-7 SMMR derived global snow parameters, Ann. Glaciol., 9, 39-44, 1987.

Cohen, J. and Rind, D.: The effect of snow cover on the climate, J. Climate, 4, 689-706, 1991.

Derksen, C., Walker, A., and Goodison, B.: A comparison of 18 winter seasons of in situ and passive microwave derived snow water equivalent estimates in Western Canada, Remote Sens. Environ., 88, 271-282, 2003.

Fierz, C., Armstrong, R. L., Durand, Y., Etchevers, P., Greene, E., McClung, D. M., Nishimura, K., Satyawali, P. K., and Sokratov, S. A.: The International Classification for Seasonal Snow on the Ground, IHP-VII Technical Documents in Hydrology No. 83, IACS Contribution No. 1, UNESCO-IHP, Paris, 1-90, 2009.

Foster, J., Hall, D., Chang, A., Rango, A., Wergin, W., and Erbe, E.: Effects on snow crystal shape on the scattering of passive microwave radiation, IEEE T. Geosci. Remote, 37, 1165-1168, 1999.

Gallet, J.-C., Domine, F., Zender, C. S., and Picard, G.: Measurement of the specific surface area of snow using infrared reflectance in an integrating sphere at 1310 and $1550 \mathrm{~nm}$, The Cryosphere, 3, 167-182, doi:10.5194/tc-3-167-2009, 2009.

Hallikainen, M.: Microwave Radiometry of Snow, Adv. Space Res., 9, 267-275, 1989.

Hallikainen, M., Ulaby, F., and Van Deventer, T.: Extinction Behaviour of Dry Snow in the 18- to $90-\mathrm{GHz}$ Range, IEEE T. Geosci. Remote, 25, 737-745, 1987.

Heggli, M., Frei, M., and Schneebeli, M.: Snow replica method for three-dimensional X-ray microtomography imaging, J. Glaciol., 55, 631-639, 2009.

Hollinger, J., Peirce, J., and Poe, G.: SSM/I Instrument Evaluation, IEEE T. Geosci. Remote, 28, 781-790, 1990.

Kelly, R., Chang, A., Tsang, L., and Foster, J.: A Prototype AMSRE Global Snow Area and Snow Depth Algorithm, IEEE T. Geosci. Remote, 41, 230-242, 2003.

Kontu, A. and Pulliainen, J.: Simulation of spaceborne microwave radiometer measurements of snow cover using in situ data and brightness temperature modelling, IEEE T. Geosci. Remote, 48, 1031-1044, 2010.

Künzi, F., Patil, S., and Rott, H.: Snow-cover parameters retrieved from Nimbus-7 Scanning Multi-channel Microwave Radiometer (SMMR) data, IEEE T. Geosci. Remote, 20, 452-467, 1982.

Legagneux, L., Cabanes, A., and Dominé, F.: Measurement of the specific surface area of 176 snow samples using methane adsorption at $77 \mathrm{~K}$, J. Geophys. Res.-Atmos., 107, 4335, doi:10.1029/2001JD001016, 2002. 
Lemmetyinen, J., Pulliainen, J., Rees, A., Kontu, A., Qiu, Y., and Derksen, C.: Multiple-layer adaptation of HUT snow emission model: comparison with experimental data, IEEE T. Geosci. Remote, 48, 2781-2794, 2010.

Mätzler, C.: Applications of the interaction of microwave with the natural snow cover, Remote Sens. Rev., 2, 259-387, 1987.

Mätzler, C.: Relation between grain-size and correlation length of snow, J. Glaciol., 48, 461-466, 2002.

Mätzler, C. and Wiesmann, A.: Extension of the Microwave Emission Model of Layered Snowpacks to Coarse-Grained Snow, Remote Sens. Environ., 70, 317-325, 1999.

Pan, J., Durand, M., Sandells, M., Lemmetyinen, J., Kim, E., Pulliainen, J., Kontu, A., and Derksen, C.: Differences between the HUT Snow Emission Model and MEMLS and Their Effects on Brightness Temperature Simulation, IEEE T. Geosci. Remote, 99, 1-19, 2015.

Proksch, M., Löwe, H., and Schneebeli, M.: Density, specific surface area, and correlation length of snow measured by highresolution penetrometry, J. Geophys. Res.-Earth, 120, 346-362, 2015.

Pulliainen, J., Grandell, J., and Hallikainen, M.: HUT snow emission model and its applicability to snow water equivalent retrieval, IEEE T. Geosci. Remote, 37, 1378-1390, 1999.

Roy, V., Goita, K., Royer, A., Walker, A., and Goodson, B.: Snow Water Equivalent Retrieval in a Canadian Boreal Environment from Microwave Measurements using the HUT Snow Emission Model, IEEE T. Geosci. Remote, 42, 1850-1859, 2004.
Schneebeli, M. and Johnson, J. B.: A constant-speed penetrometer for high-resolution snow stratigraphy, Ann. Glaciol., 26, 107111, 1998.

Schneebeli, M., Pielmeier, C., and Johnson, J. B.: Measuring snow microstructure and hardness using a high resolution penetrometer, Cold Reg. Sci. Technol., 30, 101-114, 1999.

Stiles, W. and Ulaby, F.: Dielectric properties of snow, Technical Report 527-1, The University of Kansas Center for Research, Inc. Remote Sensing Laboratory, Lawrence, Kansas, 93-103, 1981.

Takala, M., Luojus, K., and Pulliainen, J.: Estimating Northern Hemisphere Snow Water Equivalent for Climate Research through Assimilation of Space-Borne Radiometer Data and Ground-Based Measurements, Remote Sens. Environ., 15, 3517 3529, 2011.

Toure, A., Goite, K., Royer, A., Mätzler, C., and Schneebeli, M.: Near-infrared digital photography to estimate snow correlation length for microwave emission modelling, Appl. Optics, 48, 111, 2008.

Tsang, L., Chen, C.-T., Chang, A., Guo, J., and Ding, K.-H.: Dense media radiative transfer theory based on quasicrystalline approximation with application to passive microwave remote sensing of snow, Radio Sci., 35, 731-749, 2000.

Wiesmann, A. and Mätzler, C.: Microwave Emission Model of Layered Snowpacks, Remote Sens. Environ., 70, 307-316, 1999.

Wiesmann, A., Mätzler, C., and Weise, T.: Radiometric and structural measurements of snow samples, Radio Science, 33, 273 289, 1998. 
Publication V

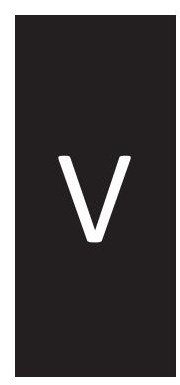





\title{
Sodankylä manual snow survey program
}

\author{
Leena Leppänen $^{1}$, Anna Kontu ${ }^{1}$, Henna-Reetta Hannula ${ }^{1}$, Heidi Sjöblom ${ }^{2}$, and Jouni Pulliainen ${ }^{1}$ \\ ${ }^{1}$ Finnish Meteorological Institute, Arctic Research, Sodankylä, Finland \\ ${ }^{2}$ Finnish Environment Institute, Helsinki, Finland
}

Correspondence to: Leena Leppänen (leena.leppanen@fmi.fi)

Received: 27 November 2015 - Published in Geosci. Instrum. Method. Data Syst. Discuss.: 10 December 2015

Revised: 19 April 2016 - Accepted: 25 April 2016 - Published: 30 May 2016

\begin{abstract}
The manual snow survey program of the Arctic Research Centre of the Finnish Meteorological Institute (FMI-ARC) consists of numerous observations of natural seasonal taiga snowpack in Sodankylä, northern Finland. The easily accessible measurement areas represent the typical forest and soil types in the boreal forest zone. Systematic snow measurements began in 1909 with snow depth (HS) and snow water equivalent (SWE). In 2006 the manual snow survey program expanded to cover snow macro- and microstructure from regular snow pits at several sites using both traditional and novel measurement techniques. Present-day snow pit measurements include observations of HS, SWE, temperature, density, stratigraphy, grain size, specific surface area (SSA) and liquid water content (LWC). Regular snow pit measurements are performed weekly during the snow season. Extensive time series of manual snow measurements are important for the monitoring of temporal and spatial changes in seasonal snowpack. This snow survey program is an excellent base for the future research of snow properties.
\end{abstract}

\section{Introduction}

Snow is an important parameter in meteorological and climatological research because of its high albedo (0.80-0.90 for fresh snow), thermal insulation properties and water equivalent (Groisman et al., 1994; Cohen and Rind, 1991). Snow reflects most of the upcoming radiation back to space and reduces significantly the amount of radiation absorbed by the ground and atmosphere. This surface-albedo feedback (SAF) is a positive feedback mechanism and has potentially a major effect in global warming (Hall and Qu, 2006). Snow is a good thermal insulator. Snow cover slows down soil freezing and affects the depth of ground frost (Hardy et al., 2001). Snow cover stores the solid wintertime precipitation and releases it to water systems during the relative short snowmelt in spring. Therefore, snow has a large effect on the global water cycle and ecology, in addition to social aspects, as a water reservoir (van Dijk et al., 2014; Barnett et al., 2005).

Moreover, seasonal snow cover can be used as a proxy for monitoring the effects of climate change (HernándezHenríquez at al., 2015). The most important observed snow cover parameters are snow water equivalent (SWE), snow extent (SE) and snow depth (HS). In many applications, remote sensing is used for global daily observations. However, automatic weather station observations and manual measurements still have an important role in snow monitoring, especially in numerical weather prediction (NWP) systems (e.g. de Rosnay et al., 2014), hydrological monitoring and climate models.

Many snow properties can be measured automatically, but manual measurements are still vital for exact observations of snow structure. Snow microstructure is defined with such grain-related properties as size, shape, orientation and bonding (Fierz et al., 2009). Snowpack consists of horizontal layers having varying micro- and macrostructural properties (Colbeck, 1991). Grain metamorphism changes snow microstructure, and is driven mainly by varying temperature differences between air and ground, and the pressure of the upper snowpack (Colbeck, 1982). Therefore, vertical changes of macrostructural parameters, such as temperature and density, are related to the evolution of snow microstructure. However, the structure of snowpack is very complex and spatial variations are large even on a small scale (Rutter et al., 2014; Derksen et al., 2009). Therefore, manual observations of snow macro- and microstructure have an important role in the monitoring of temporal evolution and spatial variations of snowpack. 
This paper introduces the manual snow survey program, the long-standing and present-day manual observations of natural seasonal snowpack, of the Arctic Research Centre of the Finnish Meteorological Institute (FMI-ARC). Measurements started in 1909 with HS and SWE observations. The extent of manual snow measurements has constantly grown. In 2006 regular snow pit measurements of snow macro- and microstructure began, at first on a smaller scale and later with additional modern measurement techniques. The Sodankylä manual snow survey program aims to study the spatial and temporal variability of snowpack in varying environmental conditions typical to the boreal forest zone, including pine and spruce forests, open bogs and lake ice (e.g. Hannula et al., 2016; Lemmetyinen et al., 2015; Kontu et al., 2014; Kontu and Pulliainen, 2010). The data set is also important as a reference for the development of remote sensing instruments (Lemmetyinen et al., 2016b) and interpretation algorithms and models (Leinss et al., 2015; Schwank et al., 2014; Rautiainen et al., 2014).

In addition to Sodankylä, regular manual snow measurements are made in few places in Europe. Two measurement sites, Weissfluhjoch in Switzerland (Marty and Meister, 2012) and Col de Porte in France (Morin et al., 2012), are presented in the literature. Manual snow measurements have been made at the Weissfluhjoch site since 1936. Regular measurements include daily snow depth and depth of new snow, bi-weekly ram sonde measurements, definition of layers, grain size, grain type, hardness, temperature profile and SWE profile (Meister, 2009). Measurements at the Col de Porte site were made in 1993-2011. Weekly snow pit measurements included penetration resistance with ram sonde, temperature, density, snow type, LWC and grain size (Morin et al., 2012).

Both Weissfluhjoch and Col de Porte are located in the Alps in central Europe, at altitudes of 2540 and $1325 \mathrm{~m}$, respectively. The environment of the Sodankylä measurement site (altitude $185 \mathrm{~m}$ ) is very different from the Alpine sites. At the Alpine sites, the duration of daylight is longer and the Sun's elevation angle is higher than in Sodankylä, especially during polar night. Thus, increased solar radiation and higher air temperature lead to more frequent melting and refreezing events and a shorter snow cover period. The unforested Weissfluhjoch site has additional effects of wind and slope compared to Col de Porte and Sodankylä sites. Additionally, the FMI-ARC data set includes measurements in several sites in Sodankylä with different land cover types including pine forest on mineral soil, open peat bog and lake ice, while the Weissfluhjoch site has gravel cover and the Col de Porte site has grass cover. However, both of these sites have a longer time series of snow pit measurements than the Sodankylä site. All of these sites also have automatic snow and weather observations.

The measurements of the Sodankylä manual snow survey program have been exploited in several studies. Leppänen et al. (2015) compared manual snow microstructure measure- ments to a snow model. Snow pit data were used in the development and validation of a new method to measure SWE by differential interferometry (Leinss et al., 2015) and a new ground-snow radiative transfer model at L-band (Schwank et al., 2014). They were also applied in the monitoring of soil processes (Rautiainen et al., 2012), in the retrieval of snow density and ground permittivity from L-band radiometry (Lemmetyinen et al., 2016a) and in the study of seasonally and spatially varying snow cover brightness temperature (Lemmetyinen et al., 2015). Cheng et al. (2014) applied lake ice measurements to validate buoy-based measurements of lake snow and ice thicknesses. Moreover, snow pit and lake ice measurements were applied by Kontu et al. (2014) to study the effect of snow and ice-covered lakes and wetlands to microwave brightness temperature simulation accuracy. In addition, Kontu and Pulliainen (2010) used the snow pit measurements to simulate a time series of brightness temperatures and compared the results to spaceborne microwave radiometer measurements. Salminen et al. (2009) studied the reflectance spectra of snow-covered ground in different snow conditions in order to assess the feasibility of satellite sensors to mapping of snow-covered area in boreal forests. Meinander et al. (2008) found a diurnal decrease in snow UV albedo, and explained this by daily metamorphosis of the snow surface.

The measurement sites as well as the measurement techniques, instruments and error sources of each parameter are described in Sect. 2. Section 3 presents the data sets, lists the measurements and sites in each set and describes the measurement protocols. In addition, some examples of the data are shown. Section 4 summarises the data availability, and Sect. 5 is the summary of the paper.

\section{Measurement sites and methods}

\subsection{FMI-ARC station}

Sodankylä is located above the Arctic Circle in the boreal forest zone, and its snow conditions fall in the taiga class (Sturm and Holmgren, 1995). The FMI-ARC station is located in $67.368^{\circ} \mathrm{N}, 26.633^{\circ} \mathrm{E}, 7 \mathrm{~km}$ south of the Sodankylä town centre. A map of the research station area and surroundings, including the manual snow measurement sites, is shown in Fig. 1. The station is a member of the WMO (World Meteorological Organization) Global Cryosphere Watch network.

The manual snow measurement sites, with short listings of their automatic measurements, are presented in more detail in this section. FMI-ARC also hosts other snow-related automatic measurement sites, which are presented in more detail in this special issue, such as the micrometeorological mast (Kangas et al., 2016), the road weather station (Sukuvaara et al., 2016), the UV measurement field (Meinander et al., 2016; Mäkelä et al., 2016), the distributed soil moisture and frost stations (Ikonen et al., 2015) and the optical lab- 
oratory (Lakkala et al., 2016). In addition, a 7-year data set for driving and evaluating snow models has been collected by Essery et al. (2016).

In the $100 \mathrm{~km} \times 100 \mathrm{~km}$ area around FMI-ARC (Fig. 1a, referred to as "the Sodankylä area" later on), the most common land cover types in Corine Land Cover 2006 (Törmä et al., 2008) are coniferous forest on mineral soil (32\%), open peat bogs $(23 \%)$, and coniferous forest on peatland (8\%). The FMI-ARC (Fig. 1c) station area covers coniferous forests and open areas on mineral soil, as well as open peat bog.

Based on the 30-year (1981-2010) meteorological statistics (Pirinen et al., 2012), the first snow typically falls in Sodankylä in October, while snow melt-off takes place in mid-May. The snow maximum of $79 \mathrm{~cm}$ in average occurs in late March. Monthly mean air temperature is below $0{ }^{\circ} \mathrm{C}$ from November to April, and the yearly mean temperature is $-0.4{ }^{\circ} \mathrm{C}$. Measured air temperature varies between $-49.5^{\circ} \mathrm{C}$ (January 1999) and $+30.9^{\circ} \mathrm{C}$ (July 1988). Mean yearly total precipitation is $527 \mathrm{~mm}$ and monthly mean wind speed above treetops is between 2.5 and $2.9 \mathrm{~m} \mathrm{~s}^{-1}$.

In addition to the 30-year wind speed averages, a wind sensor (WAA25 by Vaisala, Helsinki, Finland) at $18 \mathrm{~m}$ height (above treetops) at the micrometeorological mast site about $170 \mathrm{~m}$ from the intensive observation area (IOA) area measured an average wind speed for 10-year period (2006-2015) of $2.2 \mathrm{~m} \mathrm{~s}^{-1}$ with a standard deviation of $1.26 \mathrm{~m} \mathrm{~s}^{-1}$. Another sensor (Ultrasonic Anemometer 2-D by Thies Clima, Göttingen, Germany) at $1.5 \mathrm{~m}$ height in a forest opening about $500 \mathrm{~m}$ from the IOA area measured a 2-year (2014-2015) mean value during the snow season from mid-September to mid-May each year of $1.17 \mathrm{~m} \mathrm{~s}^{-1}$ with a standard deviation of $0.56 \mathrm{~m} \mathrm{~s}^{-1}$. These measurements highlight the very low wind speeds in the forested areas and the forest openings of the FMI-ARC station.

Synoptic weather observations have been made in Sodankylä since 1908 (Tietäväinen et al., 2010), first in the town centre and since 1913 at the current research station area. Today two institutes share the station: Sodankylä Geophysical Observatory (SGO), which was established in 1913 as Magnetic Observatory and is presently part of the Oulu University, and FMI observatory, which was established in 1949 and continues the meteorological data records at the site.

\subsection{Measurement sites}

This section describes the manual measurement sites in alphabetical order. Maps with locations of all the measurement sites are in Fig. 1. Photos from most of the measurement sites are in Fig. 2.

\subsubsection{Airport}

The airport site is an open area on mineral soil located on the premises of Sodankylä airport about $3 \mathrm{~km}$ north of FMI-ARC (a)

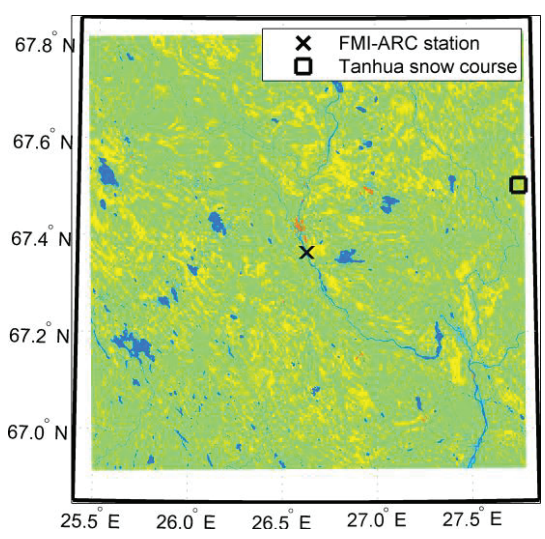

(b)

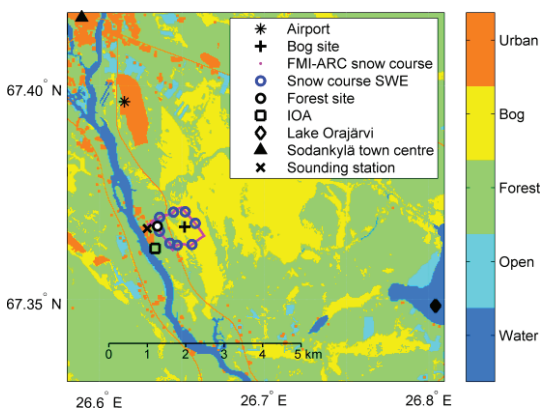

(c)

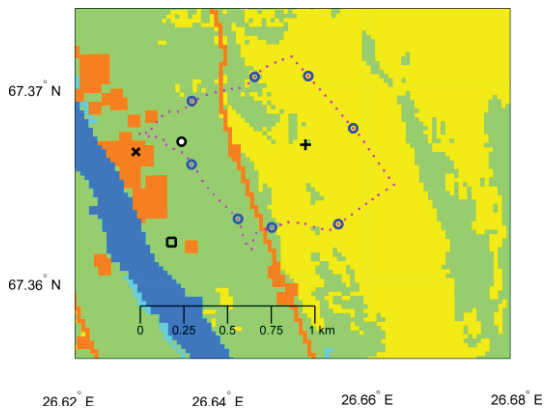

Figure 1. Maps of (a) the $100 \mathrm{~km} \times 100 \mathrm{~km}$ area around FMI-ARC station, (b) the FMI-ARC station and surroundings, and (c) a closeup of the FMI-ARC station area with the manual measurement sites. In (b) and (c), individual measurement locations of the snow course are marked. The legend and colour scale of maps (a) and (c) are the same as in (b). All the maps are in orthographic projection. The background of the maps is Corine Land Cover 2006 aggregated into five general classes. 
(a)

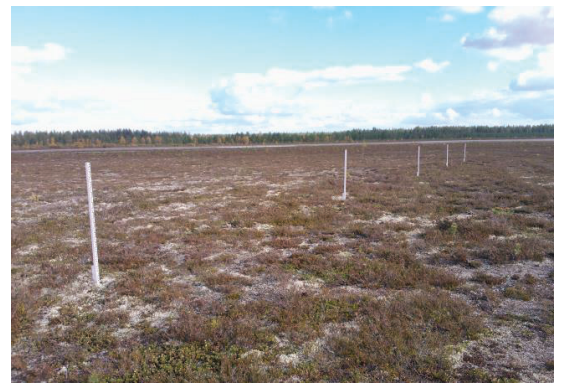

(b)

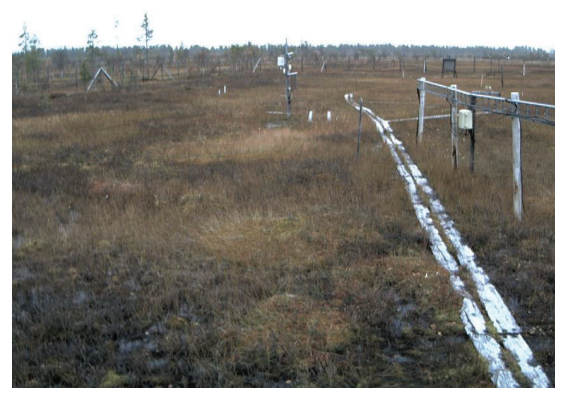

(c)

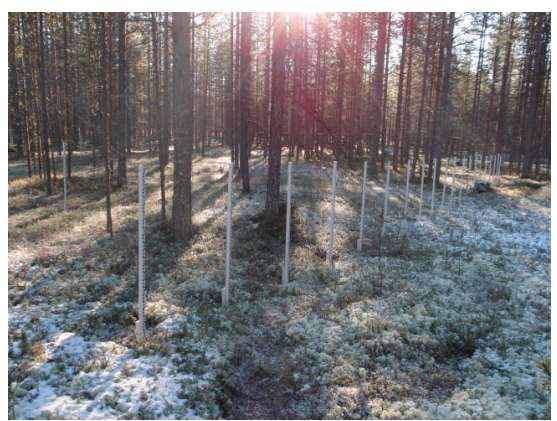

(d)
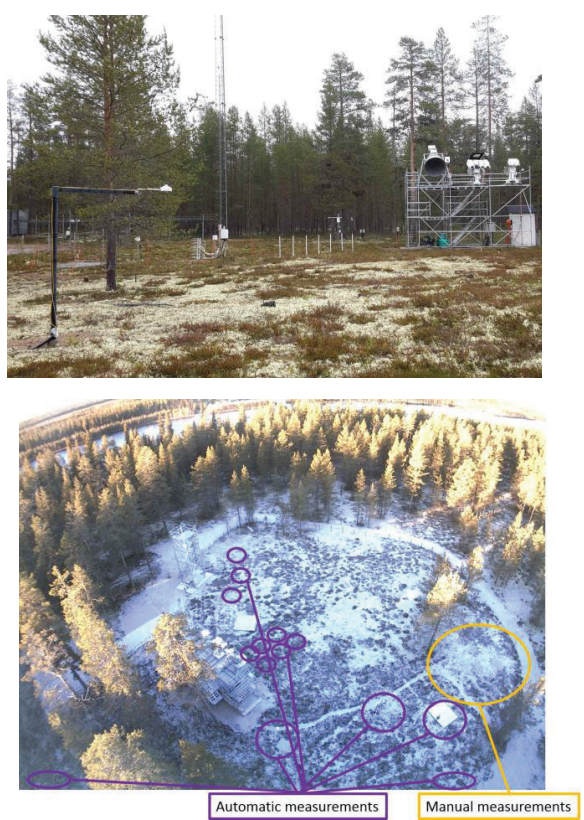

(e)

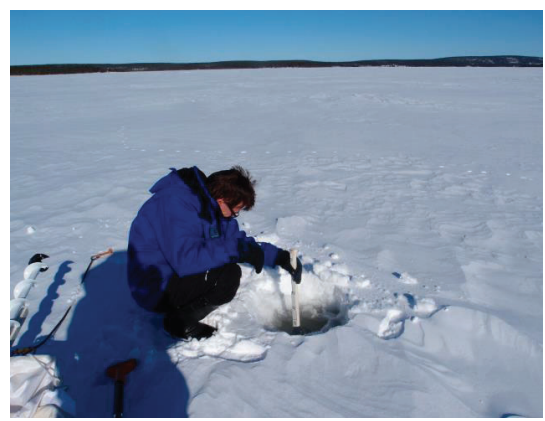

Figure 2. Snow measurement sites: (a) airport, (b) bog site, (c) forest site, (d) IOA, (e) Lake Orajärvi.

(* in Fig. 1b). The vegetation on the area is heather, crowberry and lichen, which are sparse and typically $10-15 \mathrm{~cm}$ high (Fig. 2a). There are no automatic measurements on this site. HS (from fixed stakes) and SWE have been measured every 5 days in January and March since 1972. The site was chosen for measurements since it is one of the few large open areas on mineral soil closed from public in the vicinity of FMI-ARC.

Geosci. Instrum. Method. Data Syst., 5, 163-179, 2016

\subsubsection{Bog site}

Open peat bogs are the second most common land cover type in the Sodankylä area with a coverage of $23 \%$ (Corine Land Cover 2006). The manual snow measurement site was established in 2009 on an area that already hosted automatic UV measurements. The bog site ( + in Fig. 1b, c) is located about $1 \mathrm{~km}$ northeast from the main snow measurement site IOA. The bog site is a moss-covered peat bog with low vegetation (grass and twigs) as shown in Fig. 2b. The water level varies 
due to precipitation and time of year; every spring during and after snowmelt the bog site is completely submerged, but the autumn conditions might range from completely submerged to completely dry. Typically snow accumulates over a smooth ice layer, which is infrequently penetrated by low vegetation. Wind redistributes snow and levels the snowpack surface. With direct sunlight it adds evaporation from the snowpack and hard crust layers are formed easier to the snowpack surface than in forested areas.

Automatic observations of HS (SR50 by Campbell Scientific Inc., Logan, Utah, USA), SWE (Gamma Water Instrument by Astrock, Sodankylä, Finland), broadband albedo (CMA11 by Kipp \& Zonen, Delft, Netherlands), snow temperature profile (13 pcs. 107-L by Campbell Scientific Inc., Logan, Utah, USA), air temperature (PT100, Vaisala, Helsinki, Finland), relative humidity (HMP155, Vaisala, Helsinki, Finland), soil frost (15 pcs. of SEC sensor by LISTEC, Isen, Germany) and soil dielectric constant, electric conductivity and temperature (9 pcs. of 5TE by Decagon Devices, Pullman, Washington, USA) are made. More details about instrumentation (description, coordinates, sensor types and data availability) can be found from http://litdb.fmi.fi/ peatland.php. Manual snow pit measurements were made regularly (2-4 times per month) in 2009-2015. After 2015 SWE is measured manually only occasionally for calibration of automatic measurements.

\subsubsection{Sodankylä snow course}

The Sodankylä snow course (dots and circled dots in Fig. 1b and c) is a $4 \mathrm{~km}$ route in the vicinity of the FMI-ARC station crossing forested and open areas on mineral and organic soil. The Sodankylä snow course has 80 HS measurement locations, out of which 5 are in forest opening, 10 in pine dominated forest, 23 in spruce dominated forest, 5 in broadleafdominated forest and 37 in bog. The snow course has been measured regularly since 1959 .

\subsubsection{Forest site}

The forest site is in a sparse pine forest on mineral sandy soil located in the FMI-ARC station area (o in Fig. 1b and c). Coniferous forest on mineral soil is the most common land cover type (32\%, Corine Land Cover 2006) in the Sodankylä area. The ground is covered with lichen (Cladonia rangiferina), lingonberry, cloudberry and moss as shown in Fig. 2c. The area has been fenced since 1958 allowing the lichen to grow undisturbed by reindeer. HS (from fixed stakes) and SWE have been measured every 5 days in January and March since 1972. There are automatic soil temperature (109-L by Campbell Scientific Inc., Logan, Utah, USA) and short- and longwave radiation (CNR4 by Kipp\&Zonen, Delft, The Netherlands) measurements at the site. Until 2014 there were automatic flux measurements of $\mathrm{CO}_{2}$ (LI840 from Li-Cor, Lincoln, Nebraska, USA) and $\mathrm{CH}_{4}$ (G1301 from
Picarro Inc., Santa Clara, California, USA). More details and data of the automatic measurements can be found at http://litdb.fmi.fi/lichen_fence.php.

\subsubsection{Intensive observation area}

The main present-day measurement site is the IOA (square in Fig. $1 \mathrm{~b}$ and c). The IOA consists of a forest clearing (diameter about $40 \mathrm{~m}$ ) and the sparse pine forest around it as shown in Fig. 2d (lower). Vegetation in the opening is mainly very low lichen $(<2 \mathrm{~cm})$ and some heather $(\sim 10 \mathrm{~cm})$ as shown in Fig. 2d (upper). Pine saplings are removed from the measurement area. The soil is composed of sand (70\%), silt (29\%) and clay $(1 \%)$ with a thin organic layer on top. The opening is shaded from most of the direct sunlight and protected from the wind by the forest surrounding it. As described in Sect. 2.1, mean wind speed on a similar forest opening at $1.5 \mathrm{~m}$ height is only $1.17 \mathrm{~m} \mathrm{~s}^{-1}$. Wind has a minimal effect on snow accumulation, and there is almost no snow redistribution by wind.

The measurement site was established in 2006 and today it hosts numerous automatic measurements: snow temperature profile (13 pcs. of 107-L by Campbell Scientific Inc., Logan, Utah, USA), HS (2 pcs. of SR50 by Campbell Scientific., Logan, Utah, USA), precipitation from distrometer (Thies Clima, Göttingen, Germany), brightness temperature with microwave radiometers $(1.4 \mathrm{GHz}$ from ELBARA-II by GAMMA Remote Sensing and Consulting AG, Gümligen, Switzerland (Schwank et al., 2010) and 10.6, 18.7, 21, 36.5, 89 and $150 \mathrm{GHz}$ from RPG-8CH-DP and RPG-4CH-DP radiometers by Radiometer Physics GmbH, Meckenheim, Germany), broadband albedo (CMA11 by Kipp \& Zonen, Delft, The Netherlands), spectral albedo (Field Spec pro JR by Analytical Spectral Devices, Boulder, Colorado, USA), SWE (SSG-1000 by Sommer Messtechnik, Koblach, Austria), air temperature (2 pcs. of PT100, Vaisala, Helsinki, Finland), air humidity (2 pcs. of HMP sensor, Vaisala, Helsinki, Finland), soil moisture and temperature (8 pcs. of Hydra Probe by Stevens Water Monitoring Systems, Portland, Oregon, USA), soil moisture (5 pcs. of ThetaProbe by Delta-T Devices, Cambridge, UK), soil temperature (2 pcs. of QMT103 by Vaisala, Helsinki, Finland) and soil dielectric constant, electric conductivity and temperature ( 9 pcs. of 5 TE by Decagon Devices, Pullman, Washington, USA). More details about instrumentation (description, coordinates, sensor types and data availability) can be found at http://litdb.fmi.fi/ioa.php. Snow pit measurements have been made regularly (2-4 times per month during the snow season) since 2006. The IOA snow course (HS from fixed stakes) has been measured together with the snow pit since 2009. Most of the automatic measurements, as well as the manual snow pits, are located in the forest clearing. In addition, several measurement campaigns have been performed at the IOA with variable instrumentation for snow measurements. 


\subsubsection{Lake Orajärvi}

Water courses and water bodies cover $3 \%$ the Sodankylä area (Corine Land Cover 2006). Lake Orajärvi is located $10 \mathrm{~km}$ east from FMI-ARC (Figs. 1b, 2e) and it is the closest lake to FMI-ARC. The measurement site on the lake is fixed, it is $400 \mathrm{~m}$ from the nearest shore and away from the snow mobile tracks crossing the lake.

Times of freezing and melting of the lake depend on air temperature; the lake usually freezes in December and melts in April, but the dates are not recorded. Freezing depends on the amount of snow fall during the process; if air cools before any heavy snowfall, the ice gets thick quickly, but heavy snowfall on thin ice slows down the ice formation. Typically water rises through cracks in the ice during the winter and refreezes over the solid ice. Snow is affected by strong sunlight in the springtime, strong (compared to e.g. the IOA) wind, the large temperature gradient between ice and air due to very shallow snowpack and water on ice. Snow on lake ice is quite heterogenic: wind-driven dunes, snow mobile tracks and water on ice are quite common. Thus, the representativeness of the snow stratigraphy measurements is problematic.

The site has no automatic measurements. Ice measurements (ice depth, ice layers and HS) have been made regularly (once or twice per month) from three fixed sites since 2008. Snow pit measurements were made regularly (once or twice per month) in 2008-2014.

\subsubsection{Sounding station}

The sounding station was built in 1949 when the FMI observatory was established, and it is the heart of meteorological observations in FMI-ARC ( $\times$ in Fig. $1 b$ and $c)$. The area is mostly open with some sparse coniferous trees on mineral soil. Manual surface synoptic observations (SYNOP) observations, including daily snow depth, have been performed at the weather station next to the sounding station since 1949. Today there are numerous automatic measurements at the site, including an automatic weather station, solar radiation measurements and greenhouse gas column observations, which are described at http://litdb.fmi.fi/soundingst.php.

\subsubsection{Tanhua snow course}

Tanhua area is located $50 \mathrm{~km}$ northeast of FMI-ARC (Fig. 1a). The land cover is similar to FMI-ARC station with coniferous forests on mineral soil and open peat bogs. Tanhua snow course has 80 measurement locations, out of which 6 are in forest opening, 41 in pine dominated forest, 4 in spruce dominated forest and 29 in bog. In 2009-2014, FMI measured a $4 \mathrm{~km}$ long snow course in Tanhua monthly during a measurement campaign related to ESA CoReH20 satellite mission preparation. The area was chosen from the planned satellite flight track.

Geosci. Instrum. Method. Data Syst., 5, 163-179, 2016

\subsection{Measurements and instruments}

This section defines the measurement protocols for each parameter and instruments used in each measurement. The measurement locations and years are listed for each parameter in Table 1 . The availability of each data set is listed in Table 3 .

\subsubsection{Density and SWE}

\section{Bulk density and SWE}

Bulk SWE and density is measured with a Finnish type snow tube (originally Melander and Korhonen, 1923; more details in Finnish in SYKE, 2015). It is made of black plastic tubing, and is $70 \mathrm{~cm}$ high and $10 \mathrm{~cm}$ in diameter. There is a removable lid with a handle on one end of the tube, and the other end is re-enforced with a sharpened metal ring. Each tube is paired with a scale and the pair is calibrated to show SWE directly. A centimetre scale on the outside of the tube allows for the measurement of HS for density calculation.

The tube is first weighed empty to check the calibration (e.g. if several measurements are performed, some snow might be stuck in or on the tube and cause an offset). The tube is pushed vertically into snow until it hits the ground. Snow depth is recorded. Snow is removed from around the tube to allow a small flat shovel to be slid below the tube and used to seal the bottom when the snow sample is extracted. The tube is turned upside down, cleaned of any snow on the outside and vegetation inside, and weighed (Fig. 3b). The scale shows SWE directly. The offset is subtracted from the measured SWE. If there is more than $70 \mathrm{~cm}$ snow, several samples are taken on top of each other and weighed separately.

Vegetation and ground surface clearly affect the accuracy with which all the snow and only the snow (i.e. no vegetation or soil included) can be sampled. This can be minimised by the selection of the measurement site. The systematic error of the tube and scale is minimised by regular calibration measurements using standardised weights. In calibration measurement, the zero position of the scale can be tuned with a screw. The tube and scale are calibrated as a pair.

\section{Profile with samplers}

Density profile is measured similarly, but using a smaller sampler. Until 2014, the wedge-shaped RIP 2 cutter (Snowmetrics, Fort Collins, Colorado, USA) was used (Fig. 3c). Since 2015, a self-made box sampler (Fig. 3c) has been used. The self-made box sampler is a rectangular frame open at both ends. It has a handle on one end. Both samplers are $10 \mathrm{~cm} \times 10 \mathrm{~cm} \times 5 \mathrm{~cm}$ (total height of the box sampler, maximum height of the wedge sampler).

Density profile is measured in $5 \mathrm{~cm}$ steps beginning from the closest 5 or $10 \mathrm{~cm}$ below the snow surface. The bag or bucket used in snow weighting is first weighed empty. The 


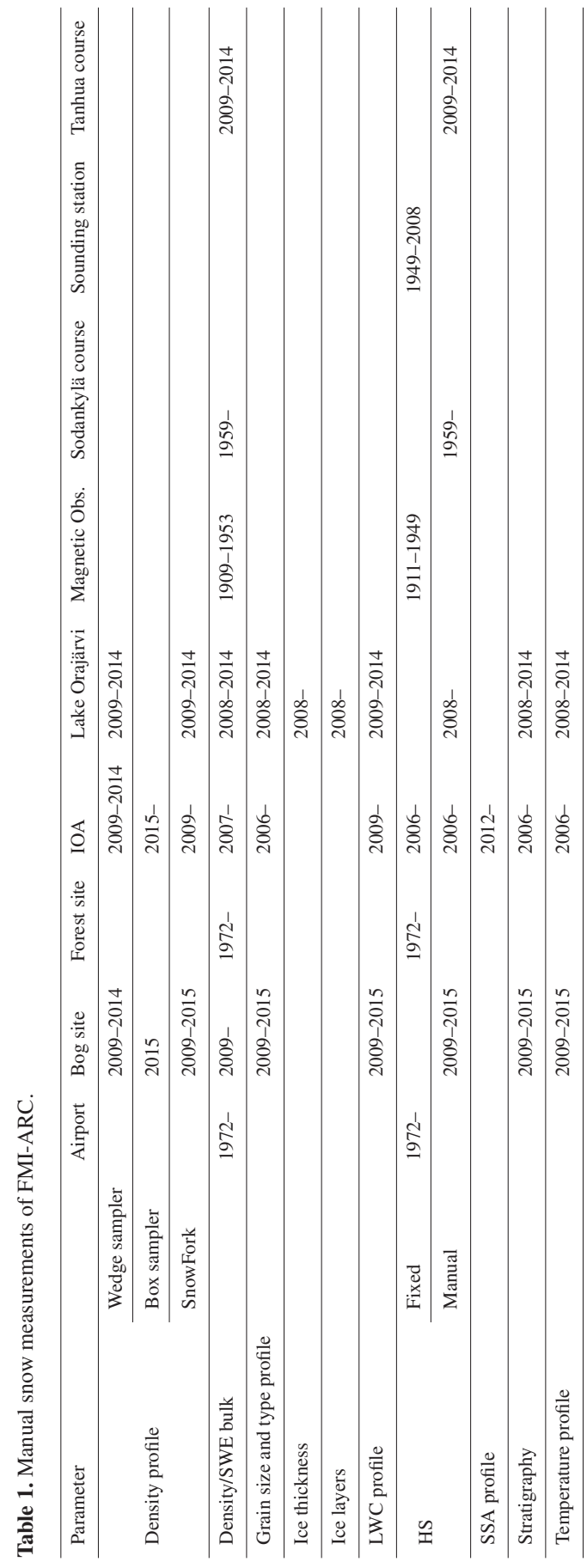

sampler is inserted into snow pit wall horizontally and perpendicular to the wall. The sampler is sealed; the RIP 2 cutter has a flat metal plate lid, while the box sampler has a rectangular frame that seals both ends. Snow sample is extracted and all snow is cleaned from the outside of the sampler. The snow sample put in a plastic bag or a small bucket, and weighed. Either mechanical or digital scale can be used. The mechanical spring balance (Pesola AG, Schindellegi, Switzerland) is more reliable in very cold conditions, while the digital one (OCS-1, Shenzhen West-Boao Science $\&$ Technology Co., Shenzhen, China) is easier to use. The whole snow profile is sampled and weighed in this manner.

Successive samples are not taken directly on top of each other, as snow might be disturbed from previous sampling, but the samples form a checkerboard pattern. Vegetation affects the measurement accuracy of samples from close to the ground. Problems with sampling occurs also in light new snow at top of the snowpack. Hard crust layers are difficult to penetrate with the sampler. On the other hand, keeping large coarse grains inside sampler is tricky. In those cases, occasionally successful sampling is not possible. With the RIP 2 cutter, snow escapes easily from the sampler especially if there are thin ice layers mixed with soft snow in the sampled layer. In addition, the pit wall has to be very smooth and the sampler needs to be inserted absolutely perpendicular to the wall to extract a good snow sample. These error sources are much smaller when the box sampler is used. Another possible error source is not weighting all the sampled snow (e.g. some of it stays in the sampler). This could be avoided by weighting the whole sampler with the snow, but in this case there is a bigger possibility of weighting additional snow that is, e.g., stuck on the sampler. One possible error source is having some snow from previous measurements already inside the sampler. These error sources are minimised by carefully cleaning the sampler and weighting bag or bucket between and during the measurements.

There is a difference between densities from the wedge and box samplers arising from the fact that snow is not homogeneous. Both of the samplers are $5 \mathrm{~cm}$ high, but when the box sampler gives an average density for the sampled snow, the wedge-shaped one gives a weighted average: most of the sampled snow is from the bottom of the sampled layer. In a homogeneous snow layer the difference is small, but as the vertical variation in the snowpack increases (i.e. the thinner and more varied the layers are), the difference between the samplers increases.

\section{Profile with SnowFork}

Measurement with the SnowFork is described in Sect. 2.3.4.

\subsubsection{Grain size and type}

Grain size $E$ of a layer is defined as "the average size of its grains", and the size of a grain is "its greatest extension mea- 
(a)

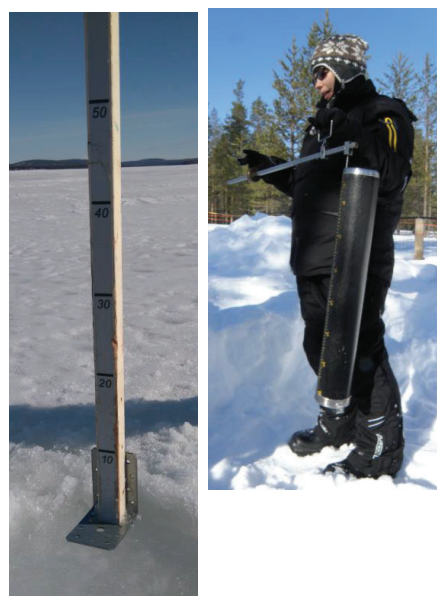

(f)

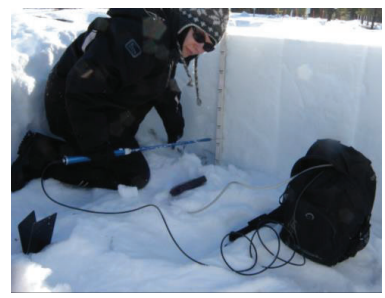

(i)

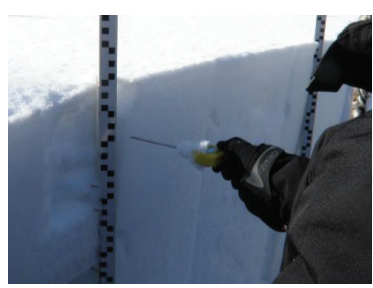

(c)

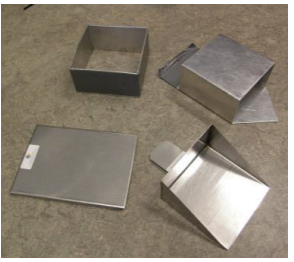

(e) (d)
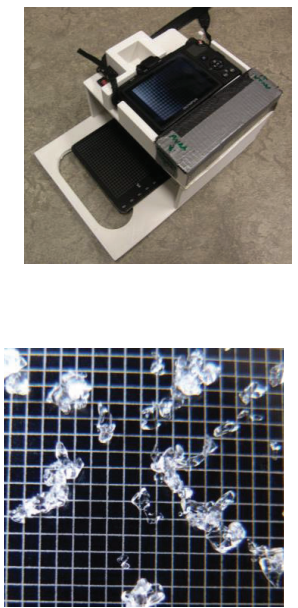

(h)

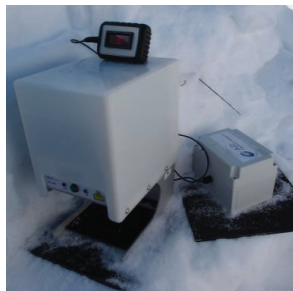

(j)

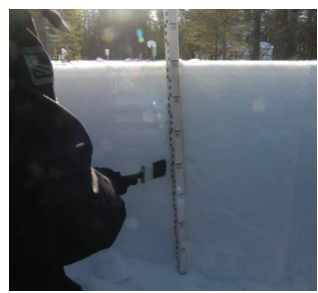

(k)

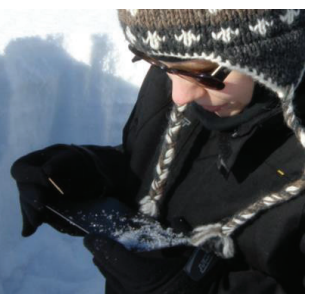

Figure 3. Photos of snow pit measurements: (a) tool for ice thickness measurements, (b) bulk SWE measurement with SWE tube, (c) box sampler and wedge sampler for density profile, (d) camera and stand for macro-photography, (e) two examples of snow grains on $1 \mathrm{~mm}$ grid, (f) SnowFork, (g) IceCube, (h) snow sample preparation for IceCube, (i) temperature measurement, (j) determining layers with brush and (k) definition of grain size and type in field.

sured in millimetres" in Fierz et al. (2009). Grain type describes shape and/or origin of a snow grain. Both parameters are defined for each layer in the field according to definitions by Fierz et al. (2009). In addition, macro-photographs of snow grains of each layer are taken against a $1 \mathrm{~mm}$ reference plate (by Sear) using a digital camera (resolution $3648 \times 2736$ and focal length $28 \mathrm{~mm}$ or resolution $3072 \times 2304$ and focal length $10 \mathrm{~mm}$ ) and self-made illuminated stand (Fig. 3d) from every layer in the snowpack. Layer detection is described in Sect. 2.3.7. Typical grains from each layer are photographed so that the grains are separated on the clean and ice free plate as well as possible without breaking them (Fig. 3e). Three photographs are taken from every layer to ensure success of photography and to have mildly differently orientated grains in all photographs. Photographs of different layers are separated by an empty photo. 
Post-processed grain size and type are estimated visually from the photographs on computer screen. Largest extent of an average grain and average largest grain (snow grain size $E$ and size of the largest grains $E_{\max }$, Fierz et al., 2009) are estimated with $0.25 \mathrm{~mm}$ resolution. It is possible to measure the size of a single grain with a much higher resolution, but practise has shown that error arising from multiple observers defining the average value for a layer is of this magnitude. Grain type estimation is based on classification by Fierz et al. (2009). Mostly used morphological grain classes are precipitation particles, decomposing and fragmented precipitation particles, surface hoar, rounded grains, faceted crystals, melt forms and depth hoar. The subclasses are listed by Fierz et al. (2009).

Main error sources are related to choosing and setting up the grains from snowpack to the plate and visual estimation of the snow grains. Estimation of grain size from the photographs is exposed to error from separating grains from clusters and positioning grains so that it is possible to estimate the largest extent. Visual estimation is also sensitive to observer-related bias. Advantages of post-processed grain size related to direct visual estimation of grain size and grain type in the field are the possibility of having a more accurate image than the with bare eye or magnifying lens, and the repeatability of the estimation. The measurement errors are described more closely by Leppänen et al. (2015).

\subsubsection{Ice thickness}

Ice thickness is measured with a wooden snow depth probe (Sect. 2.3.5), which has a small metal plate attached perpendicular to the probe at the $0 \mathrm{~cm}$ level (Fig. 3a). Thickness is measured by inserting the probe in a drill hole, attaching the metal plate below the ice, and reading the height of the ice surface level from the centimetre scale (Fig. 2e).

If the water surface level is higher than the ice surface, it is very difficult to read the ice thickness from the probe accurately. However, this situation is very rare. Another source of measurement errors is a bent metal plate, but this problem is easy to check and fix before performing the measurement.

\subsubsection{Liquid water content}

Liquid water content (LWC) describes the amount of liquid water in the snowpack, and can be derived, e.g., from the electrical conductivity of snow. The SnowFork instrument (Toikka Ltd., Engineering, Espoo, Finland) (Sihvola and Tiuri, 1986, Fig. 3f), measures the dielectricity of snow between two metal rods. The resonant frequency, attenuation and $3 \mathrm{~dB}$ bandwith are recorded, and inserted into equations by Sihvola and Tiuri (1986), which are used to derive density and LWC through real and imaginary parts of permittivity.

Measurement procedure includes calibration measurement in air and measurements from snowpack every $10 \mathrm{~cm}$. Snowpack is measured by pushing the metal rods of the Snow-
Fork horizontally and perpendicularly inside the smoothened snow pit wall to the desired height. Output values (attenuation, $3 \mathrm{~dB}$ bandwidth and resonant frequency) are recorded from the screen, and subsequently the instrument is ready for the next measurement. It is also possible to get density and LWC directly from the SnowFork, but the equations it uses are less accurate than the full equations by Sihvola and Tiuri (1986).

The equations used in deriving the density and LWC from the dielectric measurement assume that the surrounding material is homogeneous. There are two frequent cases, where this assumption is not valid: (1) at the surface and bottom of the snowpack close to air, ground or vegetation, and (2) if there is air around the rods (from the user moving the rods too much especially in very fluffy surface snow or large depth hoar crystals). Any metal objects (e.g. thermometer) close to the SnowFork cause errors, and must be removed before measurements. Another small error source is the fact that snow densifies when the rods are inserted. A comparison of the SnowFork and sampler densities (unpublished) showed that on average, the SnowFork gives $40 \mathrm{~kg} \mathrm{~m}^{-3}$ lower densities than the wedge sampler. In addition, the frequency measurement accuracy of the SnowFork is not enough to determine very low moisture contents (less than $\sim 1 \%$ ). An error in the measured height depends on the horizontal levelling of the SnowFork during the measurement.

\subsubsection{Snow depth}

HS can be measured either by a fixed stake or using a manual probe. In both cases, the instrument is the same wooden stake with $1 \mathrm{~cm}$ graduated scale (Figs. 2c, 3j). The cross section of the stake is $3 \mathrm{~cm} \times 3 \mathrm{~cm}$. A fixed stake is fastened in a vertical position with the $0 \mathrm{~cm}$ mark at ground surface to another smaller stake that is pushed into ground. Typical measurement errors are induced by a small pit or a pile of snow formed around the stake. This is minimised by removing the possible pile and estimating the true snow surface depth around the stake. Another error source is vegetation growing around the stake. However, lichen and moss grow very slowly and the error can be reduced by removing them from the stakes.

If the stake is used manually, the probe is pushed through the snow until it hits ground. Ground is recorded as $0 \mathrm{~cm}$ for HS. Measurement errors are caused by hard ice layers or vegetation that prevent the probe from hitting ground. These are minimised by repeating the measurement 3 times.

\subsubsection{Specific surface area}

Microstructural parameter specific surface area (SSA) is the ratio between surface area of ice and its mass in the snow sample (Legagneux et al., 2002). The IceCube instrument (A2 Photonic Sensors, Grenoble, France) (Fig. 3g, h) (Zuanon, 2013) is similar to DUFISSS presented by Gallet 
et al. (2009), but it uses only $1310 \mathrm{~nm}$ wavelength laser for reflectance measurements. Measurement procedure includes calibration, snow sampling, measurement of the snow samples with the instrument, and conversion of measured values to SSA with software. Calibration is made by measuring six differently shaded calibration standards; results are inserted afterwards to the software with measurement results.

Measurements are made from every $3 \mathrm{~cm}$ from whole snowpack. Snow is collected from certain height of the snowpack to $2.45 \mathrm{~cm}$ high and $6 \mathrm{~cm}$ diameter sample holder with a spatula or a sampling tool provided with the instrument. Very light snow (e.g. fresh snow) needs compaction to avoid reflection from the bottom of the sampler holder instead of the snow. The surface of the sample is smoothed and broken grains are removed with a spatula to avoid additional scattering of the laser. Sampling of very coarse grained snow or ice layers is difficult, because the sample surface should be even and smooth. The outside of the sample holder has to be clean of snow. The measurement is made by inserting the prepared snow sample into the instrument under the laser, and reading the corresponding voltage from a screen. Afterwards a software provided by the instrument manufacturer is used to convert the measured values to SSA. A logger, which records and shows SSA values directly in the field, is also available from the manufacturer, but it is not in use at FMI-ARC.

Measurement errors originate mainly from the sample preparation (e.g. packing of the snow to sample holder, smoothing of the sample surface, and height of the sample). The orientation of snow grains in the sample affects the observed reflectance; therefore, slightly different results can be measured by rotating the sample during measurement. Successful calibration measurements are also needed for accurate results. A further discussion of error sources is presented by Leppänen et al. (2015).

\subsubsection{Stratigraphy}

Horizontal layers of the snowpack are defined from smoothened snowpack wall from visual appearance and differences of hardness, wetness, grain size and grain type with the help of a paintbrush (for removing very soft layers, Fig. 3j) and tooth picks (for detecting thin hard layers). Grain size and type, hardness and wetness are estimated with a hand scale for every layer as described by Fierz et al. (2009). Grain size and type are estimated visually against the same $1 \mathrm{~mm}$ reference grid, which is used for macrophotography (Sect. 2.3.2 and Fig. 3k). Upper heights of the layers are recorded with accuracy of $5 \mathrm{~mm}$ and marked with toothpicks. Completed layer profile in snowpack is photographed.

Most of the errors related to the stratigraphy originate from inhomogeneities of the snowpack. Layer interfaces are not always clear, instead the snow structure might change gradually. Occasionally, layers are not continuous or a layer includes inhomogeneous spots inside it, which cannot be recorded as separate layer. Errors are also related to the used accuracy, very thin layers might not be recorded separately. There are also observer-related biases in layer definition and estimation of layer properties with hand scale. Especially, hardness is related to power, which is used for pushing hand, four fingers, one finger, pen or blade to the snowpack. Grain size estimation also depends on the observer. Therefore, stratigraphy is defined by one person for a snow pit. The discussion of error sources is presented by Leppänen et al. (2015).

\subsubsection{Temperature}

Temperature is measured with TH310 thermometers (Milwaukee Electronics Kft., Szeged, Hungary). The thermometer is first cooled in air and air temperature is recorded. The $\sim 10 \mathrm{~cm}$ long probe of the thermometer is inserted completely horizontally and perpendicularly into snowpack and left to reach thermal equalisation for a few minutes until the reading does not change anymore (Fig. 3i). Measurements are made every $10 \mathrm{~cm}$ from snowpack starting from snow surface towards ground, also ground surface temperature is recorded. Snow surface temperature is measured by inserting the thermometer probe under the uppermost $\sim 5 \mathrm{~mm}$ of snow.

One error source is the height and angle at which the thermometer is inserted into the snowpack. Surface temperature has an error related to amount of covering snow. When the Sun's elevation is high enough, solar radiation may have an effect on the temperature in the uppermost measurements. Ground surface temperature has an error related to the position of the thermometer tip, as measurements inside vegetation (lichen and moss) or soil are different from snow. Thermometer needs to be calibrated for correct results.

\section{Data sets}

This section describes the data sets and lists their measurements and sites.

\subsection{Snow pit}

Snow pits have been measured at the IOA, the bog site and Lake Orajärvi (Sect. 2.2.5, 2.2.2 and 2.2.6, and Fig. 2). The observation years with different instruments and measurement sites are presented in Table 1. Main problems in measurements are the duration of day light in mid-winter during the polar night, very cold air temperature in mid-winter and positive air temperature in spring. Measurements are made usually in the morning (while it is still cold) or midday (to have enough light). Air temperature limit for measurements is $-25^{\circ} \mathrm{C}$; if the weather is colder, measurements are shifted to another day. The bog site and Lake Orajärvi become impassable in the melting period, and therefore those measurements are usually finished before the measurements at the IOA. 


\subsubsection{Procedure}

At the beginning of the measurement day, instruments that need thermal stabilisation are moved outside for cooling. All equipment is gathered on a sledge and transferred to the measurement site where they are kept in the shade to avoid warming. Snow pit measurements are made by $2-3$ observers at a time. Snow pit observations are made on same fixed areas to allow for the comparison of measurements between years. Snowpack is disturbed as little as possible, and passage to the measurement areas is limited to one track. A new snow pit is dug at least $\sim 50 \mathrm{~cm}$ away from the old ones to avoid changes in the snow structure due to previous pit measurements. This introduces spatial heterogeneity in the measurements, but is unavoidable due to the destructive nature of the measurements. Spatial variability is unaccounted, but the snow pit sites were chosen to be flat without large vegetation or topography variations. The removed snow is placed on already used areas, and the snow surface is levelled after the measurements.

The examined snow pit wall is in the shade to avoid temperature changes and melting caused by solar radiation. The wall is smoothened with a shovel or a metal plate. Measurements are commenced immediately after digging the pit to avoid additional metamorphism. A snow pit measurement includes photography of the surroundings (landscape, sky, snow pit area, ground), temperature profile $(10 \mathrm{~cm}$ interval) simultaneously with the definition of horizontal layers and stratigraphy, density and LWC profile (10 cm interval) with the SnowFork, density profile ( $5 \mathrm{~cm}$ interval) with a sampler, bulk SWE, SSA profile ( $3 \mathrm{~cm}$ interval) and HS in presented order. The number of measurements included in the snow pit has increased; in 2006 only HS, temperature profile, grain sizes and stratigraphy were recorded. In 2015 a new protocol defining the order and placement of the different measurements in the pit was defined (Fig. 4). This insures that grain size and SSA measurements are made next to each other, as well as SWE and density measurements. At the end of the measurements, a photograph of the filled notebook is taken. Afterwards all equipment are dried, batteries are reloaded and data is digitised and stored.

Detailed description of the parameters, used instrumentation and measurements are in Sect. 2.3. Photographs of measurements and equipment are presented in Fig. 3. For all measurements, $0 \mathrm{~cm}$ HS is the ground.

\subsubsection{Example data}

There is a large amount of data from snow pit measurements from the last 10 winters. Therefore, only some examples of the data set are presented here. Density measurements and temperatures from different snow heights are presented in Fig. 5 from the IOA in 2013-2014. Density measurements with the SnowFork are usually smaller than measurements with the sampler or SWE tube. The average from density

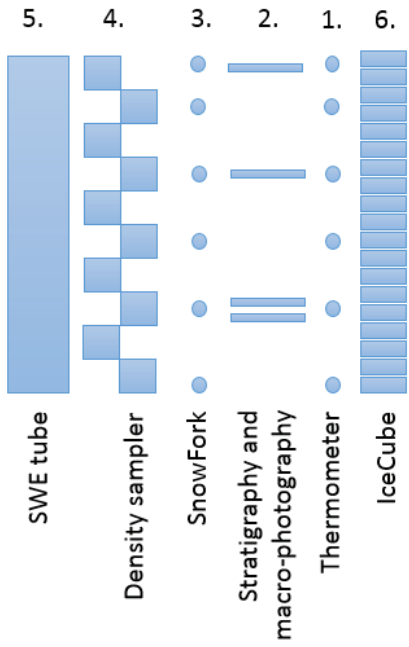

Figure 4. Snow pit measurements have been made with this plan since 2015. Measurements are made in numbered order.

sampler does not necessarily include the whole snowpack, as the surface layer of $<5 \mathrm{~cm}$ thickness is not measured, and some snow types are very difficult to sample with the cutter (e.g. hard crust layers, fragile depth hoar, soft fresh snow or slush). This explains some of the differences between the SWE tube and density sampler. In a typical temperature profile, the warmest snow is at the bottom $(0 \mathrm{~cm})$. However, the temperature of the snow surface is highly dependent on air temperature. Typically the coldest point is close to the surface (30 or $50 \mathrm{~cm}$ depending on HS).

HS and SWE from the three pit sites in 2006-2015 are presented in Fig. 6a and b, respectively, and compared to the snow course measurements. HS and SWE are largest at the IOA and smallest at Lake Orajärvi. Maximum yearly HS varied $65-106 \mathrm{~cm}$ at the IOA, $54-80 \mathrm{~cm}$ at the bog site and 23$44 \mathrm{~cm}$ at Lake Orajärvi. The HS and SWE at the bog site typically fall between the error bars of standard deviation of the measurements at the snow course, while the IOA has more snow and Lake Orajärvi has less snow than the snow course.

\subsection{Snow courses}

\subsubsection{Long snow courses}

Finnish Environment Institute (SYKE) maintains a network of 140 snow courses in Finland. Snow course measurements of SYKE and FMI began in the 1930s. Usually, there are 80 HS measurements made at regular intervals $(50 \mathrm{~m})$ along a $4 \mathrm{~km}$ course, and, in addition, 8 of these locations are chosen for SWE measurements so that each land cover type has at least one SWE measurement, and the most common have several measurements. The locations of the courses are se- 
(a)

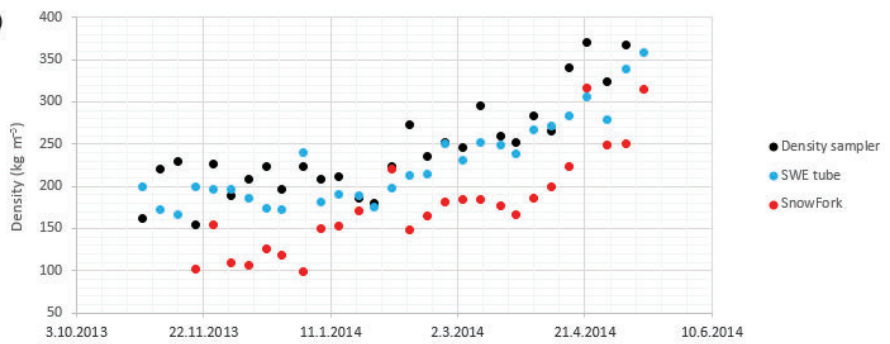

(b)

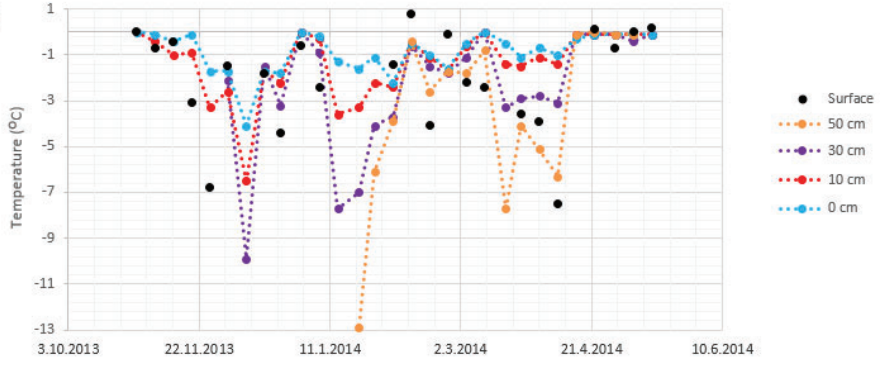

Figure 5. Example data from 2013 to 2014 snow pits at the IOA. (a) Densities from different instruments (average of density sampler profile, average of the SnowFork profile, and SWE tube). (b) Temperatures from different depths.

(a)

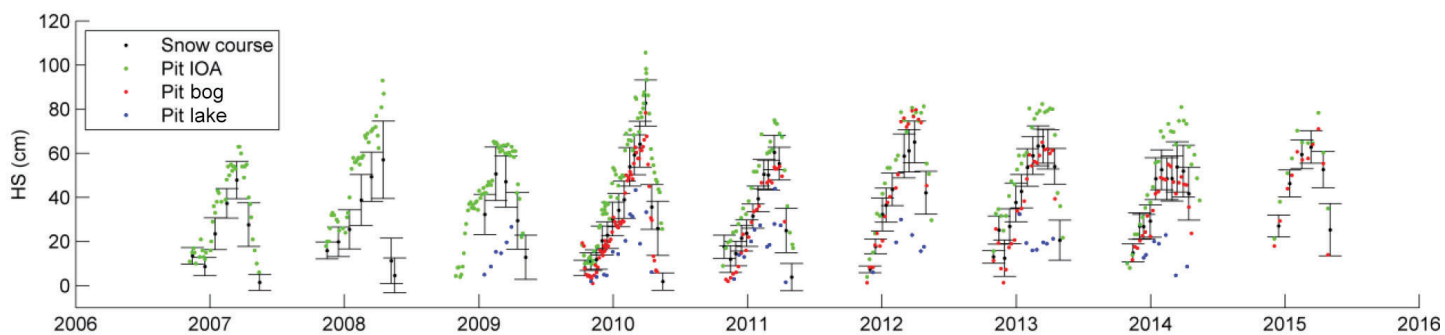

(b)

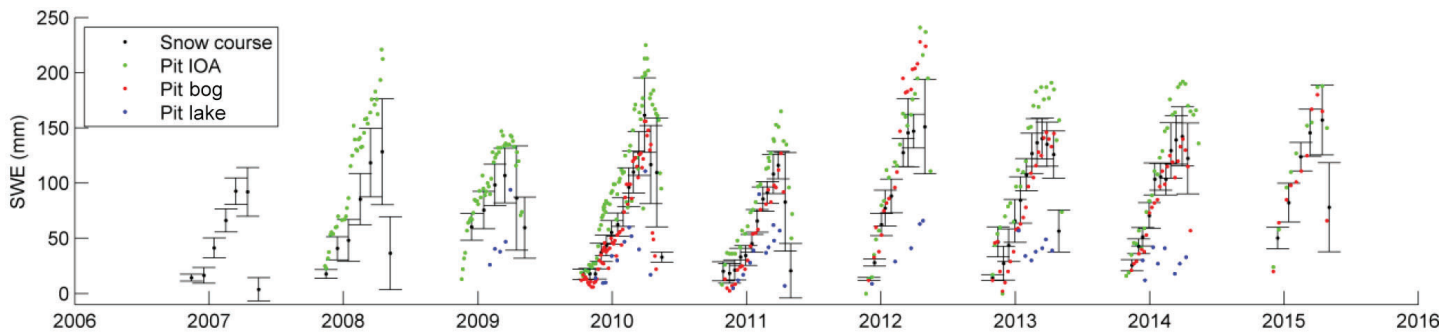

Figure 6. Time series of (a) HS and (b) SWE measurements from 2006 to 2016 from the Sodankylä snow course and from the three snow pit sites. Mean values of all measurements from the snow course with error bars of standard deviation are shown. For snow pits, the mean of three measurements is shown. 
lected for good coverage of the terrain, vegetation and land covers typical to the area. The main use for the snow course data is river runoff forecasting, and therefore the courses are located in the major watersheds. The measurement locations are classified into six categories: open area, forest opening, pine-dominated forest, spruce-dominated forest, broadleafdominated forest, and open bog. The classification of each location is made on the field when the course is established (or when there are major changes in land cover, e.g. a forest is cleared). The snow course measurements represent the variation in general snow conditions on the area and in each category.

One snow course has been located around FMI-ARC station in Sodankylä (Sect. 2.2.3) and measured by FMI personnel since 1959. The snow course is measured in the middle of each month; before 1991 only in January and March, and beginning in 1991 every month during the snow season. In 1991-1996 the course was additionally measured at the turn of the month. Moreover, in 2009-2014 FMI-ARC measured the Sodankylä snow course and an additional course in Tanhua $(50 \mathrm{~km}$ northeast of Sodankylä, Sect. 2.2.8) at the turn of the month during a measurement campaign.

Both the Sodankylä snow course and the Tanhua snow course include $80 \mathrm{HS}$ and $8 \mathrm{SWE}$ measurements at fixed sites with regular intervals along a $4 \mathrm{~km}$ course. The course is measured using a snowmobile, skis or snowshoes, and measurements are made as described in Sect. 2.3.1 and 2.3.5 from the sites marked in GPS and in the field.

\subsubsection{Short IOA snow course}

A short HS course with fixed stakes is located at the IOA. The snow course consists eight stakes in open area and nine stakes in forest. The snow course has been measured together with the IOA snow pit (2-4 times per month) since 2009 at open area and since 2011 at forest. The reading of a fixed stake is described in Sect. 2.3.5.

\subsubsection{Example data}

The averages and standard deviations of HS and SWE measurements of the Sodankylä snow course in 2006-2016 are shown in Fig. 6 together with the snow pit measurements. The measurements are analysed in Sect. 3.1.2.

\subsection{Lake ice observations}

Lake ice observations are made in Lake Orajärvi (Sect. 2.2.6) and measurements include ice thickness, ice layers and HS on ice. The measurements were began in 2008, and in 20082014 an additional snow pit was measured at the first drill site. However, due to the high variability of snow depth and stratification on lake ice, the snow pit measurements were finished because of issues with representativeness. A photograph from the ice thickness measurements on Lake Orajärvi is shown in Fig. 2e. Lake ice observations are only made when the ice is thick enough to allow for safe passage. Thus, the first ice in the autumn and the melting ice in the spring are not measured.

\subsubsection{Procedure}

Ice thickness and HS are monitored around three permanent spots $20 \mathrm{~m}$ apart. Each time, a new drill site with untouched snow is chosen close to the marked spot. Three HS measurements are made at each spot with a manual probe around the drill site (see Sect. 2.3.5). Then snow is removed from the drill site. A hole is drilled almost through the ice. The thicknesses of layers of hard ice and softer snow-ice (frozen slush and snow), as well as possible water layers inside the ice, are detected by testing the hardness of the layers with the metal plate of the ice thickness probe and by visual inspection. The hole is drilled completely through the ice, and ice thickness is measured, as described in Sect. 2.3.3. Also the level of water surface from the bottom of the ice is recorded.

\subsubsection{Example data}

Ice thickness and HS on ice observations are summarised in Table 2. Maximum measured ice thickness varied between 60 and $76 \mathrm{~cm}$, while maximum measured HS varied between 19 and $43 \mathrm{~cm}$.

\subsection{Daily HS time series}

A daily time series of HS in Sodankylä has existed since 1 January 1911, with the exception of the year 1913 (move to the research station area), autumn 1941 (World War II) and autumn 1944 (World War II), which are missing. These data have been collected from several measurement sites: in 1911-1912 all the meteorological measurements were made in the town of Sodankylä. Since 1913, the establishment of the Magnetic Observatory, the measurements have been made at the current research station area, but the exact location of HS measurements before 1949 is unknown. Since 1949 HS has been measured at the Sounding station (Sect. 2.2.7 and Fig. 1). However, the coordinates of the measurement site in the meteorological yearbook did not change in 1949, so the previous location was not far away from the current site. Despite the changes in measurement location, the data set represents the best knowledge of snow depth conditions in Sodankylä. The earliest measurements have been digitised from meteorological yearbooks.

Last manual synoptic observations were made in December 2008, and afterwards there are only automatic HS measurements available (SR50 by Campbell Scientific Inc., Logan, Utah, USA) from the Sounding station. The HS time series, as well as some other automatic and manual measurements, is available at http://litdb.fmi.fi/luo0016_data.php. 
Table 2. Summary of the lake ice observations.

\begin{tabular}{lccccc}
\hline Year & \multicolumn{2}{c}{ Ice thickness in } & & \multicolumn{2}{c}{ Maximum measured } \\
\cline { 2 - 3 } \cline { 5 - 6 } & $\begin{array}{c}\text { mid-January } \\
(\mathrm{cm})\end{array}$ & $\begin{array}{c}\text { mid-March } \\
(\mathrm{cm})\end{array}$ & & $\begin{array}{c}\text { ice thickness } \\
(\mathrm{cm})\end{array}$ & $\begin{array}{c}\text { snow depth } \\
(\mathrm{cm})\end{array}$ \\
\hline $2008-2009$ & 39 & 64 & & 70 & 19 \\
$2009-2010$ & 45 & 67 & & 68 & 43 \\
$2010-2011$ & 50 & 67 & & 70 & 29 \\
$2011-2012$ & 26 & 53 & & 60 & 28 \\
$2012-2013$ & 34 & 62 & & 70 & 32 \\
$2013-2014$ & 37 & 60 & & 60 & 23 \\
$2014-2015$ & 51 & 76 & & 76 & 30 \\
\hline
\end{tabular}

Table 3. Availability of the data during the time of the paper's preparation. Different properties of data sets are marked under the data set column. The updated version of this table with direct links to the data sets can be found in http://litdb.fmi.fi/manual_measurements.php.

\begin{tabular}{llll}
\hline Data set & Electronically available & Availability \\
\hline Snow pit & $2006-$ & On request \\
\hline IOA snow course & $2009-$ & On request \\
\hline \multirow{2}{*}{ Sodankylä snow course } & Middle of month & $1991-$ & $\begin{array}{l}\text { http://www.syke.fi/openinformation (averages), } \\
\text { on request (full data set) }\end{array}$ \\
\cline { 2 - 4 } & Beginning of month & $2009-2014$ & On request \\
\hline Tanhua snow course & & $2009-2014$ & On request \\
\hline Lake ice observations & & $2009-$ & On request \\
\hline \multirow{2}{*}{ Daily HS } & Magnetic Observatory & $1911-1949$ & http://litdb.fmi.fi/luo0016_data.php \\
\cline { 2 - 4 } & Sounding station & $1949-2008$ & On request \\
\hline \multirow{2}{*}{ SWE and HS } & Magnetic Observatory & $1914-1917,1920-1927,1941$, & $1945,1948,1951-1953$ \\
\cline { 2 - 4 } & Airport and forest & $1972-$ & On request \\
\hline
\end{tabular}

\subsubsection{Procedure}

Snow depth is read from a fixed HS stake as described in Sect. 2.3.5. Until May 1960, one value per day at 06:00 UTC was recorded. From June 1960 to December 2008, two values at 06:00 and 18:00 were recorded, but the 06:00 value is the daily snow depth. From February 2008, an automatic acoustic measurement (SR50 from Campbell Scientific Inc., Logan, Utah, USA) is recorded every $10 \mathrm{~min}$ (10 min average), with the 06:00 measurement still recorded as the daily snow depth.

\subsubsection{Example data}

The daily HS time series is shown in Fig. 7 together with the HS measurements from the airport and the forest site. Continuous snow has fallen the earliest on day 261 (year 1998) and latest on day 348 (year 2000). The last day of snow on the ground in spring has varied from day 114 (year 1937) to day 166 (year 1911). The absolute maximum HS in this data set is $119 \mathrm{~cm}$ (on 6 April 2000).

\subsection{SWE and HS time series}

There are two long time series of snow density, depth and SWE measured in Sodankylä: (1) between years 1909 and 1953 at a single measurement site and (2) an ongoing data set starting in 1972 at two sites. Until 2002, measurements were performed on the morning of 5th, 10th, 15th, 20th, 25th and the last day of every month, if there was snow on the ground. From 2002 onwards there are measurements only in January and March. The data set from 1909 to 1953 was measured by the Magnetic Observatory and the exact measurement site is unknown. Measurements from years 1914-1917, 1920-1927, 1941, 1945, 1948 and 1951-1953 are available in digitised form. The second data set from 1972 onwards is measured by FMI from two measurement sites: the airport (an open area, Sect. 2.2.1 and Fig. 2c), and the forest site 
(a)

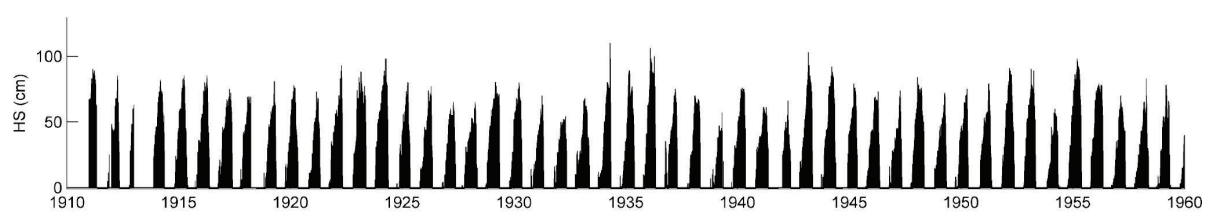

(b)

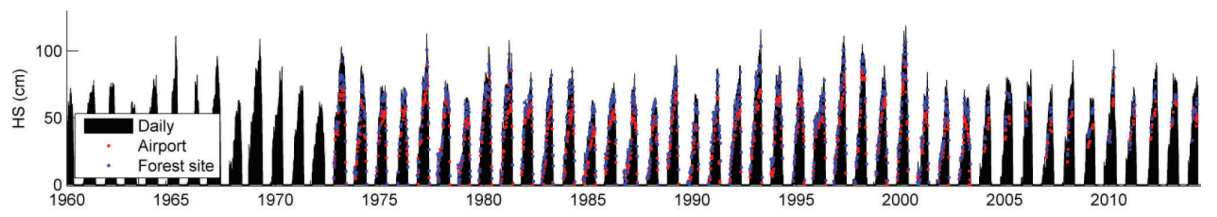

(c)

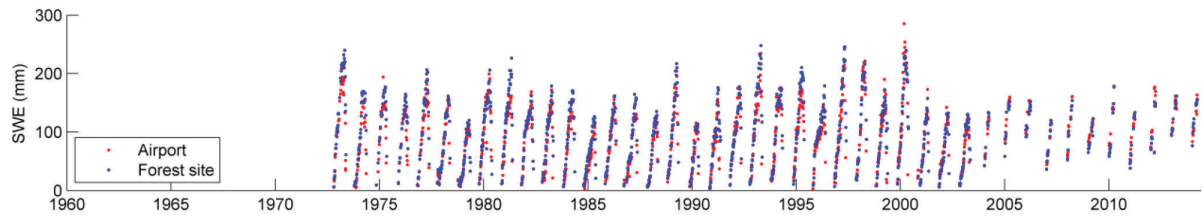

Figure 7. Time series in (a) and (b) HS measurements in 1911-2015, and (c) SWE measurements every 5 days (only in January and March from 2002) in 1972-2015.

(Sect. 2.2.4 and Fig. 2d). All SWE and HS measurements from 1972 onwards have been digitised.

\subsubsection{Procedure}

Two SWE samples are taken at each site. Until January 1924, SWE was measured by coring a cylindrical sample of snow with a tube of $100 \mathrm{~cm}^{2}$ cross sectional area, melting the snow in a covered bucket and measuring the volume of meltwater. From 1924, a special scale calibrated to show SWE (see Sect. 2.3.1) has been used to weight the cored snow sample (Fig. 4e). HS from a centimetre scale on the outside of the sampling tube is recorded; snow density can be calculated from HS and SWE.

Since 1976, HS at five fixed stakes (see Sect. 2.3.5) has been recorded at both sites. In 1972-1976, there were 9 stakes and two SWE measurements at the airport, and 25 stakes and four SWE measurements at the forest site.

\subsubsection{Example data}

The HS and SWE from the airport and the forest site are shown in Fig. 7. The HS at the forest site is comparable to the daily snow depth measurements, while the HS at the airport is typically lower; the mean difference between measurements at the forest site and the airport is $8.6 \mathrm{~cm}$. However, SWE at the two sites is about the same, the forest site has on average a $5.9 \mathrm{~mm}$ larger value. This means that snow at the airport is denser than at the forest site.

\section{Summary}

The Sodankylä manual snow survey program includes manual measurements of natural seasonal snowpack in the northern Finland. Measurements are performed at several diverse measurement sites at FMI-ARC. The station is equipped with a comprehensive set of tools for the manual measurements of snow and extensive reference instrumentation for automatic snow measurements and meteorological measurements. Measurements of HS and SWE have been made since 1909 (available since 1911 and 1914, respectively), and exact observations of snow macro- and microstructure have been made and available since 2006 from the snow pits. This paper presents a summary of the collected data sets.

\section{Data availability}

The availability of the data is described in Table 3. The details on how to download the data can be found in http:// litdb.fmi.fi/manual_measurements.php. The digitising of the 
earliest measurements is ongoing and details will be updated to http://litdb.fmi.fi/manual_measurements.php. The averages of the SYKE snow course data are available from SYKE database (http://www.syke.fi/openinformation), and full measurement data from SYKE on request (details in http://litdb.fmi.fi/manual_measurements.php).

Acknowledgements. We thank the personnel of FMI-ARC, who participated in the manual snow measurements. Anita Sassali and Hanne Suokanerva are acknowledged for digitizing the HS and SWE time series. Pirkko Kaukonen from SGO and the staff of FMI library in Helsinki provided information of the earliest measurements. The manuscript preparation was supported by the EU 7th Framework Program project "European-Russian Centre for cooperation in the Arctic and Sub-Arctic environmental and climate research" (EuRuCAS, grant 295068).

Edited by: C. Ménard

\section{References}

Barnett, T. P., Adam, J. C., and Lettenmaier, D. P.: Potential Impacts of a Warming Climate on Water Availability in Snow-Dominated Regions, Nature, 438, 303-309, 2005.

Cheng, B., Vihma, T., Rontu, L., Kontu, A., Pour, H. K., Duguay, C., and Pulliainen, J.: Evolution of snow and ice temperature, thickness and energy balance in Lake Orajarvi, northern Finland, Tellus A, 66, 21564, doi:10.3402/tellusa.v66.21564, 2014.

Cohen, J. and Rind, D.: The effect of snow cover on the climate, J. Climate, 4, 689-706, 1991.

Colbeck, S. C.: An overview of seasonal snow metamorphism, Rev. Geophys. Space Phys., 20, 45-61, 1982.

Colbeck, S. C.: The layered character of snow covers, Rev. Geophys., 29, 81-96, 1991.

Derksen, C., Sturm, M., Liston, G. E., Holmgren, J., Huntington, H., Silis, A., and Solie, D.: Northwest territories and Nunavut snow characteristics from a subarctic traverse: Implications for passive microwave remote sensing, J. Hydrometeorol., 10, 448463, 2009.

de Rosnay, P., Balsamo, G., Albergel, C., Muñoz-Sabater, J., and Isaksen, L.: Initialisation of land surface variables for numerical weather prediction, Surv. Geophys., 35, 607-621, 2014.

Essery, R., Kontu, A., Lemmetyinen, J., Dumon, M., and Ménard, C. B.: A 7-year dataset for driving and evaluating snow models at an arctic site (Sodankylä, Finland), Geosci. Instrum. Method. Data Syst. Discuss., doi:10.5194/gi-2015-35, in review, 2016.

FMI-ARC database: http://litdb.fmi.fi/manual_measurements.php, last access: 11 May 2016.

Fierz, C., Armstrong, R. L., Durand, Y., Etchevers, P., Greene, E., McClung, D. M., Nishimura, K., Satyawali, P. K., and Sokratov, S. A.: The International Classification for Seasonal Snow on the Ground, IHP-VII Technical Documents in Hydrology $\mathrm{N}^{\circ} 83$, IACS Contribution $\mathrm{N}^{\circ}$ 1, UNESCO-IHP, Paris, 2009.

Gallet, J.-C., Domine, F., Zender, C. S., and Picard, G.: Measurement of the specific surface area of snow using infrared reflectance in an integrating sphere at 1310 and $1550 \mathrm{~nm}$, The Cryosphere, 3, 167-182, doi:10.5194/tc-3-167-2009, 2009.
Groisman, P. Y., Karl, T. R., Knight, R. W., and Stenchikov, G. L.: Changes of snow cover, temperature, and radiative heat balance over the Northern Hemisphere, J. Climate, 7, 1633-1656, 1994.

Hall, A. and Qu, X.: Using the current seasonal cycle to constrain snow albedo feedback in future climate change, Geophys. Res. Lett., 33, L03502, doi:10.1029/2005GL025127, 2006.

Hannula, H.-R., Lemmetyinen, J., Kontu, A., Derksen, C., and Pulliainen, J.: Spatial and Temporal Variation of Bulk Snow Properties in North Boreal and Tundra Environments Based on Extensive Field Measurements, Geosci. Instrum. Method. Data Syst. Discuss., doi:10.5194/gi-2015-37, in review, 2016.

Hardy, J. P., Groffman, P. M., Fitzhugh, R. D., Henry, K. S., Welman, A. T., Demers, J. D., Fahey, T. J., Driscoll, C. T., Tierney, G. L., and Nolan, S.: Snow depth manipulation and its influence on soil frost and water dynamics in a northern hardwood forest, Biogeochemistry, 56, 151-174, 2001.

Hernández-Henríquez, M. A., Déry, S. J., and Derksen, C.: Polar amplification and elevation-dependence in trends of Northern Hemisphere snow cover extent, 1971-2014, Environ. Res. Lett., 10, 044010, doi:10.1088/1748-9326/10/4/044010, 2015.

Ikonen, J., Vehviläinen, J., Rautiainen, K., Smolander, T., Lemmetyinen, J., Bircher, S., and Pulliainen, J.: The Sodankylä insitu soil moisture observation network: an example application to Earth Observation data product evaluation, Geosci. Instrum. Method. Data Syst. Discuss., 5, 599-629, doi:10.5194/gid-5599-2015, 2015

Kangas, M., Rontu, L., Fortelius, C., Aurela, M., and Poikonen, A.: Weather model verification using Sodankylä mast measurements, Geosci. Instrum. Method. Data Syst., 5, 75-84, doi:10.5194/gi5-75-2016, 2016.

Kontu, A. and Pulliainen, J.: Simulation of spaceborne microwave radiometer measuremetns of snow cover using in situ data and brightness temperature modeling, IEEE T. Geosci. Remote, 48, 1031-1044, 2010.

Kontu, A., Lemmetyinen, J., Pullainen, J., Seppänen, J., and Hallikainen, M.: Observation and modeling of the microwave brightness temperature of snow covered frozen lakes and wetlands, IEEE T. Geosci. Remote, 52, 3275-3288, 2014.

Lakkala, K., Suokanerva, H., Karhu, J. M., Aarva, A., Poikonen, A., Karppinen, T., Ahponen, M., Hannula, H.-R., Kontu, A., and Kyrö, E.: Optical laboratory facilities at the Finnish Meteorological Institute - Arctic Research Centre, Geosci. Instrum. Method. Data Syst. Discuss., doi:10.5194/gi-2015-43, in review, 2016.

Legagneux, L., Cabanes, A., and Dominé, F.: Measurement of the specific surface area of 176 snow samples using methane adsorption at $77 \mathrm{~K}$, J. Geophys. Res., 107, 4335, doi:10.1029/2001JD001016, 2002.

Leinss, S., Wiesmann, A., Lemmetyinen, J., and Hajnsek, I.: Snow water equivalent of dry snow measured by differential interferometry, IEEE J. Sel. Top. Appl., 8, 3773-3790, 2015.

Lemmetyinen, J., Derksen, C., Toose, P., Proksch, M., Pulliainen, J., Kontu, A., Rautiainen, K., Seppänen, J., and Hallikainen, M.: Simulating seasonally and spatially varying snow cover brightness temperature using HUT snow emission model and retrieval of a microwave effective grain size, Remote Sens. Environ., 156, 71-95, 2015.

Lemmetyinen, J., Schwank, M., Rautiainen, K., Kontu, A., Parkkinen, T., Mätzler, C., Wiesmann, A., Wegmüller, U., Derksen, C., Toose, P., Roy, A., and Pulliainen, J.: Snow den- 
sity and ground permittivity retrieved from L-band radiometry: Application to experimental data, Remote Sens. Environ., doi:10.1016/j.rse.2016.02.002, online first, 2016a.

Lemmetyinen, J., Kontu, A., Pulliainen, J., Vehviläinen, J., Rautiainen, K., Wiesmann, A., Mätzler, C., Werner, C., Rott, H., Nagler, T., Schneebeli, M., Proksch, M., Schüttemeyer, D., Kern, M., and Davidson, M.: Nordic Snow Radar Experiment, Geosci. Instrum. Method. Data Syst. Discuss., doi:10.5194/gi-2015-29, in review, 2016b.

Leppänen, L., Kontu, A., Vehviläinen, J., Lemmetyinen, J., and Pulliainen, J.: Comparison of traditional and optical grain-size field measurements with SNOWPACK simulations in a taiga snowpack, J. Glaciol., 61, 151-162, 2015.

Mäkelä, J. S., Lakkala, K., Koskela, T., Karppinen, T., Karhu, J. M., Savastiouk, V., Suokanerva, H., Kaurola, J., Arola, A., Lindfors, A. V., Meinander, O., Leeuw, G., and Heikkilä, A.: Data flow of spectral UV measurements at Sodankylä and Jokioinen, Geosci. Instrum. Method. Data Syst. Discuss., doi:10.5194/gi-2015-42, in review, 2016.

Marty, C. and Meister, R.: Long-term snow and weather observations at Weissfluhjoch and its relation to other high-altitude observatories in the Alps, Theor. Appl. Climatol., 110, 573-583, 2012.

Meinander, O., Kontu, A., Lakkala, K., Heikkilä, A., Ylianttila, L., and Toikka, M.: Diurnal variations in the UV albedo of arctic snow, Atmos. Chem. Phys., 8, 6551-6563, doi:10.5194/acp-86551-2008, 2008

Meinander, O., Aarva, A., Poikonen, A., Kontu, A., Suokanerva, H., Asmi, E., Neitola, K., Rodriguez, E., Sanchez, R., Mei, M., de Leeuw, G., and Kyrö, E.: Bipolar long-term high temporal resolution broadband measurement system for incoming and outgoing solar UV radiation, and snow UV albedo, at Sodankylä $\left(67^{\circ} \mathrm{N}\right)$ and Marambio $\left(64^{\circ} \mathrm{S}\right)$, Geosci. Instrum. Method. Data Syst. Discuss., doi:10.5194/gi-2015-31, in review, 2016.

Meister, R.: Snow profiling at Weissfluhjoch, International snow science workshop, 27 September-2 October 2009, Davos, Switzerland, 2009.

Melander, G. and Korhonen, V. V.: Uusi lumentiheysmittari, in: Esitelmät ja pöytäkirjat 1922, Suomalainen tiedeakatemia, 39-42, 1923.

Morin, S., Lejeune, Y., Lesaffre, B., Panel, J.-M., Poncet, D., David, P., and Sudul, M.: An 18-yr long (1993-2011) snow and meteorological dataset from a mid-altitude mountain site (Col de Porte, France, $1325 \mathrm{~m}$ alt.) for driving and evaluating snowpack models, Earth Syst. Sci. Data, 4, 13-21, doi:10.5194/essd-4-13-2012, 2012.

Pirinen, P., Simola, H., Aalto, J., Kaukoranta, J.-P., Karlsson, P., and Ruuhela, R.: Climatological statistics of Finland 19812010,Finnish Meteorological Institute reports, 2012.

Rautiainen, K., Lemmetyinen, J., Pulliainen, J., Vehviläinen, J., Drusch, M., Kontu, A., Kainulainen, J., and Seppänen, J.: L-band radiometer observations of soil processes in boreal and subarctic environments, IEEE T. Geosci. Remote, 50, 1483-1497, 2012.

Rautiainen, K., Lemmetyinen, J., Schwank M., Kontu, A., Menard, C. B., Mätzler, C., Drusch, M., Wiesmann, A., Ikonen, J., and Pulliainen, J.: Detection of soil freezing from L-band passive microwave observations, Remote Sens. Environ., 147, 206-218, 2014.
Rutter, N., Sandells, M., Derksen, C., Toose, P., Royer, A., Montpetit, B., Langlois, A., Lemmetyinen, J., and Pulliainen, J.: Snow stratigraphic heterogeneity within ground-based passive microwave radiometer footprints: Implications for emission modeling, J. Geophys. Res. Earth Surf., 119, 550-565, 2014.

Salminen, M., Pulliainen, J., Metsämäki, S., Kontu, A., and Suokanerva, H.: The behaviour of snow and snow-free surface reflectance in boreal forests: Implications to the performance of snow covered area monitoring, Remote Sens. Environ., 113, 907-918, 2009.

Schwank, M., Wiesmann, A., Werner, C., Mätzler, C., Weber, D., Murk, A., Völksch, I., and Wegmüller, U.: ELBARA II, an Lband radiometer system for soil moisture research, Sensors, 10, 584-612, 2010.

Schwank, M., Rautiainen, K., M'tzler, C., Sahli, M., Lemmetyinen, J., Pulliainen, J., Vehviläinen, J., Kontu, A., Ikonen, J., Menard, C. B., Drusch, M., wiesmann, A., and Wegmüller, U.: Model for microwave emission of a snow-covered ground with focus on L band, Remote Sens. Environ., 154, 180-191, 2014.

Sihvola, A. and Tiuri, M.: Snow fork for field determination of the density and wetness profiles of a snow pack, IEEE T. Geosci. Remote, GE-24, 717-721, 1986.

Sturm, M. and Holmgren, J.: A seasonal snow cover classification system for local to global applications, J. Climate, 8, 1261-1283, 1995.

Sukuvaara, T., Mäenpää, K., and Ylitalo, R.: Vehicular networking and road weather related research in Sodankylä, Geosci. Instrum. Method. Data Syst. Discuss., doi:10.5194/gi-2015-23, in review, 2016.

SYKE: Hydrologisen seurannan ryhmä: Hydrologisen seurannan kenttätöiden toimintakäsikirja (Handbook of field work of hydrological monitoring), available at: http://www.ymparisto.fi/download/noname/, 2015 (in Finnish).

SYKE database: http://www.syke.fi/openinformation, last access: 11 May 2016.

Tietäväinen, H., Tuomenvirta, H., and Venäläinen, A.: Annual and seasonal mean temperatures in Finland during the last 160 years based on gridded temperature data, Int. J. Climatol., 30, $2247-$ 2256, 2010.

Törmä, M., Haakana, M., Hatunen, S., Härmä, P., Kallio, M., Katila, M., Kiiski, T., Mäkisara, K., Peräsaari, J., Piepponen, H., Repo, R., Teiniranta, R., and Tomppo, E.: Finnish Corine 2006 project: determining changes in land cover in Finland between 2000 and 2006, Proc. SPIE 7110, Remote Sensing for Environmental Monitoring, GIS Applications, and Geology VIII, 71100V, doi:10.1117/12.800148, 2008 .

van Dijk, A. I. J. M., Renzullo, L. J., Wada, Y., and Tregoning, P.: A global water cycle reanalysis (2003-2012) merging satellite gravimetry and altimetry observations with a hydrological multi-model ensemble, Hydrol. Earth Syst. Sci., 18, 2955-2973, doi:10.5194/hess-18-2955-2014, 2014.

Zuanon, N.: IceCube, a portable and reliable instruments for snow specific surface area measurement in the field, International Snow Science Workshop Grenoble-Chamonix MontBlance-2013 proceedings, 1020-1023, 2013. 
